\title{
Open Call for
}

Research Projects

Óscar Rodil Marzábal, María del Carmen Sánchez Carreira,

Jorge Alberto López Arévalo, Emmanuel Arrazola Ovando

\section{Progress in the Pattern of}

Intra-industrial Trade between

the European Union and Latin

America: The Cases of Brazil

and Mexico
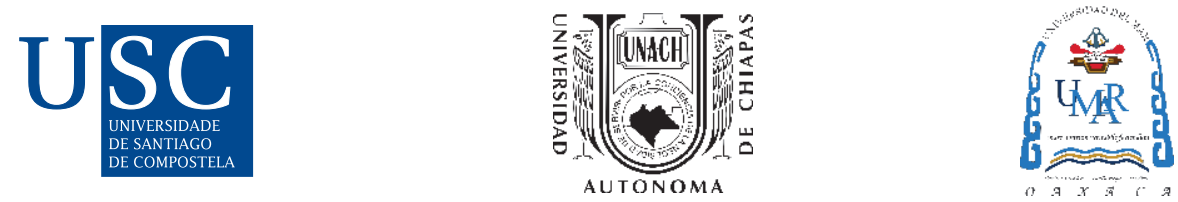


\section{EU-LAC FOUNDATION, 2016}

Hagedornstraße 22

20149 Hamburg, Germany

www.eulacfoundation.org

\section{AUTHORS:}

Óscar Rodil Marzábal, University of Santiago de Compostela, Spain (Head of Study); María del Carmen Sánchez Carreira, University of Santiago de Compostela, Spain; Jorge Alberto López Arévalo, Autonomous University of Chiapas, Mexico;

Emmanuel Arrazola Ovando, University of the Sea, Mexico

TEXT REVISION AND EDITING: Anna Barrera and Viviana Lozano

GRAPHIC DESIGN: Tina Jochemich, Jona Diedler

PRINT: Scharlau GmbH

ISBN: 978-84-608-6332-8

DOI: 10.12858/0216EN1

Note: This study was financed by the EU-LAC Foundation. The EU-LAC Foundation is funded by its member states and the European Union. The contents of this publication are the sole responsibility of the authors and can not be considered as the point of view of the EU-LAC Foundation, its member states or the European Union.

This book was published in 2016.

This publication is copyright but the text may be used free of charge for the purposes of advocacy, campaigning, education, and research, provided that the source is properly acknowledged. The copyright holder requests that all such use be registered with them for impact assessment purposes. For copying in any other circumstances, or for reuse in other publications, or for translation and adaptation, permission must be secured from the Foundation. 



\section{ABSTRACT}

This study examines changes in the pattern of intra-industrial trade (exchange of different varieties of the same good) between the European Union (EU) and the countries of Latin America (LA) over the last two decades, paying special attention to the cases of Brazil and Mexico. It focuses on the extent to which these trade relations are changing from a traditional profile based on complementarity (inter-industrial) and on static advantages (provision of resources) to a more modern, competitive profile - as a result of growing intra-industrial specialisation based on dynamic factors (economies of scale, product differentiation, etc.). The study's starting premise is that the changes affecting the pattern of trade are related with the foreign direct investment (FDI) flows for which multinational companies are responsible. The relevance of the subject of this study resides in the economic changes occurring worldwide which are shifting the centre of gravity of the world economy and causing continuous transformation of global chains of production. In this regard, the study seeks to provide insights into how these changes translate to the pattern of trade between the EU and LA, in a context characterised by the superimposition of the processes of globalisation, regional integration and relocation of production. On the theoretical level, the research benefits to a large extent from contributions by the New Theories of International Trade which converge in the explanation of the phenomenon of intra-industrial trade vis-à-vis traditional (inter-industrial) trade. Additionally, aspects of Neo-Technological Theories such as the Product Life-Cycle Theory are considered, as well as other contributions in FDI's explanatory framework including the OLI paradigm or the Export Platform Theory that aim at the construction of a framework integrating FDI and trade theories. The study is organised into the following seven sections: 1) Review of the theoretical framework; 2) Changes on the world economic stage; 3) Overview of FDI and trade between the EU and LA; 4) A comparative analysis of trade barriers and FDI; 5) Analysis of general and sectorial rules in the field of intraindustrial trade between the EU and LA: The cases of Brazil and Mexico; 6) Analysis of the FDI of Brazil and Mexico with their main European Union partners; 7) Integration of both dimensions in the input-output framework. The statistical information on which the study is based stems from various sources. For the analysis of trade, the data basically come from the World Trade Organisation (WTO), the United Nations (UN-Comtrade) and the Spanish Ministry of Economy and Competitiveness (Datacomex). For the study of the FDI, this publication relies on data from the United Nations Conference on Trade and Development (UNCTAD), the International Monetary Fund (IMF), the Organisation for Economic Cooperation and Development (OECD), Eurostat (the statistical office of the European Union), and the Economic Commission for Latin America and the Caribbean (ECLAC). 


\section{TABLE OF CONTENTS}

Progress in the pattern of intra-industrial trade between

the European Union and Latin America: the cases of Brazil and Mexico

1 The theoretical framework of intra-industrial trade and

foreign direct investment: Towards an integrated explanatory

framework

1.1. Theoretical and conceptual approach to intra-industrial trade

1.2. An approach to the theoretical and conceptual framework of international direct investment

1.3. Towards the construction of an integrated explanatory framework of intra-industrial trade and foreign direct investment

2 Changes in the world economic scenario:

Globalisation and global value chains

2.1. Globalisation as engine of change of the world economy

2.2. The emergence of global value chains

3 The European Union's commercial and production relations with

Latin America in general and Brazil and Mexico in particular: An overview

3.1. Trade between the European Union and Latin America:

Characteristics and evolution

3.2. Zooming in: The European Union's trade with Brazil and Mexico

3.2.1. Recent trends

3.2.2. Sectorial characteristics

3.3. Foreign direct investment between the European Union and

Latin America: Characteristics and evolution

3.3.1. Foreign direct investment from a comparative global perspective

3.3.2. Foreign direct investment in Latin America and the Caribbean

3.3.3. Foreign direct investment of the European Union

3.3.4. Investment relations between the European Union and Latin America

3.4. Zooming in: The European Union's foreign direct investment in 
4 Comparative analysis of trade and investment restrictions

5 Analysis of Brazil and Mexico's intra-industrial trade with its main European Union partners

5.1. Methodological aspects of measurement of intra-industrial trade

5.2. Comparative analysis of Brazil and Mexico's intra-industrial trade with the main European economies today

5.2.1. Overview

5.2.2. Overview disaggregated by product

5.3. Patterns in the growth of Brazil's intra-industrial trade with the main European economies

5.3.2. Overview disaggregated by product

5.4. Patterns in the growth of Mexico's intra-industrial trade with the main European economies

5.4.1. Overview

5.4.2. Overview disaggregated by product

5.5. Dynamic analysis of Brazil and Mexico's intra-industrial trade with the main European economies

5.5.1. Overview

5.5.2. Overview disaggregated by product

6 Analysis of foreign direct investment between the European Union, Brazil and Mexico

6.1. Comparative analysis of Brazil and Mexico's foreign direct investment with the main European economies today

6.1.2. Sectorial analysis

6.2. Patterns in the evolution of Brazil's foreign direct investment with the main European economies

6.3. Patterns in the evolution of Mexico's foreign direct investment with the main European economies 
7 Integration of the two dimensions: Insertion of trade and production within the framework of global input-output

7.1. Inter-sectorial relations within the input-output framework

7.1.1. The inter-sectorial relations of Brazil with its main European Union partners

7.1.2. The inter-sectorial relations of Mexico with its main

European Union partners

7. 2. Foreign direct investment and intra-industrial trade:

Evidence of two connected realities 


\section{LIST OF ABBREVIATIONS}

$\begin{array}{ll}\text { ASEAN } & \text { Association of Southeast Asian Nations } \\ \text { BRICS } & \text { Brazil, Russia, India, China and South Africa } \\ \text { CAP } & \text { Common Agricultural Policy } \\ \text { CDIS } & \text { Coordinated Direct Investment Survey } \\ \text { CNAE } & \text { National Classification of Economic Activities } \\ \text { DATACOMTEX } & \text { Statistical Database on Foreign Trade of the Ministry of } \\ & \text { Economy and Competitiveness of Spain } \\ \text { ECLAC } & \text { Economic Commission for Latin America and the Caribbean } \\ \text { EUROSTAT } & \text { Statistical Office of the European Union } \\ \text { FDI } & \text { Foreign Direct Investment } \\ \text { GATT } & \text { General Agreement on Tariffs and Trade } \\ \text { GDP } & \text { Gross Domestic Product } \\ \text { GVC } & \text { Global Value Chains } \\ \text { IMF } & \text { International Monetary Fund } \\ \text { MBP6 } & \text { Balance of Payments and International Investment Position Manual } \\ \text { NAFTA } & \text { North American Free Trade Agreement } \\ \text { OECD } & \text { Organisation for Economic Co-operation and Development } \\ \text { OLI } & \text { Ownership, Location and Internalization Paradigm } \\ \text { TTIP } & \text { Transatlantic Trade and Investment Partnership } \\ \text { UN-COMTRADE } & \text { United Nations Commodity Trade Statistics Database } \\ \text { UNCTAD } & \text { United Nations Conference on Trade and Development } \\ \text { WTO } & \text { World Trade Organization } \\ & \end{array}$




\section{INTRODUCTION}

\section{Context}

This study deals with production and trade relations between the European Union (EU) and Latin America (LA), two very distinct and diverse regions. They are not as different in terms of demographic size, although LA is bigger, with 627 million inhabitants in 2014 compared with 508 million of the EU. However, in the economic realm, the differences are much more evident, and the order is reversed. In this case, LA's gross domestic product came to $\$ 6.2$ billion, far below the EU's $\$ 18.5$ billion (US $\$$ at current prices, in both cases). ${ }^{1}$ These figures translate into a notable difference when GDP per capita is considered, being between twice and three times higher in the case of the EU, depending on whether it is expressed in monetary units or in the equivalence of acquisitive power. One aspect that makes this study particularly interesting is that trade of goods between the two regions nearly tripled between 2000 and 2014, reaching its maximum level of $\$ 278,000$ million in 2013 (ECLAC 2015). However, its rate of growth has been lower than that undergone by trade of these two regions with the rest of the world, - with a marked irruption of China in both markets. ${ }^{2}$

Although these are two regions with a considerable number of countries (28 in the case of the EU and 19 in the case of LA), most of their trade relations and foreign direct investment (FDI) are concentrated in a very small group of them, which has been taken into account in choosing the subject of study. So, without forgetting the overall panorama, the mayor part of the study focuses on the relations between the two main economies of LA, Brazil and Mexico, ${ }^{3}$ with the following six EU countries: Germany, Spain, France, Italy, the Netherlands and the United Kingdom.

1 Data on Latin America and the Caribbean (19 countries) and on the EU-28 from CEPALSTAT (ECLAC) and World Bank, respectively.

2 According to ECLAC's es (2015b), between 2000 and 2014, China's share of Latin American (LA) exports rose from 1 to $9 \%$ (reaching its maximum in 2013 , with $10 \%$ ), while its share of imports rose from just over $2 \%$ to $16 \%$. This means the European Union (EU) has been ousted by China as the second market of origin of its imports (after the United States). In the last decade, the Asian giant has also irrupted in the foreign trade of the EU, especially as an exporter of goods (ECLAC 2015).

3 Ample evidence on the importance of Brazil and Mexico in the context of LA exists. These two economies account for about $52 \%$ of the total population and 57\% of the gross domestic product of LA overall (sources: WTO - Trade Profiles and CEPALSTAT). 
Furthermore, it can be pointed out that, although these are very important economies on the world economic stage ${ }^{4}$ there are striking differences between the different parties. For example, the trade ratio per inhabitant of the EU (average 2011-2013) is four times higher than that of Brazil ${ }^{5}$ and almost twice (1.8) that of Mexico. These differences are also shown in their production and trade specialisations, agricultural products being a very important proportion of Brazil's exports (37.4\% of exports of goods in 2013), compared with the EU (7.6\%) and Mexico (6.6\%); and exports of fuels and mining products being relatively important in the case of Brazil (24.2\% of exports of goods in 2013) and Mexico (15.9\%), compared with the EU (9.2\%). Similarly, manufactured goods represent around three quarters of exports of goods in the case of both the EU $(76.7 \%)$ and Mexico $(74.9 \%)$, while in Brazil they barely represent more than a third (35.1\%). These characteristics with regard to manufactured goods are reversed in the case of imports, being much more important in the case of Brazil (72.3\%) and Mexico (79.1\%) than that of the EU (55.5\%).

The foregoing draws a pattern of specialisation which for one thing has complementary traits typical of economies with different levels of development, but, for another, has characteristics favouring the study of insertion of these economies in a world market characterised by the irruption of global value chains. These worldwide chains of production, arising from the combination of the globalisation process with new production strategies of multinational companies, are leading to changes in the pattern of international trade which can be seen, among other things, in the increasing importance of the exchange of intermediate goods between economies. As a result, economies become part of various worldwide production processes, taking part in specific segments or stages of the different production chains, losing the traditional sense of national production for exportation of end-consumer goods.

In this new context, it seems particularly interesting to understand patterns of commercial specialisation, and especially changes in the field of intra-industrial trade, referring to the exchange of different varieties of the same good. This kind of trade, first identified in the light of the beginning of the European integration process, is widespread worldwide, especially in trade between developed countries. One incentive for this study is precisely to add to the analysis of intra-industrial trade case studies of economies with a different development level, such as Brazil and Mexico in comparison with their main European partners. In this regard, this study incorporates a North-South dimension into the analysis of intra-industrial trade, in contrast to many

4 According to the World Trade Organisation (WTO Trade Profiles), in 2013, the EU (excluding intra-EU trade) occupied the first position in the world exports ranking and second place in the world imports ranking (behind the United States); Brazil was in 16th place in both rankings; and Mexico was in the 10th and 9th position respectively. In terms of the share of world trade in goods, the EU accounted for about 15\%, Brazil 1.3\% and Mexico 2\%. These differences are even greater in the case of trade in services, where the EU has a share of over $20 \%$ (25\% in the case of exports), while its relative importance for Brazil (0.8\% of export share and $1.9 \%$ of import share), and especially Mexico $(0.4 \%$ of export share and $0.7 \%$ of import share), is much lower.

5 This figure clearly shows Brazil's greater orientation towards its internal market. 
previous studies which tended to focus exclusively on North-North relations. It shall be pointed out that, although a low level of intra-industrial trade is to be expected, given the complementarity observed in the trade specialisation profiles, especially in the case of Brazil and the EU, the real points of interest are the evolution of sectorial patterns and trends as well as their relationship with FDI processes.

\section{Objectives}

Taking all the foregoing into consideration, the central objective of this study is to examine the pattern of intra-industrial trade (exchange of different varieties of the same good) between the EU and the countries of LA over the last two decades, paying special attention to the cases of Brazil and Mexico. Finally, the extent is examined to which these trade relations are changing from a traditional profile based on complementarity (inter-industrial) and on static advantages (provision of resources) to a more modern, competitive profile, which can be understood as the result of an increased intra-industrial specialisation based on dynamic factors (economies of scale, product differentiation, etc.). This analysis departs from the hypothesis that the changes affecting trade patterns are related with FDI flows promoted by multinational companies.

\section{Interest and motivation}

The interest and relevance of the subject under investigation are explained by the economic changes occurring worldwide which are shifting the centre of gravity of the world economy and causing continuous transformation of global chains of production. In this regard, the study aims to explore how these changes translate to the pattern of trade between the EU and LA, in a context characterised by the superimposition of the processes of globalisation, regional integration and relocation of production.

\section{Structure of the study}

The study is structured in seven sections, as well as the introduction and conclusions. The first section focuses on the theoretical framework of intra-industrial trade and FDI and sheds light into their interrelationship. The second section presents a brief outline of the changes occurring in the international economic context, highlighting globalisation and the formation of global value chains in particular. The third section provides a general analysis of the trends in trade and FDI in the relations between the EU and LA. This is followed by a comparison of the levels of trade protection and restrictions on FDI so as to contextualise the framework in which the trade and investment flows have developed over time. The fifth section focuses on the intra-industrial trade relations of Brazil and Mexico with their main European partners (Germany, Spain, France, Italy, the Netherlands and the United Kingdom). In the fifth chapter, FDI rules are examined, together with the sectorial and business implications for these economies. Finally, the seventh section is intended to be complementary, integrating trade and FDI through the analysis of intersectorial 
relations in the input-output framework and by assessing the degree of coincidence between FDI and the progress of intra-industrial trade in several selected sectors.

\section{Sources used}

The statistical information on which this study relies stems from various official sources. For the analysis of trade flows three databases have been used. First, for the general analysis of trends in trade, the international trade statistics of the World Trade Organisation (WTO) and the Datacomex database of the Spanish Ministry of Economy and Competitiveness have been used. For the more disaggregated sectorial analyses and calculation of the intra-industrial trade indices, the UN-COMTRADE database of the United Nations constituted the starting point. With regard to FDI, the sources used stemmed from the United Nations Conference on Trade and Development (UNCTAD), the International Monetary Fund (IMF), the Organisation for Economic Cooperation and Development (OECD), and the Statistical Office of the European Union (EUROSTAT). 


\section{THE THEORETICAL FRAMEWORK OF INTRA-INDUSTRIAL TRADE AND FOREIGN DIRECT INVESTMENT: TOWARDS AN INTEGRATED EXPLANATORY FRAMEWORK}

There is a long tradition of studies related with international trade and FDI in the economic literature. In recent decades, this knowledge production has been nurtured even more by the intensification of globalisation of the world economy. However, it should be pointed out that although both theoretical traditions have developed in parallel, there are notable points of convergence.

The theoretical framework of trade preceded the establishment of economics as an academic discipline (see, e.g., the contributions from the schools of cameralism and mercantilism). However, it did not properly materialise until the contributions of classic authors like Adam Smith (1776) and David Ricardo (1817). It was the latter, particularly, who laid the foundations for what is nowadays considered the Traditional Theory of International Trade, also known as the Theory of Comparative Advantage. This contribution was the basis for later developments in the framework of neoclassical theory, through the Heckscher-Ohlin model (1919/1933), in this case supported on the source of resource provision. This theoretical corpus turning around the idea of Ricardian comparative advantage was for a long time the theoretical framework that helped explaining traditional trade based on intersectorial (inter-industrial) trade flows, i.e., the exchange of different products.

However, the phenomenon of intra-industrial trade (exchange of differentiated varieties of the same type of product), discovered in the middle of the 20th century, was not explained until the surge of the New Theories of International Trade (Linder 1961; Balassa 1966; Grubel and Lloyd 1975; Krugman 1979, 1980; Krugman and Helpman 1985; 
Krugman and Obstfeld 1995; Fontagné et al. 2005, among others). This new theoretical corpus provided an explanation for the new pattern of trade specialisation based on the convergence of factors linked to contexts of imperfect competition, such as economies of scale, product differentiation, and a mass of consumers with diverse preferences.

The phenomenon of the internationalisation of production (foreign direct investment), which was incorporated at a later date in the discipline of economics, has also been extensively dealt with in the literature. In this regard, various theoretical approaches that have aimed to inquire into both its explanatory factors and its direction can be mentioned.

The Neoclassical Theory of International Trade establishes as a cause of this phenomenon the search for better returns for a factor - capital - whose accumulation is assumed to be exposed to decreasing returns. This theoretical focus established the hypothesis according to which FDI flows would run from more developed countries disposing of more capital to less developed countries, whose lower availability of capital promised higher returns for this investment. However, even though this theoretical explanation might have fitted observed findings when internationalisation was in its initial stages, it has been at odds with reality for several decades. This reality continues to be characterised by a heavy concentration of investment flows in the more developed countries - both regarding their origin and their destination.

Other noteworthy theoretical approaches tended to focus on more specific explanatory factors, particularly the Foreign Portfolio Investment Theory, the Monopolistic Advantage Theory, and the Product Life Cycle Theory (Vernon 1966). However, nowadays the most widespread approach to FDI is the Eclectic Theory or OLI Paradigm (Dunning 1993) which explains the observed phenomenon by arguing that multinational companies would make use of three kinds of advantage: ownership advantages, location advantages, and internalisation advantages.

\subsection{Theoretical and conceptual approach to intra-industrial trade}

On the theoretical level, the intra-industrial trade problem began in the 1960s with the studies of Verdoorn (1960), Balassa (1963) and Grubel (1967), among others, whose main reference was constituted by the most ambitious process of economic integration of that time: the European Economic Community (now the European Union), created by the 1957 Treaty of Rome. These authors began with the empirical observation that an increasing part of the trade flows between the countries being integrated matched a specialisation pattern different from the traditional inter-industrial one, consisting of the exchange of different products. What was new was that a growing part of the international 
trade exchanges took place within the same industries and sectors. This new form of international trade gave rise to the economic concept which today is known as intraindustrial trade.

There have been notable developments in analysis of intra-industrial trade, especially from the New Theories of International Trade which since the 1990s have increasingly incorporated new explanatory elements through the contributions of authors like Krugman (1995), Grossman and Helpman (1990), among others. These approaches have led to two different, and to a certain extent opposing, patterns of countries' trade specialisations: inter-industrial specialisation (exchange of different products) and intraindustrial specialisation (exchange of different varieties of the same product).

The explanations the current theoretical framework provides for each kind of specialisation are notably different. The case of inter-industrial specialisation adequately reflects the core of Classical and Neoclassical Theory of Trade, as exemplified by the explanation of David Ricardo, who showed that in order for two countries to engage in trade and in order for this trade to be beneficial for both, it sufficed that there was relative difference (and not an absolute one, as previously stated by Adam Smith) in the production costs of goods. Thus, Ricardo's Comparative Advantage Theory predicted that each country would tend to export those goods that it was able to produce at lower relative costs (although without managing to explain the reason for these differences). A century later, the Swedish economists Heckscher and Ohlin $(\mathrm{H}-\mathrm{O})$ offered an explanation for these relative cost differences referring to countries' unequal factor endowments, although it must be recognised that this proposition relied on several rather restrictive suppositions (two countries, two kinds of goods, no international mobility of factors, etc.). In short, this kind of explanations can help understand, for example, why some countries export certain types of goods and import other completely different ones.

However, neither the contribution of Ricardo nor that of $\mathrm{H}-\mathrm{O}$ can explain another increasingly important dimension of international trade: intra-industrial trade. In fact, their approaches even contradict the existence of this kind of trade, because according to $\mathrm{H}-\mathrm{O}$, export and import sectors should differ according to each country's advantages (exports) and disadvantages (imports). This prediction does not work well in a country which imports and exports varieties of the same product. This explanatory framework does not contemplate a situation in which an economy imports and exports similar goods or substitutes at the same time. Of course, the foregoing should not be understood as a critique of the theories of Ricardo and of Heckscher and Ohlin, considering that these were developed in a historical context when intra-industrial trade did not yet exist.

For the purpose of explanation, the two types of trade (inter and intra-industrial) can be 
differentiated using a simple model of two countries ( $A$ and $B$ ) and two types of goods $(X$ and $Y$ ) into different scenarios. In the first scenario (Figure 1 ), it is assumed that country $A$ has a comparative advantage in good $X$, and specialises in its production, while country $B$ specialises in good $\mathrm{Y}$. In this type of situation, the trade pattern drawn is an inter-industrial one, because the distribution of comparative advantages between the countries leads each of them to specialise in a single type of good, acquiring other goods from other countries. The trade relations established therefore in this situation are unilateral: trade flows related with each type of good flow in a single direction (good $X$ moves from country A to country $B$, and good $Y$ goes in the opposite direction). This is the type of trade specialisation considered in the models based on the Ricardian theory of comparative advantage and in the Heckscher-Ohlin model, with the only proviso that, in the former, the source of the comparative advantage lies in the technological differences between countries while, in the latter, this source derives from the greater or lesser factorial abundance related with production of the different goods.

Figure 1. Inter-industrial trade pattern (one-way flows)

\section{Country A}

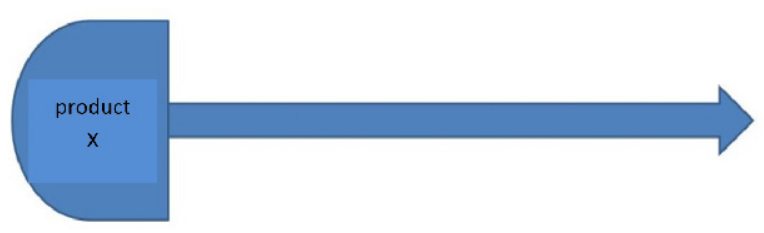

Country B

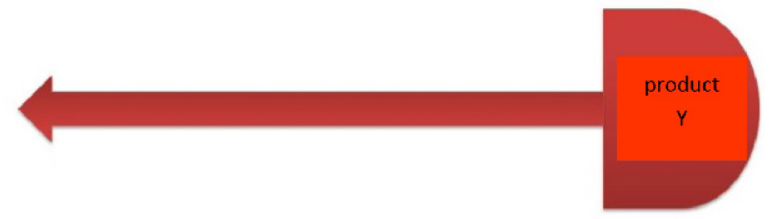

Source: Prepared by the authors

To understand the change in the trading pattern brought by the emergence of intraindustrial trade, let us suppose a second scenario (Figure 2 ) in which, unlike the previous one, country $\mathrm{B}$ also specialises in the production of a variety of good $\mathrm{X}$, taking advantage of the convergence of a series of factors. In this context, the trading pattern is clearly different from the one previously described, because now, although trade in good $Y$ is still unilateral and so inter-industrial in nature, trade in good $X$ has transformed into bilateral trade, that is to say, reciprocal exchange of the same good, and so is intra-industrial trade. 
Figure 2. Intra-industrial trade pattern (two-way flows)

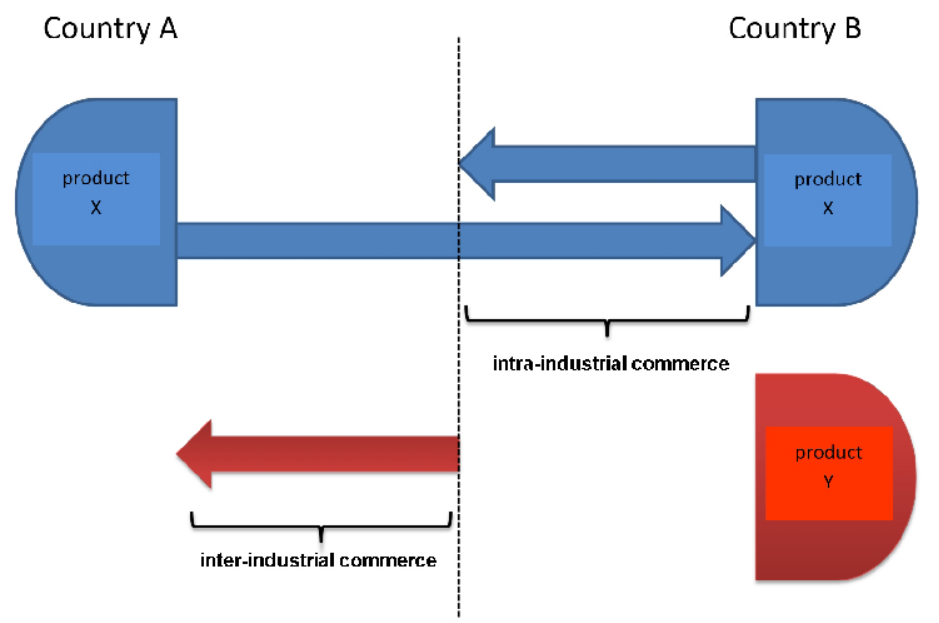

Source: Prepared by the authors

Among the explanatory elements modern trade theory provides us nowadays, through the models of imperfect competition, economies of scale and different varieties, intra-industrial trade appears as a result of the existence of increasing returns, companies capable of differentiating products without incurring additional costs and consumers with diverse preferences. On the one hand, economies of scale encourage concentration of production, giving rise to intensive commercial exchanges because ample demand is supplied from the same production point. On the other hand, each company can differentiate products from those of rival companies to cut demand into segments and thereby maintain a certain degree of monopoly over its variety. Finally, an indispensable requirement for the emergence of intra-industrial trade is the existence of a mass of end consumers with different preferences for the multiple varieties of a product on offer. It can be deduced that these three conditions tend to acquire greater importance in processes of economic integration in which economies of a certain development level are involved. This explains why certain areas of integration such as Europe have played the lead in this type of exchange.

Various processes have paralleled the surge of intra-industrial exchanges and, to a certain extent, these have also been driven by the latter. A specific role in this regard have played the advances in trade liberalisation, particularly of industrial products, that have occurred both worldwide (GATT, WTO) and regionally (EU, NAFTA, ASEAN, Mercosur, Central American Common Market, etc.), and which have been especially driven by the expansion of intracompany trade in the search for free mobility of both intermediate and final goods favourable to multinational companies. Some relatively recent studies (Navaretti, Haaland and Venables 2002; OECD 2002; Helpman 2006) introduce this last aspect into the 
analysis of intra-industrial trade, focusing on the role played by multinational companies which have become the authentic leaders of the current globalisation process.

To summarise, three explanatory models for intra-industrial trade can be identified: first, intra-industrial trade based on product differentiation and economies of scale (the most general, widespread explanation); secondly intra-industrial trade in functionally homogeneous goods (closely linked to frontier trade and periodic or seasonal trade); and finally, intra-industrial trade based on the technology gap as well as product life-cycle and internationalisation of the production process (intracompany trade).

Another differentiation is that existing between vertical and horizontal intra-industrial trade. In this regard, the term "horizontal intra-industrial trade" is used when two independent chains of production carry out international exchange of goods in the same industry with the same level of elaboration. The term "vertical intra-industrial trade" is used when the same chain of production is located in different countries, giving rise to re-exportation of goods (Dussel and León González 2001).

On the methodological level, indicators have been designed to quantify the greater or lesser presence of intra-industrial trade in the exchanges of different economies, notably the Grubel-Lloyd Index (GLI). This is built on the basis that bilateral trade flows between countries can be divided into two groups, one corresponding to inter-industrial trade, referring to net trade flow (a country's net exports to the rest of the world), the other to intra-industrial trade, which coincides with the remaining trade flows (total flow minus net flow). This index has values between 0 and 1 according to the nonexistence (value 0 ) or total existence (value 1) of intra-industrial trade. ${ }^{6}$ For calculation of the aggregated index, a corrected formula is often used in order to avoid the destabilising effect of trade balance. ${ }^{7}$ Other studies, such as that of Cárdenas and Dussel (2011), also use the index proposed by Hamilton and Kniest which measures the marginal intraindustry trade, i.e., only measuring aggregate trade as a whole.

One aspect to consider in measurement of intra-industrial trade is that it can be noticeably affected by the disaggregation level. The best way to deal with this is to use the greatest available sectorial disaggregation in order not to classify trade flows as intra-industrial trade when, in reality, they are inter-industrial. ${ }^{8}$ In this study, the statistical sources

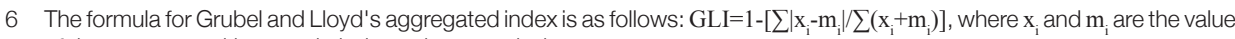
of the exports and imports in industry $\mathrm{i}$, respectively

7 The corrected version of the aggregated Grubel-Lloyd index is given by this formula:

GLI $_{\text {corrected }}=\left[\left(\mathrm{x}_{\mathrm{i}}+\mathrm{m}_{\mathrm{i}}\right)-\sum\left|\mathrm{x}_{\mathrm{i}}-\mathrm{m}_{\mathrm{i}}\right|\right] /\left[\sum\left(\mathrm{x}_{\mathrm{i}}+\mathrm{m}_{\mathrm{i}}\right)-\left|\sum \mathrm{x}_{\mathrm{i}}-\sum \mathrm{m}_{\mathrm{i}}\right|\right]$, where $\mathrm{x}_{\mathrm{i}}$ and $\mathrm{m}_{\mathrm{i}}$ are the value of the exports and imports, respectively, in industry $\mathrm{i}$.

8 It may sometimes occur that there is a high Grubel-Lloyd (GL) index due to an aggregation error which is not necessarily an indicator of intra-industrial trade (Haiti's trade in manufactured goods with the United States is a good example: the high GL index is the result of assembly operations reflecting provisions and prices of different factors) (Bulmer-Thomas 2000). 
consulted for the cases of Mexico and Brazil in their bilateral relations with their main European partners are taken from a complete sectorial disaggregation for the six digit level of the Harmonized Commodity Description and Coding System, with information from the United Nations Commodity Trade Statistics Database (UN Comtrade).

Furthermore, it should be pointed out that most studies considering intra-industrial trade refer to developed countries, whereas trade of so-called emerging countries is much less studied. One of the peculiarities of the present study, in turn, is that it focuses on trade of developed countries (EU countries) with emerging countries (Brazil and Mexico), - the two main exporting economies in LA.

\subsection{An approach to the theoretical and conceptual framework of international direct investment}

Next to intra-industrial trade this study focuses on FDI. Its dynamics may be associated with the search for resources, lower transaction costs, and multinational companies' strategies to access new markets. It is thus not difficult to understand that this phenomenon also has an impact on international trade in one way or another.

In the case at hand, a particular detail of interest is the fact that in recent years the economies of LAa have become one of the world regions with greatest attraction for and issuing of FDI flows. This is the opposite trend, in general terms, to that displayed by developed economies, including EU countries.

Although there are various definitions of FDI, one of the best-known is the one established by the International Monetary Fund (IMF), according to which it is a long-term investment based on the lasting interest of a non-resident investor who acquires a significant degree of influence or level of control over a resident company's administration and management. The lasting nature of the relationship is assumed to exist when at least $10 \%$ of the shares of the receiver company have been acquired, although financial transactions between companies of the same group, reinvestment of profits and real-estate investments are also calculated as FDI (International Monetary Fund 2009).

With regard to identification of explanatory factors behind FDI, it must be pointed out that there are many theories and empirical studies which have tried to shed light on this matter. In this regard, some of the best-known traditional explanations emerged from Theories of International Trade. 
Specifically, the neoclassical model of Heckscher-Ohlin (Heckscher 1919; Ohlin 1933) does not consider mobility of production factors (labour and capital), because this model assumes that price equalling of these factors is achieved through trade, so no incentives exist for their movement across countries' borders. However, Mundell (1957) showed that when there are barriers preventing free trade, incentives emerge for capital to move from countries where it is relatively plentiful (capital-abundant countries) to other countries where capital is relatively scarce in relation to the labour factor (labour-abundant countries). This is because the combination of countries' different factor endowments and restrictions on free movement of products through trade leads to international differences in the remuneration of the factors; these remuneration are higher for relatively scarce factors (the labour factor in capital-abundant countries and the capital factor in labour-abundant countries). Capital movement would eventually lead to an international balancing of the price of these factors.

This is how this theory explains the existence of FDI flows based on differences between countries in their relative endowments of production factors. These differences cause international capital movements in search of increased returns. Consequently, this theoretical model predicts that FDI flows would move from countries in which capital is relatively abundant (developed countries) towards countries in which this factor is relatively scarce (underdeveloped or developing countries). However, it should be stressed that the dynamics predicted by this theory are far from realistic, considering that FDI flows tend to run in the opposite direction as the one predicted. ${ }^{9}$

Another theory offering a combined explanation of trade flows and FDI is the Product Life-Cycle Theory formulated by Vernon (1966). This theory represents a turnabout with regard to traditional models of international trade, by shifting international differences in comparative costs to the background and concentrating its explanation on the life-cycle products typically go through from their emergence as innovations until they become standardised products for mass consumption. So FDI emerges from the need to maintain market share while a product moves along the path of its progressive standardisation, jeopardising the initial power of monopoly.

Although the product life-cycle hypothesis fits a continuum of situations, different stages can be identified for the purpose of illustration. In the first stage, a company launches an innovative product on the market and its earnings are channelled exclusively through monopoly trade (the typical case of a patented product), being exported from the "innovator" country to countries with a medium-to-high income level. In the second

9 Multiple studies, statistics and reports from official institutions and sources (UNCTAD, FMI, OECD...) have been observing for some time phenomenon that has already entered the category of empirical normality, consisting of most of the origins and destinations of FDI flows being developed countries. 
stage, when the product has surpassed its initial difficulties of market access and is in an incipient standardisation phase, FDI begins to flow from the innovator country to the medium-to-high income countries so that production can be carried out directly in those countries, enabling competition under better conditions with potential rival companies, benefiting from lower transport costs and other specific advantages (relatively abundant labour factor, production and technological capabilities, etc.). The original exports are thus replaced by direct supply from these markets as well as from the markets of other countries with a lower development level. In the third stage, the product has already reached a high level of standardisation and is oriented towards mass consumption. In this stage, the strategy to maintain market share necessarily includes cost reduction, evoking production relocation processes with FDI flows towards the countries with a lower development level, which end up becoming exporter countries to the rest of the world, including the initial innovator country.

The Product Life-Cycle Theory thus combines in a single explanatory framework trade and FDI, which appear as substitute instruments, oriented towards the maintenance of a market share threatened by the progressive standardisation of products and the consequent loss of monopoly power. In any case, it is a theory that has been criticised for its "speculative" nature and which does not manage to explain clearly the importance and influence of the various factors on investment decisions.

In addition, there are other theoretical arguments offering complementary if partial explanations about possible factors which might sometimes lie behind certain investment decisions. One of these refers to the International Portfolio Investment hypothesis, according to which companies make direct investment abroad to achieve greater diversification both of their activities and of their geographic location. This double diversification helps companies protect themselves from negative effects of economic cycles on their activity and, hence, on their profits. This theory can partly explain the phenomenon of reciprocal investment between large economic regions because, except for very serious world recessions, multinational companies could avoid the damaging effects arising from less important (national) shocks.

The Monopolistic Advantage Theory, in turn, assumes that companies basically carry out FDI with the aim of obtaining a position of some importance, even domination, in a world context characterised by the presence of globalised markets. In this regard, multinational companies would try to acquire competitors, suppliers and/or other companies that in some way were related with their production and commercial activity. On the empirical level, the most notable implications of this theory include the business concentration phenomena in which multinationals take part. 
From a more up-to-date point of view, it can be said that attempts to build an explanatory framework for FDI have basically been focused on theoretical models and empirical analyses of bilateral nature which do not take a key aspect into account: that decisions influencing FDI flows involve multilateral relations between regions. These relations are based on interdependencies generated between countries' characteristics and investment decisions (Blonigen et al. 2007). The various reasons that may bring about these interdependencies include the existence of agglomeration economies, the benefits deriving from establishment of an export platform oriented towards multiple markets, and the localisation criteria of a specific stage in a production chain.

Nowadays, there are various theoretical strands that try to explain the determining factors of FDI by focusing on industrial organisation. However, a distinction should first be made between two types of FDI which respond to different dynamics and rationales. Specifically, we are referring to the traditional separation between horizontal and vertical FDI, - a separation that originates in distinct investment strategies multinational companies can follow. In the case of horizontal FDI, this strategy is orientated towards finding markets, with the aim of enlarging the existing market. This type of strategy is closely linked to facets related with a market's size and structure, as well as trade and investment barriers. Therefore, a respective investment strategy would, on one hand, try to overcome barriers such as high transport costs or strong entry barriers and, on the other hand, aim at generating and take advantage of economies of scale (Markusen and Venables 2000).

There are various theoretical approaches to horizontal FDI, among which the "proximityconcentration" hypothesis (Horstmann and Markusen 1992; Brainard 1993, 1997) stands out. Accordingly, multinationals tend to expand their business horizontally, creating production centres in other countries, as long as the advantages arising from proximity to the consumers in these foreign markets are greater than the advantages associated with concentration of production. ${ }^{10}$

On the other hand, it is not difficult to see that this horizontal FDI concept also has implications in terms of international trade. In fact, a horizontal expansion strategy using FDI may lead to changes which affect both the direction of trade flows and their intensity. From this point of view, it is interpreted that FDI behaves in a way like a replacement mechanism for international trade (Egger et al. 2004). A typical example in this regard is the case of a multinational company opting to establish a production centre in a foreign country with the aim of supplying the consumers in that market and nearby markets (countries in the proximity) directly, consequently reducing its exports from the country of origin.

10 It should be pointed out that most of the models provided are bilateral (two economies) and based on other simplifying assumptions, such as two differentiated products, the same, homothetic demand function, constant substitution elasticity, etc. 
The other type of FDI - vertical FDI - is based on an entirely different rationale as compared to that operating in horizontal FDI. In this case, the objective behind a vertical investment strategy is to find specific supplies and assets (raw materials, energy resources, etc.) necessary for its production cycle. The essence of vertical FDI, therefore, lies in international differences in factor endowment and is directed towards territories endowed with production resources or factors of interest which are scarce or even nil (non-existent resources) in a given country of origin.

Relevant progress in the theoretical conceptualization of vertical FDI can be found in the works of Helpman (1984, 2006), Helpman and Krugman (1985), Markusen (1984, 2002), Ethier and Horn (1990), Brainard (1993), Markusen and Venables (1998, 2000) and Markusen and Maskus (2002), among others. One particular treatment is given by the Factor Proportions Theory (Helpman 1984; Markusen 1984; Helpman and Krugman 1985), which states that FDI would flow towards locations where the relative abundance of a factor allowed its acquisition at a low cost. Essentially, this theory proposes a model based on complementarity between international trade and FDI which explains the existence of investments based on the existence of incentives which are not cancelled out through trade and give rise to the location of production plants in countries with relatively abundant endowment of the labour factor, and from which the different markets can be supplied.

Other explanations deriving from the concept of vertical FDI and implied in the analysis of global value chains deserve special mention. These developments are based on the idea of vertical specialisation (Findlay 1978; Feenstra 1998; Blonigen et al. 2007), which conceives the creation of value chains layered in different stages of the same production cycle. According to this approach, FDI is a mechanism allowing specific advantages associated with different locations to be taken advantage of, leading to each country specialising in a specific segment of a product's value chain.

From a general perspective, FDI associated with the creation of global value chains also has important implications for international trade, because it gives a new shape to trade flows in which countries import the necessary supplies for the production of a kind of good which will then be exported to a different country. These processes lead to a logic according to which the goal of becoming an important great exporter necessarily implies to also become an important importer. A greater or lesser amount of trade barriers and investment, as well as the costs of factors and production resources in the country receiving the investment, constitute critical elements for an agent interested in partaking in these chains.

There are also theoretical approaches which try to combine the two concepts of FDI. One such is the "capital-knowledge" model of Markusen (1995), where knowledge is a critical factor in investment decision-making, and may be created, fragmented and disseminated 
across borders to the different subsidiaries. This model develops a scenario in which central plants tend to be located in territories characterised by a relatively abundant endowment of qualified labour, while production plants are located in places with a relatively abundant endowment of unqualified labour. In short, unlike the basic model of horizontal FDI, this model includes the existence of different factorial proportions between the central plant and subsidiaries and allows horizontal FDI decisions to be combined with other vertical decisions (Blonigen et al. 2007).

Today, the Eclectic Theory or OLI Paradigm (Dunning 1980, 1993) has become widespread, which posits the idea that investment decisions of multinational companies respond to the simultaneous existence and exploitation of three kinds of advantage: ownership advantages, location advantages, and internalisation advantages. The first type of advantage (ownership advantages) implies that a corporation owns a tangible and / or intangible asset which gives the corporation a competitive advantage over its rivals. The assets providing this kind of advantage are diverse, including greater production capacity, greater technical know-how, patents, brands, etc. In any case, this kind of advantage alone cannot explain the FDI decisions of multinational enterprises, but needs to be combined with other types of advantage to become a determinant of FDI flows.

The second kind of advantage of the OLI Paradigm is location advantages, which refer to the specific characteristics (stimuli) of a particular territory (country), converting it into an attractive place for an enterprise to invest and establish itself there, with the aim of exploiting these advantages. The stimuli associated with this type of advantage are varied and either of a static nature (those based on provision of resources, for example) or dynamic (legal and institutional framework, tax incentives, political incentives, innovation capabilities and systems, etc.). Advantages of this type, particularly those associated with the location of the FDI destination, have been widely studied in the literature, with those associated with the size of the internal market and availability of low-cost labour having acquired the most importance.

The third type of advantage considered by the OLI Paradigm is internalisation advantages; it refers to the transaction ${ }^{11}$ and coordination costs inherent in any process of production externalisation, such as franchises, ${ }^{12}$ as well as the reduction of the risks related to this kind of process to a minimum. ${ }^{13}$

11 To a certain extent, in considering this kind of advantage, the Eclectic Theory is an extension of the transaction costs theory of Ronald Coase (1937).

12 In this regard, it should be taken into account that if a firm chooses to set up franchise or license agreements in order to access a foreign market, it loses a proportion of the total potential profits arising from exploitation and supply of that market due to costs implied by the entering into contracts with third party companies or the control costs of compliance with contracts and agreements.

13 A company could also lose part of the total potential profit because of risks arising from externalities of production associated with the problem of asymmetric information. For example, the risk exists that the local company appropriates the multinational corporation's technology and know-how (the latter is practically unavoidable). 
In this regard, it must be admitted that companies have different alternatives such as franchises, trade and FDI to internationalise and supply foreign markets. While these alternatives have different advantages and drawbacks, it should be stressed that FDI avoids the inconveniences of the others while combining all their advantages. Although Dunning's Eclectic Theory has gained supporters over the past decades because of its explanatory depth and amplitude, some weaknesses such as its low predictive power have also become manifest.

Finally the profound changes taking place on the world stage mean that the interpretation of FDI flows is becoming increasingly complex. This has also implied the traditional separation between horizontal and vertical FDI to become relatively obsolete and difficult to include in the explanation of multinational corporations' strategies. New explanatory theories of FDI emerged, such as the Export Platform Theory, the main novelty of which is that it integrates supply to regional markets through the establishment of an export platform attending to the markets of third countries (Motta and Norman 1996; Ekholm et al. 2007; Baltagi et al. 2007; Bergstrand and Egger 2007). In this regard, there are elements related with the regulator framework that may be decisive factors when it comes to facilitating establishment of an export platform, such as treaties and agreements to reduce trade and investment barriers between countries in particular region. In this case, in a way, a substitution relationship for FDI is established among the potential receiving economies, because only one will be chosen to operate as the platform for exports to the surrounding markets.

The Export Platform Approach manages to combine in a single explanatory framework the two FDI categories (horizontal and vertical) together with a multilateral approach (relations between several countries), as it includes the aim of supplying foreign markets (the logic behind horizontal FDI) with exploitation of the advantages of localisation associated with the factor endowment of the country behaving as "host" to the FDI and which will act as the export platform. This theoretical explanation also allows highly relevant aspects to be considered, such as the increasing heterogeneity and dependence characterising FDI flows,from a perspective in which the territory takes a central role in integrating different investment strategies. ${ }^{14}$ As a result, there is growing interest in the study of the spatial relations and structures behind FDI decisions that can only be understood from a multilateral perspective.

It should be pointed out that in the simplest models, in which there have also been developments in the field of New Economic Geography, the size of the potential market is not as important as the specific characteristics of the economy aspiring to become the export platform,

14 Bear in mind that not only the characteristics of the country or territory where an export platform is set up are a critical factor, but so are the the characteristics of the potential market surrounding it. 
although transport costs can be decisive (Blonigen et al. 2007). Complex FDI models, ${ }^{15}$ which incorporate the existence of global value chains, consider the possibility of linkages between FDI flows of neighbouring economies, combining the search for markets with complementarity based on exploiting advantages associated with specific assets. In this case, the network of relations can become highly complex and have an impact on the coexistence of trade flows of intermediate and final goods, as well as intra- and inter-firm trade.

\subsection{Towards the construction of an integrated explanatory framework of intra-industrial trade and foreign direct investment}

As has been shown, multiple points of convergence between theoretical approaches related to trade and FDI exist. In this regard, we have seen how the "traditional" theoretical framework for international trade already found explanations for FDI against the background of the presence of barriers to its development (Mundell 1957). Another example is the Product Life-Cycle Theory (Vernon 1966), which envisions the interlaced sequence of trade flows and FDI with the aim to maintain a certain share of the market. A common trait of these initial theoretical approaches was their understanding of FDI as a substitute for trade (Myro 2014). Furthermore, subsequent strands such as Dunning's OLI paradigm (1993) use arguments which, in one way or another, identify FDI and trade as elements with different (but not unrelated) explanatory factors.

This convergence has enabled a more integrative and complete approach to two phenomena linked to internationalisation of economies which in reality are part of the actual globalisation process. It is precisely in the framework of this process that the conformation of global value chains becomes of particular relevance, and where the relation between FDI and trade acquires greater complexity, giving rise to mixed horizontal and vertical FDI.

With respect to later theoretical developments, relevant insights into the integration of the analysis of trade and of FDI have been provided. This line of studies initiated in the 1980s by Markusen (1984) and Helpman (1984) who aimed at integrating FDI in the framework of international trade theory and analysing the role of transnational corporations from the point of view of industrial organisation. As mentioned above, from the mid 1990s onwards, a number of authors (Brainard, Venables, Feenstra, Melitz and Blonigen, among others) have formulated interesting explanations (Myro 2014) contributing to these advances.

Additionally, these contributions have differentiated between horizontal and vertical FDI, - two kinds of investment which have ultimately tended to co-occur in an increasingly

15 See, e.g., Baltagi et al. (2007), or Hayakawa and Matsuura (2011), for an econometric application of this type of model. 
complex manner. In a way, the idea of a "world company", a term increasingly used in recent years, allows for the integration of the two co-occurring processes in which intrafirm relations play a central role. In fact, the internationalisation processes occurring now are of ever greater complexity (Helpman 2011), which renders the in-depth analysis of the differentiating traits underlying FDI flows between these countries difficult, but at the same time enormously interesting. There is no doubt that the changes occurring in the world economy in recent decades, where global value chains, complex production networks and intra-firm trade are becoming increasingly important, need to be seriously considered in the new intra-industrial trade flows.

In short, the phenomena related to trade and FDI require an integrated analysis from a multilateral perspective by modern FDI theoretical approaches (consider, for example, what has been said about the exporter platform hypothesis). This comprehensive analysis is the only way to achieve an understanding of the logic and explanatory factors underlying both investment decisions and establishment of the trade flows occurring between countries. FDI cannot be understood without considering the respective trade flows, and the latter, in turn, cannot be understood without considering the decisions underlying investment. 


\section{CHANGES IN THE WORLD ECONOMIC SCENARIO: GLOBALISATION AND GLOBAL VALUE CHAINS}

\subsection{Globalisation as engine of change of the world economy}

In recent decades there have been significant changes on the global economic stage, expressed in different forms and degrees of depth. Essentially, we are facing a phase of (often difficult) transition between a previous and a new era. Like any historical process, this phase is subject to contingencies and to towards new and unexpected directions (Robinson 2013).

All types of change tend to be associated with globalisation. However, it should be stressed that there is no unequivocal consensus on the beginnings of globalisation and, therefore, about the definition of the phenomenon itself. Some authors who refer to the revolutionary nature of the economic change, indicate that we are now experiencing a rupture (Caputo 1999; Martínez González-Tablas 2003; Guillén 2007) or systemic emergency (Boisier 2003); others, by contrast, question this view. For example, Krugman (2004) considers it a presumption to say that the global economy was invented at the end of the 20th century. Other authors, like Amin or Wallerstein, argue that the world-system is about 500 years old, while André Gunder Frank and Barry K. Gills (1993) put its origin back to five thousand years ago (Martínez González-Tablas 2000). Others maintain that there were no fundamental changes at all and that globalisation was no more than the imperialist stage studied by Marxist authors like Lenin, Bujarin, Hilferding, Luxembourg and Kautsky. In contrast, Hardt and Negri (2005) claim that we are facing a new, superior phase of capitalism which goes beyond imperialism and which they call Empire.

In an attempt to integrate all the foregoing, Arthur Guillén (2007) proposes that, although there have been different globalising waves throughout history, from the Mediterranean 
cities of the 14th century, to the trading and colonial capitalism of the 15th to 18th centuries, the industrial capitalism of the 19th-century, or to the birth and development of the monopolistic capitalism of the end of the 19th and beginning of the 20th centuries, the present globalisation process has specific features converting it to something of a qualitatively distinct nature vis-à-vis the earlier cases. For instance, it is associated with the technological revolution that has enabled instantaneous flows of speculative financial capital as well as the fragmentation and production relocation which have led to the development of intra-firm and intra-industry trade, all of which has favoured the unprecedented expansion of trade and investment flows that has taken place in recent decades (Lopez and Peláez 2010). ${ }^{16}$

Robinson (2013) wonders: Does globalisation refer to a process or to a condition? Is it a new phenomenon dating back to the end of the 20th century? Is it the culmination of centuries of capitalism and modernity? Or has it been occurring for thousands of years? Is it the core of the economic, political or cultural process? Is it adequate to conceive of globalisation as a continuation of earlier historical processes in quantitative terms? Or should we understand it as a discontinuity, a qualitative change, and an entirely new era? To him, globalisation constitutes a transition from a world economy to a global economy, a new era (not a rupture or continuity per se) in the history of global capitalism. That is to say, for Robinson (2013) globalisation represents a fundamental change in the global social structure which changes and transforms the actual functioning of the system we live in.

In previous eras, every country developed its national economy, and the various national economies connected with each other by trade and finance in an integrated international market called the world economy. Different national economies and forms of production became connected in a larger social formation or world system. Each country developed national accumulation circuits which were externally linked to other similar national circuits by the exchange of goods and capital flows. Today, we see that this has changed, as there is a growing globalisation of the production process. In this process, national systems of domestic production have become fragmented and integrated externally as parts of new national circuits of accumulation (Robinson 2013).

Today we can say that all multinational enterprises participate in global circuits of accumulation, intra-industrial trade has intensified and intra-firm trade has emerged. The latter was non-existent prior to globalisation, which we take to be a historical-structural process with a material basis in the technological revolution which has enabled relocation

16 However, other authors such as O’Rourke and Williamson (1999), Lindert and Williamson (2002), Obstfeld and Taylor (2002) and Findlay and O'Rourke (2002) question this idea, arguing that, while the mobility of goods and factors across borders have reached unprecedented figures, it is probable that international mobility of goods and capital (in relative terms) is no greater than a century ago. 
of production which has been accompanied by incomplete deregulation of markets (product and capital markets, but not the labour market) and is an irreversible process. What is reversible is the model of management and regulation that has accompanied globalisation, since it corresponds to the earlier logic of a world economy. To confuse globalisation and its regulation as if these would constitute the same phenomenon would mean to fall into positions similar to those adopted by the Luddite movement in industrialrevolution England. Globalisation is structural, while its management and regulation are cyclical and must give way to a new institutional architecture responding to the new logic. To consider globalisation and its regulation as one phenomenon is thus to attribute them a post-factum existence, equivalent to an understanding of our lives in the present with the end of history.

Globalisation is a phenomenon that did not begin 5,000 years ago, nor 500 years ago, nor with imperialism. ${ }^{17}$ It is capitalist in its content, but has features that make it different, although now polarization is even greater than in any of the forms capitalism has assumed in its history, since it also excludes entire regions of the world and even regions of the countries it includes.

The successive technological revolutions, particularly those associated with the new information and communication technologies, provided productive and financial capital with greater mobility and flexibility, which has evoked production relocation and the development of intra-firm trade, which have been unimportant previously, as well as the so-called model of accumulation with financial predominance. The main participants in production, consumption, flows of FDI and trade are the industrialised and so-called emerging countries, while low and medium income countries are only included when they are functional or have certain characteristics that allow them to be integrated in the accumulation of global capital, otherwise they are not of interest and dispensable. This is the nature of the new international division of labour, where countries or regions within countries that are not included in globalisation have remained locked in an obsolete division of labour. In this case, the main form social distortions take is the increase in the very poor, excluded masses (Amin 2005). The recent heavy migratory waves in both the Mediterranean and North America are mainly, though not exclusively, the result of these trends and of new conflicts, and they are mounting in a global tragedy. The countries and regions included in this process can give false impressions, because even though they marginally increased their participation in production, FDI and trade in labourintensive manufacturing or fragmented parts of the global factory, their integration is subordinate to the production relocation needs of the industrialised countries, to which, for this activity, they are interesting as producers rather than as consumers. The prewhen the first human populations crossed the Bering Strait 15,000 or 20,000 years ago. 
globalisation distinction between industrialized and non-industrialized countries or those exporting manufactured goods or raw materials has undergone important changes, because some medium and, to a slightly lesser extent, low-income countries have been incorporated in the fragmented mechanism of the global factory and "produce" and "export" manufactured products as new industrial enclaves that are part of the extension of industrialised countries' production relocation process beyond their national borders, as an extension of the production process at a global level.

\subsection{The emergence of global value chains}

International trade has undergone important changes in recent decades. Reduced tariff and Non-tariff barriers and technological changes have favoured internationalisation of production processes, in which some services which had not been not marketable have become relevant (Ferrando 2013).

World production has multiplied nearly 6 times since 1980 while trade in goods and services has multiplied 9 times measured in today's dollars. In constant \$2005, world production has multiplied by 1.5 times, and trade in goods and services by 4.7 times. Limiting ourselves to the study period, 1993-2013, while world production in 2005 dollars grew 0.7 times, trade in goods and services did so 2.2 times. ${ }^{18}$ That is to say, world trade grew far faster than actual production; this being one of the most frequently mentioned empirical regularities when the globalisation process is discussed.

It is evident that as a result of the changes that have occurred in global production, any country's exports include a greater amount of aggregate foreign value and few products are made in a single country and have only aggregate domestic value. Most global trade includes imported supplies and even supplies from third countries. Part of this trade in manufactured goods, raw materials and natural resources is also driven by cross-border FDI operating worldwide. International trade and investment are heavily interconnected through networks of production of goods and of companies that invest all over the world, and in the commercialisation of supplies belonging to cross-border value chains with different levels of complexity. These value chains, whether intra-company or inter-firm, regional or global, are called global value chains or GVC (Ferrando 2013).

The World Trade Organisation (WTO) has suggested that, nowadays, companies' operations, from product conception and component manufacture to assembly and sale

18 The figures were calculated from World Development Indicators in the World DataBank. Available from http//databank.worldbank.org/data/reports.aspx?source=world-development-indicators (accessed 20 July 2015). 
are distributed throughout the world, creating international production chains. Every day, the number of products "Made in the World" increase, ${ }^{19}$ as compared to products "Made in the EU", "Made in Brazil" or "Made in México".

According to World Investment Report. Global Value Chains: Investment and Trade for Development, success in international markets depends both on the ability to import high quality supplies and on the ability to export: intermediate supplies represent more than two thirds of goods and $70 \%$ of the services involved in international trade.

In the same study (World Investment Report 2013), it is suggested that nearly $60 \%$ of world trade today, equivalent to about $\$ 20$ billion, consists of trade of intermediate goods and services which are incorporated in various stages of production of goods and services for final consumption. The fragmentation of the production process of goods and services and the division of work and activities implied have led to the emergence of borderless production systems, which may be sequential chains or complex networks, which may in turn be global, regional or involve two countries. These systems are commonly called global value chains (GVCs).

"According to figures of the UNCTAD (2013), the average share of foreign aggregate value in developing countries' exports overall was $25 \%$ in 2010 , 3 percentage points below the world average (28\%), but significantly higher than that of the United States $(11 \%)$ and Japan (18\%). The EU has a high share of aggregate foreign value in international trade (39\%). However, this figure must be handled with care, because it includes a high intrazone trade, and the double bookkeeping that that involves should be taken into account" (Ferrando 2013: 5; own translation).

"There are various factors that applied differently depending on the country which affects the incorporation of aggregate domestic value in exports. The main ones are:

1. Size of the economy. Large economies, such as the U.S. or Japan, tend to have important internal value chains and depend less on foreign supplies. However, there are important exceptions such as China, Germany or the United Kingdom, whose exports depend on supplies from third countries.

2. Composition of exports and position in the GVCs. Countries with a large proportion of natural resources, petrol or other commodities in their exports, such as Russia or Saudi Arabia, tend to have greater aggregate value in trade, their exports are placed at the "start" of the GVCs and they require few imported

19 WTO database. Available online at: <https//www.wto.org/spanish/res_s/statis_s/miwi_s/miwi_s.htm> (accessed 22 July 2015). 
supplies. Countries exporting services on the other hand, such as India, tend to incorporate more value. In contrast, countries with export with a high chair in high segment industries may need to import more to generate exports.

3. Economic structure and export model. Countries with important ports or port infrastructure, such as Hong Kong, Singapore or the Netherlands, will have a greater share of aggregate foreign value and lower share of aggregate domestic value in their exports" (Ferrando 2013: 6, own translation).

It is to be expected that Mexico, because of the NAFTA, and EU countries will have a higher share in the GVCs, but these are figures which must be treated with care because of the double bookkeeping intra-zone trade may entail. In the case of Brazil, which is a large economy concentrated on the domestic market (relatively low openness ratio), a lower share in the global value chains is to be expected.

Graph 2.1. Openness ratio of the European Union, Latin America, Brazil and Mexico, 1993-2012

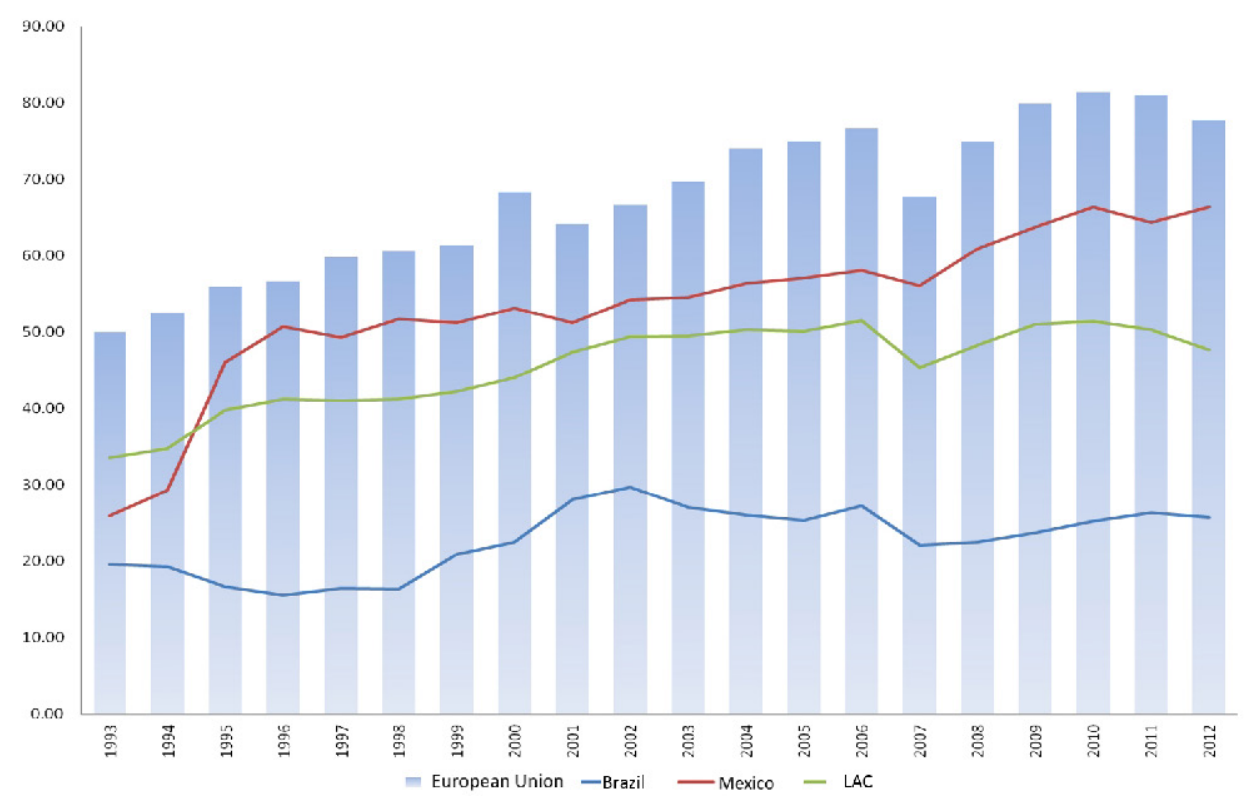

Source: World Development Indicators

It is considered that the countries or regions within countries can participate in aggregate value chains (upstream), which means aggregating foreign value from third countries to its exports, or (downstream), where its exports are incorporated as supplies for other products, for subsequent re-export. They are not exclusive, but generally occur at the 
same time. Countries increase their participation in GVCs both by increasing the imported content in exports (aggregate foreign value of exports) and by generation of greater aggregate value through commodities and services of intermediate use in third country exports. Of course, the latter mechanism has positive effects on the domestic economy, because it implies an increase in the incorporation of aggregate domestic value in exports (Ferrando 2013).

That is to say, GVCs depend on the section of the chain the region or country in question accounts for as well as on the percentage of aggregate value it has in the exported products. Thus, participating in low aggregate value activities is not the same as participating in the high value ones. 


\section{THE EUROPEAN UNION'S COMMERCIAL AND PRODUCTION RELATIONS WITH LATIN}

\section{AMERICA IN GENERAL AND BRAZIL AND MEXICO IN PARTICULAR: AN OVERVIEW}

As outlined in the previous section, the global context in which EU countries' relations with Brazil and Mexico take place is characterised by profound, rapid changes affecting both quantitative and qualitative aspects. In this regard, the deepening globalisation of the world economy and the establishment of global value chains are transforming the logic underlying the functioning of the world economy and, consequently also those of European and Latin American economies. For this reason, the changes observed today in the pattern of their production integration and intra-industrial insertion cannot be understood without placing them in context in the framework of this new global company logic.

Bearing in mind this context, and in order to initiate the analysis of the changes in the relations between Brazil and Mexico and the countries of the EU that have been occurring in recent decades, the next section offers a general overview of their characteristics and evolution.

\subsection{Trade between the European Union and Latin America:} Characteristics and evolution

For the purpose of an analysis of trade, it is necessary to start off with the relative importance of each of these regions in the world. In this regard, in 2014, the exports of all the members of the European Union (EU-28) came to a total of $\$ 6.16$ billion (including intra- 
community exports); while those of all the countries in $\mathrm{LA}^{20}$ amounted to $\$ 1.07$ billion. ${ }^{21}$ Bearing in mind that world exports in the same year totalled $\$ 19.0$ billion, the countries of the EU represented $32.4 \%$ (nearly a third) of global exports of goods, while those of the countries of LA represented 5.6\% (Graph 3.1). This demonstrates a considerable asymmetry in respect to the relative importance in trade between these two regions.

On the imports side, the differences are very similar. Global imports in 2014 amounted to $\$ 19.1$ billion, with the EU countries accounting for $\$ 6.1$ billion (32.1\%) of the world's imports. On the other hand, in the same year, LA countries imported goods of a total of $\$ 1.12$ million or $5.8 \%$ of the world's imports. ${ }^{22}$

Graph 3.1. Relative importance in world trade of that of European Union and Latin American countries (includes intra-EU trade) (2014)

Exports

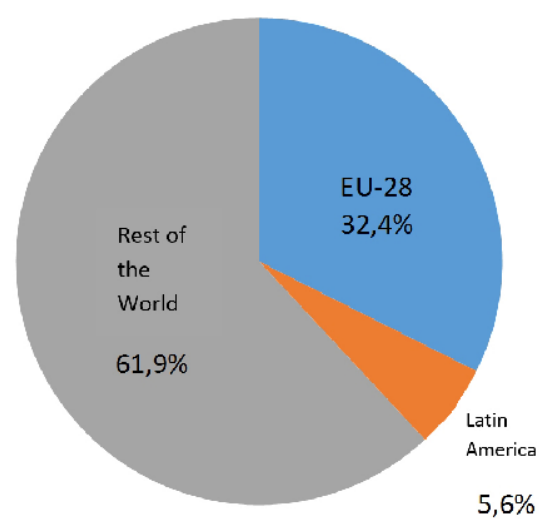

Imports

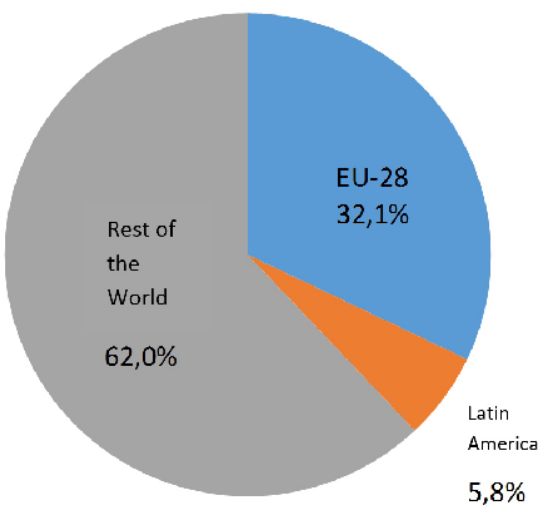

Source: Own elaboration based on WTO data and the DATACOMEX database of the Spanish Ministry of the Economy and Competitiveness

This gap is significantly reduced if intra-community trade (intra-EU) is excluded from the comparison, i.e., if the EUcountries are considered as a block, excluding trade between the member countries. In this case, their share in global trade is reduced to a percentage of about $15 \%$, while the weight of the LA countries rises above $7 \%$ of world trade (Graph 3.2).

20 The following LA countries are considered in this section's analysis: Argentina, Bolivia, Brazil, Chile, Colombia, Costa Rica, Cuba, Ecuador, El Salvador, Guatemala, Honduras, México, Nicaragua, Panama, Paraguay, Peru, the Dominican Republic, Uruguay and Venezuela.

21 International trade statistics from the World Trade Organisation (WTO). Commodities export data, value f.o.b. (US dollar at current prices).

22 International trade statistics from the WTO; commodities import data, value f.o.b. (US dollar at current prices). 
Graph 3.2. Relative importance in world trade of that of European Union and Latin American countries (not including intra-EU trade) (2014)

Exports

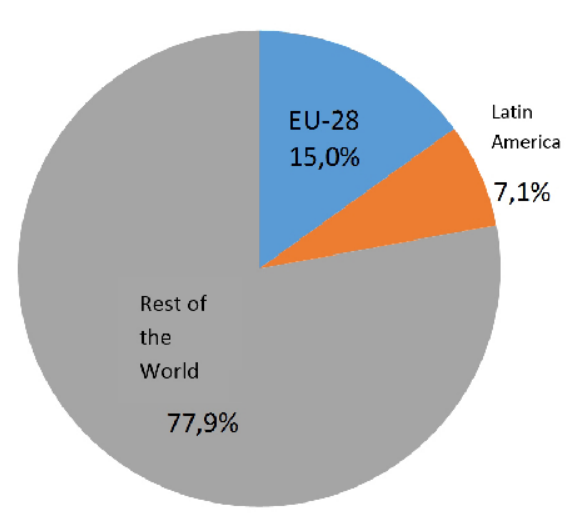

Imports

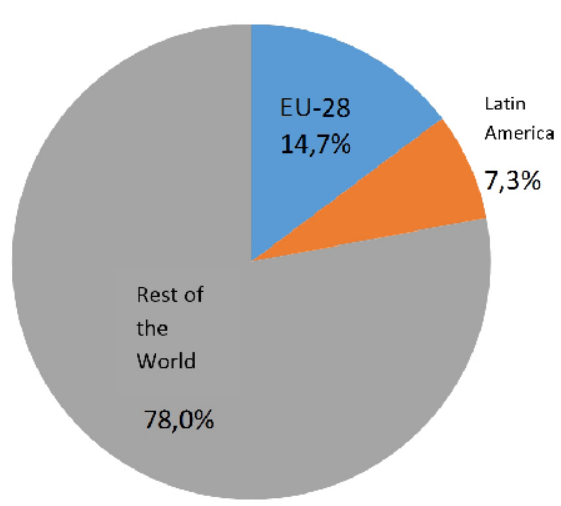

Source: Own elaboration based on WTO data and the DATACOMEX database of the Spanish Ministry of he Economy and Competitiveness

In recent decades, trade of the EU and LA has tended towards expansion, although from a comparative point of view, a more intensive growth is evident in the case of LA (Graph 3.3). Specifically, between 1999 and 2014, LA exports grew above world export rates at a cumulative annual rate of $9 \%$, while those of the EU (extra-EU) did so at a cumulative annual rate of $7.9 \%$. In the case of imports, the differences are somewhat larger, with the cumulative annual rate of $8.7 \%$ in the case of LA countries, as compared to a rate of $7.2 \%$ of EU imports. 
Graph 3.3. Comparative development of European Union (extra-EU), Latin American and world trade (1999-2014)

Compound annual growth rate, dollars at current prices
European Union
Latin America
World

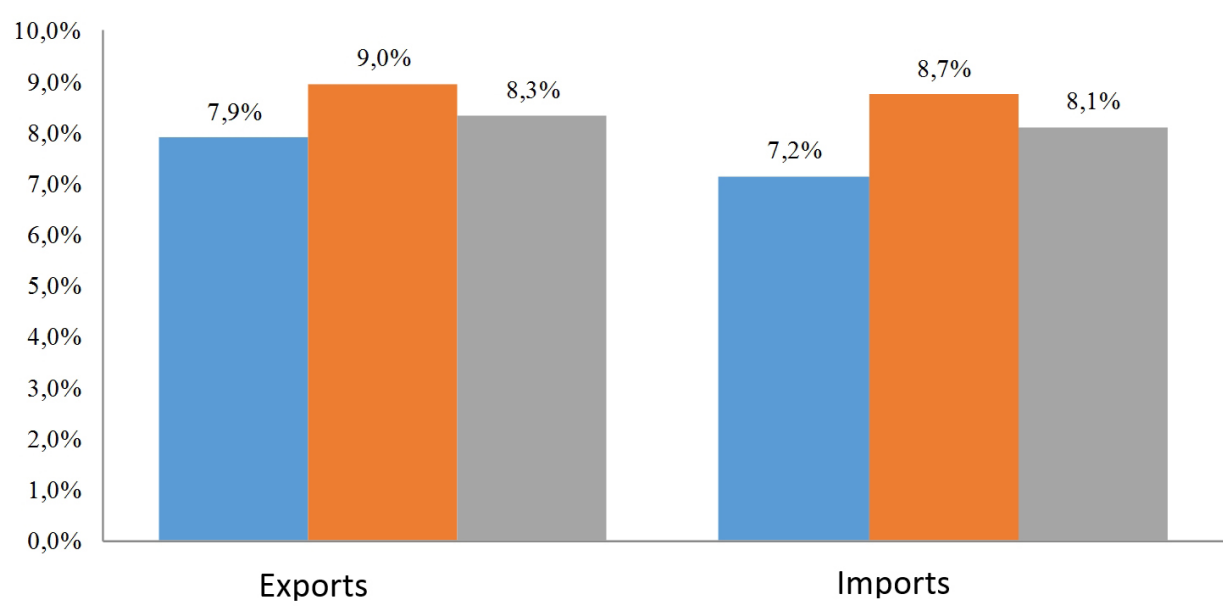

Source: Own elaboration based on WTO data

As a consequence of the disparate evolution, it should be noted that the EU has undergone a slower loss of relative weight in the world as an exporter and importer of recent decades (Graphs 3.4 and 3.5), while LA has slightly increased its relative importance, showing the emerging role of some of its economies. Something similar occurs with regard to trends when intra-EU trade is excluded, although in this case a slight decrease in the relative participation of LA countries in world trade can be stated. All these trends are part of a world context characterised by the irruption of other emerging economies, among which the BRICS, headed by China, stand out. 
Graph 3.4. Development of the relative weight of European Union and Latin American imports among world imports overall (1999-2014)

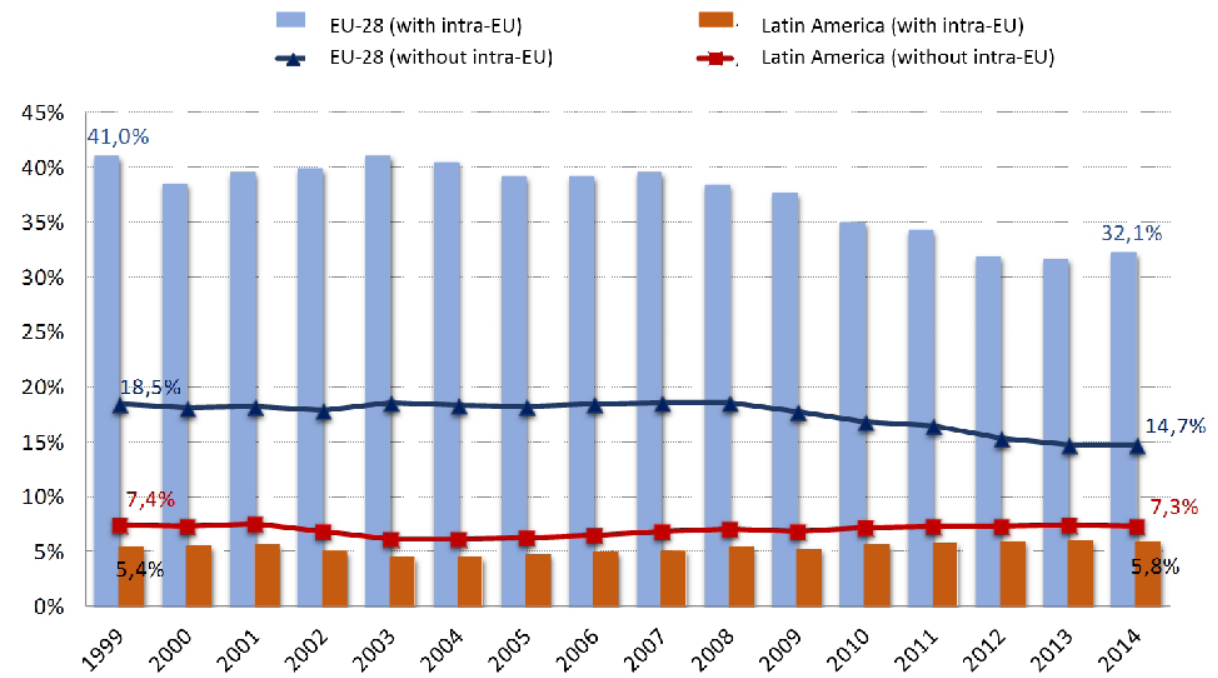

Source: Own elaboration based on WTO data and the DATACOMEX database of the Spanish Ministry of the Economy and Competitiveness

Graph 3.5. Development of the relative weight of European Union and Latin American imports among world imports overall (1999-2014)

$\begin{array}{ll}\text { EU-28 (with intra-EU) } & \text { Latin America (with intra-EU) } \\ \Rightarrow \quad \text { EU-28 (without intra-EU) } & \text { Latin America (without intra-EU) }\end{array}$

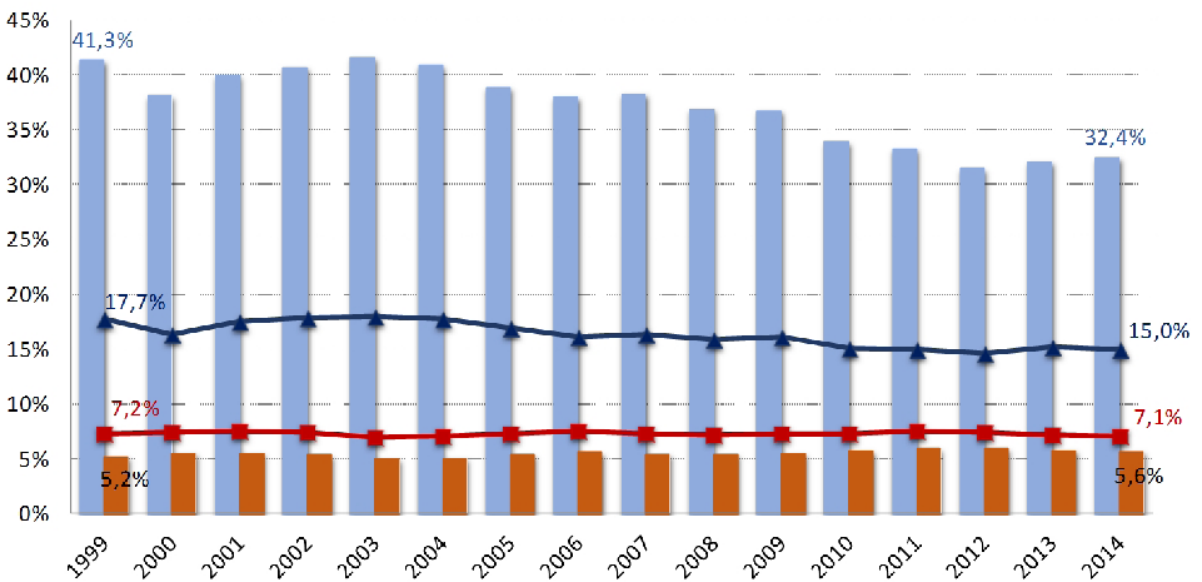

Source: Own elaboration based on WTO data and the DATACOMEX database of the Spanish Ministry of the Economy and Competitiveness 
Having assessed the importance of each of these regions in the world context, we now take a look at their degree of trade integration and how these have varied over time. In this regard, we can clearly observe an asymmetrical evolution of the relative importance in trade each region has represented for the other, respectively. EU countries have been losing weight in the trade relations of LA countries as a whole in the past two decades. This is especially true with regard to LA exports, where the EU has evolved from representing $16.7 \%$ (1993) to $11.8 \%$ (2014) and, to a lesser degree, with respect to imports, where EU countries have evolved from representing 16.0\% of LA's total imports in 1993 to $12.8 \%$ in 2014 (Graph 3.6).

Graph 3.6. Relative importance of trade flows with the European Union among Latin America's world trade (1993-2014)

$\rightarrow$ IMPORTS $\rightarrow$ EXPORTS

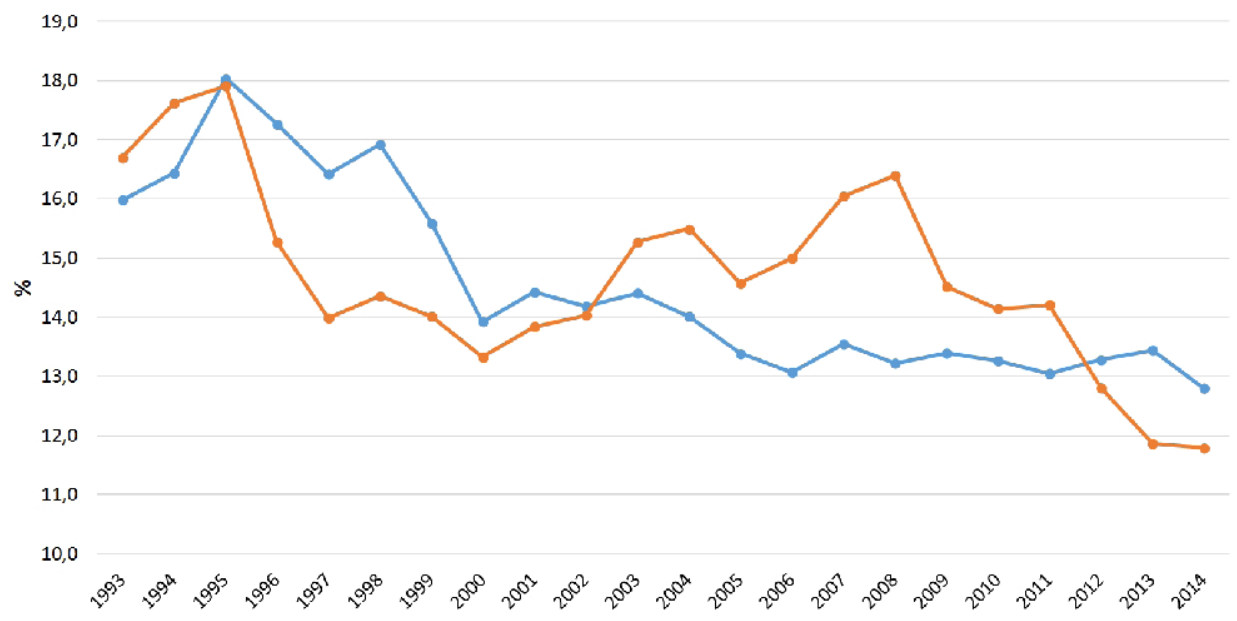

Source: Own elaboration based on WTO data and the DATACOMEX database of the Spanish Ministry of the Economy and Competitiveness

However, we do not observe proportions of a similar amount when examining the weight of in the trade relations of EU countries. In fact, in no case do EU exports to LA countries exceed $7.0 \%$ of their total sales abroad, nor do EU imports from LA exceed $6.5 \%$ in the period examined (Graph 3.7).

On the other hand, as has been pointed out, there is no reciprocal behaviour with regard to EU countries, as an increase in the relative weight of LA since the beginning of the millennium, both as destination for European countries' exports and in terms of the origin of its imports. However, this trend can begin to be seen to invert towards the end of the period under examination. 
Graph 3.7. Relative importance of trade flows with Latin America in the European Union countries' overall world trade (2000-2014)

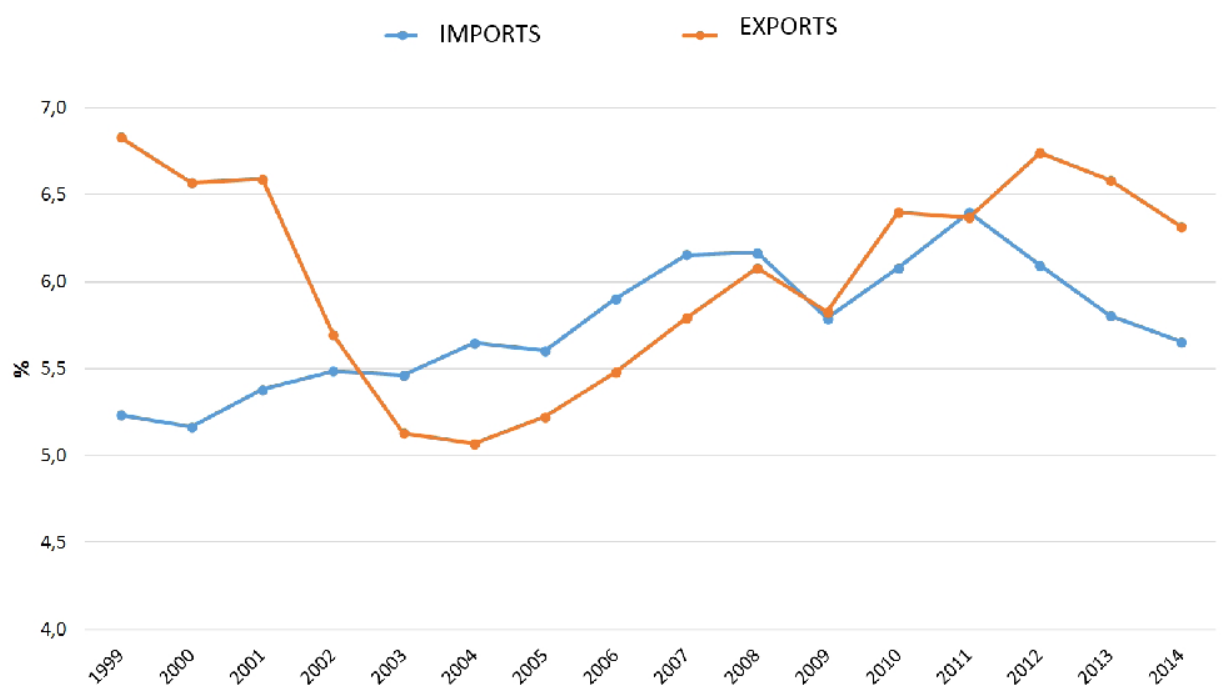

Source: Own elaboration based on WTO data and the DATACOMEX database of the Spanish Ministry of the Economy and Competitiveness

From a territorial perspective, trade flows between Latin and American countries and those of the EU are quite unequally distributed, a large part of this trade being concentrated in a small number of countries. Two of these economies, Brazil and Mexico stand out remarkably. Brazil, particularly, has a relative weight that means about a third of LA trade with the EU (Graph 3.8). These figures clearly place Brazil has the EU's main trade partner in LA.

Mexico, for its part, takes second place as the trade partner of European countries, though less because of its importance as an exporter (18.9\% of LA exports to the EU), but especially because of its importance on the import side, concentrating something over a quarter of this region's purchases the origin of which is the EU (26.4\%).

The other economies in the ranking of the EU's main LA trade partners are Argentina, Chile, Colombia, Peru and Venezuela. The remaining economies share $13.6 \%$ of LA exports and $15.4 \%$ of imports to/from EU countries. 
Graph 3.8. Latin American countries with greatest relative weight in Latin American trade relations with the European Union (2014)
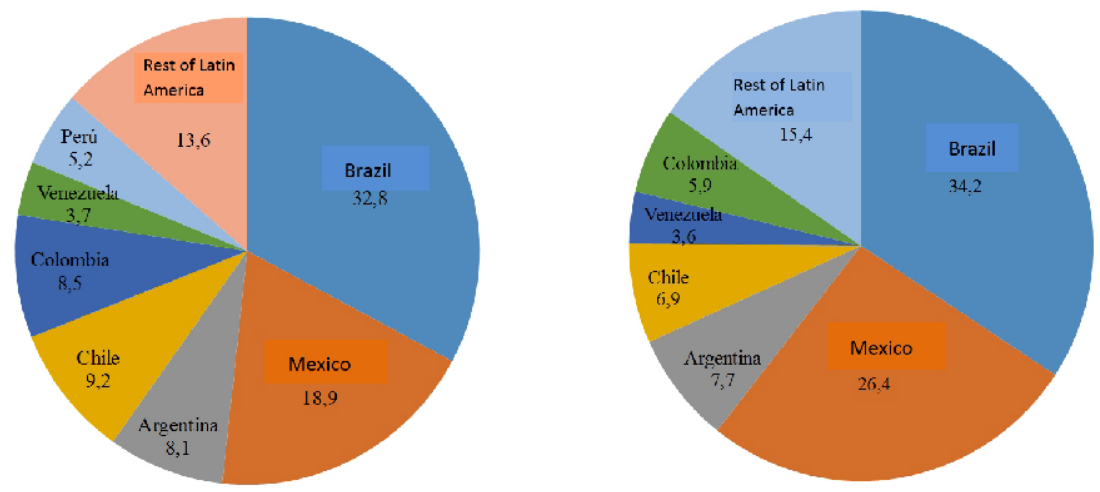

Source: Own elaboration based on WTO data and the DATACOMEX database of the Spanish Ministry of the Economy and Competitiveness

This relative importance is closely related with, among other factors, these economies' size, as it is obvious in the case of the Brazilian and Mexico economies. However, it is also of interest to analyse the importance the EU has to each of these LA economies in a framework of their respective trade relations with the world. This allows us to pick out a group of economies highly orientated towards exporting to the EU, among which Costa Rica stands out strikingly, with nearly $45 \%$ of its exports directed at the European market. With regard to the exports of the other LA economies, all of which have a relative importance of the EU as a destination below $20 \%$ of their total exports, Colombia and Brazil stand out, although with much lower differences and in a staggered way (Graph 3.9).

Mexico's lack of orientation towards the EU, with a weight of about $6 \%$ of its total exports, should also be noted, putting the earlier remarks about the importance of its trade weight in a different perspective. Behind this apparent paradox lies, first, the Mexican economy's heavy orientation towards the US market and, secondly, the growing presence of China in the area of the North American Free Trade Agreement (Rodil and López 2011; López et al. 2014). 
Graph 3.9. Relative weight of European Union exports among Latin American countries' total exports (2014)

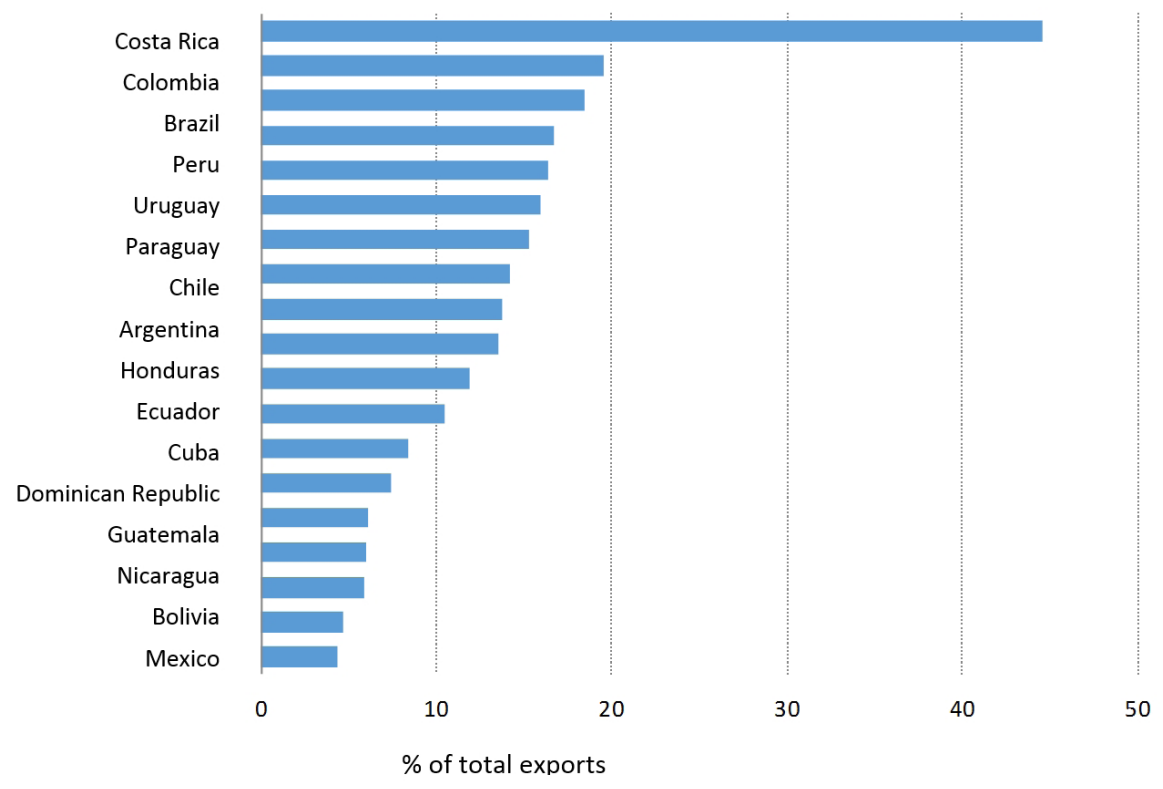

Source: Own elaboration based on WTO data and the DATACOMEX database of the Spanish Ministry of the Economy and Competitiveness

Something similar occurs when examining the import side (Graph 3.10), although in this case Brazil stands out in first place for its greater orientation towards the EU, with somewhat more than $20 \%$ of its purchases originating in that region. It is followed, with weights under $20 \%$ and staggered differences, by Uruguay, Argentina, Cuba and the rest of the countries of LA. In this case, Mexico shows greater orientation towards the EU (9\%) than observed for the case of exports. 
Graph 3.10. Relative weight of imports from the European Union among Latin American countries' total exports (2014)

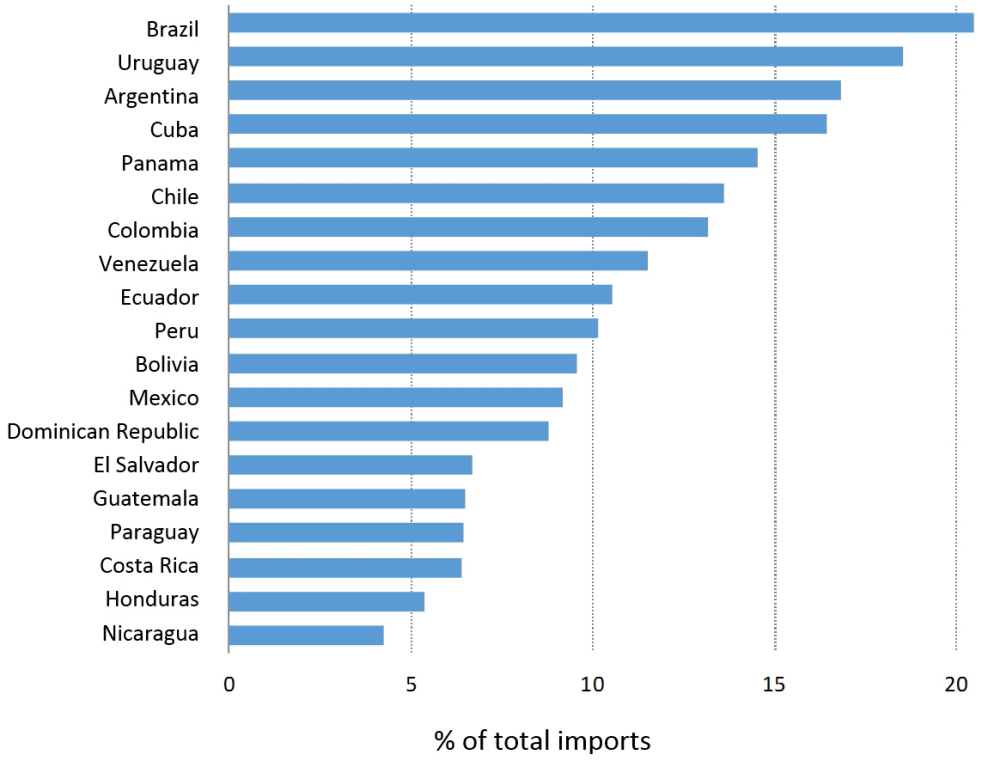

Source: Own elaboration based on WTO data and the DATACOMEX database of the Spanish Ministry of the Economy and Competitiveness

The conjunction of trade flows in and out leads us to analysis of the trade balance. From an aggregate perspective, it is observed that the overall trade balance from the point of view of LA countries follows a trend in parallel to the economic cycle, both in its relations with the world (Graph 3.11) and with the EU (Graph 3.12).

In this regard, three stages with different trends can be distinguished. The first stage runs from the beginning of the nineties to the beginning of this century, with a generalised presence of trade deficits which reached a maximum in 1998 and tended to fall from that year on. This second stage, running from 2002 to 2008, with a generalised presence of trade surpluses which reached their peak in 2006. Finally, the third stage, which began in 2008 and is characterised by a trend for trade balances to worsen. So, at the end of the period under examination, most LA countries had trade deficits both in their relations with the world and with the EU. In the latter case, Mexico and Brazil stand out especially. 
Graph 3.11. Trade balance of the countries of Latin America with the world (1993-2014)

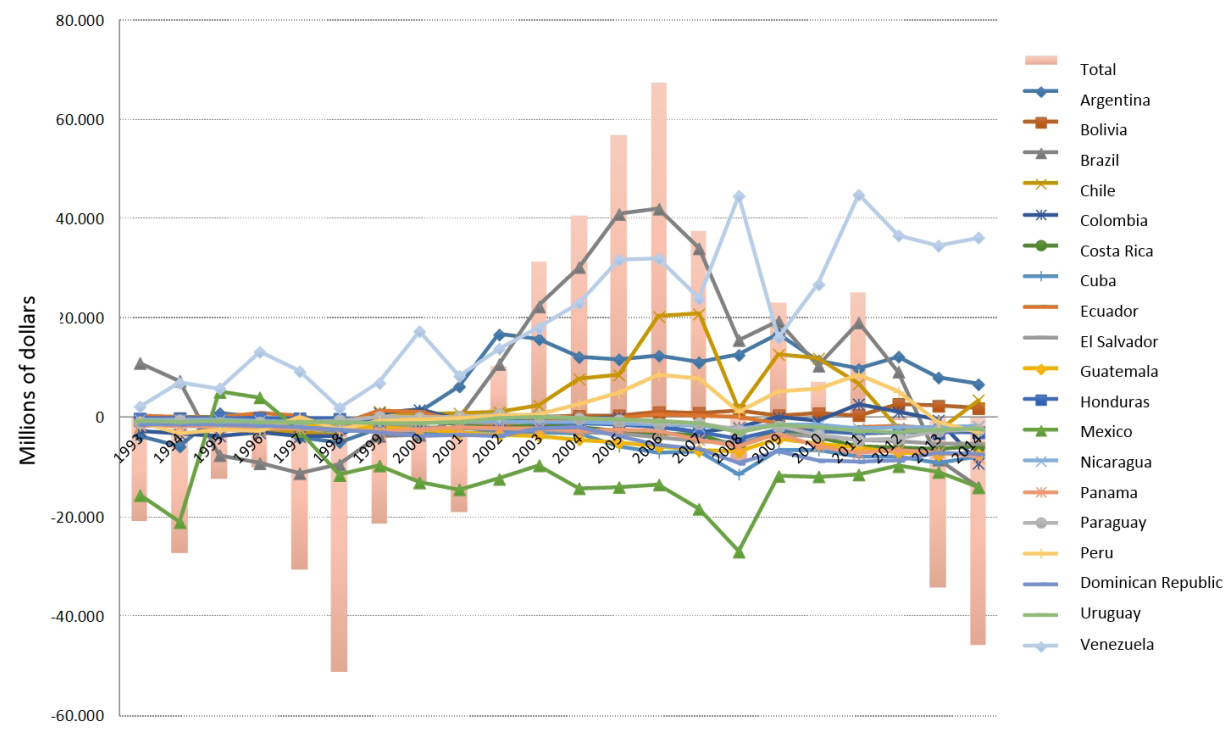

Source: Own elaboration based on WTO data and the DATACOMEX database of the Spanish Ministry of the Economy and Competitiveness

As has been said, in the period under examination (1993-2014), the trade balance of the countries of LA with the EU follows very similar trends to its trade balance with the world, although the figures are more moderate. Since 2012, LA's trade balance with the EU has increased substantially because of a heavy fall in its exports which have undergone a decrease of $17.9 \%$ between 2011 and 2014 , while its imports increased by $3.7 \%$ in the same time.

From the point of view of territorial disaggregation, two countries stand out for their great importance and influence on LA's global trade balance: Brazil and Mexico. The importance of these two economies' trade, particularly that of Brazil, in LA as a whole explains the fact that their trade balances are decisive when it comes to confronting LA's global trade balance with both the world and the EU. 
Graph 3.12. Trade balance of the countries of Latin America with the world (1993-2014)

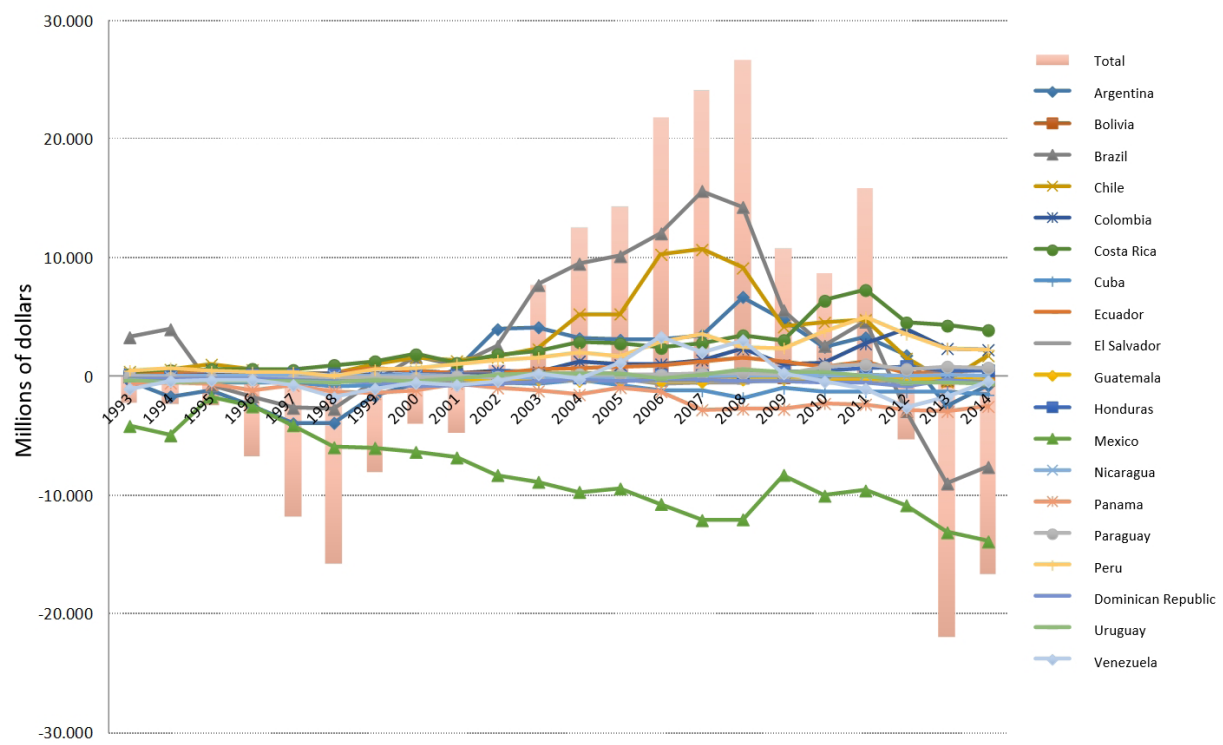

Source: Own elaboration based on WTO data and the DATACOMEX database of the Spanish Ministry of the Economy and Competitiveness

Graph 3.13. Trade balance of Latin America, Brazil and Mexico with the European Union (1993-2014)

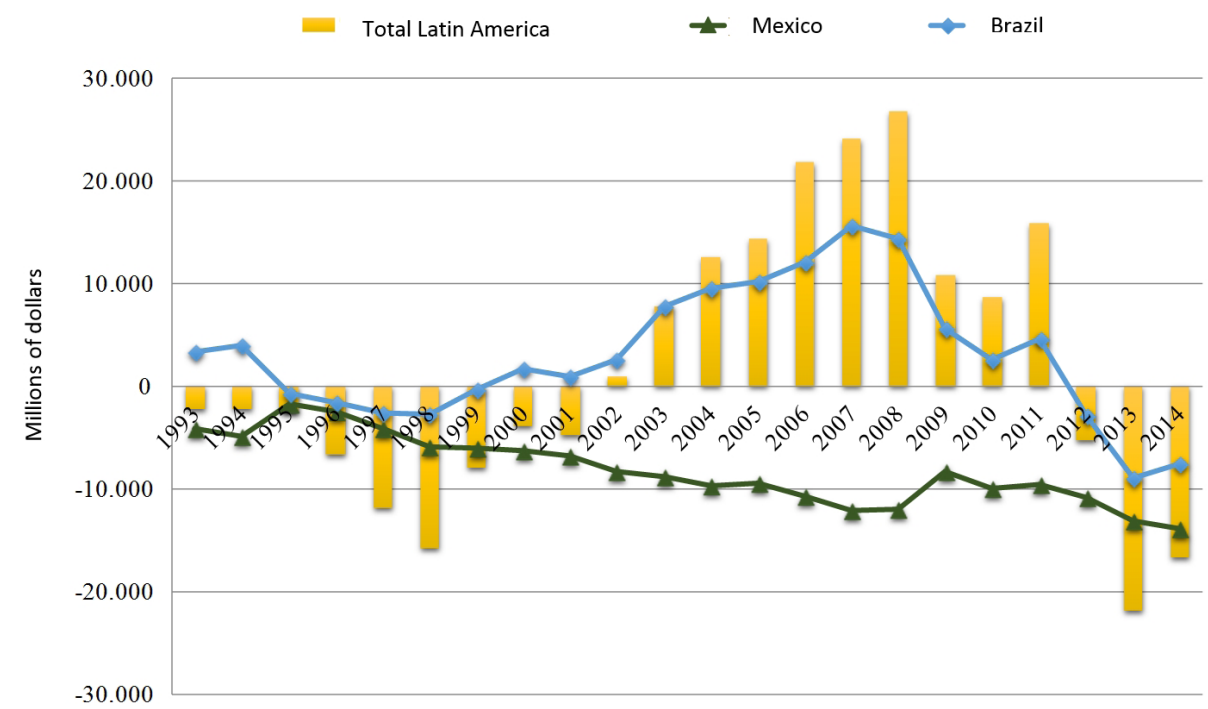

Source: Own elaboration based on WTO data and the DATACOMEX database of the Spanish Ministry of the Economy and Competitiveness 
However, the existence of differences in these two economies' behaviour, which could even be described as partly asymmetric, should also be noted. Specifically, while Brazil's development is similar to that described LA as a whole, Mexico has had an important, growing trade deficit throughout the period under examination, both in its relations with the world and particularly in its relations with the EU (Graph 3.13).

\subsection{Zooming in: The European Union's trade with Brazil and Mexico}

There are various reasons why a more detailed study of the EU's trade with Brazil and Mexico is of special interest. As was noted in the previous section, the great importance of their trade is aggregate to their economies' important sizes, as well as the different behaviour of their trade balances. So we shall now try to explain the characteristics of these trade relations with regard to trends and spatial and sectorial composition in greater detail, which will later allow us to go into the study of the characterisation and development of bilateral flows in terms of intra-industrial trade in greater detail.

\subsubsection{Recent trends}

It is not possible to the understand analysis of the trade between LA and the EU without considering the role of Brazil and Mexico. This importance has already been clearly shown when we looked at their relative weight among all trade relations between LA and the EU. To this evidence is aggregate the fact that in terms of development, their importance has been on the rise in recent decades, which reveals these economies' growing trade insertion with their European partners. In this regard, Brazil and Mexico have gone from representing something less than half LA's trade with the EU in 1993 to concentrate over $56 \%$ of this trade at the end of the period being analysed (Graph 3.14).

However, it should be pointed out that there is a clear asymmetry between Brazil and Mexico with regards to the development and size of their level of trade interrelation with the EU. In this regard, the first thing that should be stressed is of greater importance in terms of trade that the EU has for the Brazilian economy, in fact nearly $20 \%$ of its foreign trade is with its European partners. However, in the case of Mexico, the importance of its EU trade partners stands out a little over $9 \%$ of all Mexican imports and $6 \%$ of its exports (Graph 3.15).

Secondly, from the point of view of development, certainly opposing, although slight trends in the relative importance of the EU are being observed. Specifically, compared its steady loss of importance in the case of Brazil, practically since the beginning of this century, with its slight increase in the case of Mexico since the middle of the nineties. 
Graph 3.14. Development of the relative weight of Brazil and Mexico in trade between Latin America and the European Union (1993-2014)

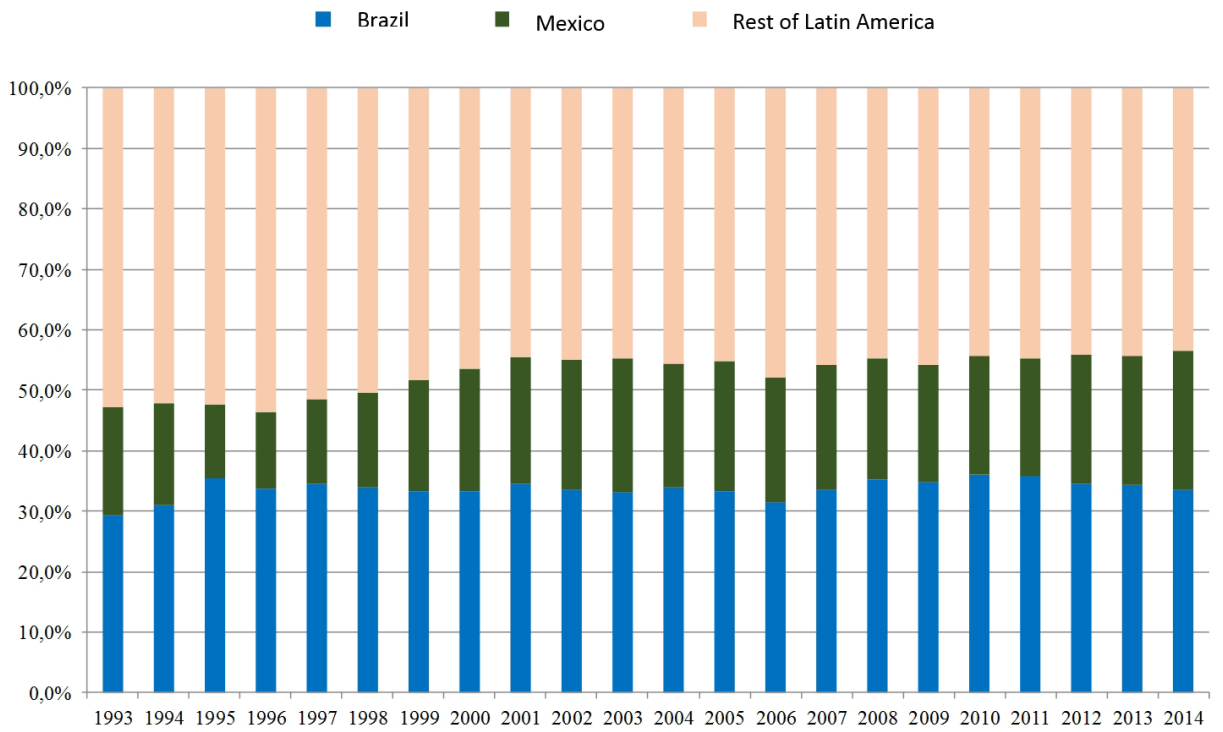

Source: Own elaboration based on WTO data and the DATACOMEX database of the Spanish Ministry of the Economy and Competitiveness

Graph 3.15. Relative weight of trade with the European Union in the total trade of Brazil and Mexico (1993-2014)

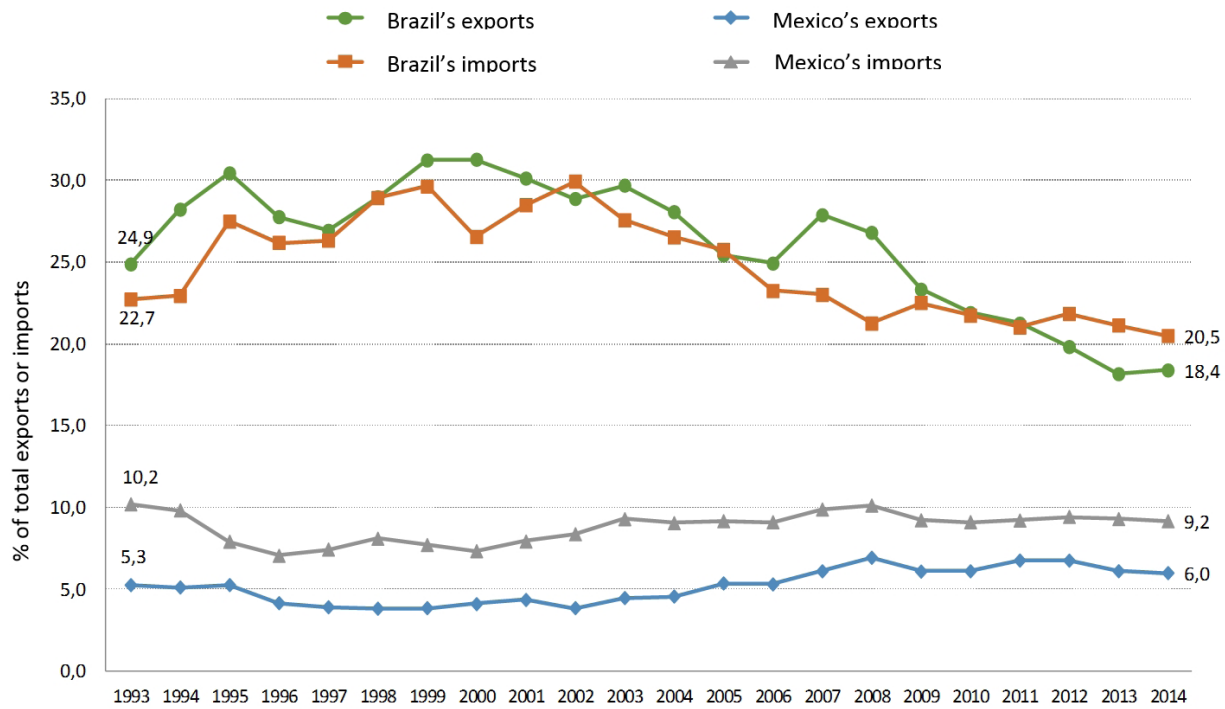

Source: Own elaboration based on WTO data and the DATACOMEX database of the Spanish Ministry of the Economy and Competitiveness 
A characteristic trait of Brazil and Mexico's trade with the EU is that, in general, it has a fairly concentrated territorial distribution, though with a downward trend. In the specific case of Brazil's imports, just five countries, Germany, France, Italy, Spain, the United Kingdom and the Netherlands, account for over three quarters as countries of origin (Graph 3.16). Germany, in particular, stands out as main supplier, providing $30 \%$ of its imports in 2013 , although in 1993 , the same country accounted for nearly $40 \%$ of Brazilian imports from the EU.

Graph 3.16. Main countries of origin of Brazil's imports from the European Union (19932013)

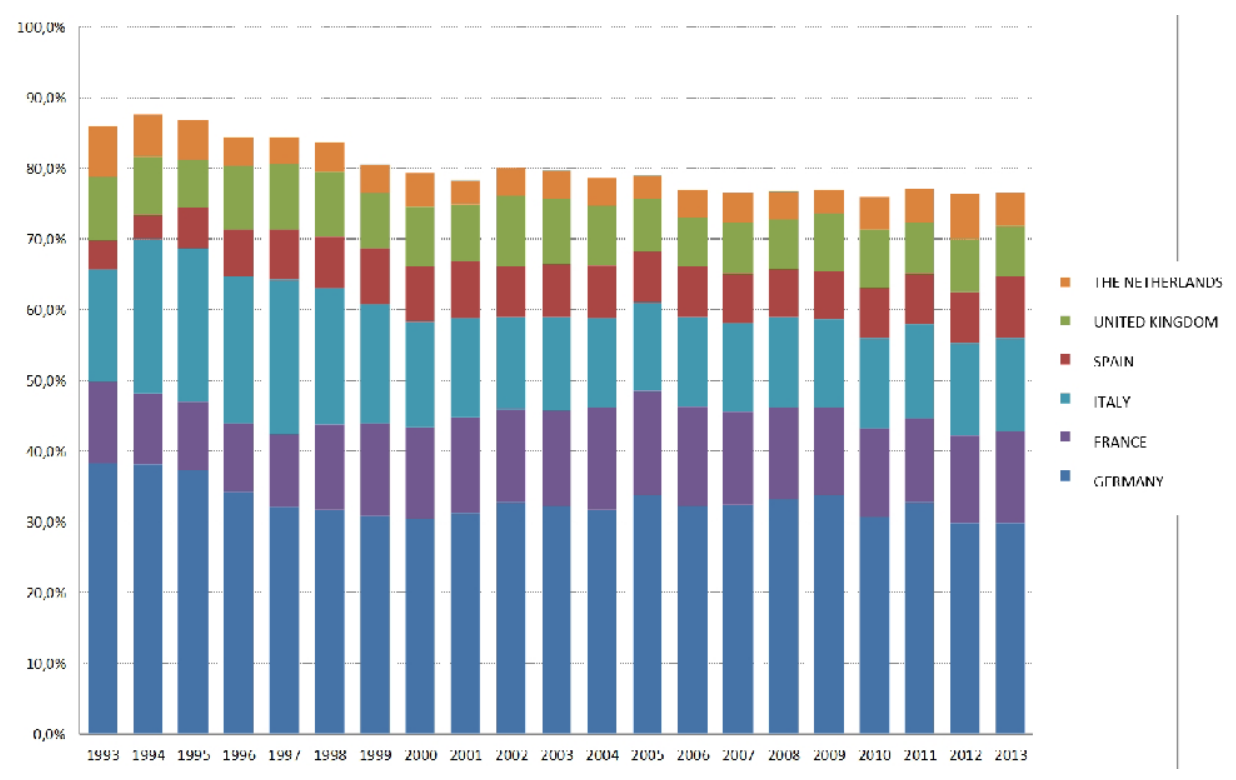

Source: Own elaboration based on the UN Comtrade Database

With regard to Mexico's imports from the EU, the same five countries as the main countries of origin account for nearly $80 \%$ of the total (Graph 3.17). Again, Germany occupies an outstanding position, accounting for nearly a third of Mexican imports from the EU in 2013. 
Graph 3.17. Main countries of origin of Mexico's imports from the European Union (1993-2013)

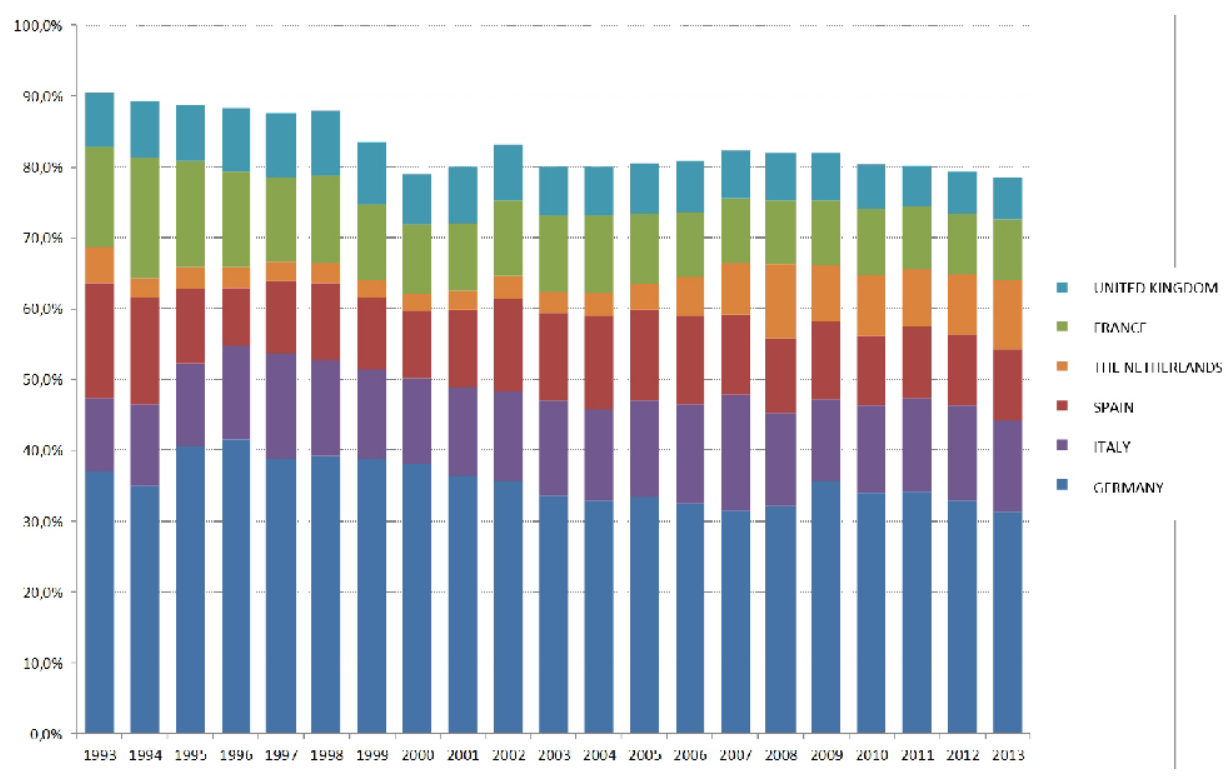

Source: Own elaboration based on the UN Comtrade Database

From the point of view of exports to the EU, the level of concentration is even higher, in both cases exceeding the figures reached in the realm of imports. So, in the case of Brazil's exports (Graph 3.18), it can be seen that the same five European countries account for over $80 \%$ of destinations. In this case, however, the Netherlands stands out as the main European destination for Brazilian exports, accounting for $36 \%$ of these exports in 2013.

In the case of Mexico, its exports to the EU also show a high level of concentration, with Spain standing out as the main country of destination, accounting for $36 \%$ of Mexican exports in 2013, followed by Germany, with 19\% (Graph 3.19). 
Graph 3.18. Main countries of destination of Brazil's exports to the European Union (1993-2013)

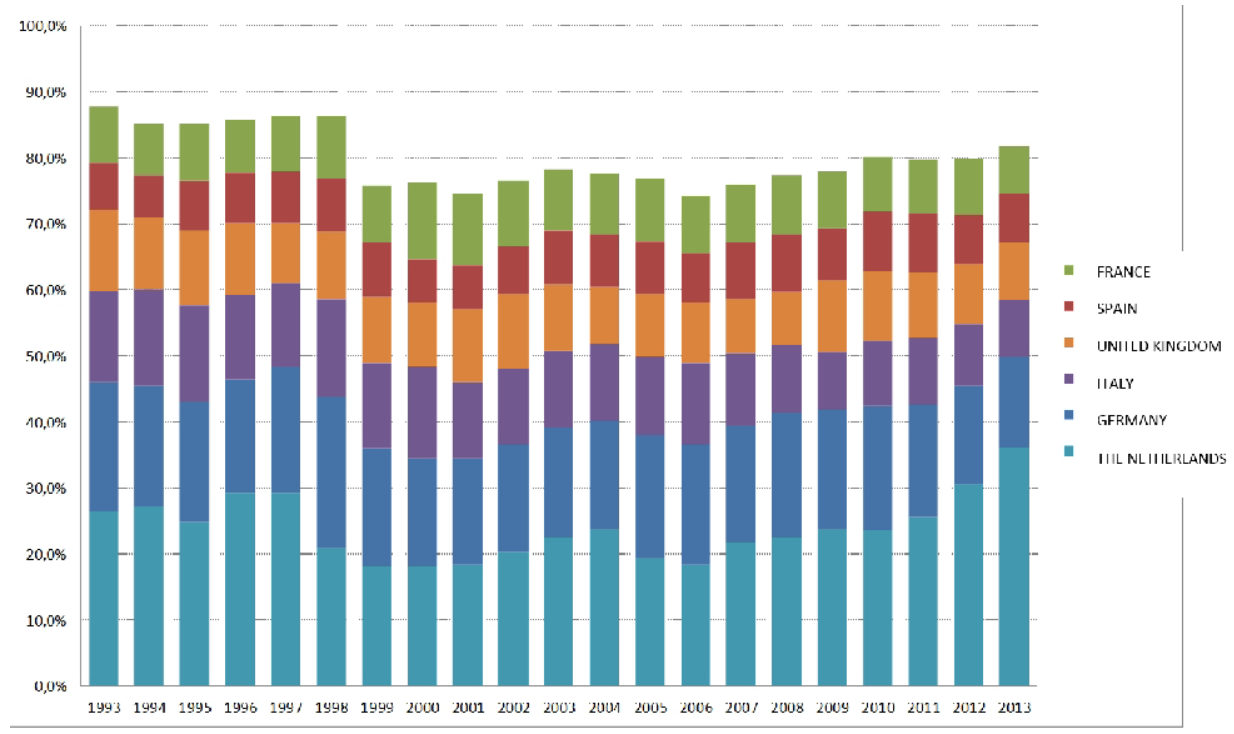

Source: Own elaboration based on the UN Comtrade Database

Graph 3.19. Main countries of destination of Mexico's exports to the European Union (1993-2013)

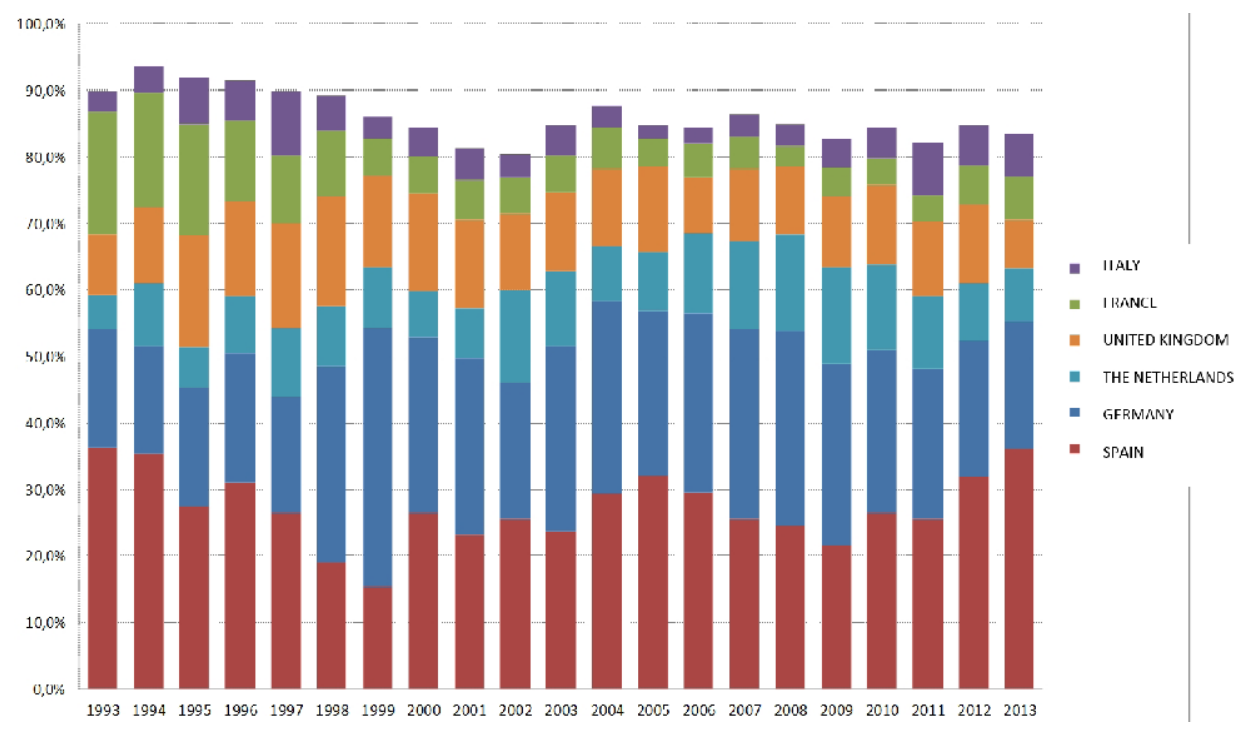

Source: Own elaboration based on the UN Comtrade Database 


\subsubsection{Sectorial characteristics}

Next to the territorial aspects of Brazil's and Mexico's trade with their main EU partners, it is interesting to examine their sectorial characterisation. In this regard, a disaggregated analysis on two levels follows: firstly, by tariff sections, and secondly, by chapters (two digits), according to the nomenclature of the Harmonized System (HS). ${ }^{23}$

With regard to imports originating in the EU, those of Brazil are concentrated in a very small number of sections. This concentration is especially heavy in purchases from Germany, where for 1993-2013, on average, four sections account for over four-fifths of the total. Of the five European countries under consideration, the Netherlands has the lowest concentration, although even here it is quite high, because nearly three quarters of the purchases Brazil makes from this country are also concentrated in only four sections (Graph 3.20).

Although the order of importance of sections may vary according to the country under consideration, the section on "Machinery and mechanical appliances; electrical equipment; parts thereof; sound recorders and reproducers, television image and sound recorders and reproducers, and parts and accessories of such articles" (Section XVI) stands out, followed by "Products of the chemical or allied industries" (Section VI) and "Transport material" (Section XVII). These three groups alone concentrate a very significant part of Mexico's imports from its European partners, easily exceeding $50 \%$, and even, depending on the case, $70 \%$ of all imports. Additionally, the importance of the sections related with "Mineral products" (Section V), "Plastic and articles thereof; rubber and articles thereof" (Section VII) and "Base metals and articles of base metals" (Section XV) should be pointed out.

The composition of Mexico's imports originating from the EU is also very concentrated, but less than in the case of Brazil. One aspect which is similar to the case of Brazil is that the highest level of sectorial concentration of purchases occurs with those from Germany, of which four fifths are concentrated in only four sections. On the other hand, in this case, Spain is the country with least sectorial concentration of Mexican imports, but even so, $58 \%$ of these purchases are also concentrated in four sections (Graph 3.21),

23 The Harmonized System (HS) was set up by the International Convention on the Harmonized Commodity Description and Coding System adopted in 1983 by the World Customs Organisation (WCO). It is a nomenclature used by over 200 countries and comprises over 5000 commodity groups. The system is organised into sections, chapters (2 digits), headings (4 digits) and subheadings (6 digits), the last two digits in the latter case (subheadings) coinciding with what is called the TARIC or Integrated Tariff code. 
Graph 3.20. Main sections relating to Brazilian imports originating in the European Union (average 1993-2013)

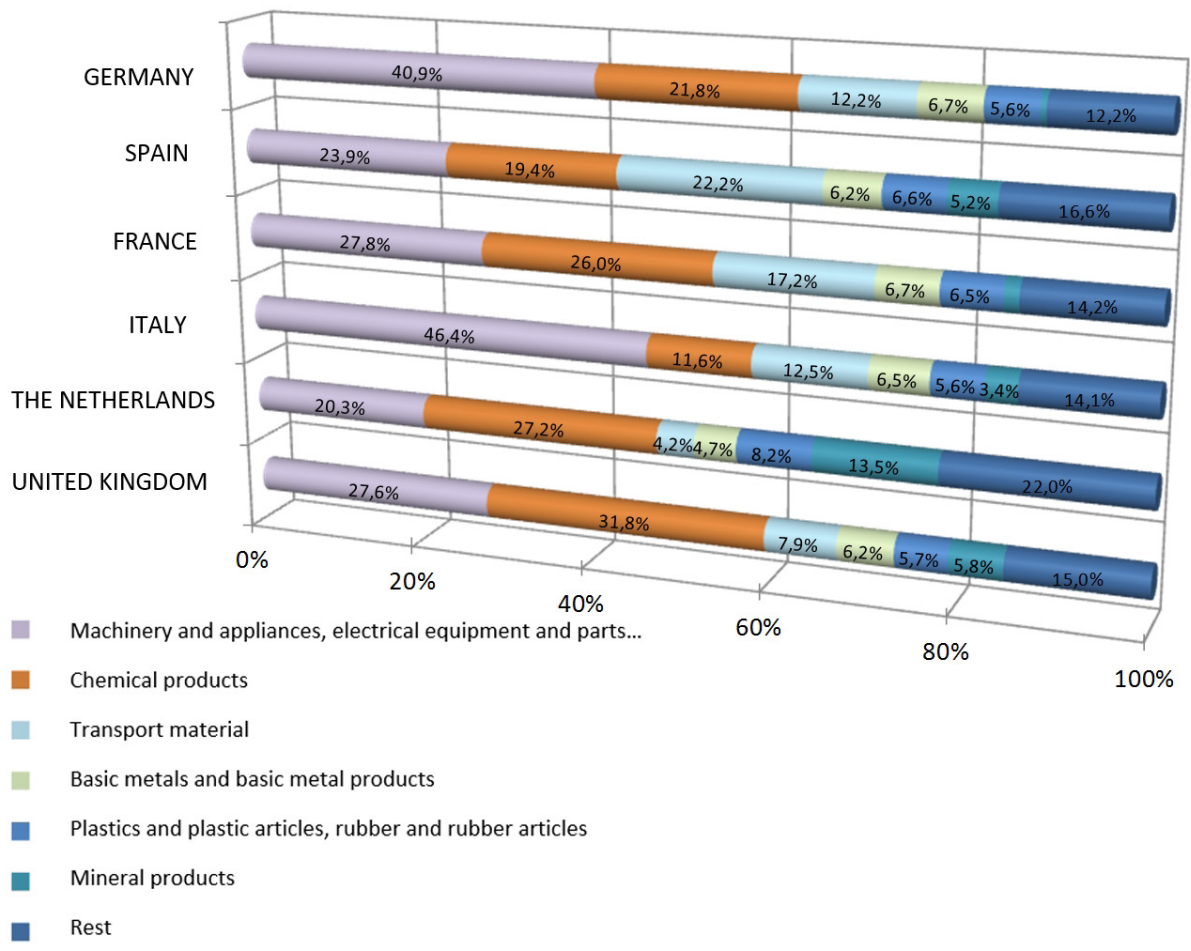

Source: Own elaboration based on the UN Comtrade Database

Although the order of importance of sections varies notably according to the country of origin in question, the most notable section is purchases related with "Machinery and mechanical appliances; electrical equipment; parts thereof; sound recorders and reproducers, television image and sound recorders and reproducers, and parts and accessories of such articles" (Section XVI). In the specific case of purchases from Germany, the next most important section is "Transport material" (Section XVII), although, in general, Mexican imports of "Products of the chemical or allied industries" (Section VI) are also important. Finally, in the case of the purchases Mexico makes from the Netherlands, the importance of "Mineral products" (Section V) should be highlighted, accounting for nearly $30 \%$ of all imports Mexico makes with origin in that European country. 
Graph 3.21. Main sections related with Mexican imports with origin in the European Union (average 1993-2013)

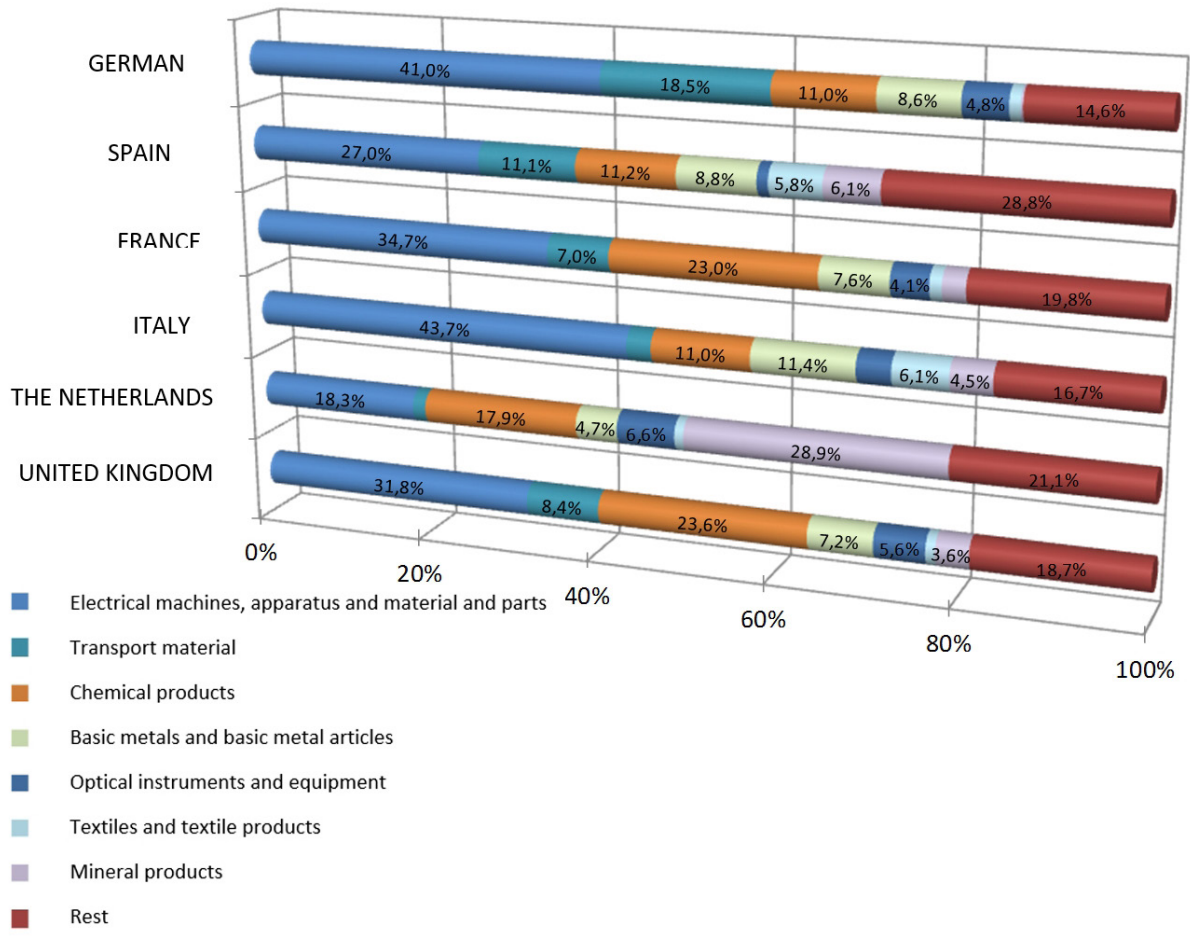

Source: Own elaboration based on the UN Comtrade Database

With regard to Brazilian exports to the EU, these have a less concentrated composition than its imports from that region. In this regard, the greatest degree of sectorial concentration is shown by Brazilian purchases from the Netherlands, where nearly three quarters are restricted to only four sections. Purchases originating in the United Kingdom, on the other hand, are those with the least unequal sectorial distribution (Graph 3.22).

With regard to product groups with the most relative weight in Brazilian sales to its main European partners, no structure is distinguishable which might serve for a general characterisation. On the one hand, "Vegetable products" (Section II) in Brazilian exports to Spain (32.3\%), the Netherlands (20.5\%), Germany $(19.2 \%)$ and Italy $(17.3 \%)$ are important, and on the other, hand exports of "Prepared foodstuffs, beverages and tobacco"(Section IV) do also have a considerable weight, especially in exports to the Netherlands (32.5\%), France (26.5\%) and the United Kingdom (18.2\%). In addition, the export weight of the sections related with "Mineral products" (Section V), "Machinery and mechanical appliances; electrical equipment; parts thereof, etc." (Section XVI), can be highlighted, especially in Brazilian exports to Germany and the United Kingdom, along 
with "Base metals and articles of base metal" (Section XV), in this case, particularly referring to sales dedicated for the Netherlands.

Graph 3.22. Main sections related with Brazilian exports to the European Union (average 1993-2013)

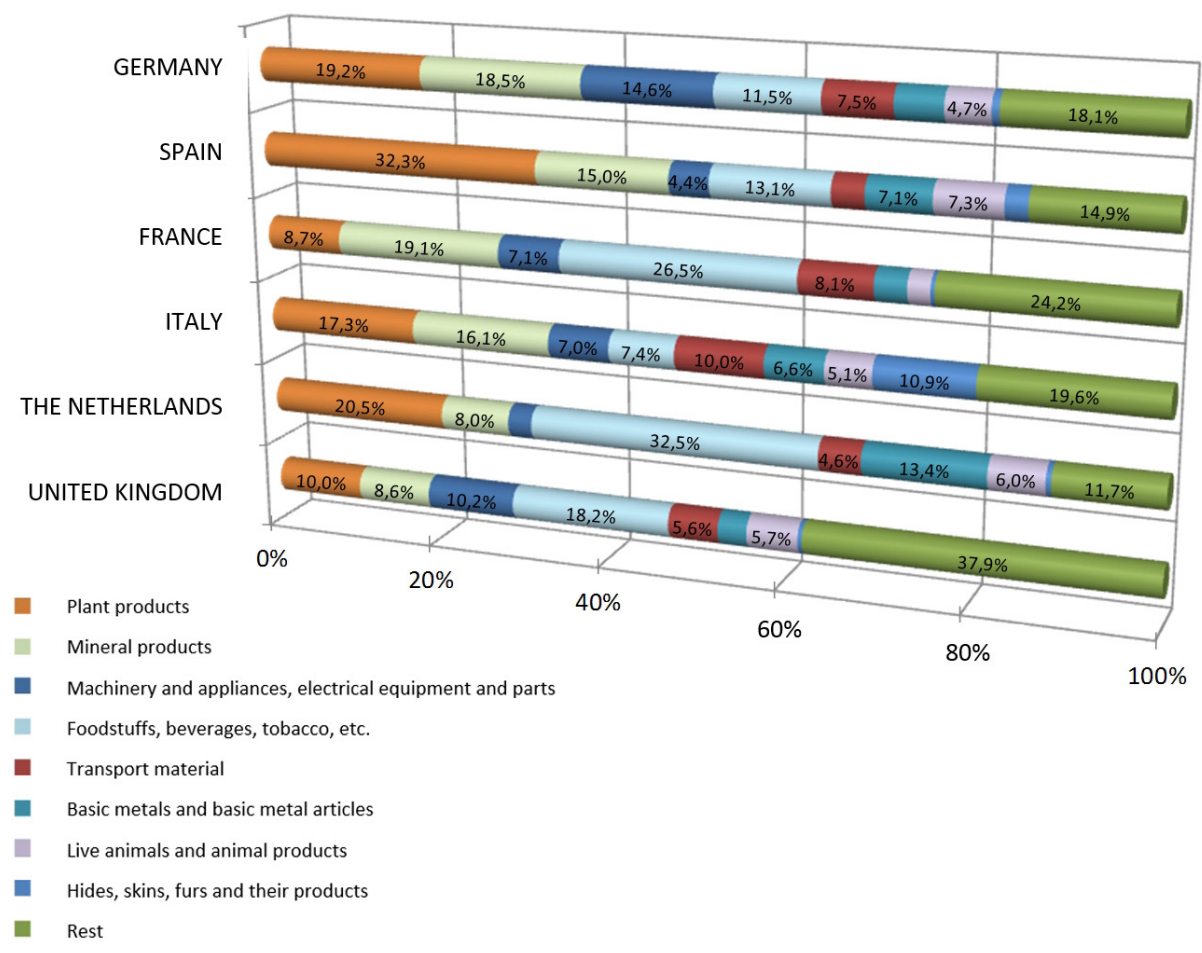

Source: Own elaboration based on the UN Comtrade Database

The analysis of the sectorial composition of Mexican exports to the EU shows a highly concentrated distribution pattern, especially in the case of Mexico's two main EU partners, Spain and Germany. The four product groups (sections) with greatest relative weight concentrate nearly $90 \%$ of Mexico's exports to Spain and over $82 \%$ of those for Germany. On the other hand, its exports to Italy are those with the lowest level of concentration, although, even so, exceeding 54\% (Graph 3.23). 
Graph 3.23. Main sections related with Mexico's exports to the European Union (average 1993-2013)

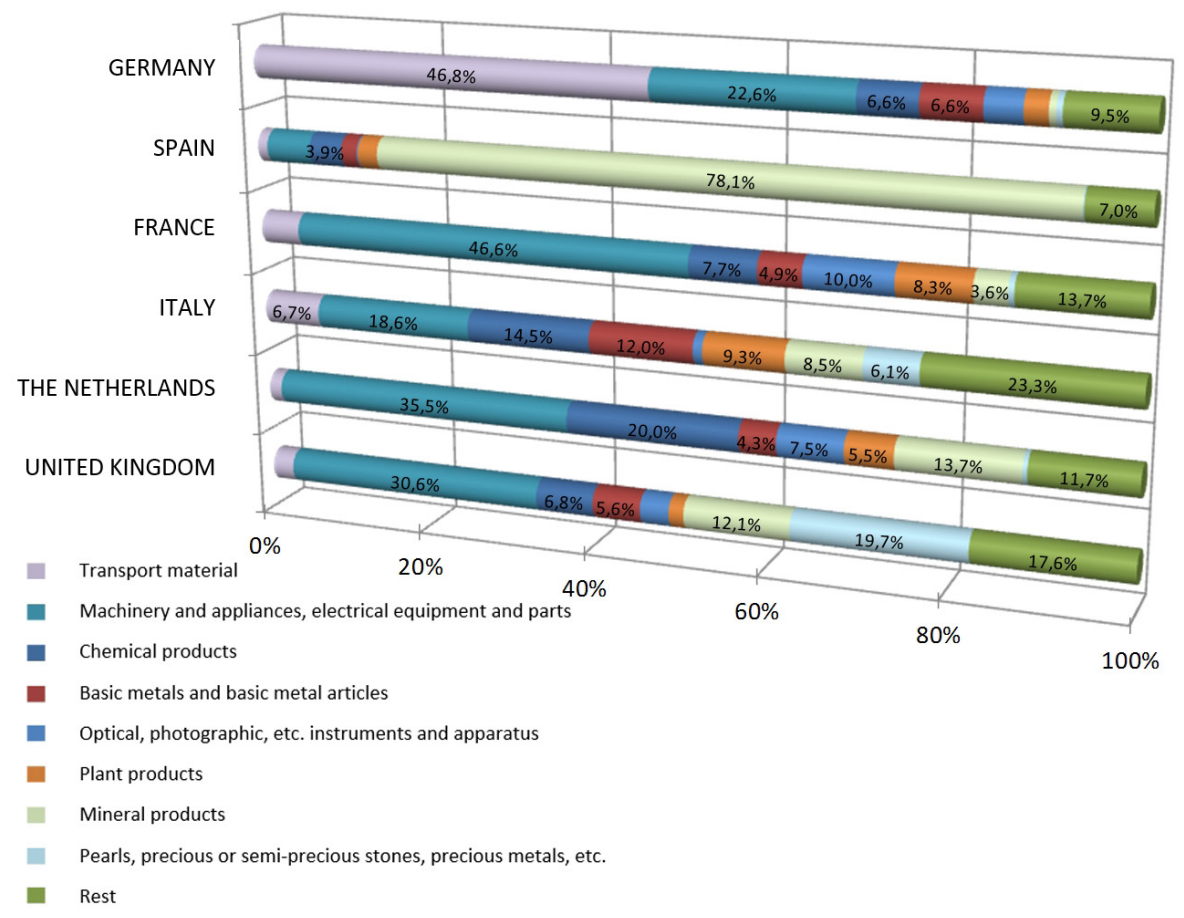

Source: Own elaboration based on the UN Comtrade Database

This sectorial distribution is more varied than that of the import side. In this regard, exports to Mexico's main EU trade partner, Spain, the extreme importance of the section "Mineral products" (Section V) can be highlighted, for they have an average relative weight for the analysed period of more than $78 \%$ of all exports. This contrasts with the much lower relative weight these products have in other bilateral flows with origin in Mexico and destination the EU. With regard to exports to Germany, the second most important European market for Mexico, sales of "Transport material" (Section XVII) stand out, concentrating nearly $47 \%$ of Mexican exports to this European country.

More generally, the importance of Mexican exports under "Machinery and mechanical appliances; electrical equipment; parts thereof, etc." (Section XVI) stand out, as they are very important in Mexico's sales to the French (46.6\%), Dutch (35.5\%), British (30.6\%) and German (22.6\%) markets. It should be borne in mind that this (machinery, parts and accessories) is one of the most important sectors in world trade in goods, being closely linked to transnational manufacturing of consumer durables. 
To complete this sectorial characterisation of Brazil and Mexico's trade with its main EU partners in greater detail, the following tables (Tables 3.1 to 3.12) help summarising the development of the five most important chapters in each bilateral relation. We have chosen to present the two directions of trade (exports and imports) together in each table, in order to better show the pattern of Brazil and Mexico's trade insertion with each of its main European partners. It also allows preliminary observation with greater clarity of the possible presence of intra-industrial trade. This aspect will be examined in depth later on (Section 5).

The five main chapters of bilateral trade between Brazil and Germany account for $66.8 \%$ of imports and $53.3 \%$ of exports. Both Chapter 84 (machinery and mechanical appliances) and Chapter 87 (automobiles, parts and accessories) are repeated on both sides of the trade balance, their development being positive in the period 1993-2013, although showing a greater growth rate on the side of Brazil's imports than that of its exports. If only preliminarily, this fact may be indicating the possible presence of intraindustrial trade, although it is true that there is an imbalance in the importance of these chapters, which have a notably greater weight on the import side.

Apart from these partly coinciding trade flows, there is a clear contrast in the composition of the bilateral trade between Brazil and Germany. This contrast can be seen in the preponderance of industrial goods and consumer durables, such as machinery, equipment, automobiles and electric and electronic appliances, in the flows from Germany to Brazil, and the importance basic products such as foods (coffee, tea, soya, etc.) and minerals have in the flows from Brazil to Germany. One example of the presence of FDI of German origin in these sectors, specifically in the automotive industry, is the case of Volkswagen do Brasil, which has operated since 1953 with its headquarters in São Bernardo do Campo.

The foregoing outlines a profile of inter-industrial trade insertion, reflected in a flow composition based on complementarity. However, the evolution of trade in these main chapters does not point to a trend towards a changing pattern of insertion. 
Table 3.1. Development of the main chapters (two digits) of Brazil's trade with Germany (1993-2013)

Brazil's imports from Germany

Chap. 84 Nuclear reactors, boilers, machinery, etc.; parts

\begin{tabular}{|c|c|}
\hline $\begin{array}{c}\text { Average } \\
\text { weight }\end{array}$ & $\begin{array}{c}\text { Variation } \\
\text { rate }\end{array}$ \\
\hline $30.5 \%$ & 8.3 \\
$11.6 \%$ & 11.3 \\
$10.4 \%$ & 7.9 \\
$8.3 \%$ & 7.8 \\
$5.9 \%$ & 11.4 \\
$66.8 \%$ & \\
\hline
\end{tabular}

Chap. 97 Motor vehicles, etc.; parts and accessoires

Chap. 85 Electrical machinery and equipment and parts thereof

Chap. 29 Organic chemicals

Chap. 90 Optical, photographic, etc. instruments and apparatus

Relative weight out of total imports

Average Variation

Brazil's exports with destination Germany

Chap. 26 Ores, slag and ash

\begin{tabular}{c|c} 
weight & rate \\
\hline $17.6 \%$ & 8.4 \\
$12.4 \%$ & 10.4 \\
$11.3 \%$ & 6.1 \\
$6.1 \%$ & 4.8 \\
$6.0 \%$ & 7.6 \\
\hline
\end{tabular}

Chap. 9 Coffee, tea, maté and spices

$53.3 \%$

Chap. 84 Nuclear reactors, boilers, machinery, etc.; parts

Chap. 87 Motor vehicles, etc.; parts and accessoires

Chap. 12 Oil seeds and oleaginous fruits

Note: Average weight means the chapter average relative weight out of the total flow in question (imports or exports)

Relative weight out of total exports

ate
0.4
6.1
.8
7.6
in the period 1993-2013. The variation rate corresponds to the annual cumulative variation rate in the period 19922013.

Source: Own elaboration based on the UN Comtrade Database

An even clearer picture of Brazil's inter-industrial insertion profile in trade with the EU can be seen by comparing the five main chapters concentrating most of this bilateral trade (50.8\% of imports and $52.8 \%$ of exports). In this regard, Brazilian imports of goods with a high industrial content (electrical machinery, appliances and material, transport material) are observable; these underwent very positive evolution in the period under consideration, showing comparatively very high variation rates. On the other side of the trade balance, Brazilian exports of food (oilseeds and oleaginous fruits, coffee, tea, etc.) and mineral products stand out, showing fairly moderate variation rates.

It must be pointed out that the elements explaining this commercial relationship include connections to direct investment coming from Europe. This is the case, for example, of the activity in Brazil of the company Helibrás, one of 20 companies operating around the world and owned by the Franco-German-Spanish company Airbus Helicopters. ${ }^{24}$ Other examples in the realm of the automotive industry, are the German multinationals Volkswagen, Fiat and Daimler AG.

24 Airbus Helicopters (Eurocopter) is a helicopter manufacturer formed in 1992 through the merger of the helicopter divisions of Aérospatiale, France, and DaimlerChrysler Aerospace AG, Germany. It is a subsidiary of the Airbus Group. In 2000, its two owners merged to create EADS, hiding the helicopter business of Construcciones Aeronáuticas to Eurocopter. Airbus Helicopters' main factories are in France (Marignane and La Courneuve), Germany (Kassel, Donauwörth and Ottobrunn) and Spain (Albacete). 
Table 3.2. Development of the main chapters (two digits) of Brazil's trade with Spain (1993-2013)

\begin{tabular}{lcc}
\hline Brazil's imports from Spain & $\begin{array}{c}\text { Average } \\
\text { weight }\end{array}$ & $\begin{array}{c}\text { Variation } \\
\text { rate }\end{array}$ \\
& $15.6 \%$ & 13.1 \\
Chap. 84 Nuclear reactors, boilers, machinery, etc.; parts & $12.5 \%$ & 44.3 \\
Chap. 88 Aircraft, spacecraft, and parts thereof & $8.3 \%$ & 13.1 \\
Chap. 85 Electrical machinery and equipment and parts thereof & $8.1 \%$ & 16.5 \\
Chap. 87 Motor vehicles, etc.; parts and accessoires & $6.4 \%$ & 14.6 \\
Chap. 29 Organic chemicals & $50.8 \%$ & \\
Relative weight out of total imports & & \\
\hline Brazil's exports with destination Spain & Average & Variation \\
& weight & rate \\
\hline Chap. 12 Oil seeds and oleaginous fruits & $21.3 \%$ & 11.5 \\
Chap. 26 Ores, slag and ash & $10.5 \%$ & 7.0 \\
Chap. 23 Residues and waste from the food industries; prepared animal fodder & $10.0 \%$ & -2.2 \\
Chap. 9 Coffee, tea, maté and spices & $5.5 \%$ & 6.8 \\
Chap. 72 Iron and steel & $5.5 \%$ & 6.3 \\
Relative weight out of total exports & $52.8 \%$ & \\
\hline
\end{tabular}

Note: Average weight means the chapter average relative weight out of the total flow in question (imports or exports) in the period 1993-2013. The variation rate corresponds to the annual cumulative variation rate in the period 19932013.

Source: Own elaboration based on the UN Comtrade Database

Bilateral trade between Brazil and France is also notably concentrated, with five chapters accounting for around $55 \%$ of its constituent flows. In this case, Brazil's trade insertion pattern is less emphatically inter-industrial, considering the presence of exports of aeronautical transport machinery and material. In any case, it should be noted that the exporter flow again includes important amounts of basic products such as food industry residues and waste and animal fodders (23.6\%), ores (15\%) and wood (5.5\%).

On the import side, next to products with a high industrial content (electrical machinery and equipment, transport material), Brazil purchases pharmaceutical products from France, which show the highest variation rate $(16.7 \%$ aggregate annual) of all the chapters selected. The important presence in Brazil of some French multinationals should be pointed out here, for example, PSA Peugeot-Citroën ${ }^{25}$ and Renault ${ }^{26}$ in the automotive industry.

25 The PSA group has a factory in Porto Real.

26 Renault do Brasil is a subsidiary of the French multinational Renault and has operated in Brazil since 1967, its headquarters being in the city of São José dos Pinhais, in the state of Paraná. 
Table 3.3. Development of the main chapters (two digits) of Brazil's trade with France (1993-2013)

Brazil's imports from France

\begin{tabular}{l|c|c} 
& Average & Variation \\
weight & rate
\end{tabular}

Brazil's exports destination France

Chap. 23 Residues and waste from the food industries; prepared animal fodder

\begin{tabular}{|c|c|}
\hline $\begin{array}{c}\text { Average } \\
\text { weight }\end{array}$ & $\begin{array}{c}\text { Variation } \\
\text { rate }\end{array}$ \\
\hline $23.6 \%$ & 6.3 \\
$15.0 \%$ & 11.5 \\
$5.8 \%$ & 9.5 \\
$5.5 \%$ & 4.4 \\
$5.1 \%$ & 9.6 \\
$55.1 \%$ & \\
\hline
\end{tabular}

Chap. 26 Ores, slag and ash

Chap. 88 Aircraft, spacecraft, and parts thereof

Chap. 44 Wood and articles of wood; wood charcoal

Chap. 84 Nuclear reactors, boilers, machinery, etc.; parts

$55.1 \%$

Note: Average weight means the chapter average relative weight out of the total flow in question (imports or exports) in the period 1993-2013. The variation rate corresponds to the annual cumulative variation rate in the period 19932013.

Source: Own elaboration based on the UN Comtrade Database

The analysis of the five chapters accounting for a large part of bilateral trade between Brazil and Italy $(65.7 \%$ of imports and $49.3 \%$ of exports) reveals a picture that comes close to a traditional trade pattern. Products with a high industrial content and high aggregate value (machinery, automobiles, electrical appliances and material, optical and photographic apparatuses, etc.) clearly predominate in Brazilian imports from Italy. On the Brazilian export side, we again see the predominance of basic products based on resources and with a low aggregate value (ores, coffee, hides, woodpulp) is repeated.

An exception that should be underlined are Brazilian exports in the motor vehicle chapter (7.7\%), even though their growth in the overall period examined is negative. In this case, this exporting activity is related to FDI activities undertaken, for example, by the car company Fiat Betim, created in 1973 in Betim (Minas Gerais), the largest subsidiary in the world of the Italian Fiat Group (Fiat S.p.A.) - constituting thereby another example of the connections existing between direct investments made by transnational companies and the dynamics followed by the trade flows of both importing and exporting economies. 
Table 3.4. Development of the main chapters (two digits) of Brazil's trade with Italy (1993-2013)

Brazil's imports from Italy

Chap. 84 Nuclear reactors, boilers, machinery, etc.; parts

\begin{tabular}{|c|c|}
\hline $\begin{array}{c}\text { Average } \\
\text { weight }\end{array}$ & $\begin{array}{c}\text { Variation } \\
\text { rate }\end{array}$ \\
\hline $36.3 \%$ & 10.4 \\
$11.2 \%$ & 7.5 \\
$10.1 \%$ & 8.4 \\
$4.4 \%$ & 8.0 \\
$3.6 \%$ & 9.9 \\
$65.7 \%$ & \\
\hline
\end{tabular}

Chap. 87 Motor vehicles, etc.; parts and accessoires

Average Variation

Chap. 85 Electrical machinery and equipment and parts thereof

Chap. 29 Organic chemicals

\begin{tabular}{c|c} 
weight & rate \\
\hline $13.7 \%$ & 9.1 \\
$10.8 \%$ & 6.1 \\
$10.8 \%$ & 13.9 \\
$7.7 \%$ & -6.9 \\
$6.3 \%$ & 16.6 \\
$49.3 \%$ & \\
\hline
\end{tabular}

Chap. 26 Ores, slag and ash

Chap. 9 Coffee, tea, maté and spices

Chap. 41 Hides and skins (other than furskins) and leather

Chap. 87 Motor vehicles, etc. parts and accessories

16.6

Relative weight out of total exports

Note: Average weight means the chapter average relative weight out of the total flow in question (imports or exports)
in the period 1993-2013. The variation rate corresponds to the annual cumulative variation rate in the period 19932013.

Source: Own elaboration based on the UN Comtrade Database

Without straying from a pattern based on complementarity (inter-industrial), bilateral trade between Brazil and the Netherlands also displays particularities which deserve attention. Specifically, the presence of fuel in Brazilian imports (13\%) is noteworthy, which have also been subject to very high variation rate $(28.2 \%$ aggregate annual for the period 1993-2013).

Trade relations between Brazil and the United Kingdom are more concentrated on imports than on exports and also have rather different profiles in the composition of the two flows. Brazilian purchases from the United Kingdom are distributed between goods of high industrial content and aggregate value (electrical machinery and equipment and parts, medicines) and others such as chemicals. With regard to exports, except for the chapter related with machinery and mechanical appliances (Ch. 84), sales of basic products (foodstuffs and raw materials, such as wood and ores) predominate.

As far as trade relations between Mexico and its main European partners are concerned, a more coherent picture in the respective trade flow composition as compared to the case of Brazil can be observed. 
Table 3.5. Development of the main chapters (two digits) of Brazil's trade with the Netherlands (1993-2013)

Brazil's imports from the Netherlands

\begin{tabular}{l|c|c} 
& $\begin{array}{c}\text { Average } \\
\text { weight }\end{array}$ & $\begin{array}{c}\text { Variation } \\
\text { rate }\end{array}$ \\
Chap. 27 Mineral fuels, mineral oils and products of their distillation & $13.0 \%$ & 28.2 \\
Chap. 84 Nuclear reactors, boilers, machinery, etc.; parts & $11.8 \%$ & 11.1 \\
Chap. 29 Organic chemicals & $10.0 \%$ & 4.0 \\
Chap. 85 Electrical machinery and equipment and parts thereof & $8.5 \%$ & -1.1 \\
Chap. 39 Plastics and articles thereof & $7.3 \%$ & 8.8 \\
Relative weight out of total imports & $50.6 \%$ &
\end{tabular}

Brazil's exports to the Netherlands

Chap. 23 Residues and waste from the food industries; prepared animal fodder

\begin{tabular}{|c|c|}
\hline $\begin{array}{c}\text { Average } \\
\text { weight }\end{array}$ & $\begin{array}{c}\text { Variation } \\
\text { rate }\end{array}$ \\
\hline $18.0 \%$ & 6.0 \\
$16.0 \%$ & 3.5 \\
$9.1 \%$ & 3.0 \\
$5.9 \%$ & 2.5 \\
$5.8 \%$ & 13.1 \\
$54.8 \%$ & \\
\hline
\end{tabular}

Chap. 12 Oil seeds and oleaginous fruits

Chap. 20 Preparations of vegetables, fruit, etc.

Chap. 76 Aluminium and articles thereof

Chap. 2 Meat and edible meat offal

$54.8 \%$

Relative weight out of total exports

Note: Average weight means the chapter average relative weight out of the total flow in question (imports or exports) in the period 1993-2013. The variation rate corresponds to the annual cumulative variation rate in the period 19932013.

Source: Own elaboration based on the UN Comtrade Database

Bilateral trade between Mexico and Germany is a clear example of this, with a very similar and concentrated composition of imports and exports. Indeed, the four chapters with most relative weight, corresponding to machinery and mechanical appliances (Ch. 84), electrical machinery and equipment (Ch. 85), automobiles (Ch. 87) and optical and photographic instruments and apparatus (Ch. 90), coincide on both sides of the trade balance. On the other hand, these four chapters, except for Chapter 84 (machinery), show more dynamism on the Mexican export side.

This leads to the conclusion, if only preliminarily and nearly intuitively, that in this case intra-industrial trade does exist, due to a higher level of coincidence observed in the composition of bilateral flows. 
Table 3.6. Development of the two main chapters (two digits) of Brazil's trade with the United Kingdom (1993-2013)

Brazil's imports from the United Kingdom

\begin{tabular}{|c|c|c|}
\hline & $\begin{array}{c}\text { Average } \\
\text { weight }\end{array}$ & $\begin{array}{c}\text { Variation } \\
\text { rate }\end{array}$ \\
\hline Chap. 84 Nuclear reactors, boilers, machinery, etc.; parts & $19.5 \%$ & 9.5 \\
\hline Chap. 29 Organic chemicals & $12.1 \%$ & 3.8 \\
\hline Chap. 85 Electrical machinery and equipment and parts thereof & $8.2 \%$ & 8.7 \\
\hline Chap. 30 Pharmaceutical products & $7.2 \%$ & 15.3 \\
\hline Chap. 38 Miscellaneous chemical products & $6.5 \%$ & 19.5 \\
\hline Relative weight out of total imports & $53.5 \%$ & \\
\hline
\end{tabular}

Brazil's exports to the United Kingdom

Chap. 84 Nuclear reactors, boilers, machinery, etc; parts

\begin{tabular}{|c|c|}
\hline $\begin{array}{c}\text { Average } \\
\text { weight }\end{array}$ & $\begin{array}{c}\text { Variation } \\
\text { rate }\end{array}$ \\
\hline $8.9 \%$ & 5.3 \\
$7.3 \%$ & 18.9 \\
& \\
$7.0 \%$ & 4.0 \\
$6.7 \%$ & -1.6 \\
$6.4 \%$ & 14.1 \\
$36.3 \%$ & \\
\hline
\end{tabular}

Chap. 71 Natural or cultured pearls, precious or semi-precious stones, precious metals

Chap. 16 Preparations of meat, fish crustaceans, molluscs, etc.

$36.3 \%$

Chap. 44 Wood and articles of wood; wood charcoal

Chap. 26 Ores, slag and ash

Relative weight out of total exports

Note: Average weight means the chapter average relative weight out of the total flow in question (imports or exports) in the period 1993-2013. The variation rate corresponds to the annual cumulative variation rate in the period $1993-$ 2013.

Source: Own elaboration based on the UN Comtrade Database

Bilateral trade between Mexico and its main European partner, Spain, reveals two features. First, there is a large asymmetry in the level of sectorial concentration, much higher in the case of exports, with $88.1 \%$ being concentrated in only five chapters (and most of them corresponding to oil exports). Secondly, a very different composition can be observed which comes close to a traditional insertion profile, characterised by advantages related to resources and not as much to dynamic advantages that are typical of high aggregate value industrial products with a notable component of innovation. In short, a pattern of trade specialisation that is closer to traditional inter-sectorial relations emerges. 
Table 3.7. Development of the main chapters (two digits) of Mexico's trade with Germany (19932013)

Mexican imports from Germany

Chap. 84 Nuclear reactors, boilers, machinery, etc.; parts

Chap. 87 Motor vehicles, etc.; parts and accessories

\begin{tabular}{|c|c|}
\hline $\begin{array}{c}\text { Average } \\
\text { weight }\end{array}$ & $\begin{array}{c}\text { Variation } \\
\text { rate }\end{array}$ \\
\hline $28.7 \%$ & 9.9 \\
$18.4 \%$ & 14.6 \\
$12.3 \%$ & 10.1 \\
$4.7 \%$ & 9.4 \\
$4.4 \%$ & -5.9 \\
$68.6 \%$ & \\
\hline
\end{tabular}

Chap. 85 Electrical machinery and equipment and parts thereof

Chap. 90 Optical, photographic, etc. ins
Chap. 99 Other miscellaneous products

Relative weight out of total imports

Mexican exports to Germany

Chap. 87 Motor vehicles, etc.; parts and accessories

\begin{tabular}{|c|c|}
\hline $\begin{array}{c}\text { Average } \\
\text { weight }\end{array}$ & $\begin{array}{c}\text { Variation } \\
\text { rate }\end{array}$ \\
\hline $46.6 \%$ & 20.4 \\
$15.2 \%$ & 4.6 \\
$7.4 \%$ & 16.0 \\
$3.8 \%$ & 13.3 \\
$3.7 \%$ & 4.5 \\
$76.7 \%$ & \\
\hline
\end{tabular}

Chap. 84 Nuclear reactors, boilers, machinery, etc.; parts

Note: Average weight means the chapter average relative weight out of the total flow in question (imports or exports)

Chap. 85 Electrical machinery and equipment and parts thereof

Chap. 90 Optical, photographic, etc.; instruments and apparatus

Chap. 72 Iron and steel

\section{orts} in the period 1993-2013. The variation rate corresponds to the annual cumulative variation rate in the period 1993 2013.

Source: Own elaboration based on the UN Comtrade Database

In the case of trade relations between Mexico and France, greater coincidence can be seen in the composition of the two sides of the trade balance. Indeed, the two main chapters on both sides are the same (Ch. 84 and 85). Furthermore, in this case, there are more chapters with an industrial content in Mexico's exports than in its imports. As far as the evolution of exports are concerned, the positive growth of Mexico's exports to France in the sectors of optical and photographic instruments and apparatus, etc. (aggregate annual 20.9\%) and automobiles (aggregate annual 16.8\%) stand out. Regarding Mexico's imports from France, the growth in Mexican purchases of pharmaceutical products (aggregate annual $17.3 \%$ ) stands out.

Bilateral trade between Mexico and Italy also has a fairly concentrated sectorial composition, with five chapters accounting for $60.2 \%$ of Mexico's exports and another five accounting for $41.5 \%$ of its purchases from Italy. Trade in machinery and mechanical appliances (Ch. 84) is considerable on both sides of the bilateral trade balance, although especially with regard to trade flow from Italy. Flows also include Mexican imports of electrical machinery and equipment, iron and steel articles, chemicals and fuels. 
Table 3.8. Growth of the two main chapters (two digits) of Mexico's trade with Spain (1993-2013)

Mexico's imports from Spain

Chap. 84 Nuclear reactors, boilers, machinery, etc.; parts

\begin{tabular}{|c|c|}
\hline $\begin{array}{c}\text { Average } \\
\text { weight }\end{array}$ & $\begin{array}{c}\text { Variation } \\
\text { rate }\end{array}$ \\
\hline $18.1 \%$ & 4.0 \\
$8.9 \%$ & 6.4 \\
$8.8 \%$ & 22.0 \\
$5.9 \%$ & 0.7 \\
$4.8 \%$ & 9.2 \\
$46.4 \%$ & \\
\hline
\end{tabular}

Chap. 85 Electrical machinery and equipment and parts thereof

Chap. 87 Motor vehicles, etc.; parts and accessories

\begin{tabular}{|c|c|}
\hline $\begin{array}{c}\text { Average } \\
\text { weight }\end{array}$ & $\begin{array}{c}\text { Variation } \\
\text { rate }\end{array}$ \\
\hline $77.6 \%$ & 11.3 \\
$4.2 \%$ & 6.1 \\
$2.7 \%$ & 15.3 \\
$1.9 \%$ & 4.6 \\
$1.6 \%$ & 30.6 \\
$88.1 \%$ & \\
\hline
\end{tabular}

Chap. 27 Mineral fuels, mineral oils and products of their distillation, etc.

Chap. 84 Nuclear reactors, boilers, machinery, etc.; parts

Note: Average weight means the chapter average relative weight out of the total flow in question (imports or exports)
in the period 1993-2013. The variation rate corresponds to the annual cumulative variation rate in the period 1993-

Chap. 29 Organic chemicals

Chap. 7 Edible vegetables and certain roots and tubers

Chap. 3 Fish and crustaceans, molluscs and other aquatic invertebrates

Relative weight out of total exports 2013.

Source: Own elaboration based on the UN Comtrade Database

Table 3.9. Growth in the main chapters (two digits) of Mexico's trade with France (1993-2013)

Mexico's imports from France

Chap. 84 Nuclear reactors, boilers, machinery, etc.; parts

\begin{tabular}{c|c}
$\begin{array}{c}\text { Average } \\
\text { weight }\end{array}$ & $\begin{array}{c}\text { Variation } \\
\text { rate }\end{array}$ \\
$18.5 \%$ & 5.0 \\
$16.3 \%$ & 5.3 \\
$7.5 \%$ & 17.3 \\
$6.1 \%$ & 4.2 \\
$5.1 \%$ & 8.8 \\
$53.4 \%$ & \\
\hline
\end{tabular}

Chap. 85 Electrical machinery and equipment and parts thereof

Chap. 30 Pharmaceutical products

Average Variation

Chap. 29 Organic chemicals

\begin{tabular}{|c|c|}
\hline weight & rate \\
\hline $28.7 \%$ & 1.0 \\
\hline $17.9 \%$ & 14.9 \\
\hline $9.9 \%$ & 20.9 \\
\hline $4.8 \%$ & 0.8 \\
\hline $3.4 \%$ & 16.8 \\
\hline $64.7 \%$ & \\
\hline
\end{tabular}

Chap. 84 Nuclear reactors, boilers, machinery, etc.; parts

Chap. 85 Electrical machinery and equipment and parts thereof

Chap. 90 Optical, photographic, etc. instruments and apparatus

Chap. 8 Edible fruit and nuts, etc.

Relative weight out of total exports

Note: Average weight means the chapter average relative weight out of the total flow in question (imports or exports) in the period 1993-2013. The variation rate corresponds to the annual cumulative variation rate in the period 19932013. 
Looking at the evolution of these flows, Mexico's sales to Italy of automobiles (aggregate annual $57.1 \%$ ) acquires special importance, as well as, to a lesser extent, sales of machinery and mechanical appliances (aggregate annual 15.3\%). Regarding Mexico's purchases from Italy, the growth undergone by fuel imports (aggregate annual 53.6\%) and articles of iron and steel (aggregate annual $31.6 \%$ ) is notable.

Furthermore, the coincidence of three industrial chapters (machinery, chemicals and articles of iron and steel) on both sides of the balance opens up the possibility of a certain presence of intra-industrial trade which will be analysed later.

Table 3.10. Growth of the main chapters (two digits) in Mexico's trade with Italy (1993-2013)

\begin{tabular}{|c|c|c|}
\hline \multirow[t]{2}{*}{ Mexico's imports from Italy } & & \\
\hline & $\begin{array}{l}\text { Average } \\
\text { weight }\end{array}$ & $\begin{array}{c}\text { Variation } \\
\text { rate }\end{array}$ \\
\hline Chap. 84 Nuclear reactors, boilers, machinery, etc.; parts & $36.6 \%$ & 8.5 \\
\hline Chap. 85 Electrical machinery and equipment and parts thereof & $7.0 \%$ & 12.2 \\
\hline Chap. 72 Iron and steel & $7.0 \%$ & 31.6 \\
\hline Chap. 29 Organic chemicals & $5.1 \%$ & 3.7 \\
\hline Chap. 27 Mineral fuels, mineral oils and products of their distillation, etc. & $4.4 \%$ & 53.6 \\
\hline Relative weight out of total imports & $60.2 \%$ & \\
\hline
\end{tabular}

Mexico's exports to Italy

Chap. 84 Nuclear reactors, boilers, machinery, etc.; parts

\begin{tabular}{|c|c|}
\hline $\begin{array}{c}\text { Average } \\
\text { weight }\end{array}$ & $\begin{array}{c}\text { Variation } \\
\text { rate }\end{array}$ \\
\hline $13.5 \%$ & 15.3 \\
$9.9 \%$ & 13.6 \\
$6.6 \%$ & 57.1 \\
$6.1 \%$ & 0.4 \\
& \\
\hline $5.4 \%$ & -3.9 \\
$41.5 \%$ & \\
\hline
\end{tabular}

Chap. 29 Organic chemicals

Note: Average weight means the chapter average relative weight out of the total flow in question (imports or exports)
in the period 1993-2013. The variation rate corresponds to the annual cumulative variation rate in the period 19932013.

Source: Own elaboration based on the UN Comtrade Database

The five main chapters making up bilateral trade between Mexico and the Netherlands account for about two thirds of Mexican imports and rather more in the case of exports. A striking feature revealed by the analysis of the sectorial composition of these flows is the fact that exactly the same chapters are repeated on both sides of the balance, although in a different order in terms of their relative weight. Thus, fuels (Ch. 27) stand out among Mexican imports, while they are relegated to the fourth place among its exports. A similar pattern is seen in the sector of electrical machinery and equipment (Ch. 85), which takes on greater importance in Mexico's exports than in its imports. Furthermore, the main variations occur in these two chapters, together with Mexican sales in Chapter 90 (optical 
and photographic instruments and apparatus, etc.), all of these displaying increases of $22 \%$ of aggregate annual rate.

The existence of this trade pattern, which to a large extent coincides, opens up the possibility of the existence of intra-industrial trade between the two countries, although, for now, it can only be observed at a preliminary stage.

Table 3.11. Growth of the main chapters (two digits) in Mexico's trade with the Netherlands (1993-2013)

\begin{tabular}{|c|c|c|}
\hline \multirow[t]{2}{*}{ Mexico's imports from the Netherlands } & \multirow[b]{2}{*}{$\begin{array}{c}\text { Average } \\
\text { weight }\end{array}$} & \multirow[b]{2}{*}{$\begin{array}{l}\text { Variation } \\
\text { rate }\end{array}$} \\
\hline & & \\
\hline Chap. 27 Mineral fuels, mineral oils and products of their distillation & $28.7 \%$ & 24.4 \\
\hline Chap. 84 Nuclear reactors, boilers, machinery, etc.; parts & $13.3 \%$ & 8.5 \\
\hline Chap. 29 Organic chemicals & $9.4 \%$ & 2.9 \\
\hline Chap. 90 Optical, photographic, etc. instruments and apparatus & $6.5 \%$ & 2.1 \\
\hline Chap. 85 Electrical machinery and equipment and parts thereof & $5.0 \%$ & 3.2 \\
\hline Relative weight out of total imports & $62.9 \%$ & \\
\hline
\end{tabular}

Mexico's exports to the Netherlands

Chap. 85 Electrical machinery and equipment and parts thereof

\begin{tabular}{c|c|}
$\begin{array}{c}\text { Average } \\
\text { weight }\end{array}$ & $\begin{array}{c}\text { Variation } \\
\text { rate }\end{array}$ \\
\hline $21.3 \%$ & 22.5 \\
$14.6 \%$ & -2.3 \\
$14.1 \%$ & 18.7 \\
$10.4 \%$ & 10.4 \\
$7.4 \%$ & 26.0 \\
$67.9 \%$ & \\
\hline
\end{tabular}

Chap. 29 Organic chemicals

Chap. 84 Nuclear reactors, boilers, machinery, etc.; parts

Chap. 27 Mineral fuels, mineral oils and products of their distillation, etc.

Chap. 90 Optical, photographic, etc. instruments and apparatus

Relative weight out of total exports

Note: Average weight means the chapter average relative weight out of the total flow in question (imports or exports) in the period 1993-2013. The variation rate corresponds to the annual cumulative variation rate in the period $1993-$ 2013.

Source: Own elaboration based on the UN Comtrade Database

The characterisation of the main trade chapters is completed with the case of bilateral trade between Mexico and the United Kingdom. This is also a case of a partially coincident trade, with the presence of chapters related to machinery and mechanical appliances (Ch. 84) and electrical machinery and apparatus (Ch. 85) on both sides of the balance. This hints to a certain extent of intra-industrial exchanges, although some differences should also be pointed out. Specifically, on the side of Mexican purchases, the importance of automobiles (Ch. 87), pharmaceutical products (Ch. 30) and organic chemicals (Ch. 29) stand out. On the other hand, with regard to purchases from Mexico originating in the United Kingdom, imports related with Chapters 71 (natural or cultured pearls, precious or semi-precious stones, precious metals, etc.) 27 (fuels) and 39 (plastics and plastic articles) are also important. 
In terms of trade evolution, a significant negative variation in Mexican exports of fuels (an aggregate annual fall of $37.4 \%$ ) is observed, with important increases (aggregate annual $19 \%$ ) in Mexican exports of Chapters 71 (pearls, precious stones and metals, etc.) and 85 (electrical machinery and equipment). Mexican imports from the United Kingdom reveal the growing importance of automobile purchases, with an aggregate annual variation of $17 \%$ in the period $1993-2013$.

Table 3.12. The growth of the main chapters (two digits) in Mexico's trade with the United Kingdom (1993-2013)

Mexican imports from the United Kingdom

\begin{tabular}{|c|c|c|}
\hline & $\begin{array}{c}\text { Average } \\
\text { weight }\end{array}$ & $\begin{array}{c}\text { Variation } \\
\text { rate }\end{array}$ \\
\hline Chap. 84 Nuclear reactors, boilers, machinery, etc.; parts & $21.0 \%$ & 9.3 \\
\hline Chap. 85 Electrical machinery and equipment and parts thereof & $10.8 \%$ & 7.9 \\
\hline Chap. 87 Motor vehicles, etc.; parts and accessories & $7.9 \%$ & 17.0 \\
\hline Chap. 30 Pharmaceutical products & $7.6 \%$ & 11.4 \\
\hline Chap. 29 Organic chemicals & $7.4 \%$ & 0.3 \\
\hline Relative weight out of total imports & $54.7 \%$ & \\
\hline
\end{tabular}

Mexican exports to the United Kingdom

Chap. 71 Natural or cultured pearls, precious or semi-precious stones, precious

\begin{tabular}{c|c} 
Average & $\begin{array}{c}\text { Variation } \\
\text { weight }\end{array}$ \\
rate
\end{tabular}
metals

$19.7 \% \quad 19.0$

Chap. 84 Nuclear reactors, boilers, machinery, etc.; parts

$19.4 \% \quad 15.3$

Chap. 85 Electrical machinery and equipment and parts thereof

$11.2 \% \quad 19.6$

Chap. 27 Mineral fuels, mineral oils and products of their distillation, etc.

$10.6 \% \quad-37.4$

Chap. 39 Plastics and articles thereof

$3.8 \% \quad 9.2$

Relative weight out of total exports

$64.7 \%$

Note: Average weight means the chapter average relative weight out of the total flow in question (imports or exports) in the period 1993-2013. The variation rate corresponds to the annual cumulative variation rate in the period 19932013.

Source: Own elaboration based on the UN Comtrade Database

\subsection{Foreign direct investment between the European Union and Latin America: Characteristics and evolution}

\subsubsection{Foreign direct investment from a comparative global perspective}

Ths study of the foreign economic relations of a country or larger region such as the EU or LA is would be incomplete if it was limited to analysis of trade. Therefore, this section deals with FDI which has been growing in importance in recent decades in the context of globalisation which also affects the production sphere. In this regard, the world's global factory, global value chains, and production relocation processes are discussed. In this 
context, multinational corporations become important protagonists of productive and economic activity.

To start with, it should be pointed out that a new methodology for FDI statistics was adopted in 2014, following revision of international standards (BPM6 ${ }^{27}$ and BD4 ${ }^{28}$ ). One of the main changes the new methodology offers is disaggregated information about direct investment between related companies as well as about reverse investment (investment by a directly invested company backwards, in its own direct investor). The term "multiterritory enterprise" is also used for the first time, referring to enterprises which carry out a substantial activity in more than one economic territory and function as an inseparable operation without separate accounts or decisions, so that separate branches cannot be recognised. The statistical information prepared with the new methodology is only available for 2013 and 2014. For this reason, in order to facilitate comparison over time to analyse recent trends, the statistical data prepared with the previous methodology (BPM5) are used.

The official FDI statistics of different organisations (UNCTAD, OECD, FMI, Eurostat) include series of both flows and stocks. FDI flows allow for the identification of recent trends, but have a strong circumstantial component which is subject not only to variations of the economic cycle, but also to those caused by the high volatility of transnational merger and acquisition operations. For this reason, FDI stocks are used to obtain a more realistic picture, as they are more stable and better reflect the country's appeal and the confidence it inspires to attract foreign investment.

FDI is an economic figure that seems to be very influenced by the economic cycle of the recipient country and even that of the investment source country. However, the volume of FDI is affected by various factors, such as regulation of and restrictions on investment; the openness of economies and regional integration processes; product price, particularly in the primary sector and/or aimed at exports, which tend to be more volatile; and the change of value in different currencies. And also by internal elements, such as institutional aspects and political and economic stability; market size, internal privatisation processes and liberalisation of economic activities or infrastructure construction (Mogrovejo 2004; Myro 2014; ECLAC 2015a; UNCTAD 2015) which are very relevant elements in the case of LA, as well as other explanatory factors identified by the various theories mentioned in the theoretical section.

We first examine FDI flows in 2014 both at the global level according to development

27 This refers to the sixth edition of the Balance of Payments and International Investment Position Manual, BPM6, released in 2009 and in use since 2014. It updates MBP5, released in 1993.

28 BD4 refers to the fourth edition of the OECD Benchmark Definition of Foreign Direct Investment. Therefore, the OECD's definition of FDI is referred to. The BD4 methodology recommends collecting FDI statistics in two ways: either including or excluding the Special Purpose Entities (SPE). These are transit or intermediation transactions which may have a very high value while, at the same time, not generating investment in fixed assets nor employment in the country which is the immediate receiver. UNCTAD does not consider these entities' flows as long as the available statistics so allow, in the same way as it excludes offshore or transnational financial centres. 
level and by large regions (Table 3.13). The FDI received globally amounted to $\$ 1.23$ billion in 2014. Over half of the received FDI (55.5\% of the world total) went to developing countries, while developed countries represented $40.6 \%$. Transition economies received $\$ 48,100$ million, equivalent to $3.9 \%$ of the total FDI in 2014 . This territorial distribution could be surprising if it was not taken into account that we were analysing a flow variable, as well as the change observed especially since the beginning of the 21 st century - the important growth of developing economies -, as will be seen later when we examine the development of FDI.

Among the developing economies, Asia, which received nearly $38 \%$ of global FDI, stands out. This converts it to the main FDI recipient region in the world. This relevance would be incomprehensible without considering the role of China, which in the period 1990-2014 multiplied its FDI amount by 36.9 and recorded an aggregate annual growth rate of $16.2 \%$. Therefore, in 2014, China became the main FDI recipient economy and the third largest issuer. ${ }^{29}$ Latin America and the Caribbean is the second most important region among developing economies, with an amount of FDI received in 2014 of $\$ 159,000$ million, which represents $13 \%$ of the world total, a figure greater than that for North America (11.9\%). Africa's presence is residual, equivalent to $4.4 \%$ of the total.

Table 3.13. FDI inflows and outflows in the world by region in 2014

\begin{tabular}{lc|c|c|c}
\hline & \multicolumn{2}{c}{ FDI inflow } & \multicolumn{2}{c}{ FDI outflow } \\
& $\begin{array}{c}\text { Millions of } \\
\text { dollars }\end{array}$ & $\%$ & $\begin{array}{c}\text { Millions of } \\
\text { dollars }\end{array}$ & $\%$ \\
\hline Developed economies & $498,761.7$ & 40.61 & $822,826.3$ & 60.77 \\
EU-28 & $257,566.5$ & 20.97 & $280,123.9$ & 20.69 \\
North America & $146,261.0$ & 11.91 & $389,563.0$ & 28.77 \\
Japan & $2,089.8$ & 0.17 & $113,628.8$ & 8.39 \\
Developing economies & $681,386.7$ & 55.47 & $468,147.8$ & 34.57 \\
Latin America and the Caribbean & $159,404.9$ & 12.98 & $23,325.9$ & 1.72 \\
Africa & $53,912.1$ & 4.39 & $13,072.9$ & 0.97 \\
Asia & $465,285.2$ & 37.88 & $431,591.2$ & 31.87 \\
- China & $128,500.0$ & 10.46 & $116,000.0$ & 8.57 \\
Transition economies & $48,114.1$ & 3.92 & $63,072.1$ & 4.66 \\
World total & $1,228,262.5$ & 100 & $1,354,046.2$ & 100
\end{tabular}

Among the developed economies, the importance of the $\mathrm{EU}^{30}$ stands out. The FDI received by the $28 \mathrm{EU}$ countries amounted to $\$ 257,000$ million in 2014 , representing $21 \%$ of the world total. North America received an amount of FDI of $€ 146,000$ million,

29 In 2014, the main foreign direct investment issuing economy was the United States, followed by Hong Kong. China takes third place. In 2013, China was the second most important FDI recipient economy in the world, after the US, and the third most important investor, after the US and Japan.

30 Unless otherwise indicated, whenever the EU is mentioned in this section, it refers to the EU-28. 
equivalent to approximately $12 \%$ of the world total. Finally, Japan only received a little over $\$ 2,000$ million $(0.17 \%$ of the world total).

FDI is made up of three main types of components: capital contributions, profit reinvestment and other capital (referring to intercompany loans). The composition of FDI according to these types is substantially different for developed and developing economies. In 2014, most FDI in developed economies came from profit reinvestment $(81 \%)$, the other two components representing approximately $10 \%$ each. In contrast, in developing economies, capital contributions were important, representing $55 \%$ of total FDI, followed by profit reinvestment (35\%). Finally, the capital was equivalent to $10 \%$ of the total FDI received. So, profit reinvestment predominate in developed economies today, while in developing economies, most investment is capital contributions. Even so, FDI composition in either of these spheres and even in any particular country also displays important variations over time. The growth in profit reinvestment in LA means that in recent years (since 2010), it has exceeded $40 \%$, reaching $53 \%$ in 2014 . Multinational corporations tend to repatriate about $50 \%$ of their investment and reinvest the other 50\% (ECLAC 2015a).

Two basic types of FDI can be distinguished according to their form of entry: new investment (greenfield) created by a company and acquisition of existing companies through merger and acquisition processes. FDI distribution shows the predominance of the first of these forms of entry, new or greenfield investment, which was equivalent to $\$ 695,577$ million in 2014 , representing $56.6 \%$ of FDI. Meanwhile, $31.7 \%(\$ 398,899$ million) corresponded to FDI aimed at acquisitions of existing companies and mergers.

The sectorial distribution of these two FDI components is shown in Table 3.14. New investment is basically concentrated in service sector activities (representing $49 \%$ of the total) and manufacturing (44.9\%). The primary sector accounts for $6.1 \%$ of total new investment, basically directed at mining, extractive industries and petroleum, while the importance of agriculture, fishing and forestry is very residual.

The main service activities are business services (10.5\%), electricity, gas and water (9.4\%), construction (9.1\%), transport, storage and communications $(8.7 \%)$. Less important are financial activities, representing $5.2 \%$ of new investment, or trade $(3.4 \%)$. In manufacturing activities, the motor vehicle and other transport equipment branches (representing $11.6 \%$ of total new investment in 2014) stand out. The following branches are chemicals $(5.8 \%)$, electrical and electronic equipment $(4.7 \%)$, coking and petrol refining $(4.6 \%)$, textiles, leather and clothes making (4.1\%), mentality and metal products (3.1\%), and food, drink and tobacco (also 3.1\%). 
Table 3.14. Sectorial distribution of new investment and mergers and acquisitions in the world in 2014

\begin{tabular}{|c|c|c|c|c|}
\hline \multirow[b]{2}{*}{ Sector } & \multicolumn{2}{|c|}{ New Investment } & \multicolumn{2}{|c|}{ Mergers and acquisitions } \\
\hline & $\begin{array}{l}\text { Millions of } \\
\text { dollars }\end{array}$ & $\%$ & $\begin{array}{l}\text { Millions of } \\
\text { dollars }\end{array}$ & $\%$ \\
\hline Primary & $42,389.66$ & 6.09 & $39,947.71$ & 10.01 \\
\hline Agriculture, hunting, fishing and forestry & 22.00 & 0.003 & 581.18 & 0.15 \\
\hline Mining, extractive industries and petroleum & $42,367.66$ & 6.09 & $39,366.53$ & 9.87 \\
\hline Manufacturing & $312,414.33$ & 44.91 & $145,910.74$ & 36.58 \\
\hline Food, drink and tobacco & $21,321.05$ & 3.07 & $30,993.61$ & 7.77 \\
\hline Textiles, clothes making and leather & $28,257.35$ & 4.06 & $2,890.91$ & 0.72 \\
\hline Wood working industry & $5,980.31$ & 0.86 & 437.95 & 0.11 \\
\hline Paper industry & - & - & 930.25 & 0.23 \\
\hline Publishing & 45.30 & 0.01 & 193.55 & 0.05 \\
\hline Coking plants and oil refining & $31,677.16$ & 4.55 & $-9,368.41$ & -2.35 \\
\hline Chemicals & $40,161.32$ & 5.77 & $25,085.87$ & 6.29 \\
\hline Pharmaceuticals & - & - & $47,828.42$ & 11.99 \\
\hline Rubber and plastic products & $11,751.37$ & 1.69 & 823.61 & 0.21 \\
\hline Non-metal mineral products & $9,129.29$ & 1.31 & $1,680.97$ & 0.42 \\
\hline Metallurgy and metal products & $21,351.22$ & 3.07 & $3,071.81$ & 0.77 \\
\hline Machinery and equipment & $13,602.04$ & 1.96 & $12,473.83$ & 3.13 \\
\hline Electrical and electronic equipment & $32,811.40$ & 4.72 & $20,343.22$ & 5.10 \\
\hline Precision instruments & $3,349.67$ & 0.48 & - & - \\
\hline Motor vehicles and other transport equipment & $80,917.95$ & 11.63 & 508.40 & 0.13 \\
\hline Furniture making & - & - & 65.22 & 0.02 \\
\hline Other manufactured products & $12,058.88$ & 1.73 & $7,951.54$ & 1.99 \\
\hline Services & $340,772.85$ & 48.99 & $213,040.40$ & 53.41 \\
\hline Electricity, gas and water & $65,054.11$ & 9.35 & $17,836.02$ & 4.47 \\
\hline Construction & $63,256.89$ & 9.09 & $2,345.17$ & 0.59 \\
\hline Trade & $23,808.20$ & 3.42 & $24,578.92$ & 6.16 \\
\hline Hotels and restaurants & $8,954.58$ & 1.29 & $16,825.41$ & 4.22 \\
\hline Transportation, storage and communications & $60,522.11$ & 8.70 & $-51,587.56$ & -12.93 \\
\hline Financial services & $36,073.35$ & 5.19 & $134,861.09$ & 33.81 \\
\hline Business services & $72,659.12$ & 10.45 & $51,629.97$ & 12.94 \\
\hline Education & 897.90 & 0.13 & $1,255.87$ & 0.31 \\
\hline Health and social services & $2,330.77$ & 0.34 & $1,892.30$ & 0.47 \\
\hline Other services & $7,215.82$ & 1.04 & $13,403.21$ & 3.36 \\
\hline \multirow[t]{2}{*}{ Total } & $695,576.84$ & 100.00 & $398,898.85$ & 100.00 \\
\hline & & \multicolumn{3}{|c|}{ Source: Own elaboration based on UNCTAD date } \\
\hline
\end{tabular}

With regard to investment in mergers and acquisitions, there is also a clear predominance of the services sector, which represents $53.4 \%$ of the total amount corresponding to mergers and acquisitions in 2014. More than a third (36.6\%) of mergers and acquisitions in the world take place in the manufacturing sector and $10 \%$ in the primary sector. 
Financial services are the main branch of services, representing a third $(33.8 \%)$ of the total investment under consideration. The other branches account for much lower percentages, but business services (12.9\%) stand out. The next most important branches are trade $(6.2 \%)$, electricity, gas and water (4.5\%), and hotels and restaurants $(4.2 \%)$. In the manufacturing sector, the main activities are pharmaceuticals (12\%), food, averages and tobacco $(7.8 \%)$, chemicals $(6.3 \%)$, electrical and electronic equipment $(5.1 \%)$ and machinery and equipment (3.1\%). In the primary sector, nearly all investment is again dedicated to the activity of mining, extractive industries and petroleum.

The FDI invested in the world reached an amount $\$ 1.35$ billion in 2014 . Its analysis shows the importance of the developed economies which, with an investment amount of $\$ 823,000$ million, represent $60.8 \%$ of the world total. Developing economies issued foreign investment to a value of $\$ 468,000$ million, equivalent to a little over a third $(34.6 \%)$ of the world total. Investments made abroad by transition economies came to $\$ 63,000$ million ( $4.7 \%$ of the world total).

Among the developed economies, North America was the biggest foreign investor, making investment abroad of $\$ 389.5$ thousand million in 2014 , representing $28.8 \%$ of the world total. In second place was the EU-28, with an FDI outflow of $\$ 280,000$ million, representing $20.7 \%$ of the world total. Japan issued $\$ 113,629$ million of FDI in 2014 , equivalent to $8.4 \%$ of the world total. The main foreign investment issuing region is Asia, which belongs to the developing economies, and contributes with $31.9 \%$ of foreign investment made in the world. The importance of LA and the Caribbean is low, issuing an investment amount of $\$ 23,000$ million, representing $1.7 \%$ of the world total. The lowest contribution is from Africa, with a little less than $1 \%$ of world investment.

It can be said, therefore, that developed economies continue to be the main issuers of foreign investment, while developing economies have become the main recipients. In addition, important regional differences are observed as inflows and outflows of FDI are analysed. Asia and the EU-28 stand out in inflows of foreign investment, and Asia also stands out in ouflows, as well as North America. In fact, North America together with Japan and, to a lesser extent, the transition economies are the only regions which are more important in the world percentage of FDI outflow than in FDI inflow. In the other regions, the amount of FDI inflow is greater than the FDI outflow. The EU-28 has a similar weight in the world in these two magnitudes (21\% inflow and $20.7 \%$ outflow), while the difference is much more significant in LA and the Caribbean (13\% inflow and only $1.7 \%$ outflow).

Growth in FDI inflows in the world in recent decades (1990-2014) shows a clearly positive trend (Graph 3.24), in spite of the variations registered over time, which are generally 
not unrelated to the growth of the economic cycle. This is reflected in the behaviour of global FDI flows in the recession in the first few years of this century and especially, in the current crisis, showing a decrease since 2007, when they reached a historic peak. Although the continuous downward trend in global FDI has been reversed since 2010, behaviour is variable, and in 2014, the FDI level prior to the present financial crisis had still not been reached.

Graph 3.24. Growth of FDI inflows according to development level (1990-2014)

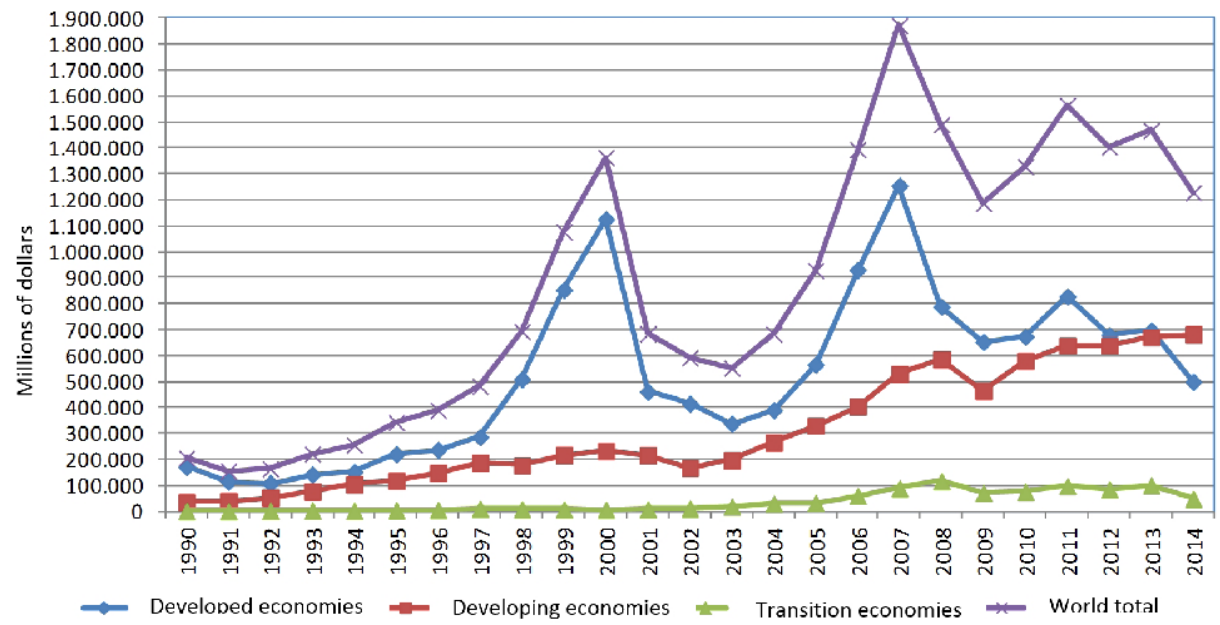

Source: Own elaboration based on UNCTAD data

The global trend described corresponds to the behaviour of the developed economies and contrasts with the trend of continued growth of FDI flows in developing economies, with occasional exceptions in a few years (1998, 2002 and 2009). This growing trend has continued even in the current crisis, leading to two developments in 2014 which deserve attention. Firstly, developing economies reached their maximum historic peak by the inflow of FDI rising to $\$ 681,387$ million. Secondly, the developing economies became the largest FDI recipients, exceeding the amount received by developed economies for the first time.

In the overall period being examined (1990-2014) the amount of FDI received annually in the world was multiplied by six, representing an aggregate annual growth rate of $7.8 \%$. In keeping with the trends followed by developed and developing economies, the biggest increase is seen in the latter group. The FDI inflow of developing economies was multiplied by 19.7 , increasing to an annual aggregate rate of $13.2 \%$, while in developed economies, the FDI inflow nearly tripled (it was multiplied by 2.9 ), representing an annual aggregate growth of $4.6 \%$. The transition economies started off with very low figures $(0.04 \%$ of the 
world total in 1990) and increased their FDI inflow to an annual aggregate rate of $31.2 \%$.

Graph 3.25. Development of the relative weight of global FDI inflows according to development level (1990-2014)

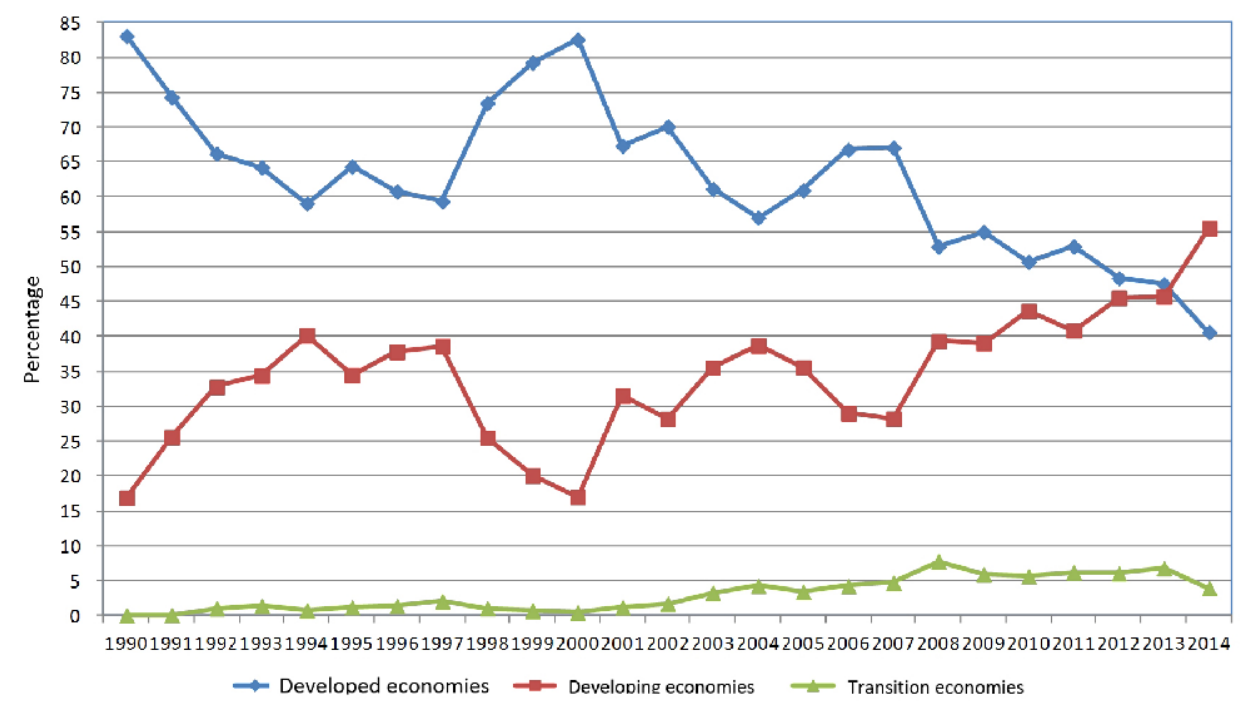

Source: Own elaboration based on UNCTAD data

As a result of the trends of the recent decades, significant changes have occurred in the relative weight of developed, developing and transition economies worldwide (Graph 3.25). The developed economies, which received $83 \%$ of foreign investment in 1990 , show a clearly falling trend and, in spite of some variations (such as the growth in their relative weight in the periods $1997-2000$ and 2004-2007), have been below $50 \%$ of total global investment since 2012. In 2014, they only represented $40 \%$ of global FDI, being surpassed by the developing economies for the first time. In 1990, these economies represented $16.9 \%$ of total FDI worldwide and followed a growth trend which, in spite of some variations (such as relative weight loss in the periods 1997-2000 and 20042007, which can be explained by the greater FDI growth of the developed economies), surpassed $40 \%$ since 2010 and reached 55.5\% in 2014. Transition economies started off at a low level in 1990, and followed a growth trend that led them to a peak in 2008 (7.8\%). The figures since then are lower, in spite of the growth in the period 2010-2013, interrupted by a decrease in 2014 , leaving their relative importance at $3.9 \%$ of the world total.

The analysis of the trends observed in the period 1990-2014 by large regions (Graph 3.26) demonstrates the increase in inflows in any of the regions considered and also the 
progress of the less developed economies and particularly, Asia. Traditionally, the main recipient region of FDI has been the $\mathrm{EU}$, also displaying one of the most varying trends, together with North America. The EU is the region most affected by the present crisis in the behaviour of FDI inflows, having been surpassed by a share between 2010 and 2014 (with the exception of 2011).

The FDI inflow of the EU follows a clear growth trend, reaching its peak in 2007. Although a few reductions were observed at the beginning of the nineties (1990-1992), in the period 2000-2004, in 2008 and 2010 and most recently from 2011 until 2014, in the entire period the amount of FDI was multiplied by 2.7, with an annual aggregate growth rate of $4.2 \%$. The trend in North America is very similar, growing at a rate slightly below that of the EU (annual aggregate growth of $4.1 \%$, the initial amount being multiplied by 2.6 ). North America's better behaviour as compared to the EU should be remarked upon, especially in its initial stage, which explains the fact that in 2008, for the first and only time, North America's FDI amount exceeded that of the EU.

The most favourable development is that followed by Asia which, beginning in third position, with an FDI amount of $\$ 22,900$ million, became the main foreign investment recipient region in 2014 , accounting for an amount of $\$ 465,285$ million. This means investment multiplied by 20.3 in the period 1990-2014, having a compound annual growth rate of $13.4 \%$. The growth trend was only interrupted occasionally, in 1998, 2000-2002, and 2009 and 2012. Africa has a compound growth rate of 13\%, its FDI inflow being multiplied by 19 , this increase being especially notable in the first decade of the $21 \mathrm{st}$ century. The third growth region is LA and the Caribbean, with a CAGR of $13.0 \%$, its FDI inflow being multiplied 18.7 times between 1990 and 2014. So, it grew from $\$ 8,537$ million at the beginning of the period under consideration $\$ 159,405$ million in 2014 . Its behaviour in recent decades has been growing, even in recent years, with the exceptions of 1993 , the period 1999-2003 and 2006 and 2014.

The relative weight of the different regions varies following the trends described, as shown in Graph 3.27. In the case of the EU, the trend is a reduction in its relative weight to practically half, over the period 1990-2014. Beginning with $46.7 \%$ in 1990, after an initial reduction that led it to represent $30.1 \%$ in 1997, it recovered to $50.4 \%$ in 2000 . After that, in spite of some variations, the trend has been downward, especially in recent years, leading to the fact that in 2014 it only represented $20.9 \%$ of the world total, one of the lowest figures of all those reached in the period under analysis. The trend seen in the development of North America's relative weight is very similar to that of the EU, its importance being significantly reduced in the overall period, from $27.3 \%$ to $11.9 \%$. 
Graph 3.26. Development of FDI inflows to large regions (1990-2014)

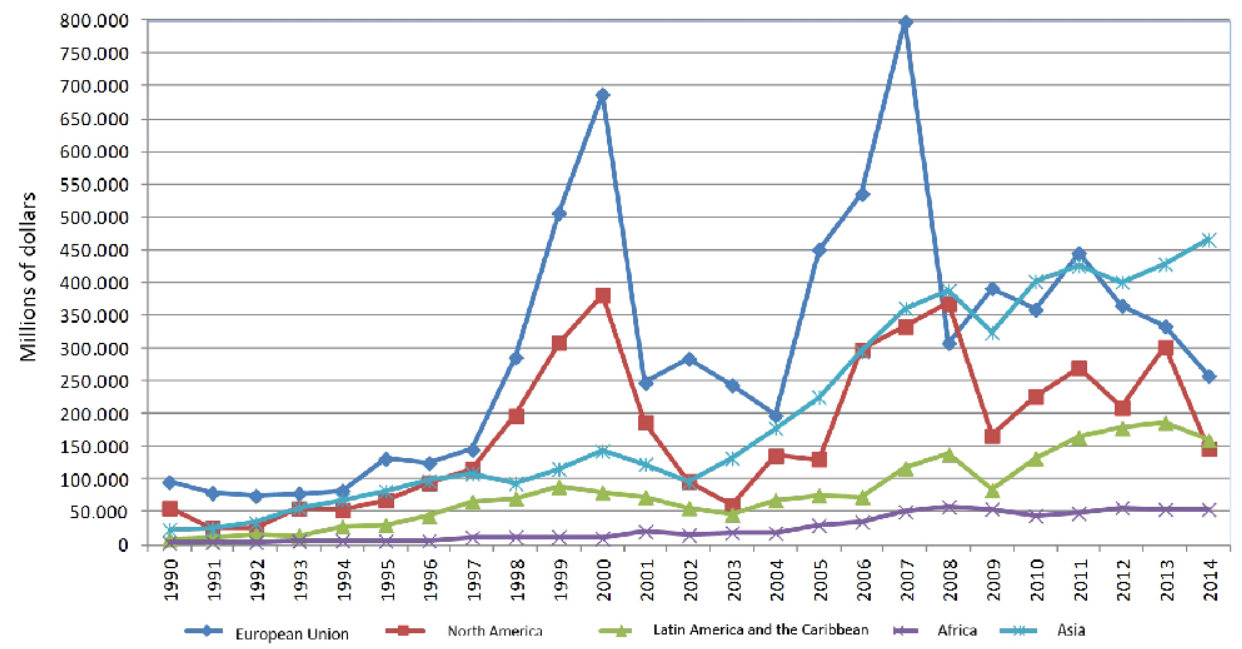

Source: Own elaboration based on UNCTAD data

Its greatest weight was registered in 2000 , when it represented $27.9 \%$ of the world total. The other regions show a clear trend of increasing importance, explained by their greater growth compared with the behaviour of the developed economies. In the case of Asia, when it began the period it represented $11.2 \%$ of the world total and, in spite of occasional times of reduction (especially in the second half of the nineties), reached $37.9 \%$ in 2014, this region's greatest relative weight. In 1990, LA and the Caribbean received $4.2 \%$ of foreign investment in the world, and came to represent $13 \%$ in 2014 , and lower figure than its historic peak of $13.7 \%$, achieved in 1997. Africa's weight in global FDI is very marginal, beginning from a contribution of only $1.4 \%$ in 1990 . In spite of the variations recorded, a growth trend is observed, especially in the 21 st century, leading it to contribute with $4.4 \%$ of global FDI in 2014 .

The FDI issued in the world grew in the period 1990-2014 (Graph 3.28), and the investment amount abroad was multiplied by 5.6, amounting to an increase in the annual amount as a compound rate of $7.4 \%$. There are important fluctuations in the evolution of FDI issued. The notable decrease at the beginning of the 2000s was first followed by strong growth until a peak in 2007 ( $\$ 2.13$ billion), after which it began a downward path, although there were swings (like the growth in the years 2000, 2011, 2013 and 2014) which did not reach peak figures. With slight differences, this general global trend is observed in the developed economies, given their weight in the world total. The main difference can be seen in a slower rate of growth in the developed economies, with a compound annual growth rate of $5.4 \%$, which multiplies the amount of investment issued by these economies by 3.6 in the period under consideration (1990-2014). 
Graph 3.27. Growth of relative weight of global FDI inflows by large region (1990-2014)

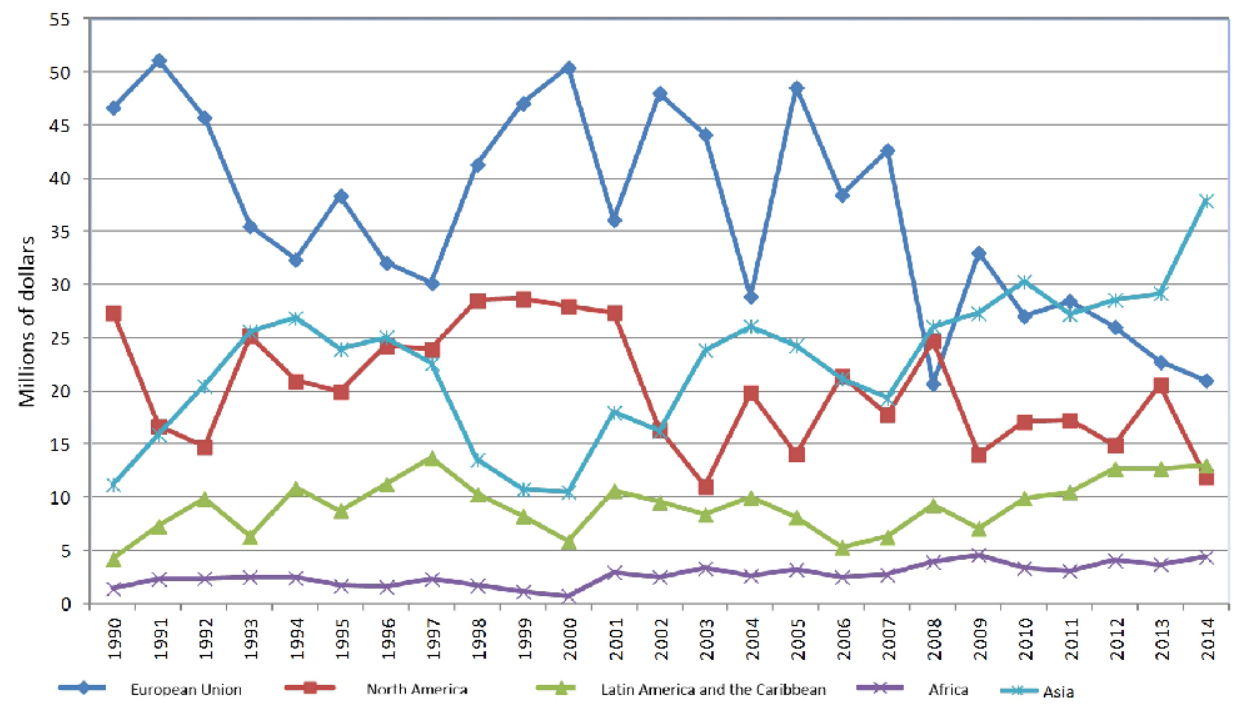

Source: Own elaboration based on UNCTAD data

Developing economies show a growing trend, with some variations (like the reductions seen in 1991, 1998, 2005, 20092012 and in the period 2001-2003), reaching their peak ( $\$ 468.2$ thousand million) in 2014. This figure is 35.7 times the amount issued by this group of economies in 1990. The compound annual growth rate is $16.1 \%$ throughout the period analysed. Transition economies began with very low figures $(\$ 1,566$ million in 1992) and although their trend is very variable (with large descents, as at the beginning of the nineties, or important increases as in 1997, in the more recent periods 2001-2008, 2010-2011 or the year 2013, when it reached the peak of $\$ 91,496$ million), in the period overall (1992-2014), they multiplied avoiding by 40.3, recording a compound annual growth rate of $18.3 \%$.

The behaviour of the foreign investment issued follows a very similar growth pattern to that of foreign investment received, and the developed economies continue to play the mayor role. In spite of the progress of the developing economies, it has not been sufficient to overcome the greater differences that existed at beginning of the period. In general, the growth rate is higher in foreign investment inflow than outflow in the regions considered by level of development (developed economies, developing economies and world total), with the exception of the transition economies in which the opposite is occurring, specifically as investment outflow is growing at a faster rate than inflow. 
Graph 3.28. FDI outflow growth according to development level (1990-2014)

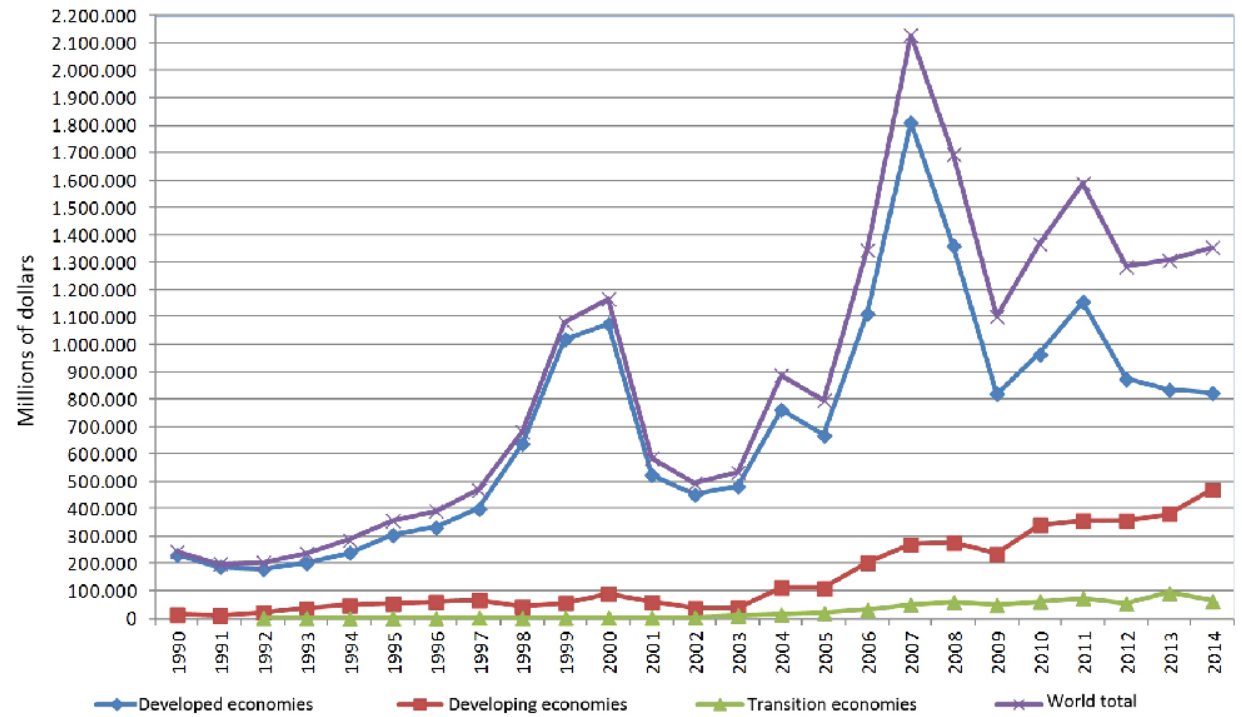

Source: Own elaboration based on UNCTAD data

Growth of the FDI outflow of the different regions in recent decades translates into changes in their relative importance (Graph 3.29). The clear trend is loss of relative weight by the developed economies, while the other two regions (developing economies and transition economies) are gaining importance in the world total. In 1990, the developed economies issued $94.6 \%$ of global FDI and, in spite of fluctuations (like the recovery in the period 19971999 , which put their importance at $94.58 \%$ in 1999), they have not regained their initial relative weight. The falling curve is clearer from the beginning of the 2000 s on and particularly after 2007, until in 2014 it represents its minimum figure of $63.9 \%$ of the world total.

In 1990, the developing economies only represented $5.4 \%$ of FDI outflow in the world. Although the trend has swings, with strong variations over the period being analysed (such as the force in the period 1994-1999, until their minimum global relative weight of $5.2 \%$ was reached in 1999), there is a clear upward direction in their relative weight. So, in 2014 , they reached their maximum relative importance, representing $34.6 \%$ of the world total. Transition economies represented a very small proportion of $0.77 \%$ of the world total in 1992. The trend they follow oscilliated considerably: their minimum relative weight of $0.11 \%$ occurred in 1994 and their maximum of $7.01 \%$ in 2013 . In the overall period 1992-2014, they gained in importance globally and came to represent $4.7 \%$ in 2014.

A significant reduction in the initial differences in the relative weights of regions over the 
period 1990-2014 can thus be observed, although the predominance of the developed economies continues.

Graph 3.29. Growth in relative weight of global FDI outflows according to level of development (1990-2014)

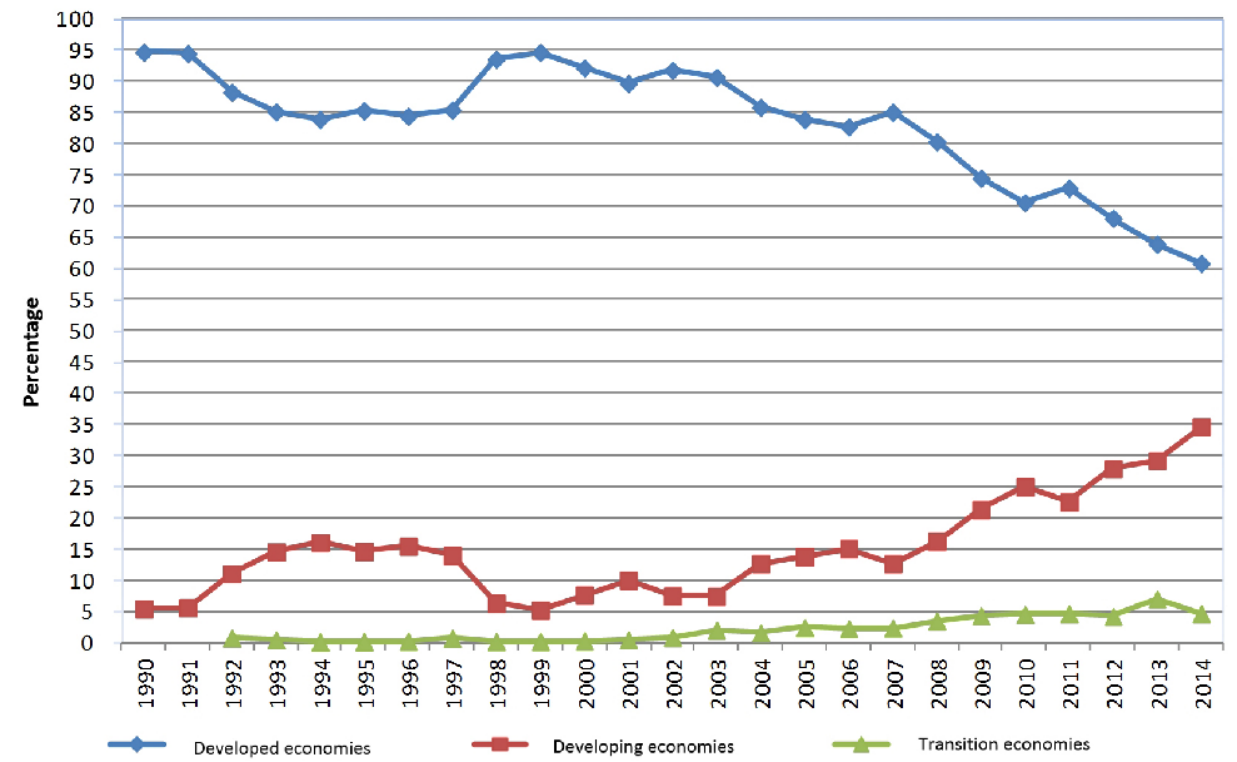

Source: Own elaboration based on UNCTAD data

The evolution over the period $1990-2014$ is clearly positive in absolute terms of the amount of FDI outflow in the four large areas considered (Graph 3.30). However, it should be noted that important oscilliations over time - in coherence with the volatility of flows were observed in all four regions, In addition, as indicated above, developing economies experienced the greatest growth.

The EU, the main FDI issuer between 1990 and 2011, displayed considerable oscilliations throughout the period under consideration: a notable decrease at the beginning of the nineties until in 1993, an extended period of strong growth, reaching an amount of $\$ 793.7$ thousand million in 2000. A later decrease was interrupted in 2003 , with a rhythm of growth which was slower first and later much faster, to reach its historic peak of $\$ 1.18$ billion in 2007. Since then it has followed a falling trend, except for 2010 and 2011. In fact, the EU became the third global FDI issuer in 2014. In spite of these oscilliations, which demonstrate the cyclical, volatile nature of FDI flows, over the period 1990-2014, the EU's FDI outflow was multiplied by 2.1 , as the result of a compound annual growth rate of $3.2 \%$. 
Graph 3.30. FDI outflow growth by large region (1990-2014)

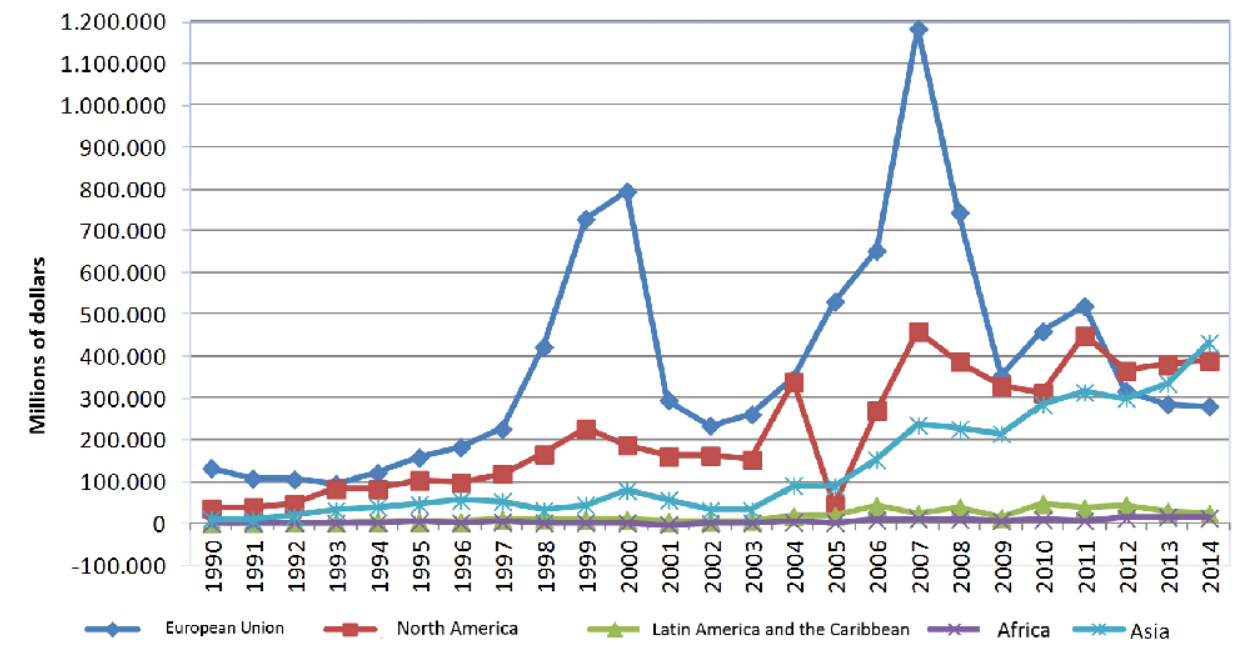

Source: Own elaboration based on UNCTAD data

North America represented a larger increase than the EU, recording an accumulative annual growth rate of $10.4 \%$ and multiplying its FDI outflow by 10.8 in the period 1990 2014. Its growth in the nineties was similar to that of the EU, although its oscillations turned out smoother, while in the 2000s it displayed a clearer growth curve, resulting in a position very close to the EU in 2009, and an overhaul it in the more recent 2012-2014 period. Asia's greater growth, recording a compound annual growth rate of $16 \%$ and multiplying the amount by 39 between 1990 and 2014, converted it into the main FDI outflow region in 2014, having been the third in 1990. Its growth behaved better in the 2000s, with a significant advance, in spite of the swings, such as the important descent in 2002 or the smaller one in the period 2007-2009 or that of 2012.

Latin America and the Caribbean followed a clear growth trend in the period 1990-2014, recording an annual growth rate of $12.6 \%$. However, important oscilliations were noted, such as the decreases in 1993, 1995, 2007, 2009 and 2011, the period 1998-2001 and the more recent 2012-2014. With regard to the period of growth, the first part of the 2000s can be pointed out, specifically the period 2001-2006, when it reached the peak of $\$ 42,000$ million in 2006 . The figure corresponding to 2014 ( $\$ 23.3$ thousand million) is much lower than that of 2006, but is 17.1 times 1990's FDI (\$1367.1 million).

Finally, in the case of Africa, although its importance is very low throughout the period, its evolution was also favourable, with a compound annual growth rate of $13.3 \%$. So the amount of its $1990 \mathrm{FDI}$ outflow (equivalent to $\$ 659.5$ million) was multiplied by 19.8 , to 
reach $\$ 13.1$ thousand million in 2014. Its curve also shows important oscilliations, with large drops at the beginning of the nineties and 2000s, actually reaching a negative figure (-\$2644.3 million) in 2001. Beginning in 2005, it followed a trend of large increases (with some exceptions in occasional years such as in the period 2007-2009 for the years 2011 and 2014), reaching its historic peak of $\$ 15,950.6$ million in 2013.

As a result of the trends described, the relative weight of the different regions has varied over the period under consideration (Graph 3.31). The trend shows a reduction of the relative importance of EU outflow FDI in the world total, while the weight of the other three regions considered has increased due to their higher growth. In 1990, the EU represented $54.2 \%$ of the world total of foreign investment issued, and in 2014 its importance had been reduced by more than a half, to $20.7 \%$ of the world total, - its lowest contribution historically. Furthermore, it developed from the top FDI issuing region to the second place in 2012 and the third position in 2014. During that period, its relative weight fluctuated, increasing in the second half of the nineties to reach its maximum relative weight of $68.1 \%$ in 2000 .

North America nearly doubled its relative weight, beginning by representing $14.9 \%$ of global FDI outflow in 1990 to reach $28.8 \%$ in 2014. Its evolution oscillated from a growth trend at the start of the nineties, which was interrupted halfway in that decade with a notable reduction in its relative weight, coinciding with the strong growth of the EU. A new stage of greater relative weight led it to nearly equal its contribution with that of the EU in 2004. North America's weight decresed drastically in 2005 to its minimum amount, contributing with only $5.4 \%$ at global level. Afterwards, it returned to a path of growth (except for 2010 and 2014), until reaching its maximum contribution of 29\% in 2013. Since 2012 North America has exceeded the EU's contribution (by 7 percentage points in 2014), converting it into the main FDI issuing region in the world. Asia's higher growth meant that in 2014 it surpassed North America's contribution, converting Asia into the most important region in FDI issue in the world, representing $31.9 \%$ of the total. Ever since it began with $4.5 \%$ of the total in 1990 , Asia's relative weight has multiplied by 7 . In spite of the remarkable increase in its importance, significant periods of loss of relative weight were observed, as well, for instance between 1997 and 1999, which resulted in its minimum contribution (only 4.1\%). In general, its contribution increased after 2003, except in specific years, such as 2007 and 2011. 
Graph 3.31. Growth in the relative weight of FDI outflow globally by large region (19902014)

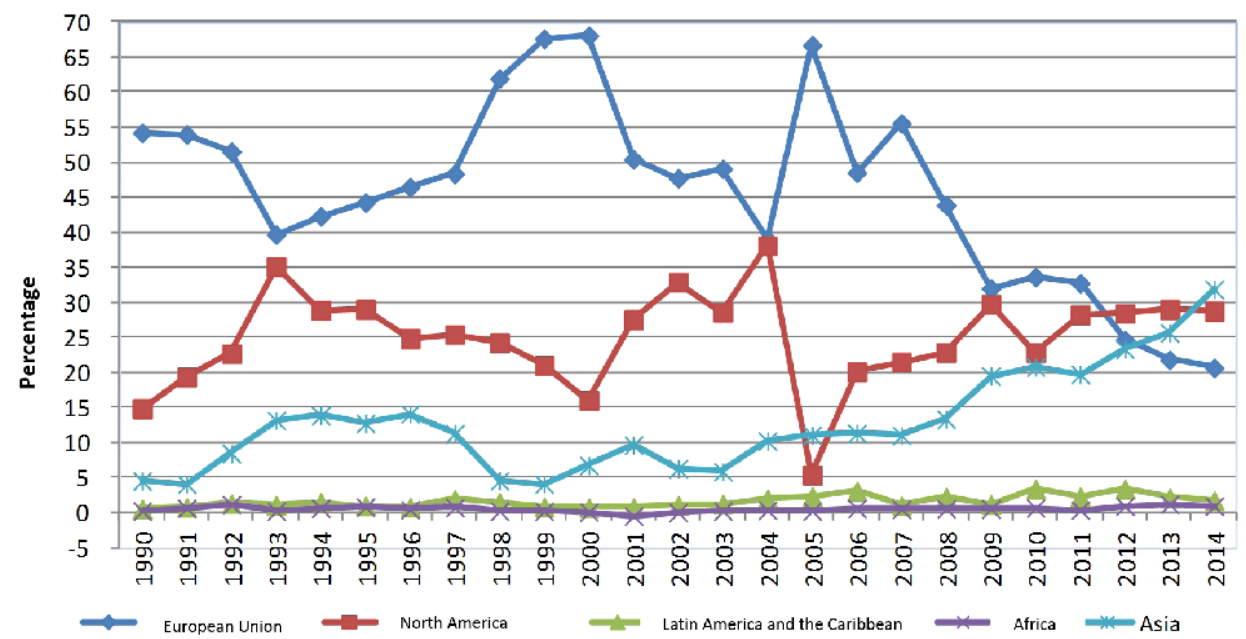

Source: Own elaboration based on UNCTAD data

The relative weight of LA and the Caribbean tripled in the period 1990-2014, because it began with a contribution of $0.56 \%$ of global FDI outflow in 1990 and represented $1.7 \%$ in 2014. Its growth had important swings, and except for the period 2000-2006, the fluctuations do not allow periods of three or more years with the same trend to be identified. In 2010, it reached its maximum contribution to global FDI (3.4\%), a figure repeated in 2012 .

Africa made the smallest contribution to FDI outflow globally, when it represented only $0.27 \%$ of the total in 1990 . Even after multiplying its weight by 3.5 , it only contributed with $0.97 \%$ in 2014 . The fluctuations throughout the period took it to reach its maximum relative weight in 2013 , when it represented $1.22 \%$ of the world total. Its lowest figure was observed in 2001 , when its issued FDI was actually negative (representing $-0,45 \%$ of the total), followed by 2002 , when it only contributed $0.02 \%$.

The accumulated FDI stock in the world amounted to approximately \$26 billion in 2014, equivalent to $33.6 \%$ of the world GDP (Table 3.15). The FDI stock received was basically concentrated in the developed economies, with an amount of $\$ 17$ billion, representing $65 \%$ of the world total. The developing economies accounted for an accumulated amount of $\mathrm{FDI}$ that comes to $\$ 8.3$ billion, equivalent to $31.9 \%$ of the world total. The transition economies have accumulated FDI of $€ 725$ billion, $2.8 \%$ of the world total. It should be stressed that the differences in the weight of each region are smaller if the amount of accumulated investment in relation to the GDP of that particular region is taken 
into account. In this sense, the total amount of FDI inflow received by the developed economies were equivalent to $37.4 \%$ of their GDP, while in the developing economies that amount was $28.3 \%$, and in the transition economies, $27.8 \%$.

In the developed economies, the EU stands out as the most important region by total amount of FDI received in 2014 , with $\$ 9.2$ billion, which represents $35.2 \%$ of the world total and $49.6 \%$ of the EU's GDP. Next is North America, with a total over $\$ 6$ billion, accounting for $23.2 \%$ of the world total and $31.5 \%$ of its GDP. Japan's importance is very low, the total of FDI received amounting to $\$ 170.6$ million, equivalent to $0.7 \%$ of the world total and $3.7 \%$ of the Japanese GDP. In the developing economies, the main FDI receiving region is Asia, with a total of $\$ 5.7$ billion, which represents $21.8 \%$ of the world total and $26.9 \%$ of the Asian GDP. In that region, China represents $4.2 \%$ of total FDI stock inflow up to 2014, an amount representing $10.5 \%$ of its GDP. Latin America and the Caribbean received a total amount of FDI of $\$ 1.9$ billion, equivalent to $7.3 \%$ of the world total and to $32.7 \%$ of its GDP. Thus, LA and the Caribbean was the developing economy with the biggest FDI stock inflow and the second global destination according to this indicator, behind the EU and ahead of North America. The lowest importance corresponds to Africa, with an amount of only $\$ 709$ million and $2.7 \%$ of the world total. However, it must be taken into account that this amount is important to that region's economy, representing $29.1 \%$ of its GDP. This means the FDI stock inflow in relation to its GDP is greater than that of Asia or North America.

\begin{tabular}{|c|c|c|c|c|c|c|}
\hline & \multicolumn{3}{|c|}{ FDI inflow } & \multicolumn{3}{|c|}{ FDI outflow } \\
\hline & $\begin{array}{c}\text { Millions of } \\
\text { dollars }\end{array}$ & $\begin{array}{l}\% \text { in the } \\
\text { world }\end{array}$ & $\begin{array}{l}\% \text { of } \\
\text { GDP }\end{array}$ & $\begin{array}{l}\text { Millions of } \\
\text { dollars }\end{array}$ & $\begin{array}{l}\% \text { in the } \\
\text { world }\end{array}$ & $\begin{array}{l}\% \text { of } \\
\text { GDP }\end{array}$ \\
\hline Developed economies & $17,003,802.2$ & 65.30 & 37.4 & $20,554,819.2$ & 79.44 & 45.2 \\
\hline EU-28 & $9,171,795.18$ & 35.22 & 49.6 & $10,434,829.07$ & 40.33 & 56.4 \\
\hline North America & $6,041,199.6$ & 23.20 & 31.5 & $7,033,194.7$ & 27.18 & 36.6 \\
\hline Japan & $170,615.1$ & 0.66 & 3.7 & $1,193,136.6$ & 4.61 & 25.8 \\
\hline Developing economies & $8,310,054.6$ & 31.91 & 28.3 & $4,833,045.7$ & 18.68 & 16.7 \\
\hline Latin America and the Caribbean & $1,893,553.54$ & 7.27 & 32.7 & $663,970.27$ & 2.57 & 11.5 \\
\hline Africa & $709,174.0$ & 2.72 & 29.1 & $213,486.2$ & 0.83 & 9.5 \\
\hline Asia & $5,679,670.4$ & 21.81 & 26.9 & $3,948,830.2$ & 15.26 & 19.0 \\
\hline China & $1,085,293.0$ & 4.17 & 10.5 & $729,584.7$ & 2.82 & 7.0 \\
\hline Transition economies & $724,967.3$ & 2.78 & 27.8 & $486,891.9$ & 1.88 & 19.5 \\
\hline World total & $26,038,824.1$ & 100 & 33.6 & $25,874,756.8$ & 100 & 33.7 \\
\hline
\end{tabular}

Global FDI stock outflow has a greater concentration than the inflow. So the developed economies issued $79.4 \%$ of global foreign investment stock, $18.7 \%$ corresponding to the developing economies, and only $1.9 \%$ of the total corresponding to transition economies. 
If the importance of each region's FDI stock outflow is considered in relation to its GDP, the differences are lower, although there is still a very notable difference between the developed economies and the other two groups; in addition, the figure for transition economies is greater than that of the developing economies. In 2014, the developed economies' FDI outflow was equivalent to $45.2 \%$ of their GDP, that of the developing economies to $16.7 \%$ of their GDP and transition economies $19.5 \%$ of their GDP.

In the developed economies, the EU has the largest outflow, representing $40.3 \%$ of total FDI stocks, an amount equivalent to $56.4 \%$ of its GDP. North America occupies the second position, with $27.2 \%$ of the world total with an amount representing $36.6 \%$ of its GDP. Japan's FDI stock outflow amounted to only $4.6 \%$ of that in the world, but this figure represents more than a quarter of its GDP (25.8\%). Among the developing economies, Asia stands out with the largest FDI ouflow, 15.3\% of global FDI, equivalent to $19 \%$ of its GDP. China, which belongs to Asia, represents $2.8 \%$ in the world and $7 \%$ of its GDP. Latin America and the Caribbean is the second most important region of the developing economies, with a total FDI outflow up to 2014 of $\$ 664$ billion, representing $2.6 \%$ of the world total and $11.5 \%$ of the GDP of that region. Africa only accounts for $0.8 \%$ of the total global FDI outflow, representing $9.5 \%$ of its GDP.

Globally, all the developed regions display a greater role in investment stock outflow than inflow, as do the transition economies, while the opposite happens in the developing economies, which receive more investment than they issue.

It should be borne in mind that stocks are cumulative, so the situation in 2014 reflects the flow development described earlier on in this section. In spite of the improved growth of the less developed economies in the 1990-2014 period, the large initial gap (in 1990 they represented $23.2 \%$ of total global stock inflow, ${ }^{31}$ compared with the $76.8 \%$ of the developed economies) means the developed economies are relatively much more important, including in FDI inflow. In 2014, the developing economies became the main FDI recipients.

Graph 3.32 summarises growth of inward and outward flows and stocks in the world and in the regions with which this study is concerned. Latin America is the region with most growth in all the indicators used, with a compound growth rate over $11 \%$, somewhat more in inflows, even in inward stocks. The EU's values in the four indicators are lower, especially in flows (3.2\% and $4.2 \%$ in inflows and outflows, respectively). In stock evolution, the accumulated growth stands at rates of over $10 \%$ and slightly higher in

31 Total global FDI inflow in 1990 came to $\$ 2.19$ billion, of which $\$ 1.69$ billion corresponded to the developed economies, $\$ 510.1$ thousand million to the developing economies and only $\$ 8.7$ million to the transition economies. Total global FD outflow in 1990 was $\$ 2.25$ billion, of which $93.8 \%$ corresponded to the developed economies and $6.2 \%$ ( $\$ 139.4$ million) to the developing economies. Finally, the transition economies had a residual FDI outflow of $\$ 139.5$ million. 
outward stocks. Globally, most growth can be observed in stocks, with figures close to $11 \%$, while flows are growing at rates above $7 \%$. In both flows and stocks, inward growth is greater than outward growth.

Graph 3.32. Compound annual growth rate in the world, the EU and Latin America (1990-2014)

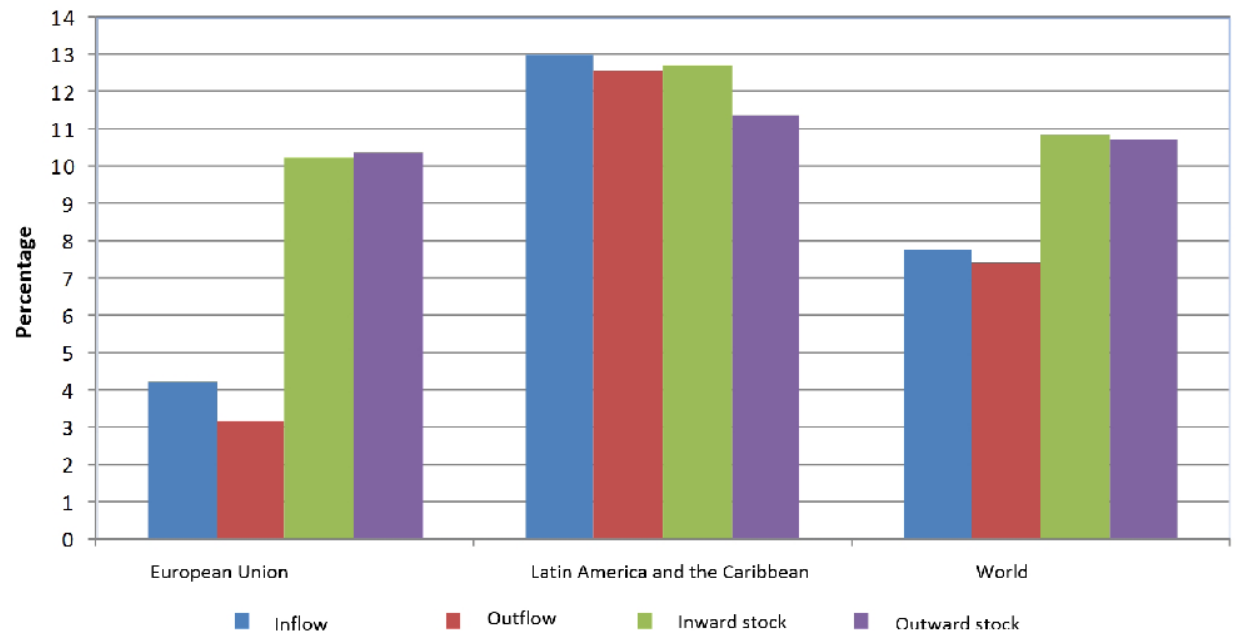

Source: Own elaboration based on UNCTAD data

If the main economies are analysed by FDI inflow in 2014 (Graph 3.33), it can be seen that there are two European countries (the United Kingdom and the Netherlands) and one Latin American country (Brazil) in the top 10, and in the top 20, there are seven European countries (in addition to the two abovementioned, Spain, Switzerland, Finland, France and Poland) and four LA countries (Chile, Mexico and Colombia as well as Brazil). The United Kingdom was the top European economy as measured by inward FDI, and in fourth position globally, behind China, Hong Kong and the United States. Next was Singapore, and in sixth place Brazil as an emerging economy. The Netherlands occupied the tenth position, followed by Chile, Spain and Mexico. Switzerland was the fifteenth most important economy, Finland ranked at place seventeen, while France and Poland occupied place nineteen and twenty, respectively. 
Graph 3.33. The twenty most important economies in the world by FDI inflow in 2014

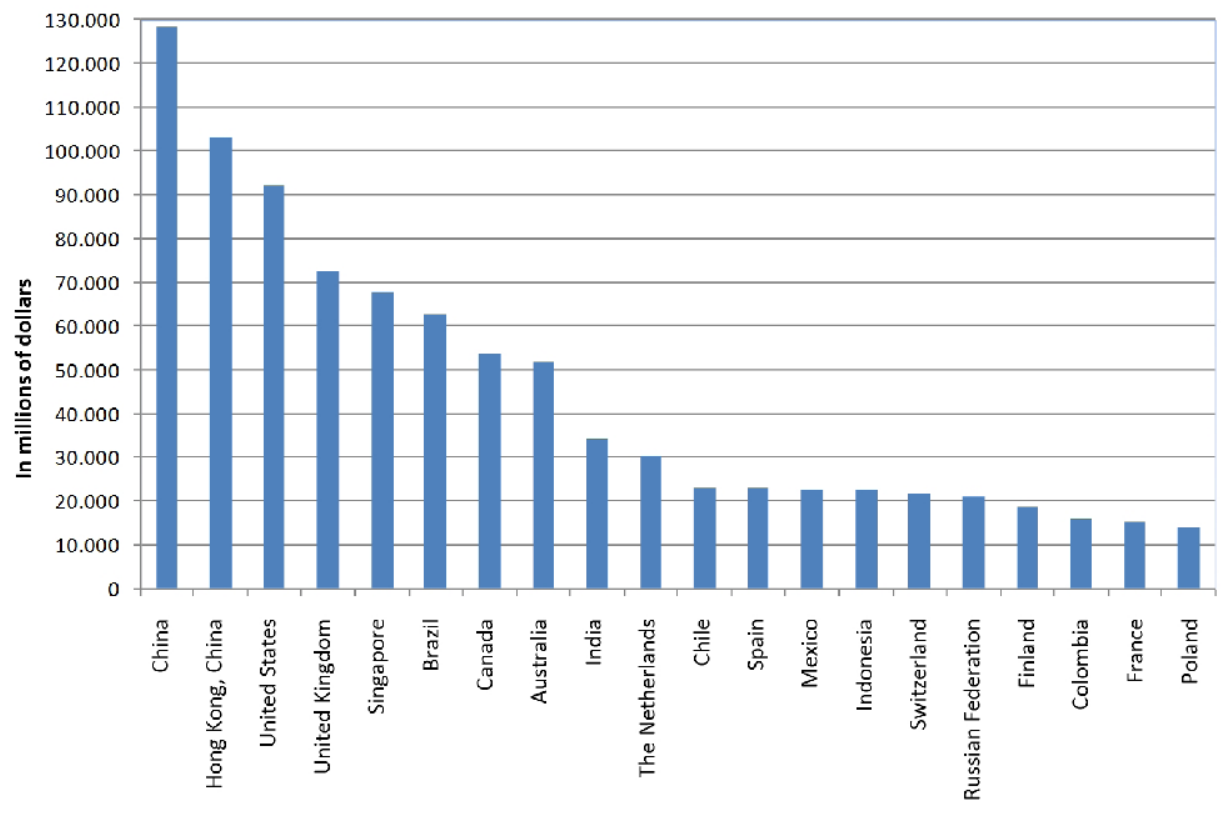

Source: Own elaboration based on UNCTAD data

The analysis of the most important economies by FDI outflow in 2014 (Graph 3.34) demonstrates that there are three European countries (Germany, France and the Netherlands) among the top ten, a number that rises to eight if we look at the twenty most important economies. Germany was the top European economy by FDI outflow in 2014, occupying the fourth place in the world, behind the United States, Hong Kong, China and Japan. France and the Netherlands were in eighth and ninth place. Ireland and Spain were the eleventh and twelfth economies according to this indicator. In fourteenth position was Italy, followed by Norway and Switzerland. Only one country from LA and the Caribbean appears in the twenty most important economies, Chile, in next-to-last place in the ranking.

Because of the high volatility of annual flows, these two classifications undergo important changes every year, thereby affecting the order of the economies. Even so, the main countries in focus of the present study tend to stay in the top positions globally. This is true for Brazil and Mexico as receivers, and the main EU countries as receivers (United Kingdom), issuers (Germany and Italy), or both receivers and issuers (the Netherlands, Spain and France).

Given the geographical aspect of this study, the FDI flows and stock of the main LA and European economies will be analysed next. 
Graph 3.34. The twenty most important economies in the world by FDI outflow in 2014

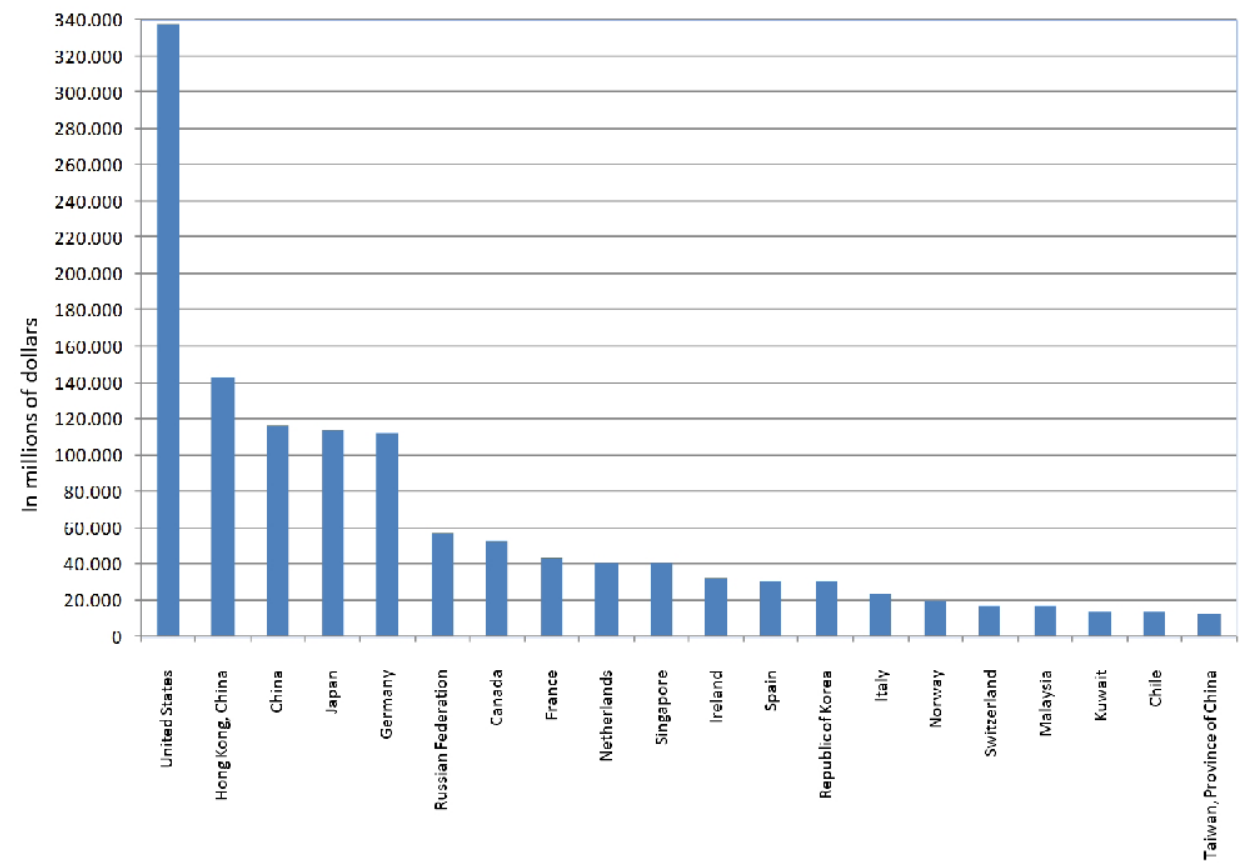

Source: Own elaboration based on UNCTAD data

\subsubsection{Foreign direct investment in Latin America and the Caribbean}

In 2014 , LA and the Caribbean received $\$ 159,404$ million of FDI, equivalent to $13 \%$ of the world total. Table 3.16 shows the distribution of the region's twenty main economies according to the different FDI indicators. Brazil, in particular, stands out. Traditionally, it is the first top FDI recipient in LA, and in 2014 it received \$62,494 million, which represents $39.2 \%$ of the total of foreign investment in Latin America and $5.1 \%$ of the world total. Next in importance are Chile and Mexico, ${ }^{32}$ with very similar FDI inflow, close to $\$ 23,000$ million, representing a little more than $14 \%$ of the total in this region and $1.9 \%$ of the world total. These three economies account for two thirds (67.9\%) of the total investment received in LA and the Caribbean. The other economies are less relevant, the largest participation being that of Colombia ( $10.1 \%$ of the region's FDI inflow) and, to a lesser extent, Peru and Argentina (both economies exceeding 4\%). Although the amounts received by the other economies seemed small, in relative terms these had considerable weight. For example, in the economies of Central America the amount of FDI tended to amount to more than $10 \%$ of GDP, while in the region's larger economies it stood at something close to $2 \%$.

32 This order of countries uses UNCTAD data. ECLAC's statistics place Mexico as the second most important economy in terms of FDI inflow and Chile third, as is traditionally the case. 
Latin America's outward FDI in 2014 was \$23,326 million, a much smaller amount than the investment received. As mentioned above, this behaviour is common among developing economies, and is repeated in all the countries in Table 3.16, with the sole exception of Venezuela. It is worth highlighting the negative flow of $\$ 3,540$ million corresponding to Brazil. This does not mean that Brazil would not make investments abroad or that its divestments would have predominated in 2014; much rather this can be explained by the volume of loans between related companies, ${ }^{33}$ which represented $\$ 23,096$ million according to ECLAC (2015a). In fact, their investments were on a similar scale to previous years, which converted Brazil into the largest economy in terms of investment outside the region.

Table 3.16. FDI inflows and outflows of the main economies of Latin America and the Caribbean in 2014

\begin{tabular}{|c|c|c|c|c|c|c|}
\hline & \multicolumn{3}{|c|}{ FDI inflow } & \multicolumn{3}{|c|}{ FDI outflow } \\
\hline & $\begin{array}{l}\text { Millions } \\
\text { of dollars }\end{array}$ & $\begin{array}{l}\% \text { out } \\
\text { of Latin } \\
\text { America } \\
\text { and the } \\
\text { Caribbean }\end{array}$ & $\begin{array}{c}\% \text { in the } \\
\text { world }\end{array}$ & $\begin{array}{l}\text { Millions } \\
\text { of dollars }\end{array}$ & $\begin{array}{l}\% \text { out } \\
\text { of Latin } \\
\text { America } \\
\text { and the } \\
\text { Caribbean }\end{array}$ & $\begin{array}{c}\% \text { in } \\
\text { the } \\
\text { world }\end{array}$ \\
\hline Brazil & $62,494.8$ & 39.21 & 5.09 & $-3,540.1$ & -15.18 & -0.26 \\
\hline Mexico & $22,794.7$ & 14.30 & 1.86 & $5,200.6$ & 22.30 & 0.38 \\
\hline Chile & $22,949.2$ & 14.40 & 1.87 & $12,999.0$ & 55.73 & 0.96 \\
\hline Colombia & $16,053.8$ & 10.07 & 1.31 & $3,899.0$ & 16.72 & 0.29 \\
\hline Argentina & $6,612.0$ & 4.15 & 0.54 & $2,117.0$ & 9.08 & 0.16 \\
\hline Peru & $7,606.6$ & 4.77 & 0.62 & 83.8 & 0.36 & 0.01 \\
\hline Uruguay & $2,754.5$ & 1.73 & 0.22 & 13.0 & 0.06 & 0.00 \\
\hline Venezuela & 320.0 & 0.20 & 0.03 & $1,024.0$ & 4.39 & 0.08 \\
\hline Ecuador & 773.9 & 0.49 & 0.06 & 33.1 & 0.14 & 0.00 \\
\hline Bolivia & 647.8 & 0.41 & 0.05 & - & - & - \\
\hline Panama & $4,718.9$ & 2.96 & 0.38 & 368.2 & 1.58 & 0.03 \\
\hline Costa Rica & $2,105.9$ & 1.32 & 0.17 & 218.1 & 0.94 & 0.02 \\
\hline Trinidad and Tobago & $2,423.0$ & 1.52 & 0.20 & 725.9 & 3.11 & 0.05 \\
\hline Dominican Republic & $2,208.3$ & 1.39 & 0.18 & 20.4 & 0.09 & 0.00 \\
\hline The Bahamas & $1,595.9$ & 1.00 & 0.13 & 397.5 & 1.70 & 0.03 \\
\hline Jamaica & 550.8 & 0.35 & 0.04 & -2.1 & -0.01 & 0.00 \\
\hline Guatemala & $1,395.8$ & 0.88 & 0.11 & 30.9 & 0.13 & 0.00 \\
\hline Honduras & $1,144.1$ & 0.72 & 0.09 & 24.1 & 0.10 & 0.00 \\
\hline Nicaragua & 840.0 & 0.53 & 0.07 & 83.9 & 0.36 & 0.01 \\
\hline El Salvador & 275.0 & 0.17 & 0.02 & 0.8 & 0.00 & 0.00 \\
\hline Latin America and the Caribbean & $159,404.9$ & 100.0 & 12.98 & $23,325.9$ & 100.00 & 1.72 \\
\hline
\end{tabular}

33 To understand this element, the high cost of capital in Brazil needs to be taken into account. Furthermore, the new methodology followed by MBP6, which changes the way loans between companies are treated, would make Brazil's FDI outflow a positive figure of $\$ 25,736$ million. 
Chile displayed an FDI outflow of $\$ 13,000$ million in 2014 , followed by Mexico, with over $\$ 5,000$ million, and Colombia, with nearly $\$ 4,000$ million. The amount of FDI outflow of Argentina, ( $\$ 2,100$ million) is also significant. The investment made by LA is heavily concentrated in these countries, because Brazil (in spite of the peculiarity mentioned), Chile, Mexico, Colombia and even Argentina represent most of the foreign investment made by the region. In fact, during the first decade of the 21st century, Brazil, Chile, Mexico and Colombia represented $90 \%$ of the total foreign investment issued by the region.

Despite of considerable fluctuations, the evolution of FDI inflows of the main economies of LA in the period 1990-2014 (Graph 3.35) show a clear growth trend. Brazil was the largest economy as measured by the amount of FDI inflow between 1996 and the present. It was the country with the highest growth of those examined, registering a compound annual growth rate of $18.9 \%$ in the period under consideration. Its inflows have grown by 63.2 times, increasing from $\$ 989$ million to approximately $\$ 62,500$ million between 1990 and 2014. A continuous growth trend has been observed throughout the decade, being especially strong in the second half of that decade. This trend was interrupted by a considerable decline at the beginning of the 2000s. Although Brazil saw a large growth in FDI inflow in 2004, it was in 2006 that a new period of considerable growth began, only being interrupted in 2010, which took it to its historic peak of \$66,660 million in 2011. Since then, the annual FDI inflow has decreased continuously, - a behaviour explained by the economic slowdown and reduction of FDI in the primary sector, largely due to the fall in prices.

Chile is the second country both in terms of amount of FDI inflow in 2014, and in the compound annual growth rate over the period 1990-2004, which amounted to $15.9 \%$. The amount of FDI received by Chile was multiplied by 34.7, rising from $\$ 661$ million in 1990 to $\$ 22,950$ million in 2014. A decline was only observed in occasional years (such as $1998,2000,2002,2005,2009$ or 2013 ), and it reached its peak of $\$ 25,000$ million in 2012, when it surpassed that of Mexico for the first time and became the second largest FDI recipient in LA and the Caribbean. In 2014 it regained the second position that it lost in 2013.

Mexico was the second economy by FDI inflow during most of the years of the period under consideration (1990-2014), excluding 2012 and 2014, when it was supassed by Chile. Its compound annual growth rate $(9.4 \%)$ is one of the lowest among these countries, and beginning with an FDI inflow of $\$ 2,633$ million, it was multiplied by 8.7 . The trend followed by Mexico in the period 1990-2014 shows large oscilliations, with years of remarkable growth, like 1991, 1994, 1997, 2004, 2007 and 2013 and the period 1999-2001, and others of decline, like the periods 1992-1993, 1994-1996, 2001-2003, 
2004-2006, 2008-2009 and 2010-2012 and the year 2014. It reached its peak of $\$ 44,627$ million in 2013 ( $\$ 44,627$ million) due to large acquisition operations, which also explains the decrease by almost a half in 2014 .

Graph 3.35. FDI inflow growth of the main economies in Latin America (1990-2014)

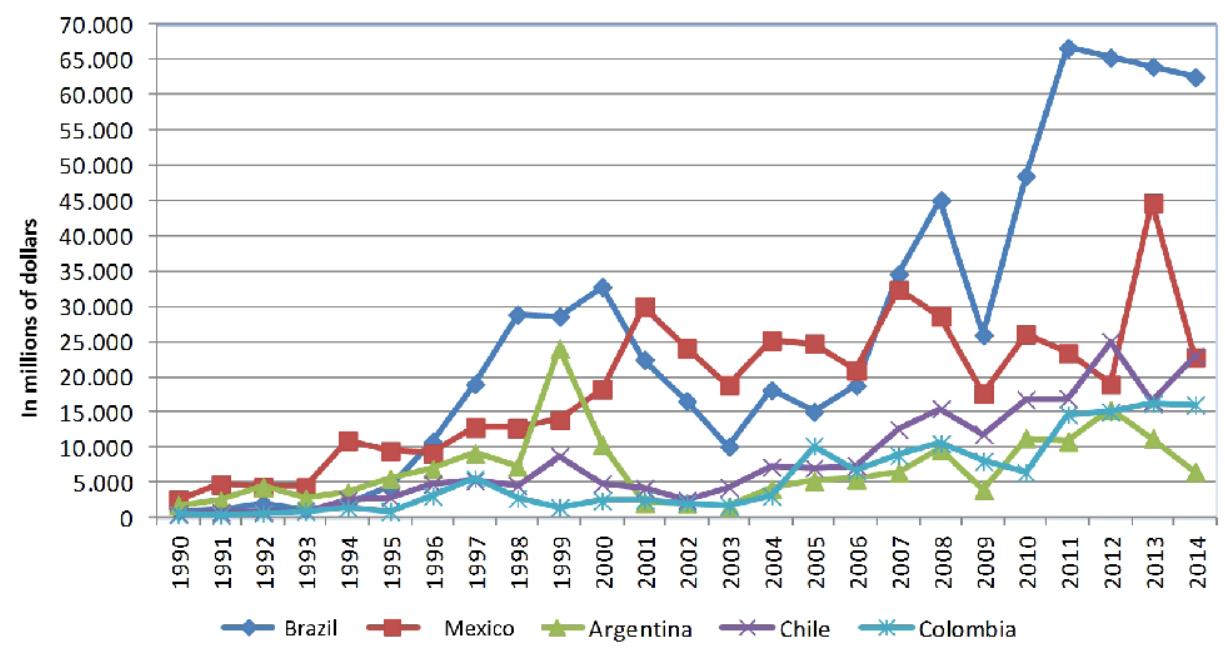

Source: Own elaboration based on UNCTAD data

Colombia and Argentina are also important economies according to the indicator under consideration, with a CAGR of $15.6 \%$ and $3.6 \%$, respectively. In turn, the amount received was multiplied by 32.1 in Colombia and 3.6 in Argentina. As a result of Colombia's larger growth, from 2005 on, its economy has tended to surpass that of Argentina, except for the years 2010 and 2012, when their figures were almost the same. Argentina's behaviour has been more variable than Colombia, with larger growth, but also more intense reductions, especially in 2000. So, Argentina's peak is observed in 1999 (approaching \$24,000 million); in contrast, Colombia's largest FDI inflow was received in 2013 (\$16,200 million), as a result of a clearly increasing trend in the 2000 s, in spite of the swings recorded.

The analysis of FDI outflow shows greater volatility, with remarkable fluctuations in the case of Brazil, which has even registered negative figures in the most recent period (2011-2014, and also in 2001 and 2009), which can be explained by the importance of intercompany loans. Its peak was reached in 2006, when it issued foreign investment to a value of $\$ 28,200$ million. Chile, beginning from very low figures, has taken second or third place in more recent years, alternating with Mexico. It is also the country with the highest compound annual growth rate $(36.4 \%)$, reaching its peak $(\$ 17,120$ million) in 2012. Mexico, while also displaying considerable oscillations (growth in the second half of the nineties and beginning of the 2000 s or the $2008-2010$ period being especially 
intense, as were the falls in the years 1991, 1993, 1995, 2000, 2002, 2008 or 2011), grew at an average compound rate of $14 \%$ and multiplied its FDI outflow by 23.3 in the period 1990-2014. Its peak was recorded in 2012, when it approximated $\$ 22,000$ million. Starting off from lower figures, Colombia and Argentina show a clear growth trend in spite of oscillations, reflected in very high growth rates, $25.7 \%$ and $18.7 \%$, respectively. Colombia reached its peak (\$8,420 million) in 2011, and Argentina did in 1997 (\$3,653 million); later on its figures were much lower and did not reach $\$ 2,500$ million again.

FDI stocks in 2014, resulting from the amount of accumulated FDI in 1990 followed by inflow and outflow between 1990 and 2014, show the clear predominance of Brazil, Mexico and Chile, followed by Colombia and Argentina. The three first countries jointly represent two-thirds of inward stock and $80.9 \%$ of outward stock.

Growth of inflows and outflows compared with the variations in GDP for Brazil and Mexico generally show a similar trend, although flow growth is much more marked than that of the economic cycle.

\subsubsection{Foreign direct investment of the European Union}

The EU received foreign investment of $\$ 257,566$ million in 2014 , which represents $21 \%$ of the world total (Table 3.17). The most important country was the United Kingdom which, with $\$ 72,241$ million, represented $28.1 \%$ of the EU total and $5.9 \%$ of the world total. It was followed by the Netherlands and Spain, which represented 11.8\% (with $\$ 30,253$ million) and $8.9 \%$ (with $\$ 22,904$ million) of the EU total. France received $5.9 \%$ of the EU total and Italy $4.5 \%$. Germany's lower importance in terms of received foreign investment must be mentioned, because it was only $\$ 1,831$ million, equivalent to $0.7 \%$ of the EU total and $0.15 \%$ of the world total. It should be explained that this is one of the lowest figures recorded for Germany, usually one of the top four FDI receiving countries. The top four countries account for over half $(55.7 \%)$ of FDI inflow.

FDI outflow shows a very different country ranking and greater concentration. Germany was the main economy by investment abroad, with an investment of $\$ 112,227$ million, equivalent to $40.1 \%$ of the EU total and $8.3 \%$ of the world total. Next in importance, though with a much smaller figure, was France, with an issued investment of $\$ 42,869$ million representing $15.3 \%$ of the EU total. The Netherlands invested $€ 40,800$ million abroad (14.6\% of the EU), followed by Ireland and Spain, each with approximately $11 \%$ of the EU total. The United Kingdom displayed a negative figure of $\$ 59,628$ million, which can be explained by the FDI composition, ${ }^{34}$ equivalent to $21.3 \%$ of the EU's FDI outflow.

34 According to Eurostat's data, the United Kingdom's outflows in 2012 and 2013 were positive, to the amount of 35,068 million and 19,439 million, respectively. 


\begin{tabular}{|c|c|c|c|c|c|c|}
\hline & \multicolumn{3}{|c|}{ FDI inflow } & \multicolumn{3}{|c|}{ FDI outflow } \\
\hline & $\begin{array}{l}\text { In millions of } \\
\text { dollars }\end{array}$ & $\begin{array}{c}\text { \% of the } \\
\text { EU }\end{array}$ & $\begin{array}{l}\% \text { in the } \\
\text { world }\end{array}$ & $\begin{array}{l}\text { In millions of } \\
\text { dollars }\end{array}$ & $\begin{array}{c}\% \text { of the } \\
\text { EU }\end{array}$ & $\begin{array}{l}\% \text { in the } \\
\text { world }\end{array}$ \\
\hline United Kingdom & $72,241.0$ & 28.05 & 5.88 & $-59,628.5$ & -21.29 & -4.40 \\
\hline Germany & $1,830.9$ & 0.71 & 0.15 & $112,227.0$ & 40.06 & 8.29 \\
\hline France & $15,191.1$ & 5.90 & 1.24 & $42,869.1$ & 15.30 & 3.17 \\
\hline Spain & $22,904.1$ & 8.89 & 1.86 & $30,688.2$ & 10.96 & 2.27 \\
\hline The Netherlands & $30,253.3$ & 11.75 & 2.46 & $40,808.7$ & 14.57 & 3.01 \\
\hline Italy & $11,450.8$ & 4.45 & 0.93 & $23,450.8$ & 8.37 & 1.73 \\
\hline Belgium & $-4,956.7$ & -1.92 & -0.40 & $8,533.5$ & 3.05 & 0.63 \\
\hline Ireland & $7,697.7$ & 2.99 & 0.63 & $31,795.2$ & 11.35 & 2.35 \\
\hline Sweden & $10,036.2$ & 3.90 & 0.82 & $12,155.8$ & 4.34 & 0.90 \\
\hline Poland & $13,882.8$ & 5.39 & 1.13 & $5,204.2$ & 1.86 & 0.38 \\
\hline Austria & $4,674.9$ & 1.82 & 0.38 & $7,690.5$ & 2.75 & 0.57 \\
\hline Luxembourg & $7,087.0$ & 2.75 & 0.58 & $-4,307.1$ & -1.54 & -0.32 \\
\hline Malta & $9,278.9$ & 3.60 & 0.76 & $2,335.3$ & 0.83 & 0.17 \\
\hline Greece & $2,171.6$ & 0.84 & 0.18 & 855.7 & 0.31 & 0.06 \\
\hline Finland & $18,624.7$ & 7.23 & 1.52 & 574.5 & 0.21 & 0.04 \\
\hline Denmark & $3,651.9$ & 1.42 & 0.30 & $10,951.9$ & 3.91 & 0.81 \\
\hline Czech Republic & $5,908.5$ & 2.29 & 0.48 & -529.3 & -0.19 & -0.04 \\
\hline Portugal & $8,807.1$ & 3.42 & 0.72 & $6,664.2$ & 2.38 & 0.49 \\
\hline Hungary & $4,039.4$ & 1.57 & 0.33 & $3,380.9$ & 1.21 & 0.25 \\
\hline Cyprus & 679.0 & 0.26 & 0.06 & $2,175.6$ & 0.78 & 0.16 \\
\hline European Union & $257,566.5$ & 100.0 & 20.97 & $280,123.9$ & 100.0 & 20.69 \\
\hline
\end{tabular}

FDI inflows of the main economies of the EU in the period 1990-2014 (Graph 3.36) show a trend with considerable oscillations, which in the case of France and Germany resulted in lower figures in 2014 than in 1990, respectively. The oscillations also imply changes in the ranking of the top five countries throughout the period under consideration. The United Kingdom is one of the top countries in FDI inflow and has one of the largest compound annual growth rates (3.7\%), and it multiplied the amount of FDI received in this period by 2.4 , starting off from $\$ 30,461$ million in 1990 to $\$ 72,240$ million in 2014 . At the end of the nineties and in the years before the current crisis, it recorded a cosiderable growth, reaching its peak ( $\$ 183,822$ million) in 2005 . Its biggest declines were observed in the periods 2000-2003 and 2007-2011.

The Netherlands ranked among the top FDI receiving countries in the EU and represented the highest accumulative annual growth rate (4.3\%), multiplying its FDI by 2.7. Considering the smaller size of its economy, its importance relative to GDP is much greater than in the other economies. In addition, it should be pointed out that, like Luxembourg and, to a lesser extent, Ireland, the Netherlands acts as an intermediary country for a large 
amount of FDI. Its progress was characterised by oscillations, reaching a peak in 2007 with $\$ 119,636$ million and its lowest figure in 2008 ( $\$ 5,777$ million, apart from the negative figure of 2010 , equivalent to $\$ 7,185$ million).

Spain ranked usually among the top five countries by FDI inflow, reaching the second position in 2012 and holding the third place in 2013 and 2014. Furthermore, it was the third country by growth of the FDI inflow in the period 1990-2014, accounting for a compound annual growth rate of $3.2 \%$ and multiplying its FDI inflow by 2.1 . Thus, it started off with an FDI inflow of \$10,800 million in 1990 and reached $\$ 22,900$ million in 2014. At the beginning of the nineties, its flows tended to decrease (except in 1993); it began period of considerable growth in 1996 and reached a peak of $\$ 39,575$ million in the year 2000. After fluctuations at the early 2000s, beginning in 2005 it experienced growth again, exceeding $\$ 64,000$ million in 2007 and reaching its historic peak of almost $\$ 77,000$ million in 2008. Since then, it has tended to decrease heavily, except for the high figures corresponding to 2010 and 2013.

Graph 3.36. FDI inflow growth of the main European Union economies (1990-2014)

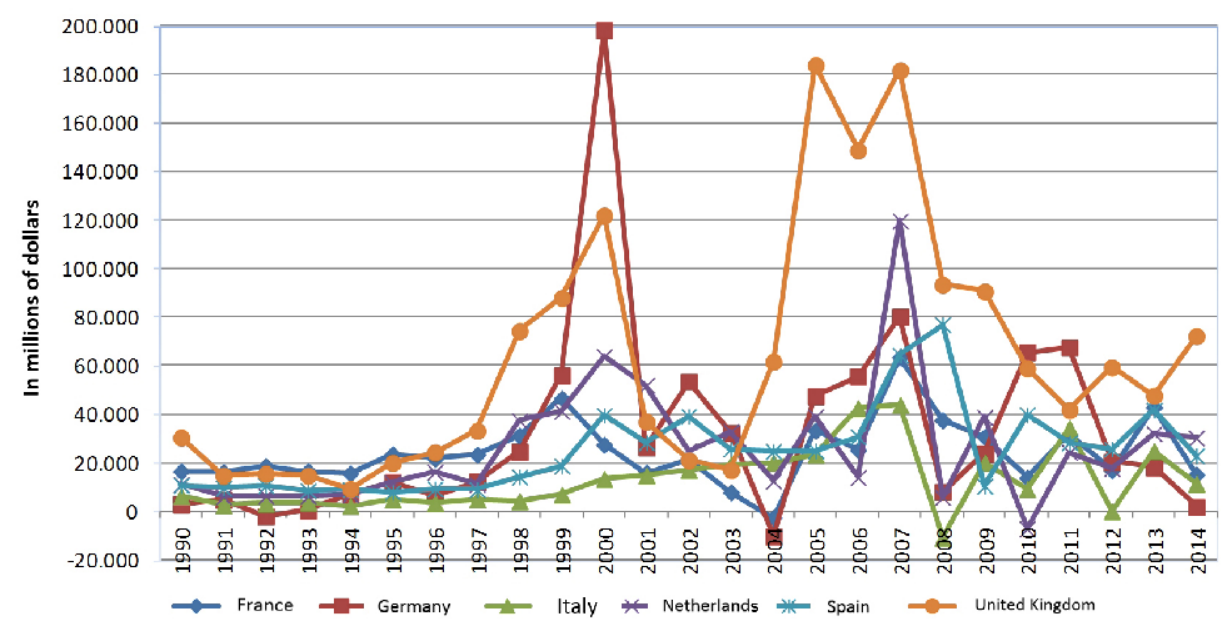

Source: Own elaboration based on UNCTAD data

Italy's FDI inflow has a cumulative annual growth rate of $2.5 \%$, an amount that multiplied by 1.8 over the period 1990-2014. There were large fluctuations in its growth, with the biggest increases observed after the beginning of the 2000s, until it reached its peak of $\$ 43,849$ million in 2007 . Ever since the oscillation has been very strong, with a year of heavy decrease followed by a large increase, and so on.

The FDI inflow of France and especially Germany has fallen at rates of $0.4 \%$ and $2 \%$, 
respectively. Their development over the period under consideration shows large fluctuations and periods of remarkable growth, as happened in France at the end of the nineties and in the middle of the 2000s, the peak of $\$ 63,500$ million being reached in 2007. In the case of Germany, it also grew strongly between 1994 and 2000, in which year it reached its highest figure of $\$ 198,276$ million, being the top country in the EU by FDI inflow for the second consecutive year. From 2004 to 2007 (year in which it slightly exceeded $\$ 80,000$ million), another period of growth for Germany was observed, and also from 2009 to 2011. Although the amount was smaller (\$65,511 million), its better behaviour in the face of the crisis put it in first place again in the two-year period 20102011. In 2014 both countries had extraordinarily low inflows.

The FDI outflow of the main EU economies showed remarkable fluctuations, even more marked than those described for FDI inflow. In fact, the ranking of the countries in the top positions also varies substantially. Generally, the countries have followed a fairly similar path, and the periods of greatest growth tended to coincide in the second half of the nineties and later from 2003 until the start of the current crisis. The two last years, particularly 2014, displayed large variations of different degree depending on the country of interest. The evolution of inflow and outflow compared with changes in GDP for the main countries of the EU show similar trends, although with much more intense oscillations in the progress of flows than in the economic cycle.

The United Kingdom is the country which was usually in the top position; but it also represents important variations, and in the last two years it even showed negative figures. In the nineties, it had large FDI growth, only interrupted in 1991 and 1996, with over $\$ 120,00$ million in 1998 and over $\$ 200,000$ million in 1999 and 2000, when it reached $\$ 235,400$ million. In first half of the 2000 s, there were large oscillations, with a remarkable reduction until 2002, followed by significant increases until 2004. This was followed by two years of decline and again a large growth in 2007, reaching the peak of $\$ 319,330$ million. In 2008 , that figure was reduced by $70 \%$, though a high figure was registered. After a heavy fall in 2009 (to only 20,562 million), a brief period of strong growth began, going to over $€ 100,000$ million in 2011. After 2011, there was a heavy, continuous decrease to negative figures in 2013 and 2014.

The country with most growth was Spain, with a cumulative annual growth rate of $10.7 \%$; its FDI was multiplied by 11.4 in the period 1990-2014. Spain started off with the amount of $\$ 2,685$ million in 1990 . After the oscillations of the initial years, a growth trend began after 1992 which became much stronger at the end of the nineties and which raised the FDI outflow at $\$ 58,213$ million in 2000 . There was a continuous decrease until 2003 , followed by annual oscillations. In the period 2005-2007 there was a strong growth again, leading Spain become the second largest FDI issuer in the EU in 2006, with over $\$ 100$ 
thousand million (specifically, \$104,208 million). The FDI made by Spain in 2007 was even larger, reaching a peak of $\$ 137,052$ million. However, the United Kingdom's higher figure put Spain in third place in the EU. In the two following years there was a large decline, followed by two years of growth. The decrease in 2012 resulted in a negative figure (\$3,982 million), mainly due to net share sales in LA (mainly in Mexico) and lower intercompany loans. 2013 and 2014 were growth years, with a figure of \$30,688 million in the last year.

Germany is one of the top countries in the EU if measured by FDI outflow, and it has in fact headed the ranking in several of the most recent years (2010, 2012 and 2014). Furthermore, it has the second largest FDI outflow growth, registering a cumulative annual growth rate of $6.6 \%$ in the period 1990-2014, multiplying thereby its value by 4.6. The year 1993 implied a change from the initial period of decrease to continuous growth (except for 1997) until 1999, when it exceeded $\$ 100$ thousand million ( $\$ 108,688$ million). A period of considerable decrease followed, with a minimum figure of approximately $\$ 5,570$ million reached in 2003. After that, Germany's FDI outflow grew strongly and reached a peak of $\$ 169,320$ million in 2007 . This was followed by a period of remarkable decline until 2013, only interrupted once by the strong growth in 2010 (when $\$ 100$ thousand million was exceeded again, more concretely: $\$ 125,451$ million). The growth observed in 2014 was very high, reaching $\$ 112,227$ million (compared with $\$ 30,109$ million in 2013).

Italy and the Netherlands have very similar growth rates, with cumulative annual growth rates of $4.8 \%$ and $4.4 \%$, respectively; and both multiplied the amount of their FDI outflow by approximately 3 (3.1 in the case of Italy and 2.8 in the case of the Netherlands). The progress of these two countries also shows large oscillations, with Italy reaching its peak of \$96,231 million in 2007 and the Netherlands in 2005 (\$106,009 million), becoming thereby the top issuer of FDI in the EU in that year. The decline in that figure in $\mathbf{2 0 0 6}$ and the strong growth of countries like Germany and Spain placed the Netherlands at the fourth position in FDI outflow in 2006. In 2013 it regained the first position with a figure of $\$ 56,926$ million, while in 2014 , it was third behind Germany and France.

France, which stood out in the initial years of this period (1990-2014) as the top FDI issuer in the EU, has the smallest growth rate with a cumulative annual growth rate of $0.5 \%$. The amount of its foreign investment was multiplied by 1.1. Its less fluctuating progress explains why during the rest of the decade it was placed between the second and fourth economy of the EU by FDI outflow. Its trend is the most stable one, although it has experienced periods of strong growth, especially in 1997-2000 and 2004-2007. Indeed, in 2000 it reached its peak of $\$ 161,948$ million. In every year in the period 2007-2009 it 
Graph 3.37. FDI outflow growth of the main European Union economies (1990-2014)

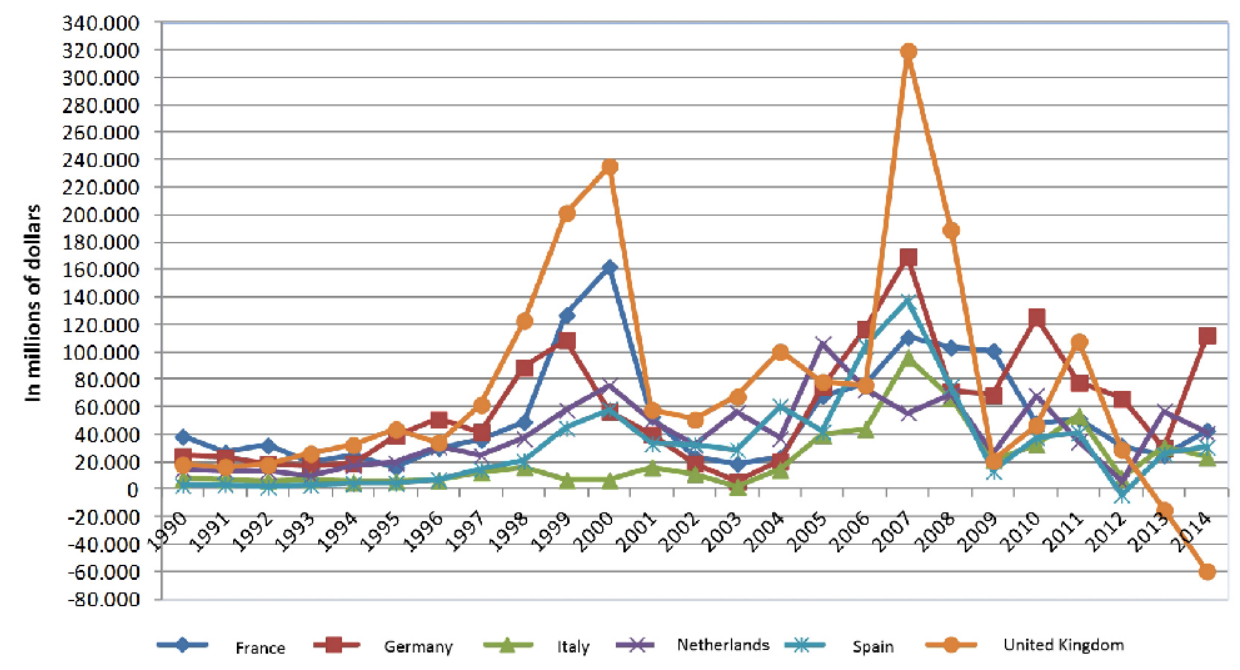

Source: Own elaboration based on UNCTAD data

exceeded $\$ 100$ thousand million, regaining the second position in the EU in 2008 (which it was able to maintain also in 2010, 2012 and 2014) and the first position in 2009.

Inflow and outflow growth compared with changes in GDP for the six EU countries in this study show a similar trend in general, although with much more intense oscillations in the evolution of flows than in the economic cycle.

FDI stocks in 2014 are the result of the initial level of FDI stock in 1990 and the development of the inflows and outflows in the period 1990-2014. The United Kingdom and Germany are the most important countries, with a combined investment abroad of $\$ 1.58$ billion, $15.2 \%$ of the EU total and $6.1 \%$ of the world total. Next is France, with $\$ 1.28$ billion, equivalent to $12.3 \%$ of the EU total and to $5 \%$ of the world total. The Netherlands comes close to a billion dollars ( $\$ 985$ thousand million), issuing $9.4 \%$ of the EU's foreign investment and $3.8 \%$ of the world total. The FDI stock corresponding to Spain amounts to $\$ 673,989$ million, a value representing $6.5 \%$ of the EU and $2.6 \%$ of the world total. Italy is the country of least importance, issuing 5.3\% of the FDI corresponding to the EU (equivalent to $\$ 548,416$ million) and $2.1 \%$ of the world total.

The combined analysis of inward and outward stocks show that Germany, France, Italy and the Netherlands play a greater role in FDI outflow that inflow (in both absolute terms and in their relative contribution in the EU or globally). The opposite occurs for the United Kingdom and Spain, given their more important role as FDI recipients. 


\subsubsection{Investment relations between the European Union and Latin America}

Bearing in mind the main purpose of this study - the analysis of economic relations (trade, paying particular attention to intra-industrial trade and foreign investment) between LA and the European Union, with a focus on the cases of Brazil and Mexico in particular - we now turn to FDI between LA and the EU from a general perspective and will focus later (Chapters 3.4 and 6) on the study of the bilateral relations between the two regions.

For the analysis of FDI inflow data according to source, we have used the information provided by the International Monetary Fund's Coordinated Direct Investment Survey (CDIS). The regional classification followed by this survey identifies a single region in Europe ${ }^{36}$ and three regions in LA and the Caribbean, which are North and Central America $^{37}$, South America ${ }^{38}$ and the North Atlantic and the Caribbean ${ }^{39}$. This territorial division is therefore broader than the subject of this study, but it allows for an initial understanding of the importance of bilateral FDI relations between LA and the EU, which will be completed in Chapters 3.4 and 6 .

The accumulated total FDI inflow in Europe up to the end of 2013 amounts to approximately $\$ 16.1$ billion, which represents $57.6 \%$ of the total accumulated FDI inflow in the world (Table 3.18). Differentiating this FDI by source, Europe itself stands out, with an investment of 11.2 billion dollars. This means that $69.7 \%$ of the foreign investment made in Europe originates from another European country. The second important region is North and Central America, from where $17.5 \%$ of European FDI stems. Another indicator of the importance of bilateral relations is the fact that more than $60 \%$ (62.2\%) of the FDI outflow of North and Central America has been directed to Europe. Therefore, the FDI received in Europe is very concentrated, with only two regions (Europe itself and North and Central America) representing $87.2 \%$ of the total FDI.

The importance of FDI to Europe originating in other regions is low. Among them, the North Atlantic and the Caribbean region stands out, with a relative weight of $6.5 \%$ and an investment of $\$ 1.03$ billion. It seems worth highlighting that $43.1 \%$ of the FDI issued by this region goes to Europe. The next region in importance is East Asia, representing 2.3\% of the FDI received in Europe. However, this region only dedicates $11.9 \%$ of its foreign investment to Europe. In contrast, South America is in the opposite situation: it only contributes $0.5 \%$ of Europe's FDI inflow, with $\$ 77,800$ million, but $50 \%$ of its investment abroad goes to Europe. A situation similar to that of South America is observed in the North Africa region, with a very small contribution in absolute terms (it is only $0.09 \%$ of the foreign investment received in Europe), but representing $77.1 \%$ of the total FDI outflow of that region. 


\begin{tabular}{|c|c|c|c|}
\hline \multirow[b]{2}{*}{ Area of origin } & \multicolumn{3}{|c|}{ Europe } \\
\hline & In millions of dollars & $\%$ by region of origin & $\begin{array}{l}\text { \% represented out of } \\
\text { the world invest- } \\
\text { ment of the region } \\
\text { of origin }\end{array}$ \\
\hline Europe & $11,205,645$ & 69.69 & 72.23 \\
\hline North Africa & 14,744 & 0.09 & 77.09 \\
\hline Sub-Saharan Africa & 40,386 & 0.25 & 17.59 \\
\hline North and Central America & $2,819,421$ & 17.53 & 62.15 \\
\hline North Atlantic and the Caribbean & $1,036,389$ & 6.45 & 43.05 \\
\hline South America & 77,799 & 0.48 & 50.03 \\
\hline Persian Gulf economies & 99,145 & 0.62 & 60.02 \\
\hline $\begin{array}{l}\text { Other Near and Middle East } \\
\text { Economies }\end{array}$ & 54,441 & 0.34 & 76.23 \\
\hline South and Central Asia & 115,009 & 0.72 & 16.80 \\
\hline East Asia & 376,224 & 2.34 & 11.90 \\
\hline Oceania and Polar Regions & 42,707 & 0.27 & 16.49 \\
\hline Unspecified & 198,050 & 1.23 & 28.23 \\
\hline World & $16,079,960$ & 100.00 & 57.63 \\
\hline
\end{tabular}

So, the analysis of the source of investments received in Europe clearly shows the importance of Europe itself and America, with the regions of North and Central America and the North Atlantic and the Caribbean standing out in absolute terms. Considering the destination of investment, the three regions dedicate over $40 \%$ of their FDI to Europe, reaching $50 \%$ in the case of South America, and $62 \%$ in the case of North and Central America.

The accumulated FDI inflow up to the end of 2013 in the three American regions amounts to $\$ 4.87$ billion. The importance of North and Central America stands out, accounting for $79.8 \%$ of the total of the foreign investment channelled to this American region, while South America receives $20.1 \%$, and the remaining $0.1 \%$ goes to the North Atlantic and the Caribbean region.

The FDI inflow in North and Central America up to the end of 2013 amounts to approximately $\$ 3.88$ billion, which is equivalent to $13.9 \%$ of the world total. Most of that investment $(59.9 \%)$ originates in Europe, which dedicates $15 \%$ of its FDI to that region. Secondly, the countries in the North and Central American region itself stand out, $21.2 \%$ of the total FDI inflow stemming from this region. At the same time, $18.2 \%$ of the region's FDI outflow stays in the region. The third most important region is East Asia, which contributes with $11.5 \%$ of the FDI inflow and dedicates $14.1 \%$ of its FDI to this region. The contribution of other regions is much smaller, the most relevant being 
the North Atlantic and the Caribbean, and South America, which contribute with $2.2 \%$ and $1 \%$ of the total FDI, respectively. South America dedicates $25.8 \%$ of its FDI outflow to North America, while this percentage in the North Atlantic and the Caribbean is only $3.5 \%$.

South America's accumulated FDI inflow until 2013 was $\$ 981,448$ million, most of which (55.1\%) stemming from Europe. The second most important origin is North and Central America, representing $20.7 \%$ of the total. The North Atlantic and the Caribbean and East Asia are less important, contributing with $5.8 \%$ and $5 \%$, respectively. South America is the source of $3.6 \%$ of the total FDI inflow in this region. North America dedicates $4.5 \%$ of its FDI to South America; Europe, 3.5\%; and the North Atlantic and the Caribbean, $2.4 \%$. The main destination of South America's FDI constitutes the region itself, representing $22.6 \%$ of the total outflow.

The North Atlantic and the Caribbean region received FDI inflow of $\$ 4,767$ million up to the end of 2013. That investment essentially comes from North and Central America and the North Atlantic and the Caribbean region itself, representing $48.0 \%$ and $45.9 \%$, respectively. Europe represents $5.9 \%$ of the total FDI inflow. The FDI inflow in this region is of marginal importance to its countries of origin.

This description of the origin of America's FDI inflow allows for the identification of its remarkable concentration, given that at least $75 \%$ of the total amount stems from two regions, in some cases reaching $94 \%$ of the total. Furthermore, it illustrates the importance of bilateral relations between Europe and America, as well as the relevance of intraregional investment. Generally, in the analysed regions the main investing economies are Europe, North and Central America and the region itself. As for the other regions included in the study, the importance of East Asia should be mentioned.

The main sector to which LA's FDI inflow goes is the services sector, in particular to the branches of telecommunications, financial activities, electricity and retail trade. An important part of South America's FDI inflow, as in the main economies of the Caribbean, is dedicated to activities related to natural resources, especially mining (especially in the cases of Chile, Colombia and Peru) and hydrocarbons (which are the main business in Bolivia, Ecuador and Venezuela, and its contribution is relevant in Colombia). In the case of Brazil, the FDI goes mainly to manufacturing activities, while in the primary sector (agriculture, mining and hydrocarbons), local companies predominate. In Central America and Mexico, part of the FDI goes to manufacturing activities, which are mostly dedicated to export (ECLAC 2015; UNCTAD 2015).

Focusing on LA's FDI in more detail, we have used the data published in the last 
UNTACD report (2015) on global investment according to the form entry. Table 3.19 entails information on announced new investment projects in 2014 with LA as recipient or investor. Beginning from the recipient perspective, LA receives $\$ 89,446$ million of new investment projects in 2014, mainly from the developed economies, representing $86.3 \%$ of the total of this type of investment. Among the developed economies, the importance of Europe, providing a little over a third (34.1\%) of LA's FDI inflow, and the United States, with $29.3 \%$, stand out. Another $11.6 \%$ of the total foreign investment directed to LA originates in Canada.

Developing economies are the source of $20.3 \%$ of LA's FDI inflow. In this regard, the Asia-Pacific region stands out, representing $13.2 \%$ of that region's total FDI inflow. One economy in that region alone - China - issues $9.1 \%$ of the FDI made in LA. Another $6.8 \%$ of LA's FDI inflow stem from the same region, making it more important than South America, issuing 3.6\% of the region's total FDI inflow, while Central America issues $2.9 \%$. Finally, transition economies only issue $0.12 \%$ of the region's total FDI.

\begin{tabular}{|c|c|c|c|c|}
\hline & \multicolumn{2}{|c|}{ Destination } & \multicolumn{2}{|c|}{ Investor } \\
\hline & $\begin{array}{l}\text { In millions of } \\
\text { dollars }\end{array}$ & $\%$ of total & $\begin{array}{l}\text { In millions of } \\
\text { dollars }\end{array}$ & $\%$ of total \\
\hline World & 89,446 & 100 & 8,689 & 100 \\
\hline Developed economies & 77,167 & 86.27 & 1,760 & 20.26 \\
\hline Europe & 30,526 & 34.13 & 551 & 6.34 \\
\hline Canada & 10,358 & 11.58 & - & - \\
\hline United States & 26,190 & 29.28 & 1,151 & 13.25 \\
\hline Developing economies & 18,170 & 20.31 & 6,651 & 76.55 \\
\hline Asia-Pacific & 11,790 & 13.18 & 481 & 5.54 \\
\hline China & 8,154 & 9.12 & 282 & 3.25 \\
\hline Hong Kong, China & 175 & 0.20 & 29 & 0.33 \\
\hline Latin America and the Caribbean & 6,084 & 6.80 & 6,084 & 70.02 \\
\hline South America & 3,229 & 3.61 & 4,201 & 48.35 \\
\hline Central America & 2,576 & 2.88 & 1,120 & 12.89 \\
\hline Transition economies & 109 & 0.12 & 278 & 3.20 \\
\hline
\end{tabular}

From the investor's point of view, LA issued investment for new projects coming to $\$ 8,689$ million in 2014 . Most of that investment went to the developing economies, which received $76.6 \%$ of the total FDI made by LA. In particular, the region of LA stands out, where $70.0 \%$ of the region's own FDI outflow is invested. Thus we can observe a clear predominance of intraregional FDI, especially from South America, which represents $48.4 \%$ of the investment made by LA, while $12.9 \%$ corresponds to 
Central America. Another $5.5 \%$ of the total of foreign investment issued by LA goes to Asia-Pacific, with China receiving 3.3\% of the total. The developed economies receive $20.3 \%$ of LAs total FDI outflow, with the United States figuring as the main recipient (with $13.3 \%$ of the world total of that region). Europe receives $6.3 \%$ of LA's total FDI outflow.

Therefore, depending on whether the investment received or issued by LA is analysed, a distinct behaviour can be identified. Not only is there a very significant difference between the amount of FDI issued and received, the former being 10.3 times the latter, but differences between the regions of origin and destination of the FDI are also notable. The received FDI stems mainly from the developed economies, especially Europe and the United States. Among the developing economies, the importance of China and intraregional investment, especially from South America, can be highlighted. Latin America's FDI outflow, in turn, is mainly directed to the developing economies as well as intraregional investment and, particularly, investment in South America. With regard to the developed economies, the United States is more important than Europe.

As regards the sectorial distribution of LA investment in either direction, the services sector predominates (although its relative importance is greater on the part of LA's investors), followed by manufacturing. The primary sector represents $12.4 \%$ of the total investment received by LA, but only $0.25 \%$ of the region's total FDI outflow is dedicated to activities in that sector. In spite of the similar sectorial structure, relevant differences are identified when branches of an activity are analysed. Thus, the industrial investment received by LA mainly goes to the activity of motor vehicles and transport material, while its FDI outflow is concentrated in the branch of food, beverages, and tobacco. In the services branch, the predominant activity in both directions is transport, storage and communications, whereas differences can be found in other branches like electricity, gas and water, trade or financial activities. Furthermore, there is an important annual variation in new investment, with a reduction of $41.6 \%$ with regard to FDI inflow in 2013 and of $57.6 \%$ in relation to outflow.

The second form of entry of FDI is company mergers and acquisitions (Table 3.20). Latin America carried out sales of companies for $\$ 25,457$ million in 2014 , while purchases of companies come to $\$ 8,440$ million. Like new investment, mergers and acquisitions are very volatile from year to year, with sales falling by $26.8 \%$ and purchases by half $(48.0 \%)$.

Sales of LA and the Caribbean companies are made essentially to the developed economies, which represent $70.5 \%$ of the total, while the developing economies account for $26.7 \%$ and transition economies $2.3 \%$. In the group of the developed economies, North America stands out, representing $42.8 \%$ of total sales in LA, followed by other 


\begin{tabular}{|c|c|c|c|c|}
\hline & \multicolumn{2}{|c|}{ Sales } & \multicolumn{2}{|c|}{ Purchases } \\
\hline & $\begin{array}{l}\text { In millions of } \\
\text { dollars }\end{array}$ & $\%$ of total & $\begin{array}{l}\text { In millions of } \\
\text { dollars }\end{array}$ & $\%$ of total \\
\hline World & 25,457 & 100 & 8,440 & 100 \\
\hline Developed economies & 17,949 & 70.51 & 8,131 & 96.34 \\
\hline Europe & $-1,269$ & -4.98 & 4,214 & 49.93 \\
\hline North America & 10,899 & 42.81 & 3,916 & 46.40 \\
\hline Other developed countries & 8,319 & 32.68 & - & - \\
\hline Developing economies & 6,797 & 26.70 & 309 & 3.66 \\
\hline Africa & 1,094 & 4.30 & 400 & 4.74 \\
\hline Latin America and the Caribbean & -251 & -0.99 & -251 & -2.97 \\
\hline South America & 248 & 0.97 & $-1,091$ & -12.93 \\
\hline Central America & -499 & -1.96 & 840 & 9.95 \\
\hline Asia-Pacific & 5,954 & 23.39 & 160 & 1.90 \\
\hline East, South and Southeast Asia & 4,954 & 19.46 & - & - \\
\hline Transition economies & 596 & 2.34 & - & - \\
\hline
\end{tabular}

developed countries which altogether contribute $32.7 \%$. Europe displays a negative value, equivalent to $5 \%$ of total sales in LA and the Caribbean in 2014 . With regard to the developing economies, the Asia-Pacific region represents $23.3 \%$ of total sales. It should be stressed that LA and the Caribbean has a negative value equivalent to $1.0 \%$ of the total sales in the same region, explained by the behaviour of Central America, with a negative figure of $1.96 \%$ of total sales, while South America contributes with a positive contribution equivalent to $0.97 \%$ of the total for the region. The negative figures of Europe and Central America can be explained by important divestments which are concentrated in the extractive industries and, particularly, in the oil branch. Africa represents $4.3 \%$ of the region's sales of companies.

The companies acquired by LA and the Caribbean in 2014 originate almost entirely $(96.3 \%)$ in the developed economies. Specifically, half of the amount of acquisitions (49.9\%) corresponds to European companies and $46.4 \%$ to North American companies. The developing economies represent $3.7 \%$ of the total of company acquisitions made by $L A$ and the Caribbean. Africa is the most important region among the developing economies, contributing with $4.7 \%$ of the figure of company acquisitions, followed by Asia-Pacific, with $1.9 \%$. As with sales, intraregional acquisitions have a negative value equivalent to $3 \%$ of the total. In this case, the explanation is given by South America's negative balance, equivalent to $13 \%$ of the total figure of company purchases made by LA and the Caribbean. However, Central America has a positive value which represents $10 \%$ of the amount of region's total acquisitions. 
In 2013, $14 \%$ of foreign investment received by LA and the Caribbean came from companies in the same region, concentrated essentially in the extractive industries. The importance of "Multilatinas" or "Translatinas" in the region has grown remarkably in the last decade, showing stagnation in the last two years. It is reflected in the fact that only five of the 20 most important acquisitions of cross-border EU companies in 2014 were made by European companies. Multilatinas are also increasing their investments globally and especially in Europe. From 2003 onwards, 31\% of LA investment has gone to Spain, $25 \%$ to Belgium and $15 \%$ to Luxembourg (ECLAC 2015b). Most multinationals originate in Brazil, followed by Mexico, while other countries like Peru, Colombia or Chile, have an increasingly relevant presence. According to the study made by Santiso (2011), of the 147 selected Multilatinas, 77 have corporate centres in Europe, mainly in the United Kingdom and Spain (twelve companies, a third of the Multilatinas, with a notable presence of Mexican companies), followed by Portugal, Belgium and Germany.

The statistical office of the EU (Eurostat) offers information on the EU's bilateral FDI inflows and outflows with different regions, including LA. This information is provided from 1994-1995 to 2012. However, in the cases of EU-25 and EU-27 which are of more recent date, the data are only available from 2001 and 2004 onwards, respectively. For this reason, EU-15 is used here, accounting for $98.2 \%$ of the total FDI inflow of EU-25 and EU-27 in 2012; and $90.5 \%$ of the FDI outflow of EU-25 and EU-27 in 2012. The importance of the EU-15 is even greater in stocks, where it accounts for $99.7 \%$ of inward FDI and $97 \%$ of outward FDI.

The analysis of bilateral flows between the EU and LA shows that the most important direction is the investment received by LA and issued by the EU (Graph 3.38). The amount of investment made by the EU received by the LA countries amounts to $€ 34,660$ million in 2012, starting off with 3,566 in 1995 and being multiplied by 9.7. Thus, in the period under consideration, investment from the EU directed towards LA grew at a cumulative annual growth rate of $12.3 \%$. However, important fluctuations have been observed throughout the period. There was strong growth in the second half of the nineties, until $€ 46,188$ million reached in 2000 , the peak until then. A period of considerable decrease followed, expressed in a value of $€ 5,388$ million in 2003 . The following years experienced a fluctuating trend, a period of growth beginning in 2005 which raised the amount of EU investment in LA to $€ 29,750$ million. After the decline in 2009 , the peak of $€ 61,168$ million was reached in 2010 . The two following years were characterized by a tendency to fall to $€ 34,660$ million in 2012. 
Graph 3.38. Growth of FDI inflow and outflow between Latin America and the EU (19952012)

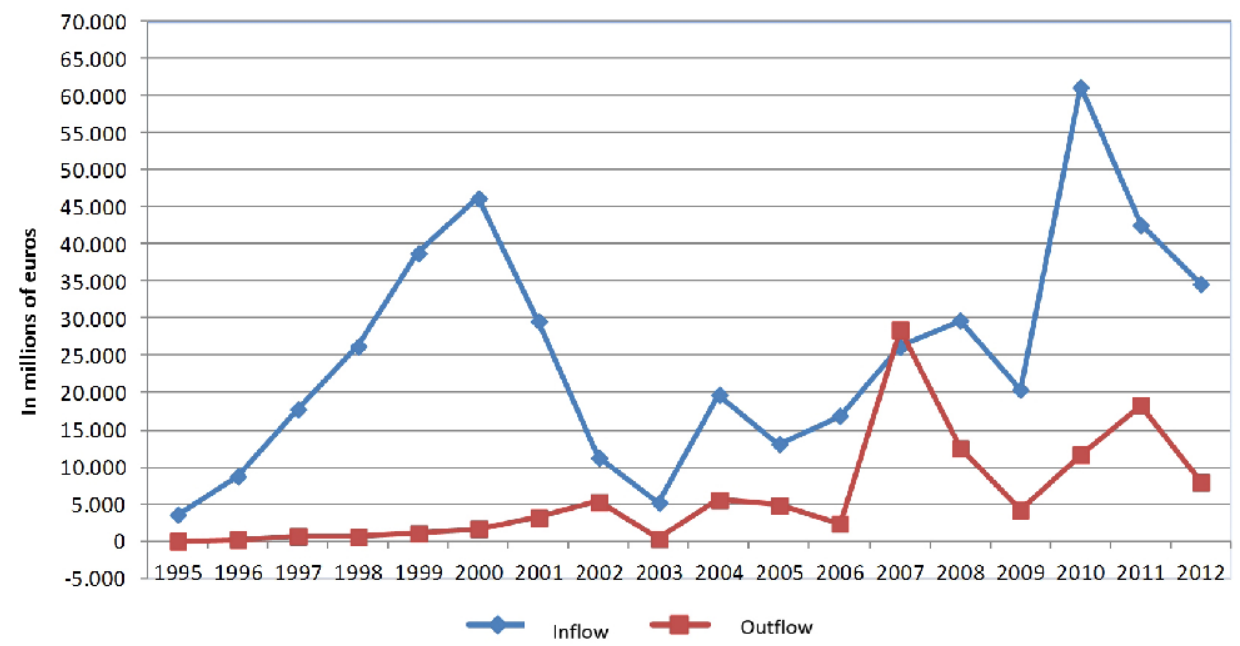

Source: Own elaboration based on Eurostat data

The fluctuations of the bilateral flows from the EU towards LA follow a trend similar to that of the global economic cycle (as is shown by the expansion halfway through the nineties, the contraction at the beginning of the 2000, and the present crisis), with some exceptions (2009, for example). Two phenomena with specifically influence the amount of FDI dedicated to Latin America also need to be mentioned. First, there was an intense privatization process carried out by many LA countries in the second half of the nineties; many European companies, and Spanish companies in particular, were involved in this process. Telecommunications, electrical energy and the financial sector are some of the activities most affected by this privatization and liberalization processes. Another relevant factor can be seen in LA's wealth of natural resources. As a result of the strong increase in prices of primary products in the nineties and especially in the middle of the 2000s, there was a notable increase in interest in investment in LA's extractive industries and natural resources.

Latin America's FDI outflow to the EU was much lower, with smaller oscillations, at least at the beginning of the period. Starting off from a negative value of $€ 7$ million in 1995, in 1996 it stood at €226 million and followed a growth trend until 2002, when it reached $€ 5,265$ million. Since then, there have been large oscillations in its behaviour, and since 2006 it has followed the same trend as inflow. Its highest value was registered in 2007, when the figure of $€ 28,476$ million was reached, a much larger amount than any other year. 
Growth in FDI stocks of the FDI between the EU and LA (Graph 3.39) is conditioned by the development described, as well as by the initial level. Stock received by LA from the EU was $€ 38,327$ million in 1994. Its growth shows a clearly positive trend, with a cumulative annual growth rate of $14.8 \%$ and the initial stock figure being multiplied by 12.1 , until reaching a peak of 462,198 million in 2012. The reduction in the EU's foreign investment stock in the countries of LA in 2002 is significant, caused by the sharp decline in the EU's outflows to that recipient from 2000 onwards due to the global economic recession.

Graph 3.39. Growth in inward and outward FDI stocks between Latin America and the EU (1994-2012)

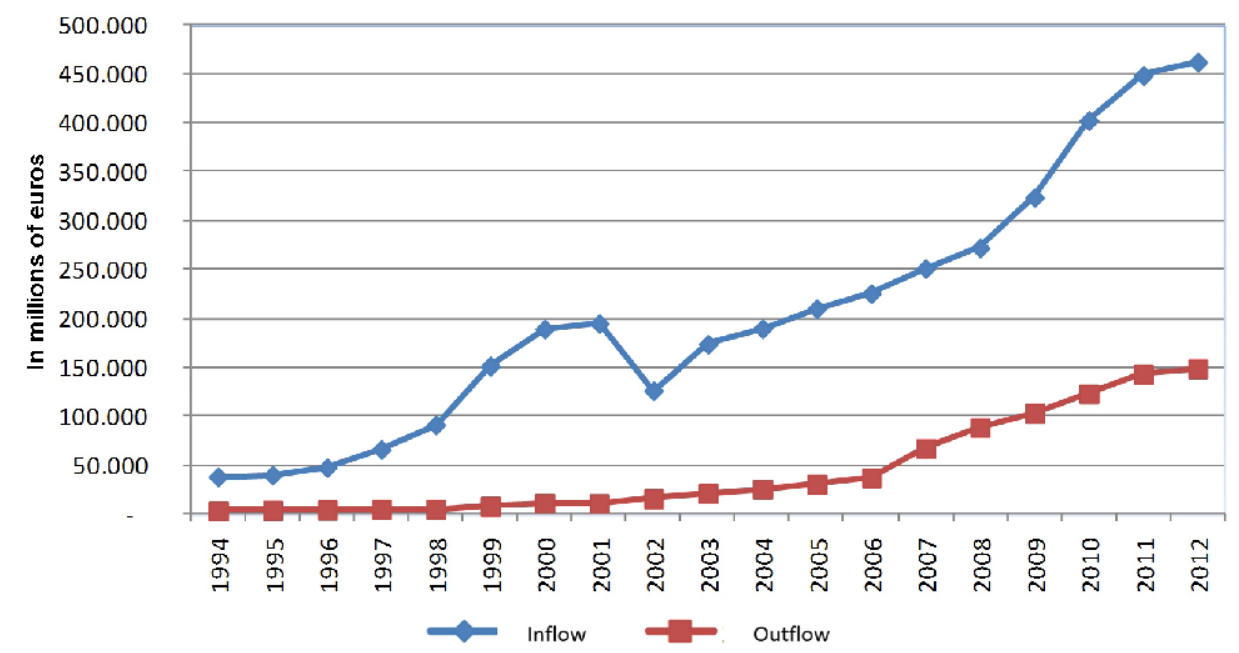

Source: Own elaboration based on Eurostat data

FDI stocks received by the EU from LA are lower, but show remarkable, continuous growth, with a cumulative annual growth rate of $22.8 \%$, much greater than the variation of the accumulated stocks in the opposite direction. So, the amount was multiplied by 40.5 in the period 1994-2012, rising from $€ 3,677$ million to $€ 148,835$ million. Growth is more intense from the mid 2000 s onwards. The crisis that has affected the EU seems to have encouraged more investment by Multilatinas or Translatinas.

\subsection{Zooming in: The European Union's foreign direct investment in Brazil and Mexico}

This section focuses on analysis of EU's FDI in Brazil and Mexico. As was shown in Section 3.3, Brazil and Mexico constitute the main LA economies, both in general terms and in terms of inward and outward FDI. The importance of those two countries is also pronounced in bilateral relations with the EU. According to the ECLAC (2015b), 46\% of 
the FDI received by Brazil in 2013 was from the EU. In Mexico, foreign investment from the EU represents $49 \%$ in the same year.

We use Eurostat as the main source of information, as this database allows to observe bilateral stocks and flows by sector. Since Eurostat data only provide information for the EU-25 and the EU-27 since 2001 and 2004, the analysis has been carried out for the EU-15. As explained in Section 3.3.4, the EU-15 accounts for almost all the foreign investment made by the EU-27 in LA, and the same can be said about LA's FDI outflow towards the EU. This concentration is also true for the cases of Brazil ${ }^{35}$ and Mexico. ${ }^{36}$

\subsubsection{Recent trends}

The bilateral flows of FDI between the EU-15 and Brazil and Mexico in 2012 (Table 3.21) behave differently according to the country analysed and the direction of the flow. Thus, the foreign investment made by the EU-15 in Brazil amounts to $€ 22,121$ million, equivalent to $5.4 \%$ of the total FDI outflow of the EU. Meanwhile, Mexico only received 86 million euros from the EU-15, which represents $0.02 \%$ of the total of FDI made by the EU globally. As will be explained below, this is an exceptionally low figure for Mexico. If we take the 2011 figure ( $€ 4,762$ million) as reference, Mexico received $0.5 \%$ of the total FDI of the EU (which issued a total of FDI of €932,977 million, more than double the 2012 amount). The behaviour of Mexico can be explained by important divestments there in 2012 by Spain as the main EU investor.

With regard to the FDI received in the EU-15, €1,939 million stem from Brazil and $€ 4,338$ million from Mexico, which is why their relative importance is very low $(0.5 \%$ and $1.1 \%$ of the EU's total FDI inflow, respectively). Again, Mexico's situation is exceptional, reaching a peak being in 2012. Taking the 2011 figure (€422 million) as reference, its contribution is very small, $0.05 \%$ of the FDI received by the EU. So, in that year Mexico issued more foreign investment in the EU than it received from there, and furthermore the amount of FDI it made in the EU was greater than that of Brazil.

Therefore, the analysis of the situation in 2012 does not show the typical behaviour of EU15 flows to Mexico. Stock data for 2012, also shown in Table 3.21, allows the exploration of the main characteristics of the bilateral FDI relationship between the EU and Brazil

35 The EU-15 represents $99.5 \%$ of the FDI made by the EU-25 and the EU-27 in Brazil in 2012 and $88.0 \%$ of the FDI made by Brazil in the EU-25 and EU-27. With regard to stocks in 2012, the EU-15 accounts for $99.8 \%$ FDI stock in Brazil from the EU-25 and EU-27, and $97.5 \%$ of the FDI stock in the EU-25 and EU-27 from Brazil.

36 The EU-15 represents $92.5 \%$ of the FDI made by the EU-25 and EU-27 in Mexico, and $88.6 \%$ of the FDI made by Mexico in the EU-25 and EU-27. With regard to stocks in 2012, the EU-15 accounts for $99.8 \%$ of the FDI stock in Mexico from the EU-25 and EU-27, and $91.5 \%$ of the FDI stock in the EU-25 and EU-27 from Mexico. 
and Mexico, with Brazil's accumulated inward FDI stock from the EU amounting to $€ 246,420$ million in 2012, and Mexico's accumulated stock amounting to €89,468 million. As well, the accumulated FDI in the EU from Brazil is nearly $€ 96$ thousand million. The EU's accumulated FDI stock from Mexico is equivalent to 20,333 million euros. Thus, the stock of accumulated FDI in Brazil and Mexico from the EU is greater than that issued by those countries to the EU. In addition, the accumulated amount corresponding to Brazil is greater than Mexico's in both directions.

Table 3.21. FDI between the EU and Brazil and Mexico in 2012 (in millions of euros)

\begin{tabular}{|c|c|c|c|c|}
\hline & \multicolumn{2}{|c|}{ Flows } & \multicolumn{2}{|c|}{ Stocks } \\
\hline & $\begin{array}{c}\text { FDI received from } \\
\text { the EU }\end{array}$ & FDI issued to the EU & $\begin{array}{c}\text { FDI received from } \\
\text { the EU }\end{array}$ & FDI issued to the EU \\
\hline Brazil & 22,121 & 1,939 & 246,420 & 95,696 \\
\hline Mexico & 86 & 4,338 & 89,468 & 20,333 \\
\hline
\end{tabular}

The evolution of the annual flows of FDI received by Brazil and Mexico from the EU in the period 1995-1992 (Graph 3.40) was characterised by large oscillations. In the case of Brazil, a positive growth trend can be identified, at a cumulative annual growth rate of $22.2 \%$, resulting in the multiplication of the annual amount by 30.3. The annual FDI issued by the EU increased from 730 million euros to 22,721 million in 2012. However, large fluctuations are observed throughout the period under consideration. In the period 19951998, there was important growth in the FDI issued in Brazil by the EU, reaching 18,107 million in the last year. The reduction in 1998 was followed by a strong fort increase in 1999, reaching 23,462 million euros, the highest value until that moment and the second highest value in the whole period analysed. The initial years of the 21 st century saw the amount of FDI made in Brazil by the EU annually being reduced, to a negative value of 1,366 million euros in 2002. After that, Brazil saw was a new rise until 2005, followed by a fluctuating trend. The period 2008-2010 was characterised by growth, which was particularly remarkable in 2010 , when the peak of 44,773 million euros was reached. The two last years in the period saw a considerable reduction and the amount of FDI in 2012 fell to a half of that in 2010 .

There are also oscillations in the FDI made by the EU in Mexico. In 2012 the volume was remarkably lower as compared to 1995 . This would indicate a compound annual reduction rate of $14.0 \%$, although it must be said that this rate was particularly affected by the extraordinarily low value in 2012. Over the 1995-2012 period, two trends can be identified, in spite of certain oscillations observed. First, there was a growth trend in the initial 1995-2004 stage, in spite of the declines of 1996, 1998, 2001 and 2003, and a peak of 10,758 million euros was reached in 2004 . The second trend points to lower annual volumes of the flows in the 2004-2012 period, in spite of the remarkable increase 
between 2007 and 2008.

Graph 3.40. Growth of the FDI flows received by Brazil and Mexico from the EU (19952012)

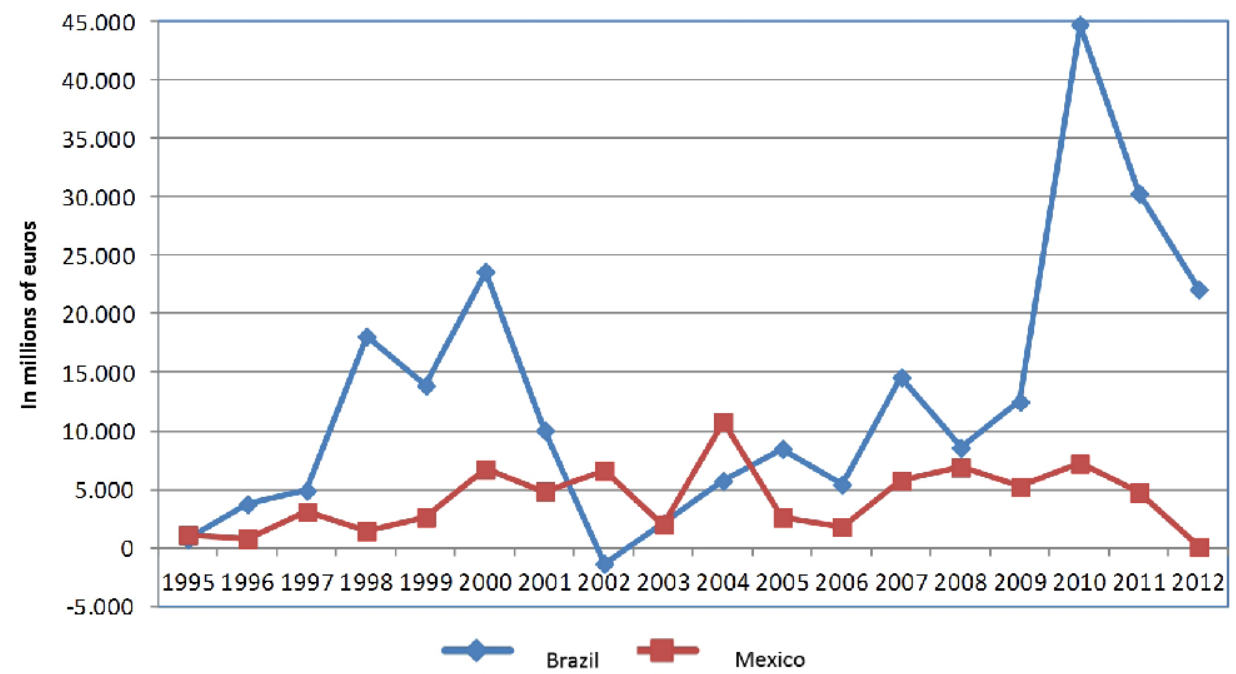

Source: Own elaboration based on Eurostat data

The evolution of the FDI flows received by the EU from Brazil and Mexico indicates that, in spite of the large oscillations, both countries show a growth trend over the period overall, beginning with particularly low figures in 1995. Brazil started off with an FDI issued in the EU of 18 million euros and after several years of fluctuations, experienced a negative value of 91 million euros in 1998. In the two following years, it grew remarkably until reaching 1,461 million euros in 2000. After that, a considerable decrease resulted in a negative value of 878 million euros in 2003. The strong growth of 2004 implied the highest figure until then, when Brazil's investment in the EU exceeded 4,000 million euros (concretely, 4,021 million). In the subsequent period, Brazil's FDI in the EU fell, with the exception of 2007 , when the investment reached 24,342 million euros, its historic peak. The large reductions of 2008 and 2009 were followed by strong growth in 2010 and 2011, Brazil's FDI in the EU on the latter year reaching 12,835 million euros, its second highest figure.

Mexico initiated the period with a negative value of $\$ 11$ million and after the oscillations of the initial years, the 1998-2000 period was of strong growth, with 1,000 million euros being surpassed for the first time in 2000 (1,052 million euros). This was followed by a period of decrease until 2006, only interrupted in 2004 and 2005 when Mexico issued investments of nearly 1,200 million euros. The period 2006 to 2009 was characterised by a strong increase, with investment surpassing 2,000 million euros at its end (exactly 
2,009 million). Declines in 2010 and 2011 were followed by strong growth in 2012, when the extraordinarily high value of 4,338 million euros was reached.

In general, growth in FDI flows between Brazil and Mexico and the EU tend to coincide with the trend followed by the FDI of those countries, which is also highly influenced by the economic cycle. However, other factors such as currency depreciation, (currencies are volatile in LA), privatization processes or merger and acquisition transactions also help to explaining the progress of these countries' FDI.

As a result of the growth of the annual FDI, the amount of accumulated foreign investment in Brazil from the EU rose at a cumulative rate of $16.1 \%$ in the period 1995-2012. The stock was multiplied by 14.8 and rose from 16,701 million euros at the beginning of the period to 246,420 million at its end. The stock of investment made in Mexico by the EU displayed a larger growth trend than Brazil, with a cumulative annual growth rate of $19.5 \%$ in the period under consideration. This means that the amount of accumulated FDI in Mexico issued by the EU grew from 3,612 million euros to 89,468 million euros in 2012, thus experiencing a multiplication by 24.8 .

In the opposite direction, Brazil's stock of FDI directed to the EU rose remarkably, with a cumulative annual growth rate of $30.1 \%$. The initial value of 841 million euros corresponding to 1994 was multiplied by over a hundred (113.8), to stand at nearly 95,700 million euros in 2012. The accumulated FDI issued by Mexico in the EU grew, as well, although to a lower degree than that of Brazil. Mexico's stock, 437 million euros in 1994, grew at a cumulative annual rate of $23.8 \%$. Thus, in 2012 the accumulated figure corresponding to Mexico's investment in the EU amounted to 20,333 million euros (with the initial figure having been multiplied by 46.5 ).

The EU constitutes the main source of the FDI received annually by Brazil during the whole 2001-2012 period (Graph 3.41). Although its relative importance varies, it usually represents over half the total FDI received by Brazil, reaching more than $60 \%(61.5 \%)$ in 2004. Its lowest participation in Brazil's annual FDI inflow corresponds to 2005, when it represented $26.5 \%$ of the total. In 2003, 2006 and even 2009 its contribution barely exceeded a third of the total. The EU represented $48.4 \%$ of the FDI received by Brazil in 2012. In general, fluctuations in the relative weight of the EU are a reflection of the general behaviour of this region, they are not as much influenced by the behaviour of other regions and their respective investment in Brazil. Only in 2005 did the United States and LA nearly reach the EU's contribution, when the EU's lowest historical investment ( $\$ 3,988$ million, that is equivalent to $26.5 \%$ of the FDI of Brazil) coincided with the highest figures of the United States ( $\$ 3,673$ million, $24.4 \%$ of the total FDI received by Brazil) and LA and the Caribbean ( $\$ 3,473$ million, representing $23.1 \%$ of the total). 
Graph 3.41. Importance of Brazil's FDI inflows from different regions and countries (2001-2012)

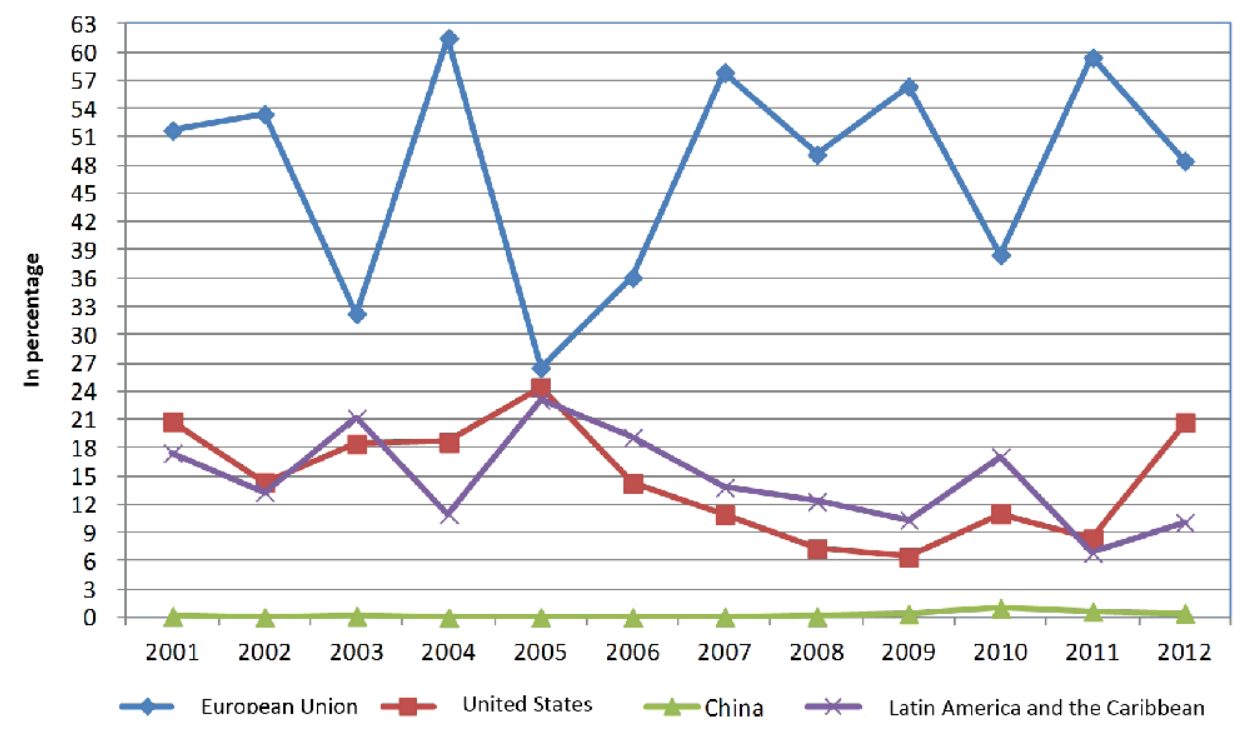

Source: Own elaboration based on UNCTAD data

At the beginning and end of the period 2001-2012, the United States was the second largest investor in Brazil, behind the EU, while during the years 2005-2010, LA was the second largest region investing in Brazil, as a result of the United States' lower FDI. Latin America followed the tendency of to the EU, except for 2005 and 2012. The United States increased its participation between 2002 and 2005, later reducing it until 2009 (when it only represented $6.4 \%$ of the total). With regard to China, in spite of its important growth (it multiplied the amount of its FDI in Brazil by 11.6 in the period 2001-2012, with a cumulative annual growth rate of $24.9 \%$ ), its participation was still very small, reaching the peak of $1 \%$ in 2010 . In 2012 , the EU represented about half $(48.4 \%)$ of the total FDI received by Brazil, while $20.7 \%$ corresponded to the United States and $10.1 \%$ to LA and the Caribbean.

In the case of Mexico, the main foreign investor during the 2001-2012 period was typically the United States (Graph 3.42). The EU normally occupied the second position with figures close to a third of the total FDI dedicated to Mexico, except in 2004, 2007 and 2010, when it became the main investor, accounting for approximately half of the investment received by Mexico and surpassing the United States. In any case, there are large oscillations in the progress of the United States and the EU, not only in the trend, but also in their participation in Mexico's total. The United States reached its peak of $\$ 21,544$ million in 2001 , when it represented $71.9 \%$ of the total, and its minimum in 2010 with 
$\$ 6,256$ million and $27.2 \%$ of the total FDI received by Mexico in that year. The EU's peak of $\$ 13,247$ million was reached in 2010 , accounting for $57.5 \%$ of the total FDI received by Mexico, while the minimum figure was seen in 2012 , with $\$ 3,586$ million, equivalent to $20.8 \%$ of the FDI. This figure is a consequence of the important decline in FDI in the period 2010-2012.

Graph 3.42. Importance of Mexico's FDI inflows from different regions and countries (1994-2012)

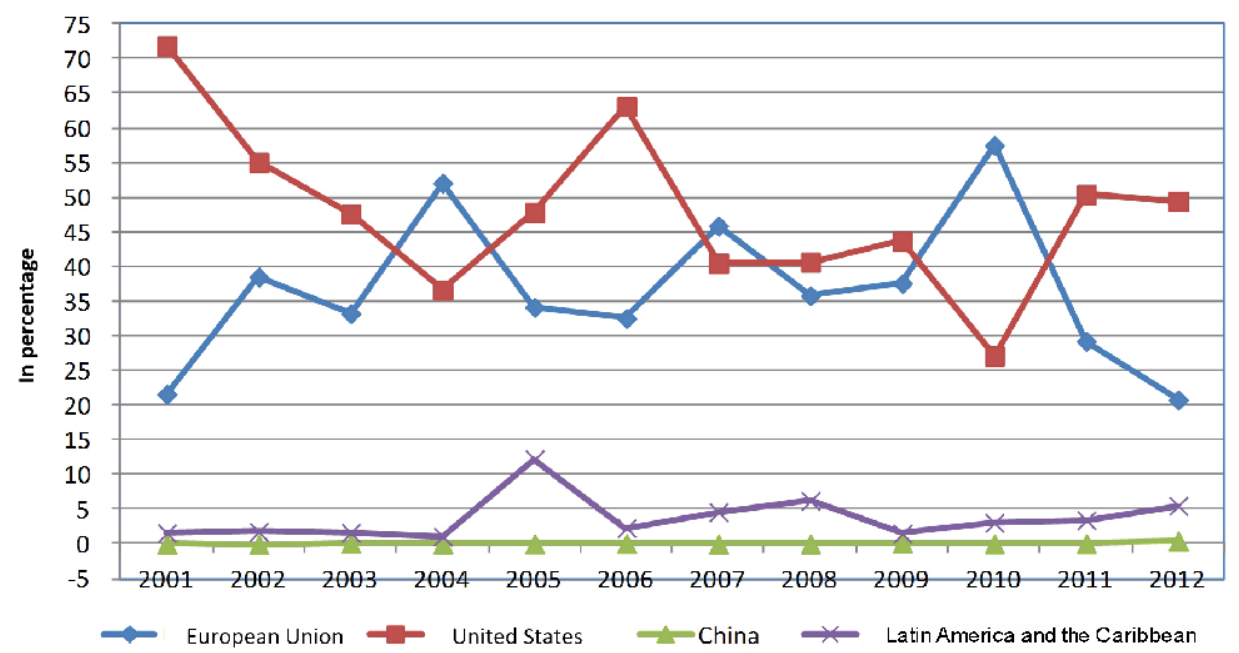

Source: Own elaboration based on UNCTAD data

Latin America and the Caribbean constitutes the third most important region among those under consideration, with a relative importance which only surpasses $5 \%$ in 2005 (when it reached its peak with a contribution of 12.3\%), 2007 and 2012, in the initial years being placed at figures under $2 \%$. China's relative presence is very small. So, in spite of its important increase (the amount of Chinese FDI dedicated to Mexico was multiplied by 34.6 in the period under consideration, with a cumulative annual growth rate of $38.0 \%$ ), their values tend to remain below $0.2 \%$. Its maximum contribution, equivalent to $0.5 \%$ (with an investment of 83 million euros), was reached in 2012.

The internationalization of production and, therefore, FDI as well, have converted multinational companies into key agents in this process. For that reason, we have analysed the economic importance of EU multinationals in Brazil and Mexico, using Eurostat's Foreign Affiliates statistics (Table 3.22). Brazil had 3,175 subsidiaries of European multinationals in 2012, employing 1,271,000 workers and with a turnover of 275 thousand million euros. There were 1,920 multinational companies of the EU 
with branches in Mexico in 2012, employing nearly 500,000 workers and presenting a turnover of 94,500 million euros. Again, EU's relations with Brazil are of greater economic importance compared with Mexico.

\begin{tabular}{lcc}
\hline \multicolumn{2}{l}{ Table 3.22. Importance of EU multinationals in Brazil and Mexico in 2012 } & \\
\hline & Brazil & Mexico \\
Number of companies & 3,175 & 1,920 \\
Employees & $1,271,206$ & 494,616 \\
Turnover (millions of euros) & 275,125 & 94,497
\end{tabular}

\subsubsection{Sectorial characteristics}

Having characterized the bilateral FDI relations between the EU and Brazil and Mexico and its recent trends, for a deeper understanding of the productive relationship we now turn to the sectorial distribution of FDI. First of all, we should stress the limitations of the available data, as not all the countries (in LA, particularly) provide information on their FDI according to sectors. Therefore, the information made available by Eurostat (the source that allows combined analysis of bilateral and sectorial FDI data), which uses the twodigit NACE classification, does not allow for the analysis of the sectorial distribution of Mexico's FDI. For this reason, we try to estimate the sectorial composition of its FDI, keeping in mind that most of the FDI in Mexico and Brazil stems from Europe. According to ECLAC data (2015a), 49\% of the FDI received in Mexico in 2013 stemmed from the EU, compared with $30 \%$ from the United States. In the case of Brazil, $46 \%$ of its FDI inflow came from the EU, $15 \%$ other countries of LA and the Caribbean and $14 \%$ from the United States.

The sectorial distribution of the total global foreign investment received by Brazil, Mexico and LA in 2014 (Graph 3.43) shows a diverse pattern. In Brazil, just as in the region as a whole, the service activities clearly predominate (representing 53\% and $47 \%$, respectively), while in Mexico the most important activity is manufacturing, accounting for $56 \%$ of the total, followed by services (which represent approximately a third). Although the primary sector (which, besides agriculture, includes mining and the extractive industries, including oil) is less important, its high relative contribution is noteworthy (11\% in Brazil and Mexico, being greater in the region overall, representing $17 \%$ of the total). It must be noted that its weight has fallen considerably compared with previous years, as a result of global price reduction primary products. ${ }^{37}$ 
The sectorial analysis of the FDI received by Brazil from the EU in 2011 (the last year for which bilateral information differentiated by sector is available; see Graph 3.44) shows the predominance of services $(36.1 \%$ of the total received FDI that can be distributed sectorially), followed by manufacturing (30.8\%). The primary sector has a relevant presence in the FDI, representing $27.9 \%$. In contrast, the energy sector has less weight, being equivalent to $5.0 \%$ of total FDI, and construction is irrelevant (0.1\%). Graph 3.44 shows the ten most important branches of activity at the NACE two-digit level. Service activities, especially financial services and telecommunications, stand out. As regards the industry sector, it is specifically the branches of coking and oil refining, the food, drinks and tobacco industry, metallurgy and the chemicals industry.

Graph 3.43. Sectorial distribution of the total FDI inflow in Latin America, Brazil and Mexico in 2014

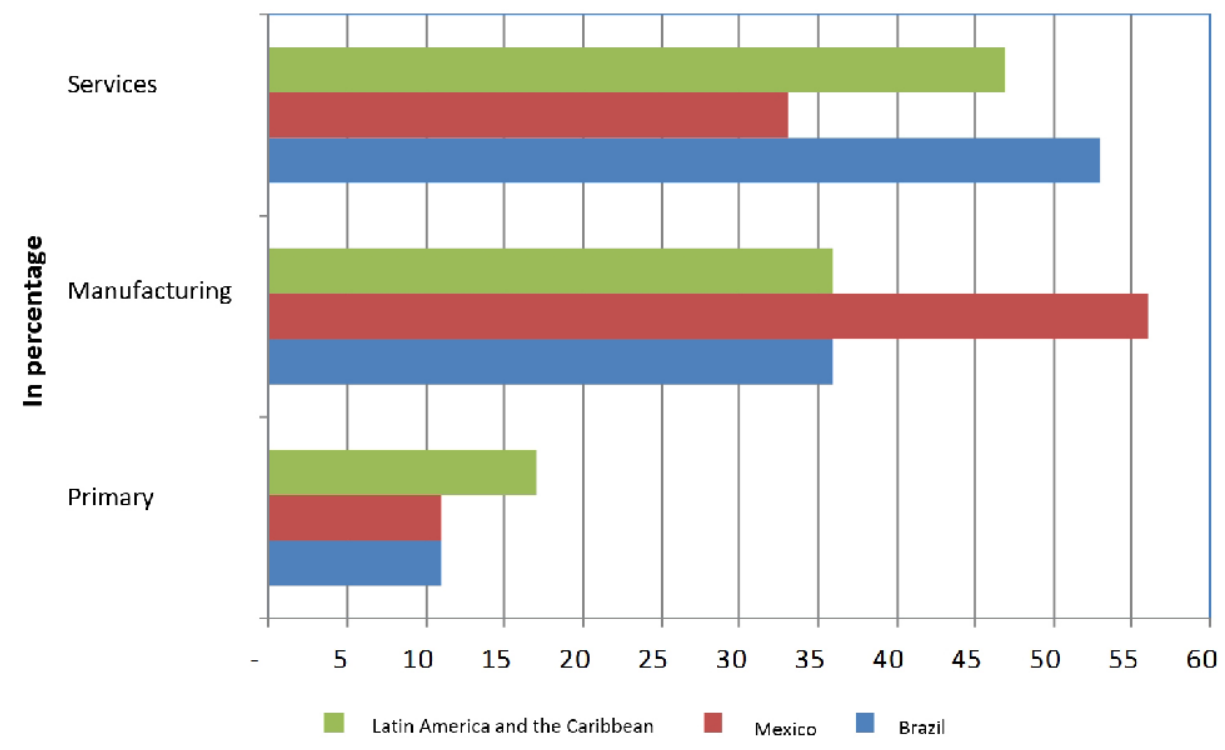

Source: Own elaboration based on ECLAC data (2015a)

If Brazil's inward FDI stocks from the EU corresponding to 2011 are analysed, the sectorial distribution shows a clear predominance of services ( $47.7 \%$ of the total), followed by the manufacturing sector (32.2\%). The mining and extractive activities sector has a significant presence, representing $17.7 \%$ of the total, and power accounts for $5.8 \%$. These figures reflect the importance natural resources and manufacturing have traditionally had among LA's FDI, a behaviour which has changed since the eighties, when services became the main activity. 
Graph 3.44. Sectorial distribution of the total FDI inflow in Latin America in 2014

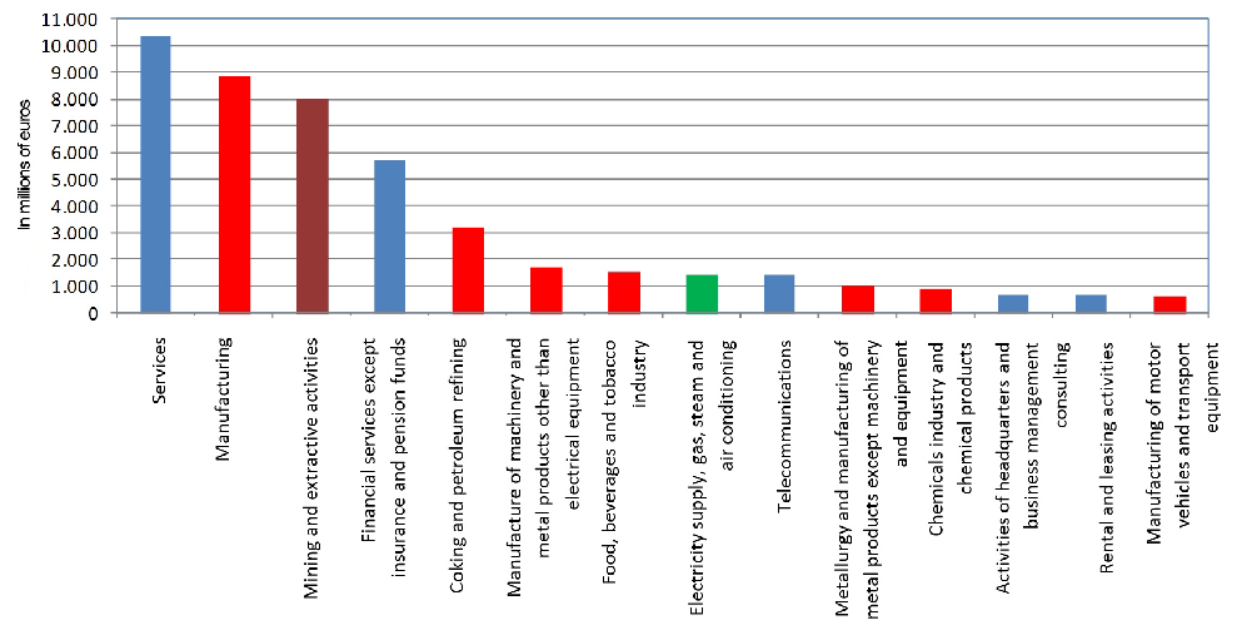

Source: Own elaboration based on Eurostat data

With respect to the full sectorial distribution of FDI inflows and outflows and inward and outward stocks between Brazil and the EU-15, in Brazil's FDI outflows towards the EU, service activities clearly predominate ( $87.1 \%$ of the total), while manufacturing activities only represent $12.6 \%$. In terms of specific branches, these are similar to inflows, except for the food, drinks and tobacco industry, which actually have a negative value.

In Mexico, the most important branches of activity by amount of FDI received in 2014 are the production of motor vehicles (which represents $19 \%$ of the total, with $\$ 4,308$ million) and financial services (representing 25\%). Other branches that should be pointed out are the hotel industry, which receives $\$ 825$ million, and the electricity sector, to which $\$ 580$ million are dedicated (ECLAC 2015a).

Taking the limitations of the data available for Mexico into account, and in order to complete the sectorial analysis, the economic figures for the EU multinationals in Brazil and Mexico differentiated by sector are presented in Table 3.23. Services activities are the most important in Brazil, both in terms of the number of companies and the turnover and employment. Meanwhile in Mexico the manufacturing sector is most important in terms of turnover (in number of companies, it is surpassed by services). The most important manufacturing activities in both countries are the production of motor vehicles and other transport equipment and petroleum production, the chemicals industry, and rubber and plastic products. In services, the branches of trade and financial activities and insurance stand out. 
Table 3.23. Sectorial distribution of EU multinationals in Brazil and Mexico in 2011

\begin{tabular}{|c|c|c|c|c|c|c|}
\hline \multirow[b]{2}{*}{ Sector } & \multicolumn{3}{|c|}{ Brazil } & \multicolumn{3}{|c|}{ Mexico } \\
\hline & $\begin{array}{l}\text { Employ- } \\
\text { ment }\end{array}$ & Entities & $\begin{array}{l}\text { Turn- } \\
\text { over }\end{array}$ & $\begin{array}{l}\text { Employ- } \\
\text { ment }\end{array}$ & Entities & $\begin{array}{l}\text { Turn- } \\
\text { over }\end{array}$ \\
\hline Mining and extractive activities & 7,854 & 76 & 5,894 & 3,380 & - & 1,704 \\
\hline Manufacturing & 526,227 & - & 121,841 & 278,073 & 875 & 49,501 \\
\hline $\begin{array}{l}\text { Petroleum production, chemicals, rub- } \\
\text { ber and plastic products }\end{array}$ & 88,577 & - & 22,168 & 36,660 & - & 8,212 \\
\hline $\begin{array}{l}\text { Manufacturing of computer, electronic } \\
\text { and optical products }\end{array}$ & - & - & - & 14,550 & 40 & 2,210 \\
\hline $\begin{array}{l}\text { Manufacturing of non-electric, non- } \\
\text { electronic machinery and equipment }\end{array}$ & 48,257 & 207 & 9,320 & - & - & - \\
\hline $\begin{array}{l}\text { Manufacturing of motor vehicles and } \\
\text { other transport equipment }\end{array}$ & 156,637 & - & 46,368 & 79,557 & 115 & - \\
\hline $\begin{array}{l}\text { Water supply, sanitation, waste man- } \\
\text { agement and decontamination }\end{array}$ & 2,915 & 22 & 350 & - & - & - \\
\hline Construction & 25,495 & 102 & 3,348 & 5,395 & 70 & 2,588 \\
\hline Services & 678,805 & 1,573 & 134,864 & 203,940 & 975 & 38,356 \\
\hline $\begin{array}{l}\text { Wholesale and retail trade; vehicle and } \\
\text { motorcycle repair }\end{array}$ & 268,618 & 562 & 44,251 & 26,156 & 322 & 10,208 \\
\hline Transport and storage & 33,568 & - & 4,955 & 11,942 & - & 1,605 \\
\hline Hotel industry & 81,685 & - & 2,781 & - & - & - \\
\hline Information and communications & 79,487 & 192 & 34,684 & 13,603 & - & 2,821 \\
\hline Financial and insurance activities & 96,691 & - & 40,678 & 48,665 & 132 & 18,745 \\
\hline Real estate activities & 5,454 & - & 104 & - & - & - \\
\hline $\begin{array}{l}\text { Professional, scientific and technical } \\
\text { activities }\end{array}$ & 28,357 & - & 3,820 & 17,504 & 156 & 1,809 \\
\hline Total & $1,271,206$ & 3,175 & 275,125 & 494,616 & 1,920 & 94,497 \\
\hline
\end{tabular}




\section{COMPARATIVE ANALYSIS OF TRADE AND INVESTMENT RESTRICTIONS}

Ever since what was called the debt crisis of the eighties, which affected all the LA economies to a greater or lesser extent, they have shown a relatively unanimous pattern in their opening towards the exterior world and their attraction of foreign capital, and particularly FDI, which has been used to a great extent for payment of external debt service and to finance current account deficits. This pattern has basically consisted of establishing the amount of FDI received as the basic criterion for evaluating the success of FDI attraction policies ("the more, the better"). This presupposed the creation of the most favourable conditions for commercial liberalization and the action of foreign capital, which implied the State establishing the lowest possible restrictions and encouraging the entrance of goods and services and capital, assuming that commercial liberalisation and the presence of foreign companies and inflows were intrinsically positive for the recipient economy, taking it for granted that there was an automatic relation between commercial liberalization and the arrival of FDI and, in some cases, that it would boost development in general.

\subsection{Trade barriers}

With regard to trade in commodities, Mexico is in general a more open economy than Brazil in all products, and essentially in manufactured products, but not so in primary products, where it has much higher tariffs on average (both simple and weighted). Here it should be pointed out that Brazil is a large food exporter, leading some to talk of the "reprimarisation" of the Brazilian economy, while Mexico is a large food importer and its exports are basically manufactured products.

The EU has a much more open tariff structure than Mexico and Brazil, both in general, and by sector. It is surprising that the EU tariffs on primary products are extremely low, 
simple average tariff $2.2 \%$ and weighted average tariff $0.4 \%$, for manufactured goods 1.4 and $1.5 \%$ respectively (Table 4.1 ). According to these figures, in theory, the EU should constitute a very open block from the tariff point of view; however, it must be remembered that the European agricultural sector is regulated by the common agrarian policy (CAP), in which non-tariff restrictions are also important, and that these constitute significant barriers to access to the European market.

It can also be seen that Brazil has a comparatively greater level of tariff protection than Mexico in the sphere of manufactured products (practically twice as much in terms of simple average tariff), while Mexico has tariffs higher than Brazil for primary products.

\begin{tabular}{|c|c|c|c|c|c|c|}
\hline & \multicolumn{2}{|l|}{ All products } & \multicolumn{2}{|c|}{ Primary products } & \multicolumn{2}{|c|}{ Manufactured products } \\
\hline & $\begin{array}{c}\text { Simple } \\
\text { average tariff }\end{array}$ & $\begin{array}{l}\text { Weighted } \\
\text { average tariff }\end{array}$ & $\begin{array}{c}\text { Simple } \\
\text { average tariff }\end{array}$ & $\begin{array}{l}\text { Weighted } \\
\text { average tariff }\end{array}$ & $\begin{array}{c}\text { Simple } \\
\text { average tariff }\end{array}$ & $\begin{array}{l}\text { Weighted } \\
\text { average tariff }\end{array}$ \\
\hline Brazil & 13.8 & 7.8 & 8.4 & 1.4 & 14.3 & 10.1 \\
\hline Mexico & 7.7 & 5.4 & 10.6 & 10.3 & 7.4 & 4.2 \\
\hline EU & 4.4 & 1.0 & 2.2 & 0.4 & 1.4 & 1.5 \\
\hline
\end{tabular}

Another type of obstacle to trade is non-tariff restrictions or barriers (technical barriers, sanitary and phytosanitary rules, etc.). With regard to non-tariff barriers, various kinds of antidumping measures are imposed by countries or economic blocks, although as a rule, the EU resorts to them much more frequently. In particular, the EU's number of antidumping measures is much higher than those of Brazil or Mexico, and the same can be said about compensatory measures, technical barriers to trade, quantitative restrictions and special safeguard measures (Tables 4.2 and 4.3). The only way in which the EU is surpassed by Brazil is in terms of sanitary and phytosanitary measures; and by both Brazil and Mexico in the realm of safeguards. That is to say, the EU's non-tariff restrictions constitute its main obstacle to trade in goods.

Table 4.2. Definitive antidumping measures from 31 December 2013, Brazil, Mexico and European Unión

\begin{tabular}{|c|c|c|c|c|}
\hline \multirow[b]{2}{*}{ Country/Territory } & \multicolumn{2}{|c|}{$\begin{array}{l}\text { Measures in place in the importing } \\
\text { country }\end{array}$} & \multicolumn{2}{|c|}{$\begin{array}{l}\text { Measures in place in the exporting } \\
\text { country }\end{array}$} \\
\hline & $\begin{array}{l}\text { Number of } \\
\text { measures }\end{array}$ & $\begin{array}{l}\text { Number of } \\
\text { products }\end{array}$ & $\begin{array}{l}\text { Simple average } \\
\text { tariff }\end{array}$ & $\begin{array}{l}\text { Weighted } \\
\text { average tariff }\end{array}$ \\
\hline Brazil & 111 & 120 & 27 & 59 \\
\hline Mexico & 1 & 2 & 3 & 1 \\
\hline EU & 4 & 13 & 39 & 50 \\
\hline
\end{tabular}


Table 4.3. Non-tariff restrictions on trade in goods from 1 June 2015, Brazil, Mexico and European Union

\begin{tabular}{lc|c|c|c|c|c|c|c|c|c|c|c}
\hline $\begin{array}{l}\text { Country/ } \\
\text { Territory }\end{array}$ & \multicolumn{2}{c}{ AD } & \multicolumn{2}{c}{ CM } & \multicolumn{2}{c}{ SPM } & \multicolumn{2}{c}{ TBT } & QR & \multicolumn{2}{c}{ SG } & SSG \\
Brazil & I & F & I & F & I & F & I & F & F & I & F & F \\
Mexico & 75 & 89 & 4 & 1 & 696 & 318 & 629 & 100 & & 2 & 2 & \\
EU & 9 & 42 & & 2 & 261 & 12 & 388 & 71 & & 2 & \\
\end{tabular}

Notes: Antidumping [AD], Compensatory Measures [MC], Sanitary and Phytosanitary Measures [SPM], Technical Barriers to Trade [TBT], Quantitative Restrictions [R], Safeguards [SG], Special Safeguards [SSG], I Initiated, F: In Force

Source: World Trade Organisation

On the other hand, it should be noted that Mexico has a Free Trade Agreement with the EU, which came into force in 2000 and which is intended to facilitate trade between the EU and Mexico. This is not this case of Brazil, for although a Free Trade Agreement between the EU and the Mercosur has been negotiated since 1999, talks have been suspended on several occasions due to differences between some Mercosur countries.

The Free Trade Agreement between Mexico and the EU establishes that:

"In practice, when this Treaty has come into effect, $48 \%$ of EU exports and $82 \%$ of Mexican exports will have free access to mutual markets. From 2003 on, 100\% of Mexican industrial products will enter the community market tariff-free, and from 2007 on, $100 \%$ of the Union's industrial products will enter the Mexican market tariff free. With regard to elimination of agricultural product tariffs, the special conditions of the sector are clear, and a gradual lowering of tariffs over ten years, import quotas and a waiting list for products to which the EU gives important support for production and export are established. 95\% of current agricultural exports from Mexico to the EU enjoy preferential access. On entry into force, tariffs are lifted on coffee, cocoa beans, chick-peas, tequila, beer, mango, papaya and guava. Orange juice and avocado will benefit from an ample quota with preferential access. Negotiation of the most sensitive products (meat, dairy products and cereals) was postponed until 2003, to give time for consolidation of the present reforms of the European Common Agrarian Policy. Concerning elimination of fishing product tariffs, four periods for tariff lowering and a waiting list for sensitive products were agreed. In 2003 the EU will free $88 \%$ of Mexican products of tariffs, and Mexico will free $71 \%$ of community products. The EU will give Mexico a quota with preferential access for Mexican canned tuna. The EU-Mexico FTA will give community suppliers access to the purchases of the Mexican public sector, under the same conditions enjoyed by Mexican suppliers. Mexico will open access to all departments of the federal government and to the semi-official enterprises, including the power and health sectors". ${ }^{38}$

38 Extract of the Mexican government press release of 29/06/2000, with the title "European Union - Mexico FTA: Start of a Strategic Relation with Europe", own translation, available from http//www.sice.oas.org/TPD/MEX_EU/Negotiations/ entrada_s.pdf (accessed 3 May 2015). 
That is to say, according to this declaration, in practice, there should be no restrictions on trade between Mexico and the EU, while in the Brazilian case, this will depend on the signing of the Free Trade Agreement with Mercosur and the terms of tariff reductions implied.

\subsection{Restrictions on foreign direct investment}

In general, it is held that FDI can drive economic growth of recipient countries because it increases the amount of accumulated physical capital (capital stock). In addition, since foreign-owned companies are usually more productive than local ones, it is expected that the benefits of the FDI, that is to say, technological and knowledge spillovers, will come through various channels, such as qualifications and mobility of workers, imitation by local companies and connections between local and foreign companies (Bacaria-Colom et al. 2013).

Nevertheless, the process of opening and capital entry have had different degrees of opening and of the regulating context (opening vs protectionism) in the relations of Mexico and Brazil with the rest of the world in general and with the EU in particular, and they have also had different impacts on the economic growth of countries.

As mentioned, above the OECD's FDI Index assesses the extent to which a country's FDI rules are restrictive according to the following four measures (OECD 2012):

1. Foreign equity limitations;

2. Discriminatory screening or approval mechanisms;

3. Restrictions on the employment of foreigners as key personnel;

4. Other operational restrictions on foreign companies (e.g. restrictions on branch offices and clauses of reciprocity).

Examining the FDI Index, we find that Mexico has a higher score (greater restrictions) than Brazil and the OECD countries with regard to equity limitations, ${ }^{39}$ and also to discriminatory screening or approval mechanisms and operational restrictions, but not restrictions on movement of the foreign personnel or foreign company directors who have total mobility. Nevertheless, examining the four indicators together, Mexico is rated

39 Foreign investors may also be required to meet other requirements, e.g., informing of their investment in the country in advance. It is worth pointing out that the maximum score for the measure "Discriminatory screening or approval mechanisms" is 0.2 and is given when approval is required for a new FDI or when there is an acquisition below $\$ 100$ million (US\$) and the corresponding share of the total equity is less than $50 \%$. Otherwise, a score of 0.1 is given when approval is required for a new FDI and for acquisitions above \$100 million (US\$) or when the corresponding share of the total equity is greater than $50 \%$. 
as having a more closed economy than Brazil and the OECD countries with regard to FDI (Table 4.4).

\begin{tabular}{|c|c|c|c|c|c|}
\hline Country & Equity limitations & $\begin{array}{l}\text { Discriminatory } \\
\text { screening or approval } \\
\text { mechanisms }\end{array}$ & $\begin{array}{l}\text { Restrictions on } \\
\text { key personnel }\end{array}$ & $\begin{array}{l}\text { Operational } \\
\text { restrictions }\end{array}$ & $\begin{array}{l}\text { FDI Index } \\
\text { Rating }\end{array}$ \\
\hline Brazil & 0.034 & 0.009 & 0.005 & 0.035 & 0.083 \\
\hline Mexico & 0.088 & 0.100 & 0.000 & 0.037 & 0.225 \\
\hline OECD & 0.056 & 0.022 & 0.002 & 0.013 & 0.091 \\
\hline
\end{tabular}

If we begin with aggregate sectors of the OECD's foreign direct investment restriction index, we find that Mexico in general terms has more restrictions than Brazil in most sectors and the total index. However, it should be considered that before 1982 Mexico was one of the most closed economies the world to foreign investment in fishing and mass media alone.

Restrictions on FDI have not been an impediment to the increase of the amount of FDI in Mexico and Brazil. Even China, the emerging country which receives most FDI, has a restrictions index much higher than Mexico and Brazil (Graph 4.1). In this regard, China's total FDI restrictions index score is 0.457 which is far higher than Mexico's (0.264) and Brazil's (0.116).

The assessment above is based on all sectors of the economy. Nevertheless, there are several sectors in Mexico where foreign investment is seriously impeded by legislation. These sectors include (FDI restrictions index score in brackets; see OECD 2012):

- $\quad$ Mass media (0.663), especially radio and TV programmes (0.975);

- Transport (0.528), with variations depending on whether it is land $(0.433)$, sea (0.550) or air (0.600); and,

- Telecommunications (0.350), especially fixed-line telecommunications (0.600).

In the case of Brazil, these are the sectors with most restrictions on FDI (FDI restrictions index score in brackets; see OECD 2012):

- Mass media (0.675), radio and TV programmes have the same score (0.675);

- Transport (0.275), with variations depending on whether it is land $(0.275)$, sea (0.025) or air (0.525); and

- Telecommunications (0.025), fixed-line telecommunications (0.025). 
Graph 4.1. FDI restriction index score by country and sector (closed=1, open=0): Mexico and Brazil, 2010

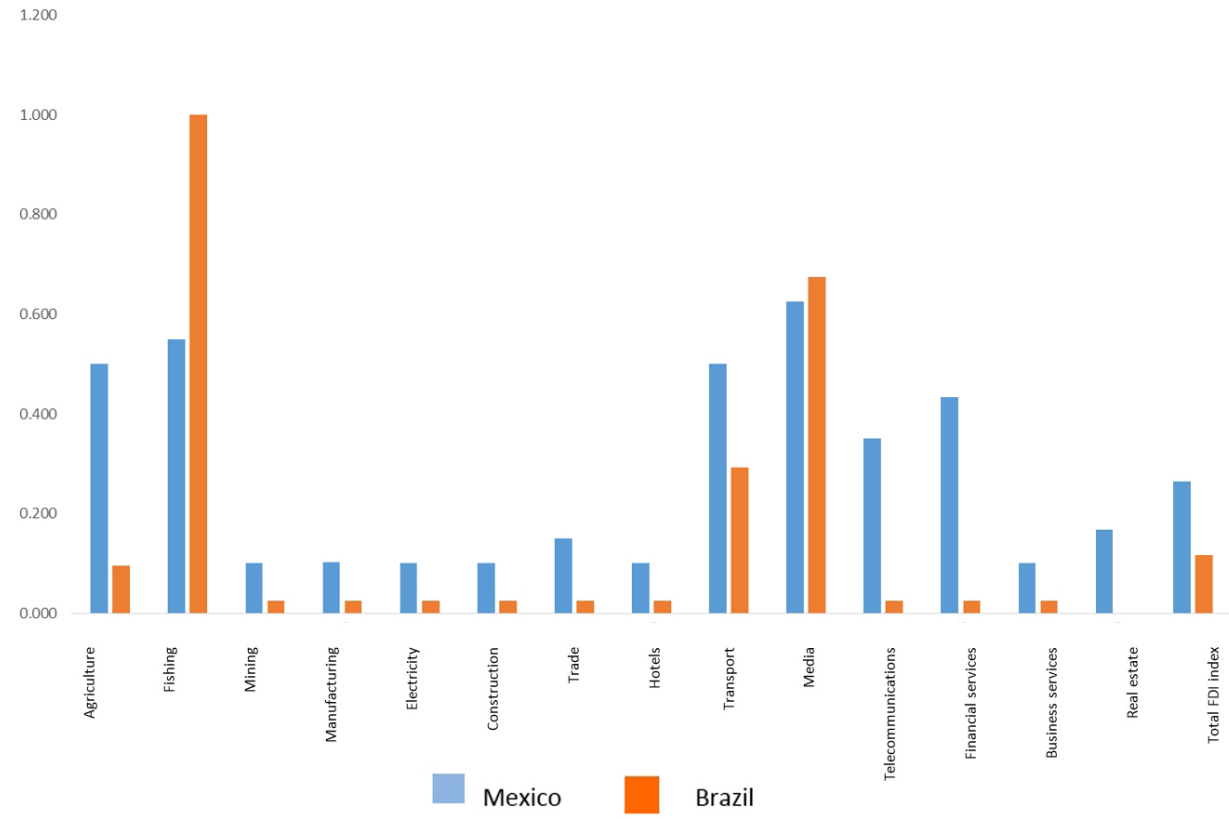

Source: Prepared by the authors based on Kalinova, B., A. Palerm and S. Thomsen (2010)

That is to say, with regard to FDI, Mexico is in general a slightly more closed economy than Brazil, even though the process of opening up to FDI in Mexico has progressed considerably since it joined the North American Free Trade Agreement (NAFTA). In this regard, various reports highlight Brazil and Mexico as very attractive markets for FDI. In fact, Mexico was placed in the top ten in 2015 (Source: AT Kearney; Table 4.5) due to its energy reform which opened up the sector to FDI. It can be seen that Brazil and Mexico are more attractive countries for FDI than many of the developed countries of the EU.

Until 2001, before China joined the World Trade Organisation (WTO), FDI was generally growing in Brazil and Mexico in relation to its importance in gross capital formation (Graph 4.2). It is foreseeable that Mexico's structural reforms will boost FDI significantly form and the Free Trade Agreement which is about to happen between Brazil and the EU will do the same, because, as has been shown in the previous sections, the EU is a very important partner to Brazil. Nevertheless, it should also be pointed out that the prevalent instability and violence in Mexico and Brazil may be a serious barrier to consolidation of FDI. 


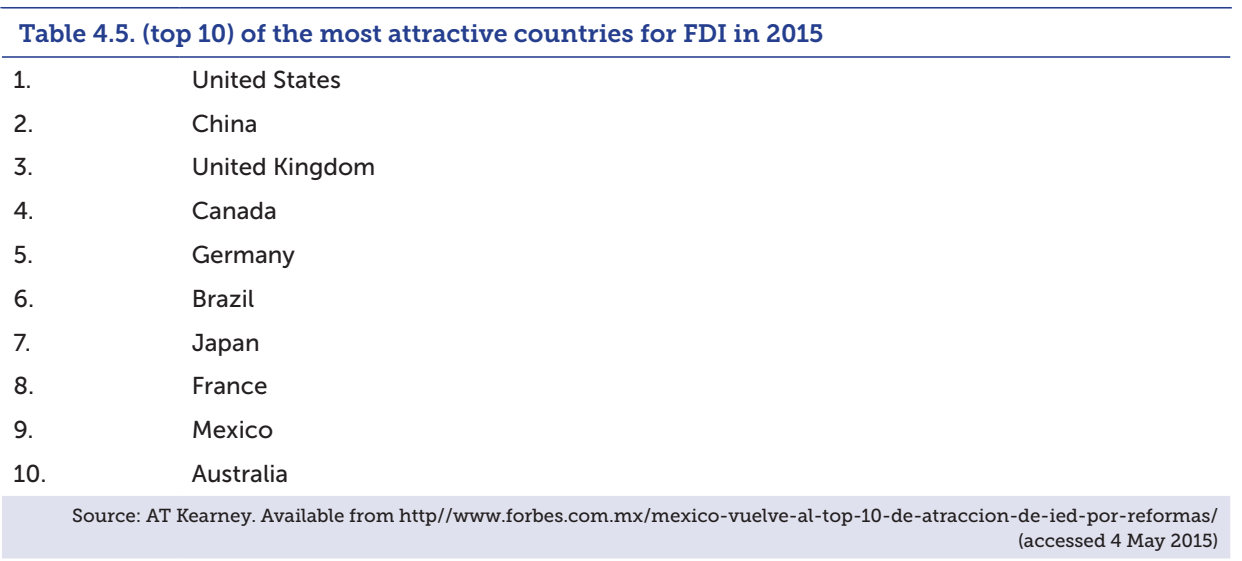

Graph 4.2. FDI inflows in relation to gross capital formation in Brazil and Mexico (\%)

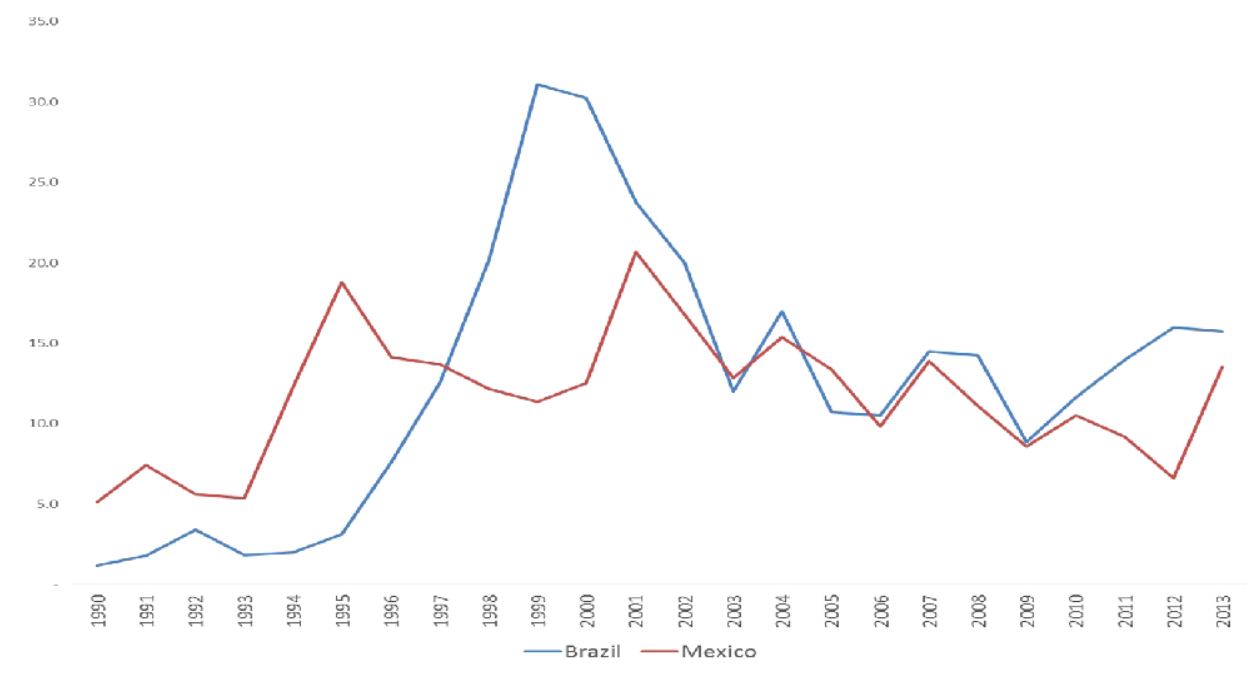

Source: UNCTAD

In short, it can be seen that Mexico has fewer barriers than Brazil to the trade of goods, although when measured by FDI they are greater than in the case of Mexico; still the structural reforms approved by Mexico's Congress of the Union in 2014 have the potential to facilitate the opening towards FDI, as long as the country's climate of violence does not halt this tendency.

Furthermore, it is interesting to see how two countries, which had developed the import substitution industrialization model, have been opening up to trade flows like those of FDI. In this regard, although they have two economic policies which appear different, the results are similar. However, as has been seen, the internal market of Brazil's economy is relatively more important than that of Mexico, which is a more outward-oriented economy. 
In the case of the EU, it has fewer barriers to goods and FDI, - with the limitation that the farming sector is regulated by the CAP which implies non-tariff measures.

In any case, the progressive growth of commercial agreements between the EU and LA can be underlined, nowadays covering a total of 26 countries in LA and the Caribbean, ${ }^{40}$ converting it into the main extra-regional partner by number of commercial agreements in the region, followed by the United States, which has free trade agreements with 11 countries in the region (ECLAC 2015b).

40 If negotiations between Mercosur and the EU were concluded successfully, nearly all the countries in LA and the Caribbean would have trade agreements with the EU; see ECLAC 2015b. 


\section{ANALYSIS OF BRAZIL AND MEXICO'S INTRA-INDUSTRIAL TRADE WITH ITS MAIN EUROPEAN UNION PARTNERS}

The central aim of this study is the analysis of the intra-industrial insertion pattern in the commercial relations of the main countries of the EU with Brazil and Mexico. The interest of this analysis is explained by the need to know to what extent this commercial insertion pattern has been increased or not by two closely related, parallel phenomena: globalisation, in general, and the spread of global value chains, in particular.

In addition to this question, there is a need to explain the qualitative changes that occurred in the commercial and productive relations between economies at different levels of development. We are particularly interested in verifying whether the hypothesis holds true according to which intra-industrial trade takes place in relations between countries of a similar level of development, or, to put it another way, the hypothesis that attributes a predominantly inter-industrial character to trade relations between countries with different levels of development, as in the case we are concerned with in this study.

\subsection{Methodological aspects of measurement of intra-industrial trade}

Methodologically, the study of intra-industrial insertion patterns requires the use of quantitative techniques, and specifically, different indices or indicators. The Grubel-Lloyd Index, named after the authors who developed it (Grubel and Lloyd 1975), is particularly relevant in this respect, but there are also other indicators that provide complementary perspectives.

Also, a series of considerations related with the use of these indices needs to be established, because not taking them into account might render the analysis less valid. 
In the specific case of the Grubel-Lloyd Index, aggregation bias and geographical bias need to be taken into account.

The Grubel-Lloyd Index (GLI, from now on) is constructed on the basis that bilateral trade flows between countries can be divided in two groups: one corresponding to interindustrial trade, related with net trade flow (a country's net exports to the rest of the world), and another related with intra-industrial trade, encompassing the remaining trade flows (total flow minus net flow). The formula applied to calculate this index is shown in formula (1), where $X_{i}$ and $M_{i}$ are the value of exports and imports of product $i$, respectively.

$$
\mathrm{GLI}_{\mathrm{i}}=1-\frac{\left|\mathrm{X}_{\mathrm{i}}-\mathrm{M}_{\mathrm{i}}\right|}{\mathrm{X}_{\mathrm{i}}+\mathrm{Mi}_{\mathrm{i}}}
$$

According to this formula, a product's GLI can have a value between 0 and 1 , where (0) is non-existence and (1) is total existence of intra-industrial trade. To understand this, it needs to be considered that the subtrahend of formula (1) is only the coefficient between the absolute value of net trade flow (trade balance) and the total value of trade flows. So this coefficient only expresses the weight represented by unilateral trade (in a single direction, or inter-industrial) out of total trade, so that, the larger (smaller) the value of the coefficient is, the lower (larger) the value of the index (GLI) will be.

Based on the foregoing, it is easy to see that a very important aspect of the measurement of intra-industrial trade is that it can be affected noticeably by the level of sectorial disaggregation used. In this regard, it is recommendable to use as much sectorial disaggregation as possible, in order to not to classify trade flows as intra-industrial when in fact they are inter-industrial. This is what one has come to be called "aggregation bias". In fact, it can sometimes happen that high GLI values are obtained, simply because of an aggregation error, without it necessarily being a credible example of the existence of intra-industrial trade. ${ }^{41}$

For that reason, in this study, great care has been taken over the treatment of properly disaggregated statistical information. In particular, the starting point is a full sectorial breakdown for the six-digit level of the Harmonized Commodity Description and Coding System, using UN-COMTRADE (United Nations Commodity Trade Statistics database) as the main source of information. This level of disaggregation has required processing of a large amount of information, over two million data, because there are a total of twelve bilateral commercial relations (Brazil and Mexico with each of the main EU economies),

41 Haiti's trade with the United States in manufactured goods is a good illustration of this problem (aggregation bias), because GLIs with relatively high values are seen associated with assembly operations based on provisions and prices of different factors, see Bulmer-Thomas 2000. 
with the respective inflows (imports) and outflows (exports), over a period of twenty-one years (1993-2013) and for more than five thousand two hundred different types of goods. On the other hand, although the basis for calculation of the GLI needs to depart from a high level of disaggregation, it is of great interest to find out how important intra-industrial flows are within trade in general, as an overall summary. For this purpose, an aggregated version of this index is established ( $G \mathrm{LI}_{\text {global }}$ ), the formula for with is given in formula (2).

$$
\mathrm{GLI}_{\text {global }}=1-\frac{\sum_{i=1}^{n}\left|X_{i}-M_{i}\right|}{\sum_{i=1}^{n}\left(X_{i}+M_{i}\right)}
$$

As can be seen, the main difference between the global GLI formula and the simple GLI formula is that in which the global version considers the sum of all the individual net trade flows, calculated separately (product by product), precisely to avoid this aggregation bias. So the $\mathrm{GLI}_{\text {global }}$ is a synthetic indicator of intra-industrial trade, the accuracy of which will depend on the level of sectorial breakdown used for its calculation. However, it should also be mentioned that this aggregate version of the GLI can be affected by the trade balance, so as an alternative, a corrected formula is often used in order to avoid this destabilising effect. The formula for this corrected version of the aggregate Grubel-Lloyd index $\left(\mathrm{GLI}_{\text {global }}^{*}\right)$ is shown in formula (3).

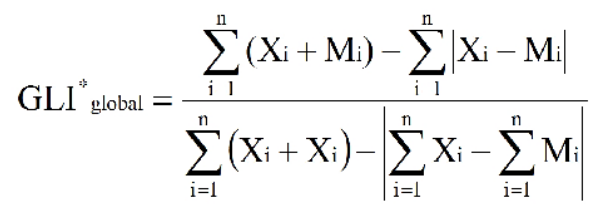

In addition to the "aggregation bias" discussed, calculation of the global GLI can also be affected by what is called "geographical bias," common in measurements of multilateral intra-industrial trade, as has been shown by authors like Fontagné and Freudenberg (1997). In this regard, spatial disaggregation of trade flows has been carried out to avoid the distortion that would come from aggregate geographic analysis at the level of the EU and/or of the countries of LA. This rendered the differentiation of the information by countries for processing an obligatory step in order to start the analysis of the intra-industrial trade with the study of bilateral trade flows. Thus, in the following sections, the analysis of intra-industrial trade starts off with the commercial relations of each of the two largest economies in LA (Brazil and Mexico) with each 
of its main EU partners (Germany, France, the United Kingdom, Spain, Italy and the Netherlands).

On the other hand, although the analysis of intra-industrial trade is usually focused on the use of the GLI, we will use other indices to complement it so as to capture the trends from a dynamic perspective. One of these is Brülhart's marginal intra-industry trade index (Brülhart 1994). The reason for this procedure is that most indicators created to measure the intra-industrial trade, such as the GLI, are designed from a static perspective and thus do not adequately reflect the changes in the volume of intra-industrial trade flow over time. ${ }^{42}$

This analytical shortcoming in static indicators has encouraged the search for another series of more suitable indicators for the analysis of the dynamics of different economies' inter-industrial or intra-industrial specialization. One of the most used indices is the Brülhart's marginal intra-industry trade index (1994), the formula for which can be seen in formula (4), where $A_{i}$ is Brülhart's marginal index for sector $i$.

$$
A_{i}=1-\frac{\left|\Delta X_{i}-\Delta M_{i}\right|}{|\Delta X|_{i}+|\Delta M|_{i}}
$$

This index varies between 0 (where all trade flow variations are inter-industrial) and 1 (with all trade flow variations being intra-industrial). Accordingly, a marginal index which is quite small means that most variations undergone in trade flows are concentrated on one of the two sides of the trade balance, while if it is large, it corresponds to an essentially intra-industrial process. Furthermore, the index of Brülhart can also be used to calculate the aggregate intra-industrial trade variation. In this case, the aggregate marginal index $\left(A_{\text {global }}\right)$ is calculated using the formula shown in formula (5), which includes a weighting coefficient for each product $\left(w_{i}\right)$, which is calculated using formula (6).

$$
\begin{gathered}
\text { Aglobal }=\sum_{i=1}^{n} W_{i} A_{i} \\
W_{i}=\frac{\left|\Delta X_{i}\right|+\left|\Delta M_{i}\right|}{\sum_{i=1}^{n}\left(\left|\Delta X_{i}\right|+\left|\Delta M_{i}\right|\right)}
\end{gathered}
$$

42 In fact, a simple comparison of the GLI at two different moments in time may give rise to completely different interpretations, because the variation in this index over time generally depends on the initial sectorial balance. This is developed in greater detail in Montaner and Orts (1996): 96-97. 


\subsection{Comparative analysis of Brazil and Mexico's intra-industrial trade with the main European economies today}

We initiate the analysis by comparing Brazil's and Mexico's intra-industrial trade in its relations with its main EU partners. In the following section we therefore examine its main characteristics and differences, both in general terms and from a disaggregate point of view.

\subsubsection{Overview}

From a general point of view, it can be stated that the degree of intra-industrial trade relations between Brazil's and Mexico and their main EU partners is small. This is shown by the calculation of the aggregate $\mathrm{GLI}\left(\mathrm{GL} \mathrm{I}_{\text {global }}\right)$, the simple version ${ }^{43}$ of which not only does not reach figures greater than $0.20(20 \%)$ in the whole 1993-2013 period, but in the last year (2013) it does not even exceed 0.11 (Table 5.1).

Table 5.1. Brazil and Mexico's intra-industrial trade with its main European Union partners (1993-2013). Uncorrected Grubel-Lloyd index (GLIglobal)

\begin{tabular}{|c|c|c|c|c|}
\hline & \multicolumn{2}{|c|}{2013} & \multicolumn{2}{|c|}{ Average 1993-2013 } \\
\hline & Brazil & Mexico & Brazil & Mexico \\
\hline Germany & 0.11 & 0.11 & 0.13 & 0.13 \\
\hline Spain & 0.04 & 0.03 & 0.06 & 0.04 \\
\hline France & 0.09 & 0.11 & 0.09 & 0.07 \\
\hline Italy & 0.06 & 0.04 & 0.08 & 0.05 \\
\hline The Netherlands & 0.02 & 0.08 & 0.04 & 0.07 \\
\hline United Kingdom & 0.05 & 0.09 & 0.08 & 0.10 \\
\hline
\end{tabular}

The corrected version of the index $\left(\mathrm{GLI}_{\text {global }}\right)$ does smooth out this evaluation to a certain degree by correcting the distorting effect of the trade balance, but without reaching very high levels. In fact, in the last year (2013) this index's figures are below 0.19 in the case of Brazil and 0.34 in the case of Mexico (Table 5.2). This provides a clear picture of the low intra-industrial profile characterising these two LA countries' insertion in their trade relations with the EU countries, analysed from an overall (global) point of view. 
Table 5.2. Brazil and Mexico's intra-industrial trade with its main European Union partners (1993-2013). Corrected Grubel-Lloyd index (GLI*global)

\begin{tabular}{|c|c|c|c|c|}
\hline & \multicolumn{2}{|c|}{2013} & \multicolumn{2}{|c|}{ Average 1993-2013 } \\
\hline & Brazil & Mexico & Brazil & Mexico \\
\hline Germany & 0.18 & 0.29 & 0.18 & 0.32 \\
\hline Spain & 0.05 & 0.04 & 0.07 & 0.05 \\
\hline France & 0.13 & 0.33 & 0.10 & 0.23 \\
\hline Italy & 0.08 & 0.12 & 0.10 & 0.22 \\
\hline The Netherlands & 0.10 & 0.10 & 0.12 & 0.10 \\
\hline United Kingdom & 0.06 & 0.16 & 0.10 & 0.14 \\
\hline
\end{tabular}

In comparative terms, albeit always in a context of low intra-industrial exchange, bilateral trade with Germany stands out, especially in the case of Mexico, the GLI (corrected) reaching an average of 0.32 (32\%) in the period 1993-2013. In the case of Mexico, trade should also be stressed with France and to a lesser extent Italy, with which Mexico's $\mathrm{GLI}_{\text {global }}^{*}$ of Mexico reaches averages of 0.23 and 0.22 , respectively, in the same period; the figure even rises to 0.33 in the case of France in the last year (2013).

In contrast, Brazil and Mexico's bilateral exchanges with the remaining countries demonstrate very low levels of intra-industrial trade. The most extreme case is that of Brazil and Mexico's bilateral trade with Spain, where a minuscule presence of this type of trade is detected, the $\mathrm{GLI}_{\text {global }}{ }$ reaching averages of 0.07 (Brazil) and 0.05 (Mexico) in the 1993-2013 period; figures that are even lower when looking at the last year (2013).

These results are not generally surprising if we consider that these are trade relations between economies with very different levels of development, which is consistent with the general hypothesis that associates intra-industrial trade presence with similar levels of development. However, from a disaggregate sectorial perspective, this does not rule out there being bilateral intra-industrial flows occurring with certain specific products.

That is why the next section analyses in greater detail the presence of this type of exchange, which most frequently takes place in industrial products of a certain technological intensity and with possibilities of differentiation.

\subsubsection{Overview disaggregated by product}

The study of the intra-industrial trade in terms of sectors, branches and products allows for a deeper, more detailed knowledge of the pattern of trade insertion of the different 
economies analysed. In this regard, it must be understood that while the calculation of the aggregate indices whose results were given in the previous section provided a summarised and interesting overview, the notable differences between products should not be ignored, - differences that only can be appreciated from a disaggregated sectorial perspective.

Therefore, we present a list of the ten main chapters (2 digits disaggregation) of the bilateral trade between Brazil (Table 5.3) and Mexico (Table 5.4) and their main EU partners and indicate their intra-industrial contents (GLI).

Several observations of interest can be made about Brazil's bilateral trade (Table 5.3). First, the high level of sectorial concentration of its bilateral trade, shown by the fact that only ten chapters represent around two thirds of Brazil's total bilateral trade with its European partners. This concentration is especially high in the case of the Brazil's trade with Germany, where $70 \%$ of their total bilateral trade is concentrated in the ten most important chapters.

Secondly, the low intra-industrial content seen in these chapters which play a leading role in these countries' bilateral trade should be stressed, being indicative of the continuous predominance of inter-industrial trade.

Thirdly, the pre-eminence of certain trade chapters in the bilateral relations of these LA countries with their European partners can be pointed out. The appearance of certain chapters is repeated, for example, the chapters on mechanical machinery (Ch. 84), automobiles (Ch. 87), electrical and electronic machinery and equipment (Ch. 85), among others. Other chapters on natural resources, raw materials or fuels also stand out, such as Chapters 26 (ores) or 27 (mineral fuels). It seems significant that in no case high GLI figures can be observed, which again hints to the pre-eminently inter-industrial nature of Brazil's trade.

In Mexico's bilateral trade with its EU partners (Table 5.4), there is more sectorial concentration as seen in the case of Brazil. This holds true specifically for the ten main chapters in which Mexico's exchanges with its European partners account for $70.6 \%$ (trade with France) and $85.9 \%$ (trade with Germany) of its total. 
Table 5.3. Intra-industrial trade in the main chapters of Brazil's bilateral trade with its main European Union partners. Grubel-Lloyd index in brackets. Average 1993-2013

\begin{tabular}{|c|c|c|c|c|c|}
\hline Germany & Spain & France & Italy & The Netherlands & U.K. \\
\hline $\begin{array}{l}84 \text { Nuclear re- } \\
\text { actors, boilers, } \\
\text { machinery, etc. } \\
(0.37)\end{array}$ & $\begin{array}{l}12 \text { Oil seeds and } \\
\text { oleaginous fruits; } \\
\text { miscellaneous } \\
\text { grains, seeds and } \\
\text { fruits, etc. }(0.01)\end{array}$ & $\begin{array}{l}84 \text { Nuclear re- } \\
\text { actors, boilers, } \\
\text { machinery, etc. } \\
(0.38)\end{array}$ & $\begin{array}{l}84 \text { Nuclear } \\
\text { reactors, boilers, } \\
\text { machinery, etc. } \\
(0.26)\end{array}$ & $\begin{array}{l}23 \text { Residues and } \\
\text { waste from the } \\
\text { food industries; } \\
\text { prepared animal } \\
\text { feed }(0.03)\end{array}$ & $\begin{array}{l}71 \text { Pearls, pre- } \\
\text { cious stones, } \\
\text { precious metals, } \\
\text { coins, etc. }(0.00)\end{array}$ \\
\hline $\begin{array}{l}87 \text { Vehicles } \\
\text { other than } \\
\text { railway or } \\
\text { tramway rolling } \\
\text { stock }(0.47)\end{array}$ & $\begin{array}{l}84 \text { Nuclear } \\
\text { reactors, boilers, } \\
\text { machinery, etc. } \\
(0.34)\end{array}$ & $\begin{array}{l}23 \text { Residues } \\
\text { and waste from } \\
\text { the food indus- } \\
\text { tries; prepared } \\
\text { animal feed } \\
(0.03)\end{array}$ & $\begin{array}{l}87 \text { Vehicles other } \\
\text { than railway or } \\
\text { tramway rolling } \\
\text { stock }(0.61)\end{array}$ & $\begin{array}{l}12 \text { Oil seeds and } \\
\text { oleaginous fruits; } \\
\text { miscellaneous } \\
\text { grains, seeds and } \\
\text { fruits, etc. }(0.01)\end{array}$ & $\begin{array}{l}84 \text { Nuclear } \\
\text { reactors, boilers, } \\
\text { machinery, etc. } \\
(0.22)\end{array}$ \\
\hline $\begin{array}{l}85 \text { Electrical } \\
\text { and electronic } \\
\text { machinery and } \\
\text { equipment } \\
(0.34)\end{array}$ & $\begin{array}{l}26 \text { Ores, slag and } \\
\text { ash }(0.02)\end{array}$ & $\begin{array}{l}26 \text { Ores, slag } \\
\text { and ash }(0.00)\end{array}$ & $\begin{array}{l}26 \text { Ores, slag and } \\
\text { ash }(0.00)\end{array}$ & $\begin{array}{l}27 \text { Mineral fuels, } \\
\text { mineral oils and } \\
\text { products of their } \\
\text { distillation, etc. } \\
(0.55)\end{array}$ & $\begin{array}{l}26 \text { Ores, slag } \\
\text { and ash }(0.00)\end{array}$ \\
\hline $\begin{array}{l}26 \text { Ores, slag } \\
\text { and ash }(0.00)\end{array}$ & $\begin{array}{l}27 \text { Mineral fuels, } \\
\text { mineral oils and } \\
\text { products of their } \\
\text { distillation, etc. } \\
(0.48)\end{array}$ & $\begin{array}{l}87 \text { Vehicles } \\
\text { other than rail- } \\
\text { way or tramway } \\
\text { rolling stock } \\
(0.28)\end{array}$ & $\begin{array}{l}85 \text { Electrical } \\
\text { and electronic } \\
\text { machinery and } \\
\text { equipment }(0.23)\end{array}$ & $\begin{array}{l}20 \text { Preparations } \\
\text { of vegetables, } \\
\text { fruit, nuts or other } \\
\text { parts of plants, } \\
\text { etc. }(0,06)\end{array}$ & $\begin{array}{l}16 \text { Preparations } \\
\text { of meat, of fish } \\
\text { or of crusta- } \\
\text { ceans, molluscs, } \\
\text { etc. }\end{array}$ \\
\hline $\begin{array}{l}29 \text { Organic } \\
\text { chemicals } \\
(0.22)\end{array}$ & $\begin{array}{l}88 \text { Aircraft, } \\
\text { spacecraft, and } \\
\text { parts thereof } \\
(0.23)\end{array}$ & $\begin{array}{l}88 \text { Aircraft, } \\
\text { spacecraft, and } \\
\text { parts thereof } \\
(0.56)\end{array}$ & $\begin{array}{l}41 \text { Raw hides } \\
\text { and skins (other } \\
\text { than furskins) } \\
\text { and leather } \\
(0.07)\end{array}$ & $\begin{array}{l}2 \text { Meat and edible } \\
\text { meat offal }(0.00)\end{array}$ & $\begin{array}{l}12 \text { Oil seeds } \\
\text { and oleaginous } \\
\text { fruits; miscel- } \\
\text { laneous grains, } \\
\text { seeds and fruits, } \\
\text { etc. }(0.00)\end{array}$ \\
\hline $\begin{array}{l}9 \text { Coffee, tea, } \\
\text { maté and } \\
\text { spices }(0.01)\end{array}$ & $\begin{array}{l}85 \text { Electrical } \\
\text { and electronic } \\
\text { machinery and } \\
\text { equipment }(0.48)\end{array}$ & $\begin{array}{l}85 \text { Electrical } \\
\text { and electronic } \\
\text { machinery and } \\
\text { equipment } \\
(0.29)\end{array}$ & $\begin{array}{l}9 \text { Coffee, tea, } \\
\text { maté and spices } \\
(0.01)\end{array}$ & $\begin{array}{l}84 \text { Nuclear } \\
\text { reactors, boilers, } \\
\text { machinery, etc. } \\
(0.62)\end{array}$ & $\begin{array}{l}44 \text { Wood and } \\
\text { articles of wood; } \\
\text { wood charcoal } \\
(0.00)\end{array}$ \\
\hline $\begin{array}{l}90 \text { Optical, } \\
\text { photographic, } \\
\text { measuring, } \\
\text { medical, etc. } \\
\text { instruments } \\
\text { and appara- } \\
\text { tus; parts and } \\
\text { accessories } \\
\text { thereof }(0.08)\end{array}$ & $\begin{array}{l}72 \text { Iron and steel } \\
(0.42)\end{array}$ & $\begin{array}{l}29 \text { Organic } \\
\text { chemicals } \\
(0.09)\end{array}$ & $\begin{array}{l}47 \text { Pulp of wood } \\
\text { or of other } \\
\text { fibrous cellulosic } \\
\text { material; waste } \\
\text { and scrap of } \\
\text { paper or paper- } \\
\text { board }(0.00)\end{array}$ & $\begin{array}{l}26 \text { Ores, slag and } \\
\text { ash }(0.07)\end{array}$ & $\begin{array}{l}64 \text { Footwear, } \\
\text { gaiters and the } \\
\text { like; parts of } \\
\text { such articles } \\
(0.00)\end{array}$ \\
\hline $\begin{array}{l}30 \text { Pharmaceu- } \\
\text { tical products } \\
(0.12)\end{array}$ & $\begin{array}{l}29 \text { Organic } \\
\text { chemicals }(0.49)\end{array}$ & $\begin{array}{l}30 \text { Pharmaceu- } \\
\text { tical products } \\
(0.06)\end{array}$ & $\begin{array}{l}29 \text { Organic } \\
\text { chemicals }(0.37)\end{array}$ & $\begin{array}{l}47 \text { Pulp of wood } \\
\text { or of other fibrous } \\
\text { cellulosic mate- } \\
\text { rial; waste and } \\
\text { scrap of paper or } \\
\text { paperboard }(0.00)\end{array}$ & $\begin{array}{l}2 \text { Meat and ed- } \\
\text { ible meat offal } \\
(0.00)\end{array}$ \\
\hline $\begin{array}{l}39 \text { Plastics and } \\
\text { articles thereof } \\
(0.13)\end{array}$ & $\begin{array}{l}23 \text { Residues and } \\
\text { waste from the } \\
\text { food industries; } \\
\text { prepared animal } \\
\text { feed }(0.02)\end{array}$ & $\begin{array}{l}27 \text { Mineral fu- } \\
\text { els, mineral oils } \\
\text { and products of } \\
\text { their distillation, } \\
\text { etc. }(0.32)\end{array}$ & $\begin{array}{l}72 \text { Iron and steel } \\
(0.54)\end{array}$ & $\begin{array}{l}72 \text { Iron and steel } \\
(0.11)\end{array}$ & $\begin{array}{l}88 \text { Aircraft, } \\
\text { spacecraft, and } \\
\text { parts thereof } \\
(0.07)\end{array}$ \\
\hline $\begin{array}{l}72 \text { Iron and } \\
\text { steel }(0.69)\end{array}$ & $\begin{array}{l}87 \text { Vehicles other } \\
\text { than railway or } \\
\text { tramway rolling } \\
\text { stock }(0.40)\end{array}$ & $\begin{array}{l}39 \text { Plastics and } \\
\text { articles thereof } \\
(0.19)\end{array}$ & $\begin{array}{l}12 \text { Oil seeds and } \\
\text { oleaginous fruits; } \\
\text { miscellaneous } \\
\text { grains, seeds and } \\
\text { fruits, etc. }(0.02)\end{array}$ & $\begin{array}{l}76 \text { Aluminium and } \\
\text { articles thereof } \\
(0.07)\end{array}$ & $\begin{array}{l}27 \text { Mineral fuels, } \\
\text { mineral oils and } \\
\text { products of their } \\
\text { distillation, etc. } \\
(0.13)\end{array}$ \\
\hline $\begin{array}{l}69.9 \% \text { of total } \\
\text { bilateral trade }\end{array}$ & $\begin{array}{l}58.4 \% \text { of total } \\
\text { bilateral trade }\end{array}$ & $\begin{array}{l}65.6 \% \text { of total } \\
\text { bilateral trade }\end{array}$ & $\begin{array}{l}65.4 \% \text { of total } \\
\text { bilateral trade }\end{array}$ & $\begin{array}{l}65.3 \% \text { of total } \\
\text { bilateral trade }\end{array}$ & $\begin{array}{l}59.4 \% \text { of total } \\
\text { bilateral trade }\end{array}$ \\
\hline
\end{tabular}


Table 5.4. Intra-industrial trade in the main chapters of Mexico's bilateral trade with its main European Union partners. Grubel-Lloyd index in brackets. Average 1993-2013

\begin{tabular}{|c|c|c|c|c|c|}
\hline Germany & Spain & France & Italy & The Netherlands & U.K. \\
\hline $\begin{array}{l}87 \text { Vehicles other } \\
\text { than railway or } \\
\text { tramway rolling } \\
\text { stock }(0.70)\end{array}$ & $\begin{array}{l}27 \text { Mineral fuels, } \\
\text { mineral oils and } \\
\text { products of their } \\
\text { distillation, etc. } \\
(0.09)\end{array}$ & $\begin{array}{l}84 \text { Nuclear re- } \\
\text { actors, boilers, } \\
\text { machinery, etc. } \\
(0.55)\end{array}$ & $\begin{array}{l}84 \text { Nuclear re- } \\
\text { actors, boilers, } \\
\text { machinery, etc. } \\
(0.09)\end{array}$ & $\begin{array}{l}27 \text { Mineral fuels, } \\
\text { mineral oils and } \\
\text { products of their } \\
\text { distillation, etc. } \\
(0.19)\end{array}$ & $\begin{array}{l}84 \text { Nuclear re- } \\
\text { actors, boilers, } \\
\text { machinery, etc. } \\
(0.70)\end{array}$ \\
\hline $\begin{array}{l}84 \text { Nuclear } \\
\text { reactors, boilers, } \\
\text { machinery, etc. } \\
(0.22)\end{array}$ & $\begin{array}{l}84 \text { Nuclear } \\
\text { reactors, boilers, } \\
\text { machinery, etc. } \\
(0.33)\end{array}$ & $\begin{array}{l}85 \text { Electrical } \\
\text { and electronic } \\
\text { machinery and } \\
\text { equipment } \\
(0.41)\end{array}$ & $\begin{array}{l}72 \text { Iron and } \\
\text { steel }(0.23)\end{array}$ & $\begin{array}{l}85 \text { Electrical } \\
\text { and electronic } \\
\text { machinery and } \\
\text { equipment }(0.48)\end{array}$ & $\begin{array}{l}85 \text { Electrical } \\
\text { and electronic } \\
\text { machinery and } \\
\text { equipment } \\
(0.62)\end{array}$ \\
\hline $\begin{array}{l}85 \text { Electrical } \\
\text { and electronic } \\
\text { machinery and } \\
\text { equipment }(0.27)\end{array}$ & $\begin{array}{l}87 \text { Vehicles other } \\
\text { than railway or } \\
\text { tramway rolling } \\
\text { stock }(0.22)\end{array}$ & $\begin{array}{l}30 \text { Pharmaceu- } \\
\text { tical products } \\
(0.03)\end{array}$ & $\begin{array}{l}27 \text { Mineral fu- } \\
\text { els, mineral oils } \\
\text { and products of } \\
\text { their distillation, } \\
\text { etc. }(0.30)\end{array}$ & $\begin{array}{l}84 \text { Nuclear } \\
\text { reactors, boilers, } \\
\text { machinery, etc. } \\
(0.58)\end{array}$ & $\begin{array}{l}71 \text { Pearls, pre- } \\
\text { cious stones, } \\
\text { precious met- } \\
\text { als, coins, etc. } \\
(0.05)\end{array}$ \\
\hline $\begin{array}{l}90 \text { Optical, } \\
\text { photographic, } \\
\text { measuring, } \\
\text { medical, etc. } \\
\text { instruments and } \\
\text { apparatus; parts } \\
\text { and accessories } \\
\text { thereof }(0.34)\end{array}$ & $\begin{array}{l}85 \text { Electrical and } \\
\text { electronic machin- } \\
\text { ery and equipment } \\
(0.21)\end{array}$ & $\begin{array}{l}90 \text { Optical, } \\
\text { photographic, } \\
\text { measuring, } \\
\text { medical, etc. } \\
\text { instruments and } \\
\text { apparatus; parts } \\
\text { and accessories } \\
\text { thereof }(0.59)\end{array}$ & $\begin{array}{l}85 \text { Electrical } \\
\text { and electronic } \\
\text { machinery and } \\
\text { equipment } \\
(0.17)\end{array}$ & $\begin{array}{l}29 \text { Organic } \\
\text { chemicals }(0.64)\end{array}$ & $\begin{array}{l}87 \text { Vehicles } \\
\text { other than rail- } \\
\text { way or tramway } \\
\text { rolling stock } \\
(0.23)\end{array}$ \\
\hline $\begin{array}{l}30 \text { Pharmaceuti- } \\
\text { cal products } \\
(0.09)\end{array}$ & $\begin{array}{l}29 \text { Organic chemi- } \\
\text { cals }(0.67)\end{array}$ & $\begin{array}{l}29 \text { Organic } \\
\text { chemicals }(0.16)\end{array}$ & $\begin{array}{l}87 \text { Vehicles } \\
\text { other than rail- } \\
\text { way or tramway } \\
\text { rolling stock } \\
(0.30)\end{array}$ & $\begin{array}{l}90 \text { Optical, } \\
\text { photographic, } \\
\text { measuring, } \\
\text { medical, etc. } \\
\text { instruments and } \\
\text { apparatus; parts } \\
\text { and accessories } \\
\text { thereof }(0.41)\end{array}$ & $\begin{array}{l}27 \text { Mineral fu- } \\
\text { els, mineral oils } \\
\text { and products of } \\
\text { their distillation, } \\
\text { etc. }(0.39)\end{array}$ \\
\hline $\begin{array}{l}39 \text { Plastics and } \\
\text { articles thereof } \\
(0.13)\end{array}$ & $\begin{array}{l}49 \text { Printed books, } \\
\text { newspapers, } \\
\text { pictures and other } \\
\text { products of the } \\
\text { printing industry, } \\
\text { etc. }(0.07)\end{array}$ & $\begin{array}{l}87 \text { Vehicles } \\
\text { other than rail- } \\
\text { way or tramway } \\
\text { rolling stock } \\
(0.40)\end{array}$ & $\begin{array}{l}29 \text { Organic } \\
\text { chemicals } \\
(0.43)\end{array}$ & $\begin{array}{l}72 \text { Iron and steel } \\
(0.63)\end{array}$ & $\begin{array}{l}30 \text { Pharmaceu- } \\
\text { tical products } \\
(0.07)\end{array}$ \\
\hline $\begin{array}{l}72 \text { Iron and steel } \\
(0.35)\end{array}$ & $\begin{array}{l}22 \text { Beverages, } \\
\text { spirits and vinegar } \\
(0.47)\end{array}$ & $\begin{array}{l}33 \text { Essential oils } \\
\text { and resinoids; } \\
\text { perfumery, cos- } \\
\text { metic or toilet } \\
\text { preparations } \\
(0.03)\end{array}$ & $\begin{array}{l}90 \text { Optical, } \\
\text { photographic, } \\
\text { measuring, } \\
\text { medical, etc. } \\
\text { instruments } \\
\text { and appara- } \\
\text { tus; parts and } \\
\text { accessories } \\
\text { thereof }(0.07)\end{array}$ & $\begin{array}{l}30 \text { Pharmaceuti- } \\
\text { cal products } \\
(0.59)\end{array}$ & $\begin{array}{l}90 \text { Optical, } \\
\text { photographic, } \\
\text { measuring, } \\
\text { medical, etc. in- } \\
\text { struments and } \\
\text { apparatus; parts } \\
\text { and accessories } \\
\text { thereof }(0.43)\end{array}$ \\
\hline $\begin{array}{l}29 \text { Organic } \\
\text { chemicals }(0.38)\end{array}$ & $\begin{array}{l}39 \text { Plastics and } \\
\text { articles thereof } \\
(0.32)\end{array}$ & $\begin{array}{l}39 \text { Plastics and } \\
\text { articles thereof } \\
(0.16)\end{array}$ & $\begin{array}{l}39 \text { Plastics and } \\
\text { articles thereof } \\
(0.35)\end{array}$ & $\begin{array}{l}39 \text { Plastics and } \\
\text { articles thereof } \\
(0.49)\end{array}$ & $\begin{array}{l}29 \text { Organic } \\
\text { chemicals } \\
(0.35)\end{array}$ \\
\hline $\begin{array}{l}73 \text { Articles of iron } \\
\text { or steel (0.11) }\end{array}$ & $\begin{array}{l}72 \text { Iron and steel } \\
(0.26)\end{array}$ & $\begin{array}{l}27 \text { Mineral fuels, } \\
\text { mineral oils and } \\
\text { products of } \\
\text { their distillation, } \\
\text { etc. }(0.11)\end{array}$ & $\begin{array}{l}30 \text { Pharmaceu- } \\
\text { tical products } \\
(0.03)\end{array}$ & $\begin{array}{l}26 \text { Ores, slag and } \\
\text { ash }(0.07)\end{array}$ & $\begin{array}{l}22 \text { Beverages, } \\
\text { spirits and vine- } \\
\text { gar }(0.69)\end{array}$ \\
\hline $\begin{array}{l}99 \text { Unspecified } \\
\text { products (0.12) }\end{array}$ & $\begin{array}{l}73 \text { Articles of iron } \\
\text { or steel }(0.22)\end{array}$ & $\begin{array}{l}99 \text { Unspecified } \\
\text { products }(0.23)\end{array}$ & $\begin{array}{l}73 \text { Articles of } \\
\text { iron or steel } \\
(0.22)\end{array}$ & $\begin{array}{l}73 \text { Articles of iron } \\
\text { or steel }(0.22)\end{array}$ & $\begin{array}{l}39 \text { Plastics and } \\
\text { articles thereof } \\
(0.71)\end{array}$ \\
\hline $\begin{array}{l}85.9 \% \text { of total } \\
\text { bilateral trade }\end{array}$ & $\begin{array}{l}77.2 \% \text { of total } \\
\text { bilateral trade }\end{array}$ & $\begin{array}{l}70.6 \% \text { of total } \\
\text { bilateral trade }\end{array}$ & $\begin{array}{l}72.6 \% \text { of total } \\
\text { bilateral trade }\end{array}$ & $\begin{array}{l}82.5 \% \text { of total } \\
\text { bilateral trade }\end{array}$ & $\begin{array}{l}74.4 \% \text { of total } \\
\text { bilateral trade }\end{array}$ \\
\hline
\end{tabular}


Additionally, certain chapters of an industrial nature appear repeatedly, for example, mechanical machinery and equipment (Ch. 84), electrical and electronic machinery and equipment (Ch. 85) and automobiles (Ch. 87). In this regard, it should be pointed out that, unlike the findings in the case of Brazil, Mexican trade has more intra-industrial content, as is shown by the GLIs calculated for these chapters. This is the case, for example, of the bilateral trade between Mexico and Germany in automobiles (Ch. 87), which is $70 \%$ of an intra-industrial nature; and that in machinery and mechanical equipment (Ch. 84) between Mexico and the United Kingdom, at a similar level in terms of its intra-industrial nature.

We can conclude from this analysis of the main trade chapters, therefore, that next to a remarkable sectorial concentration in these two LA countries' trade relations with the main European economies, their profile is predominantly inter-industrial, although with certain exceptions, especially in the case of Mexico. To a large extent this is because of the role played by the specific activity of certain transnational corporations (Volkswagen, Fiat or Daimler $A G,{ }^{44}$ for example, in the case of the automotive sector) that require the existence of a certain amount of intra-industrial flow with their European partners.

\subsection{Patterns in the growth of Brazil's intra-industrial trade with the main European economies}

Having analysed the general characteristics of Brazil's trade relations with its main European partners, we now want to understand the patterns in its growth, focusing on a period of two decades (1993-2013). What follows is thus an analysis of the trends followed by this intra-industrial trade, measured by the GLI and adopting the recommendations in the methodological section, in order to avoid both geographical and aggregation bias. In this regard, in this section, the bilateral trade flows of Brazil with each of its main European partners are dealt with, based on the aggregate indices calculated from the trade information disaggregated to six digits.

\subsubsection{Overview}

Although it seems not very important in terms of size (as has been seen in the previous section), Brazil's intra-industrial trade with its European partners is full of nuances if we looked at it over time.

The initial analysis of its evolution shows that the biennium 2007-2008 constituted a

44 These European multinationals have production plants in Puebla and Guanajuato (Volkswagen), as well as in Coahuila and Mexico State (Fiat); and Mexico City (Daimler AG). 
turning point, when a change of trend can be directly observed in the growth graphs (Graphs 5.1 and 5.2). In general terms, a slight trend of increasing intra-industrial trade can be seen in the period beginning in 1993 and ending with the start of the Great Recession in the biennium 2007-2008. It is a period that can be considered a moment of recovery and economic growth in the European economies, which went hand in hand with a remarkable expansion of their trade relations and of their FDI flows to the world and, especially, LA. It is especially evident until the beginning of this century, a new context of international economic relations starting in 2001, with China converting in a very short time from a secondary agent in the world economy into a leading agent and central axis of the global factory. This substantial change was not a trivial matter for any economy in general, nor for LA and the EU in particular, as a short glance at China's position in the ranking of main trade partners of any of these economies will confirm.

The change of trend took place later on, as we have said, from the biennium 2007-2008 onward, when a steady decline was observed in the intra-industrial trade indices of the respective bilateral flows between Brazil and its main EU partners. This phenomenon is especially evident when growth of the uncorrected GLI (GLI global $_{\text {) }}$ is examined (Graph 5.1), which facilitates a clearer picture of how Brazil's bilateral trade with all these countries has declined between 2008 and 2013.

The same change of trend, although in this case smoothed out, can be observed when growth of the corrected GLI (GLI global $_{\text {) }}$ is examined (Graph 5.2), in which growth of the GLI related with some bilateral flows (case, for example, of the trade between Brazil and the Netherlands) is more erratic, though also tending to fall.

This change of trend, indicating a clear regression in intra-industrial insertion of this large LA economy in relation to its main EU partners, takes place in a context of strong economic crisis and reorganization of the investing and productive strategies of a great part of transnational capital. Various factors are also operating in this context, such as the extension of production relocation towards other economies (Asian, in particular), the intensification of disinvestment in LA of European capital, new capital investment flows from some LA countries, such as Mexico or Brazil, towards the EU, and the effect we have already mentioned of global production activity orbiting around China. All these phenomena, which may have collateral effects on trade, can partly explain this change of trend. 
Graph 5.1. Intra-industrial trade of the bilateral trade of Brazil with its main European Union partners. Uncorrected Grubel-Lloyd index, 1993-2013

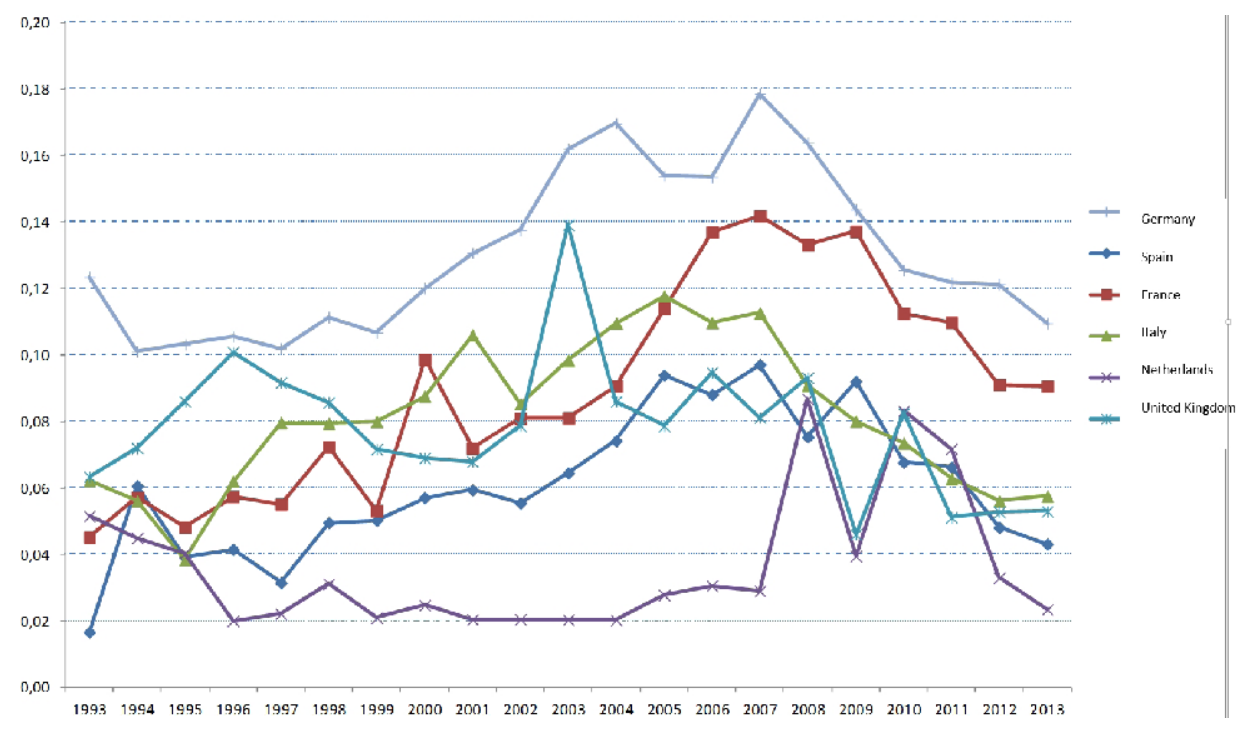

Source: Own elaboration based on UN-COMTRADE data

Graph 5.2. Intra-industrial trade of the bilateral trade of Brazil with its main European Union partners. Corrected Grubel-Lloyd index, 1993-2013

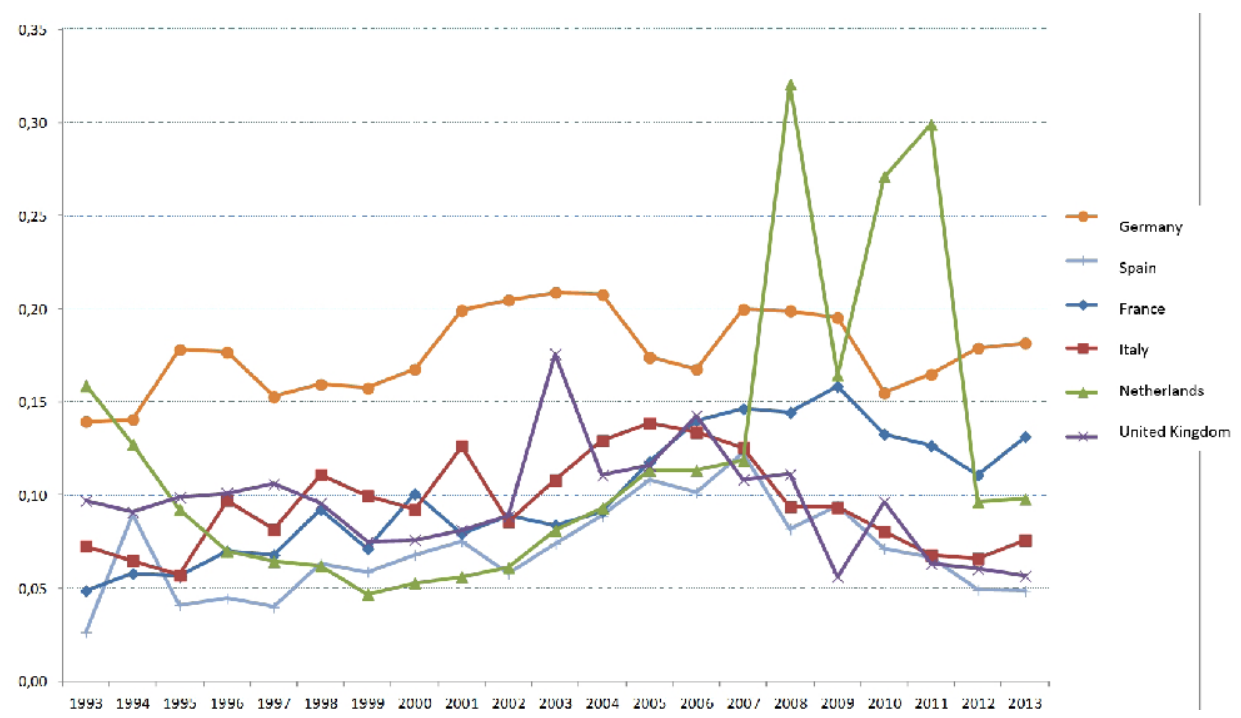

Source: Own elaboration based on UN-COMTRADE data 
In short, this characterisation of the growth of Brazil's intra-industrial trade of Brazil in the 1993-2013 period responds to multiple factors which, without being directly traderelated, could have effects on the direction and/or composition of Brazil's bilateral trade flows with its EU partners. All this helps to explain the change in trend observed after the world crisis, although its profile is still of traditional trade insertion, with clear preeminence of inter-industrial exchanges.

\subsubsection{Overview disaggregated by product}

Intensifying the level of disaggregation (6 digits) allows for a closer examination of the existence of intra-industrial trade in the exchanges of each specific product. With this objective in mind, an examination of the twenty most important products in the Brazil's relations with each of its main EU partners will now be provided.

This analysis will allow us to see to what extent the most important products in Brazil's trade exchanges with its European partners (which some cases account for $60 \%$ of bilateral trade) acquire some type of singularity in terms of intra-industrial trade, differentiating them from the low intra-industrial insertion profile observed at the aggregate level. For summary purposes, the 1993-2013 average of both the trade weight of each product and its respective GLI for period are considered.

In the case of bilateral trade between Brazil and Germany, the twenty products in a sixdigit disaggregation with most trade weight represent a third (33.3\%) of this trade (Table 5.5). In terms of analysis of intra-industrial trade, there is a clear predominance of low GLI figures, indicating a low intra-industrial character. Only two exceptions related to different engine parts of motors (products with codes 840999 and 840991) are found which have GLIs equal to or greater than 0.75 , which means there is an important volume of intrasectorial exchanges.

In the case of the bilateral trade between Brazil and Spain, the twenty products, at a six-digit disaggregation level with most trade weight represent $38.9 \%$ of this trade (Table 5.6). In relation to the analysis of the intra-industrial trade, a total predominance of figures reduced of the GLI exists, including many equal figures to zero, which indicates a character preponderantly inter-industrial. 
Table 5.5. Intra-industrial trade in 20 main products (6-digit classifications) in Brazil's bilateral trade with Germany. Grubel-Lloyd Index. Average 1993-2013

\begin{tabular}{|c|c|c|}
\hline $\begin{array}{c}\text { Product } \\
\text { (6-digit HS2012 code) }\end{array}$ & $\begin{array}{l}\text { Trade } \\
\text { weight }(\%) \\
\text { average } \\
1993-2013\end{array}$ & $\begin{array}{c}\text { GLI } \\
\text { average } \\
1993-2013\end{array}$ \\
\hline 90111 (Coffee, not roasted, not decaffeinated) & $5.0 \%$ & 0.00 \\
\hline $\begin{array}{l}260111 \text { (Iron ores and concentrates, other than roasted iron pyrites / } \\
\text { Non-agglomerated) }\end{array}$ & $4.5 \%$ & 0.00 \\
\hline $\begin{array}{l}870323 \text { (Other vehicles, with spark-ignition internal combustion } \\
\text { reciprocating piston engine, of a cylinder capacity exceeding 1,500 cc but } \\
\text { not exceeding } 3,000 \mathrm{cc} \text { ) }\end{array}$ & $2.7 \%$ & 0.17 \\
\hline $\begin{array}{l}230400 \text { (Oil-cake and other solid residues, whether or not ground or in } \\
\text { the form of pellets, resulting from the extraction of soybean oil) }\end{array}$ & $2.2 \%$ & 0.00 \\
\hline 310420 (Mineral or chemical fertilizers, potassic & $2,1 \%$ & 0,00 \\
\hline $\begin{array}{l}840999 \text { (Other parts suitable for use solely or principally with the engines } \\
\text { of heading No. } 84.07 \text { or } 84.08 \text {.) }\end{array}$ & $2.0 \%$ & 0.75 \\
\hline $\begin{array}{l}260112 \text { (Iron ores and concentrates, other than roasted iron pyrites / } \\
\text { Agglomerated) }\end{array}$ & $1.9 \%$ & 0.00 \\
\hline $\begin{array}{l}879899 \text { (Parts and accessories of the motor vehicles of headings Nos. } \\
87.01 \text { to 87.05./Other parts and accessories/Other) }\end{array}$ & $1.8 \%$ & 0.26 \\
\hline $\begin{array}{l}300210 \text { (Antisera and other blood fractions and modified } \\
\text { immunological products, whether or not obtained by means of biotech- } \\
\text { nological processes) }\end{array}$ & $1.2 \%$ & 0.02 \\
\hline 240120 (Tobacco, partly or wholly stemmed/stripped) & $1.2 \%$ & 0.00 \\
\hline $\begin{array}{l}300490 \text { (Medicaments (excluding goods of heading No. } 30.02,30.05 \\
\text { or } 30.06 \text { ) consisting of mixed or unmixed products for therapeutic or } \\
\text { prophylactic uses, put up in measured doses (including those intended } \\
\text { for administration by trans...) }\end{array}$ & $1.2 \%$ & 0.09 \\
\hline $\begin{array}{l}870322 \text { (Other vehicles, with spark-ignition internal combustion } \\
\text { reciprocating piston engine, of a cylinder capacity exceeding 1,000 cc but } \\
\text { not exceeding } 1,500 \mathrm{cc} \text { ) }\end{array}$ & $1.1 \%$ & 0.10 \\
\hline 260300 (Copper ores and concentrates) & $1.0 \%$ & 0.00 \\
\hline $\begin{array}{l}840991 \text { (Other parts suitable for use solely or principally with the engines } \\
\text { of heading No. } 84.07 \text { or } 84.08 \text { suitable for use solely or principally with } \\
\text { spark-ignition internal combustion piston engines) }\end{array}$ & $0.9 \%$ & 0.83 \\
\hline $\begin{array}{l}870840 \text { (Parts and accessories of the motor vehicles of headings Nos. } \\
87.01 \text { to } 87.05 . / \text { Gear boxes and parts thereof) }\end{array}$ & $0.9 \%$ & 0.36 \\
\hline $\begin{array}{l}847989 \text { (Machines and mechanical appliances having individual functions, } \\
\text { not specified or included elsewhere in Ch. 84). }\end{array}$ & $0.8 \%$ & 0.08 \\
\hline $\begin{array}{l}841330 \text { (Fuel, lubricating or cooling medium pumps for internal } \\
\text { combustion piston engines) }\end{array}$ & $0.8 \%$ & 0.49 \\
\hline $\begin{array}{l}870829 \text { (Other parts and accessories of bodies (including cabs) of the } \\
\text { motor vehicles of headings Nos. } 87.01 \text { to } 87.05 \text { ) }\end{array}$ & $0.7 \%$ & 0.27 \\
\hline $\begin{array}{l}903289 \text { (Other automatic regulating or controlling instruments and } \\
\text { apparatus) }\end{array}$ & $0.7 \%$ & 0.08 \\
\hline $\begin{array}{l}293339 \text { (Other compounds containing an unfused pyridine ring (whether } \\
\text { or not hydrogenated) in the structure) }\end{array}$ & $0.6 \%$ & 0.43 \\
\hline Subtotal & $33.3 \%$ & \\
\hline
\end{tabular}

In the case of bilateral trade between Brazil and France, the twenty products with most trade weight, examined at a six-digit disaggregation level, represent $41.6 \%$ of this type of trade (Table 5.7). In terms of intra-industrial trade, there is a clear predominance of 
low GLI figures, indicating a low intra-industrial character. Only two exceptions regarding two products are found: Parts of airplanes or helicopters (code 880330) and Parts of motors (code 840991), with GLIs over 0.60 , indicating a notable volume of intra-sectorial exchanges.

Table 5.6. Intra-industrial trade in the 20 main products (6-digit classification) in Brazil's bilateral trade with Spain. Grubel-Lloyd Index. Average 1993-2013

\begin{tabular}{|c|c|c|}
\hline $\begin{array}{c}\text { Product } \\
\text { (6-digit HS2012 code) }\end{array}$ & $\begin{array}{l}\text { Trade } \\
\text { weight (\%) } \\
\text { average } \\
1993-2013\end{array}$ & $\begin{array}{l}\text { GLI } \\
\text { average } \\
1993- \\
2013\end{array}$ \\
\hline $\begin{array}{l}230400 \text { (Oil-cake and other solid residues, whether or not ground or in the } \\
\text { form of pellets, resulting from the extraction of soybean oil) }\end{array}$ & $4.2 \%$ & 0.00 \\
\hline 270900 (Petroleum oils and oils obtained from bituminous minerals, crude) & $3.8 \%$ & 0.00 \\
\hline 120190 (Other soya beans, whether or not broken) & $3.2 \%$ & 0.00 \\
\hline $\begin{array}{l}260111 \text { (Iron ores and concentrates, other than roasted iron pyrites / Non- } \\
\text { agglomerated) }\end{array}$ & $3.1 \%$ & 0.00 \\
\hline 90111 (Coffee, not roasted, not decaffeinated) & $2.9 \%$ & 0.00 \\
\hline 100590 (Maize except seed corn) & $2.4 \%$ & 0.00 \\
\hline $\begin{array}{l}260112 \text { (Iron ores and concentrates, other than roasted iron pyrites / Non- } \\
\text { agglomerated) }\end{array}$ & $2.3 \%$ & 0.00 \\
\hline 260300 (Copper ores and concentrates) & $1.6 \%$ & 0.00 \\
\hline $\begin{array}{l}271019 \text { (Petroleum oils and oils obtained from bituminous minerals, other than } \\
\text { crude; preparations not elsewhere specified or included, containing by weight } \\
70 \% \text { or more of petroleum oils or of oils obtained from bituminous minerals, } \\
\text { these oils being the basic constituents of the preparations, other than those } \\
\text { containing biodiesel and other than waste oils: Other: Distillate and residual } \\
\text { fuel oils) }\end{array}$ & $1.4 \%$ & 0.05 \\
\hline 20714 (Frozen cuts and offal of fowl of the species gallus domesticus) & $1.1 \%$ & 0.00 \\
\hline 20714 (Trozos y despojos, congelados de aves de la especie Gallus domesticus) & $1,1 \%$ & 0,00 \\
\hline $\begin{array}{l}870899 \text { (Other parts and accessories of the motor vehicles of headings Nos. } \\
87.01 \text { to } 87.05 \text { ) }\end{array}$ & $1.0 \%$ & 0.30 \\
\hline $\begin{array}{l}300490 \text { (Medicaments (excluding goods of heading No. } 30.02,30.05 \text { or } 30.06 \text { ) } \\
\text { consisting of mixed or unmixed products for therapeutic or prophylactic uses, } \\
\text { put up in measured doses (including those intended for administration by } \\
\text { trans...) }\end{array}$ & $0.9 \%$ & 0.10 \\
\hline $\begin{array}{l}880240 \text { (Aeroplanes and other aircraft, of an unladen weight exceeding 15,000 } \\
\mathrm{kg} \text { ) }\end{array}$ & $0.9 \%$ & 0.09 \\
\hline 20230 (Meat of bovine animals, frozen / boneless) & $0.9 \%$ & 0.00 \\
\hline 310420 Mineral or chemical fertilizers, potassic & $0,8 \%$ & 0,00 \\
\hline / Potassium chloride & $0.8 \%$ & 0.00 \\
\hline $\begin{array}{l}860310 \text { (Self-propelled railway or tramway coaches, vans and trucks, other } \\
\text { than those of heading No. } 86.04 \text { / Powered from an external source of } \\
\text { electricity) }\end{array}$ & $0.8 \%$ & 0.09 \\
\hline $\begin{array}{l}470329 \text { (Pulp of wood/of other fibrous cellulosic material; waste etc. Chem } \\
\text { wood pulp, soda/sulphate, other than dissolving // Semi-bleached or bleached } \\
\text { // Non-coniferous) }\end{array}$ & $0.7 \%$ & 0.00 \\
\hline 720110 (Non-alloy pig iron containing by weight $0.5 \%$ or less of phosphorus) & $0.7 \%$ & 0.02 \\
\hline Subtotal & $38.9 \%$ & \\
\hline
\end{tabular}


Table 5.7. Intra-industrial trade in the 20 main products (6-digit classification) in Brazil's bilateral trade with France. Grubel-Lloyd Index. Average 1993-2013

\begin{tabular}{|c|c|c|}
\hline $\begin{array}{c}\text { Product } \\
\text { (6-digit HS2012 code) }\end{array}$ & $\begin{array}{l}\text { Trade } \\
\text { weight (\%) } \\
\text { average } \\
1993-2013\end{array}$ & $\begin{array}{l}\text { GLI } \\
\text { average } \\
1993- \\
2013\end{array}$ \\
\hline $\begin{array}{l}230400 \text { (Oil-cake and other solid residues, whether or not ground or in the } \\
\text { form of pellets, resulting from the extraction of soybean oil) }\end{array}$ & $10.6 \%$ & 0.00 \\
\hline $\begin{array}{l}260111 \text { (Iron ores and concentrates, other than roasted iron pyrites / Non- } \\
\text { agglomerated) }\end{array}$ & $5.7 \%$ & 0.00 \\
\hline 880330 (Parts of aeroplanes or helicopters) & $2.8 \%$ & 0.62 \\
\hline 270900 (Petroleum oils and oils obtained from bituminous minerals, crude) & $2.6 \%$ & 0.00 \\
\hline 90111 (Coffee, not roasted, not decaffeinated) & $1.8 \%$ & 0.00 \\
\hline $\begin{array}{l}300490 \text { (Other medicaments (excluding goods of heading No. } 30.02,30.05 \text { or } \\
30.06 \text { ) consisting of mixed or unmixed products for therapeutic or prophylac- } \\
\text { tic uses, put up in measured doses (including those intended for administra- } \\
\text { tion by trans...) }\end{array}$ & $1.8 \%$ & 0.02 \\
\hline $\begin{array}{l}470329 \text { (Pulp of wood/of other fibrous cellulosic material; waste etc. Chem } \\
\text { wood pulp, soda/sulphate, other than dissolving // Semi-bleached or } \\
\text { bleached // Non-coniferous) }\end{array}$ & $1.7 \%$ & 0.00 \\
\hline $\begin{array}{l}870829 \text { (Other parts and accessories of bodies (including cabs) of the motor } \\
\text { vehicles of headings Nos. } 87.01 \text { to } 87.05 \text { ) }\end{array}$ & $1.7 \%$ & 0.06 \\
\hline $\begin{array}{l}880240 \text { (Aeroplanes and other aircraft, of an unladen weight exceeding } \\
15,000 \mathrm{~kg} \text { ) }\end{array}$ & $1.6 \%$ & 0.14 \\
\hline $\begin{array}{l}260112 \text { (Iron ores and concentrates, other than roasted iron pyrites / Non- } \\
\text { agglomerated) }\end{array}$ & $1.3 \%$ & 0.00 \\
\hline $\begin{array}{l}293319 \text { (Other compounds containing an unfused pyridine ring (whether or } \\
\text { not hydrogenated) in the structure) }\end{array}$ & $1.2 \%$ & 0.01 \\
\hline $\begin{array}{l}870323 \text { (Other vehicles, with spark-ignition internal combustion reciprocating } \\
\text { piston engine, of a cylinder capacity exceeding } 1,500 \mathrm{cc} \text { but not exceeding } \\
3,000 \mathrm{cc} \text { ) }\end{array}$ & $1.2 \%$ & 0.03 \\
\hline $\begin{array}{l}870899 \text { (Other parts and accessories of the motor vehicles of headings Nos. } \\
87.01 \text { to } 87.05 \text { ) }\end{array}$ & $1.2 \%$ & 0.24 \\
\hline 300220 (Vaccines for human medicine) & $1.2 \%$ & 0.01 \\
\hline $\begin{array}{l}880230 \text { (Aeroplanes and other aircraft, of an unladen weight exceeding } \\
15,000 \mathrm{~kg} \text { ) }\end{array}$ & $1.0 \%$ & 0.02 \\
\hline 882012 (Helicopters of an unladen weight exceeding 2,000 kg) & $1.0 \%$ & 0.00 \\
\hline $\begin{array}{l}840991 \text { (Other parts suitable for use solely or principally with the engines of } \\
\text { heading No. } 84.07 \text { or } 84.08 \text { suitable for use solely or principally with } \\
\text { spark-ignition internal combustion piston engines) }\end{array}$ & $0.9 \%$ & 0.68 \\
\hline $\begin{array}{l}870840 \text { (Gear boxes and their parts of the motor vehicles of headings Nos. } \\
87.01 \text { to } 87.05 \text { ) }\end{array}$ & $0.9 \%$ & 0.09 \\
\hline 292690 (Nitrile-function compounds, nes) & $0.8 \%$ & 0.01 \\
\hline $\begin{array}{l}260200 \text { (Manganese ores and concentrates, including ferruginous manganese } \\
\text { ores and concentrates with a manganese content of } 20 \% \text { or more, calculated } \\
\text { on the dry weight) }\end{array}$ & $0.7 \%$ & 0.01 \\
\hline Subtotal & $41.6 \%$ & \\
\hline
\end{tabular}

In the case of bilateral trade between Brazil and Italy, the twenty products at a six-digit disaggregation level with most trade weight represent a little over a third (35.3\%) of this trade (Table 5.8). Analysis of intra-industrial trade shows a clear predominance of low GLI figures, including many equal to zero, which indicates a mainly inter-industrial character. 
The only exception found is regarding Parts of motors (code 840999), with a GLI equal to 0.50 .

Table 5.8. Intra-industrial trade in the 20 main products (6-digit classification) in Brazil's bilateral trade with Italy. Grubel-Lloyd Index. Average 1993-2013

\begin{tabular}{|c|c|c|}
\hline $\begin{array}{c}\text { Product } \\
\text { (6-digit HS2012 code) }\end{array}$ & $\begin{array}{l}\text { Trade } \\
\text { weight (\%) } \\
\text { average 1993- } \\
2013\end{array}$ & $\begin{array}{l}\text { GLI } \\
\text { average } \\
1993- \\
2013\end{array}$ \\
\hline 90111 (Coffee, not roasted, not decaffeinated) & $5.5 \%$ & 0.00 \\
\hline $\begin{array}{l}260112 \text { (Iron ores and concentrates, other than roasted iron pyrites / Non- } \\
\text { agglomerated) }\end{array}$ & $4.2 \%$ & 0.00 \\
\hline $\begin{array}{l}470329 \text { (Pulp of wood/of other fibrous cellulosic material; waste etc. Chem } \\
\text { wood pulp, soda/sulphate, other than dissolving // Semi-bleached or } \\
\text { bleached // Non-coniferous) }\end{array}$ & $3.7 \%$ & 0.00 \\
\hline $\begin{array}{l}260111 \text { (Iron ores and concentrates, other than roasted iron pyrites / Non- } \\
\text { agglomerated) }\end{array}$ & $3.7 \%$ & 0.00 \\
\hline $\begin{array}{l}230400 \text { (Oil-cake and other solid residues, whether or not ground or in the } \\
\text { form of pellets, resulting from the extraction of soybean oil) }\end{array}$ & $2.2 \%$ & 0.00 \\
\hline $\begin{array}{l}410411 \text { (Bovine (including buffalo) or equine hides and leather, without hair } \\
\text { on, whether or not split but not further prepared) }\end{array}$ & $1.8 \%$ & 0.03 \\
\hline $\begin{array}{l}870899 \text { (Other parts and accessories of the motor vehicles of headings Nos. } \\
87.01 \text { to } 87.05 \text { ) }\end{array}$ & $1.5 \%$ & 0.30 \\
\hline 20230 (Meat of bovine animals, frozen / boneless) & $1.5 \%$ & 0.00 \\
\hline $\begin{array}{l}870323 \text { (Other vehicles, with spark-ignition internal combustion } \\
\text { reciprocating piston engine, of a cylinder capacity exceeding } 1,500 \mathrm{cc} \text { but } \\
\text { not exceeding } 3,000 \mathrm{cc} \text { ) }\end{array}$ & $1.4 \%$ & 0.32 \\
\hline 410712 (Whole hides and skins) & $1.1 \%$ & 0.01 \\
\hline $\begin{array}{l}847989 \text { (Machines and mechanical appliances having individual functions, } \\
\text { not specified or included elsewhere in Ch. 84). }\end{array}$ & $1.1 \%$ & 0.04 \\
\hline $\begin{array}{l}870829 \text { (Other parts and accessories of bodies (including cabs) of the motor } \\
\text { vehicles of headings Nos. } 87.01 \text { to } 87.05 \text { ) }\end{array}$ & $1.0 \%$ & 0.22 \\
\hline $\begin{array}{l}840999 \text { (Other parts suitable for use solely or principally with the engines of } \\
\text { heading No. } 84.07 \text { or } 84.08 \text {.) }\end{array}$ & $1.0 \%$ & 0.50 \\
\hline $\begin{array}{l}271019 \text { (Petroleum oils and oils obtained from bituminous minerals, other } \\
\text { than crude; preparations not elsewhere specified or included, containing by } \\
\text { weight } 70 \% \text { or more of petroleum oils or of oils obtained from bituminous } \\
\text { minerals, these oils being the basic constituents of the preparations, other } \\
\text { than those containing biodiesel and other than waste oils: Other) }\end{array}$ & $0.9 \%$ & 0.31 \\
\hline $\begin{array}{l}870421 \text { (Other vehicles with compression-ignition internal combustion } \\
\text { piston engine (diesel or semi-diesel) / g.v.w. not exceeding } 5 \text { tonnes) }\end{array}$ & $0.9 \%$ & 0.11 \\
\hline $\begin{array}{l}300490 \text { (Medicaments (excluding goods of heading No. } 30.02,30.05 \text { or } \\
30.06 \text { ) consisting of mixed or unmixed products for therapeutic or } \\
\text { prophylactic uses, put up in measured doses (including those intended for } \\
\text { administration by trans...) }\end{array}$ & $0.9 \%$ & 0.02 \\
\hline $\begin{array}{l}880240 \text { (Aeroplanes and other aircraft, of an unladen weight exceeding } \\
15,000 \mathrm{~kg} \text { ) }\end{array}$ & $0.8 \%$ & 0.00 \\
\hline 841430 (Compressors of a kind used in refrigerating equipment) & $0.7 \%$ & 0.09 \\
\hline $\begin{array}{l}842240 \text { (Other packing or wrapping machinery (including heat-shrink } \\
\text { wrapping machinery) }\end{array}$ & $0.7 \%$ & 0.22 \\
\hline $\begin{array}{l}842230 \text { (Machinery for filling, closing, sealing, or labelling bottles, cans, } \\
\text { boxes, bags or other containers; machinery for capsuling bottles, jars, tubes } \\
\text { and similar containers; machinery for aerating beverages) }\end{array}$ & $0.7 \%$ & 0.04 \\
\hline Subtotal & $35.3 \%$ & \\
\hline
\end{tabular}


With regard to bilateral trade between Brazil and the Netherlands, the twenty products in six-digit disaggregation with most trade weight, represent almost two-thirds (60.2\%) of this trade, which shows a high level of sectorial concentration (Table 5.9). The result of analysis of intra-industrial trade is GLI values of zero or near zero, indicating net interindustrial insertion.

Table 5.9. Intra-industrial trade in the 20 main products (6-digit classification) in Brazil's bilateral trade with the Netherlands. Grubel-Lloyd Index. Average 1993-2013

\begin{tabular}{|c|c|c|}
\hline $\begin{array}{c}\text { Product } \\
\text { (6-digit HS2012 code) }\end{array}$ & $\begin{array}{l}\text { Trade } \\
\text { weight (\%) } \\
\text { average } \\
1993-2013\end{array}$ & $\begin{array}{l}\text { GLI } \\
\text { average } \\
1993- \\
2013\end{array}$ \\
\hline $\begin{array}{l}230400 \text { (Oil-cake and other solid residues, whether or not ground or in the } \\
\text { form of pellets, resulting from the extraction of soybean oil) }\end{array}$ & $13.8 \%$ & 0.00 \\
\hline $\begin{array}{l}271019 \text { (Petroleum oils and oils obtained from bituminous minerals, other than } \\
\text { crude; preparations not elsewhere specified or included, containing by weight } \\
70 \% \text { or more of petroleum oils or of oils obtained from bituminous minerals, } \\
\text { these oils being the basic constituents of the preparations, other than those } \\
\text { containing biodiesel and other than waste oils: Other) }\end{array}$ & $5.3 \%$ & 0.28 \\
\hline $\begin{array}{l}470329 \text { (Pulp of wood/of other fibrous cellulosic material; waste etc. Chem } \\
\text { wood pulp, soda/sulphate, other than dissolving // Semi-bleached or bleached } \\
\text { // Non-coniferous) }\end{array}$ & $5.1 \%$ & 0.00 \\
\hline $\begin{array}{l}260111 \text { (Iron ores and concentrates, other than roasted iron pyrites / Non- } \\
\text { agglomerated) }\end{array}$ & $3.9 \%$ & 0.00 \\
\hline 270900 (Petroleum oils and oils obtained from bituminous minerals, crude) & $3.6 \%$ & 0.01 \\
\hline 200911 (Orange juice / Frozen) & $3.4 \%$ & 0.00 \\
\hline 720293 (Ferro-alloys: Ferro-niobium) & $2.9 \%$ & 0.00 \\
\hline 890520 (Floating or submersible drilling or production platforms) & $2.6 \%$ & 0.00 \\
\hline 830710 (Flexible tubing of base metal, with or without fittings / of iron or steel) & $2.5 \%$ & 0.00 \\
\hline 200919 (Orange juice) & $2.1 \%$ & 0.00 \\
\hline 760110 (Unwrought aluminium, not alloyed) & $2.0 \%$ & 0.01 \\
\hline $\begin{array}{l}848180 \text { (Other appliances for pipes, boiler shells, tanks, vats or the like, } \\
\text { including pressure-reducing valves and thermostatically controlled valves) }\end{array}$ & $1.8 \%$ & 0.11 \\
\hline $\begin{array}{l}271012 \text { (Petroleum oils and oils obtained from bituminous minerals, other than } \\
\text { crude; preparations not elsewhere specified or included, containing by weight } \\
70 \% \text { or more of petroleum oils or of oils obtained from bituminous minerals, } \\
\text { these oils being the basic constituents of the preparations, other than those } \\
\text { containing biodiesel and other than waste oils: Other) }\end{array}$ & $1.8 \%$ & 0.04 \\
\hline $\begin{array}{l}21099 \text { (Meat and edible meat offal, salted, in brine, dried or smoked; edible } \\
\text { flours and meals of meat or meat offal/ Other) }\end{array}$ & $1.7 \%$ & 0.00 \\
\hline 20714 (Frozen cuts and offal of fowl of the species Gallus domesticus) & $1.6 \%$ & 0.00 \\
\hline $\begin{array}{l}220710 \text { (Undenatured ethyl alcohol of an alcoholic strength by volume of } 80 \% \\
\text { vol or higher) }\end{array}$ & $1.5 \%$ & 0.12 \\
\hline 760120 (Unwrought aluminium, alloyed) & $1.2 \%$ & 0.12 \\
\hline $\begin{array}{l}160232 \text { (Other prepared or preserved meat of fowl of the species Gallus } \\
\text { domesticus) }\end{array}$ & $1.2 \%$ & 0.00 \\
\hline 240120 (Tobacco, partly or wholly stemmed/stripped) & $1.1 \%$ & 0.00 \\
\hline $\begin{array}{l}260112 \text { (Iron ores and concentrates, other than roasted iron pyrites / Non- } \\
\text { agglomerated) }\end{array}$ & $1.1 \%$ & 0.00 \\
\hline Subtotal & $60.2 \%$ & \\
\hline
\end{tabular}


In the case of bilateral trade between Brazil and Italy, the twenty products, considering a six-digit disaggregation level, with most trade weight represent $40.6 \%$ of this trade (Table 5.10). Analysis of the intra-industrial trade once again shows a clear predominance of zero or near-zero values of the GLI, showing a basically inter-industrial character. The only exception found is regarding Parts of motors (code 840999), with a GLI equal to 0.59.

\begin{tabular}{|c|c|c|}
\hline $\begin{array}{c}\text { Product } \\
\text { (6-digit HS2012 code) }\end{array}$ & $\begin{array}{l}\text { Trade } \\
\text { weight (\%) } \\
\text { average } \\
1993-2013\end{array}$ & $\begin{array}{l}\text { GLI } \\
\text { average } \\
1993- \\
2013\end{array}$ \\
\hline 710813 (Other semi-manufactured forms of gold) & $6.8 \%$ & 0.00 \\
\hline $\begin{array}{l}260111 \text { (Iron ores and concentrates, other than roasted iron pyrites / Non- } \\
\text { agglomerated) }\end{array}$ & $4.5 \%$ & 0.00 \\
\hline $\begin{array}{l}160250 \text { (Other prepared or preserved meat, meat offal or blood of bovine } \\
\text { animals) }\end{array}$ & $3.3 \%$ & 0.00 \\
\hline $\begin{array}{l}640399 \text { (Footwear with outer soles of rubber, plastics, leather or composition } \\
\text { leather and uppers of leather/ Other) }\end{array}$ & $2.1 \%$ & 0.00 \\
\hline $\begin{array}{l}230400 \text { (Oil-cake and other solid residues, whether or not ground or in the } \\
\text { form of pellets, resulting from the extraction of soyabean oil) }\end{array}$ & $2.1 \%$ & 0.00 \\
\hline 270900 (Petroleum oils and oils obtained from bituminous minerals, crude) & $2.0 \%$ & 0.20 \\
\hline $\begin{array}{l}470329 \text { (Pulp of wood/of other fibrous cellulosic material; waste etc. Chem } \\
\text { wood pulp, soda/sulphate, other than dissolving // Semi-bleached or bleached } \\
\text { // Non-coniferous) }\end{array}$ & $1.9 \%$ & 0.00 \\
\hline $\begin{array}{l}840999 \text { (Other parts suitable for use solely or principally with the engines of } \\
\text { heading No. } 84.07 \text { or } 84.08 \text {.) }\end{array}$ & $1.8 \%$ & 0.59 \\
\hline 380892 (Fungicides) & $1.8 \%$ & 0.00 \\
\hline $\begin{array}{l}300490 \text { (Other medicaments (excluding goods of heading No. } 30.02,30.05 \text { or } \\
30.06 \text { ) consisting of mixed or unmixed products for therapeutic or prophylactic } \\
\text { uses, put up in measured doses (including those intended for administration by } \\
\text { trans...) }\end{array}$ & $1.7 \%$ & 0.02 \\
\hline 240120 (Tobacco, partly or wholly stemmed/stripped) & $1.7 \%$ & 0.00 \\
\hline $\begin{array}{l}840734 \text { (Reciprocating piston engines of a kind used for the propulsion of } \\
\text { vehicles of Ch.87 / Of a cylinder capacity exceeding } 1,000 \mathrm{cc} \text { ) }\end{array}$ & $1.7 \%$ & 0.11 \\
\hline $\begin{array}{l}880230 \text { (Aeroplanes and other aircraft, of an unladen weight exceeding } 2,000 \\
\mathrm{~kg} \text { but less than or equal to } 15,000 \mathrm{~kg} \text { ) }\end{array}$ & $1.6 \%$ & 0.00 \\
\hline 220830 (Whiskies) & $1.5 \%$ & 0.00 \\
\hline $\begin{array}{l}880240 \text { (Aeroplanes and other aircraft, of an unladen weight exceeding 15,000 } \\
\mathrm{kg} \text { ) }\end{array}$ & $1.3 \%$ & 0.00 \\
\hline $\begin{array}{l}260112 \text { (Iron ores and concentrates, other than roasted iron pyrites / Non- } \\
\text { agglomerated) }\end{array}$ & $1.2 \%$ & 0.00 \\
\hline 90111 (Coffee, not roasted, not decaffeinated) & $1.1 \%$ & 0.00 \\
\hline 20714 (Frozen meat cuts and offal of fowl of the species Gallus domesticus) & $0.9 \%$ & 0.00 \\
\hline $\begin{array}{l}480256 \text { (Other paper and paperboard, not containing fibres obtained by a } \\
\text { mechanical process or of which not more than } 10 \% \text { by weight of the total fibre } \\
\text { content consists of such fibres Weighing } 40 \mathrm{~g} / \mathrm{m} 2 \text { or more but not more than } \\
150 \mathrm{~g} / \mathrm{m} 2 \text { ) }\end{array}$ & $0.9 \%$ & 0.00 \\
\hline 200919 (Orange juice) & $0.8 \%$ & 0.00 \\
\hline Subtotal & $40.6 \%$ & \\
\hline
\end{tabular}




\subsection{Patterns in the growth of Mexico's intra-industrial trade with the main European economies}

The previous analysis of the general characteristics of Mexico's trade relations with its main European partners drew a picture with a low presence of the intra-industrial exchanges, although slightly higher than Brazil. Now, it is of interest to explore their growth patterns over recent decades (1993-2013), accepting the methodological recommendations that allow both geographical and aggregation bias to be overcome. In this regard, in this section, Mexico's bilateral trade flows with each of its main European partners are dealt with separately, and the Grubel-Lloyd indices are calculated from the six-digit disaggregated trade information.

\subsubsection{Overview}

In the 1993-2013 period, intra-industrial trade of Mexico with its European partners showed a general growth trend towards stagnation, although with an increasing trend in the particular case of bilateral trade between Mexico and France. This fact is observable in the case of both the uncorrected GLI (GLI global $)(G r a p h$ 5.3) and the corrected GLI $\left(\mathrm{GLi}_{\text {global }}^{*}\right)($ Graph 5.4).

Graph 5.3. Intra-industrial trade in Mexico's bilateral trade with its main European Union partners Uncorrected Grubel-Lloyd index, 1993-2013

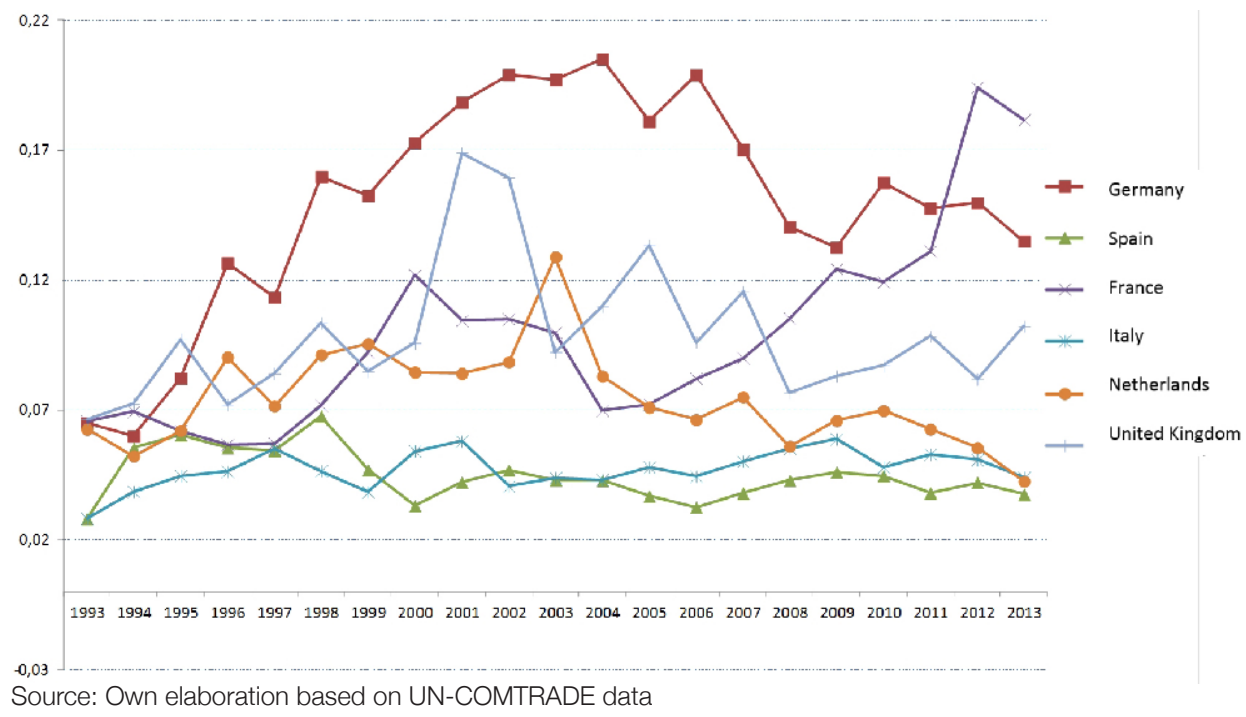

In the case of the corrected index (Graph 5.4.), it can also be seen that there was a greater presence of this type of trade in Mexico's bilateral flows with Germany and 
France, compared with its trade with the United Kingdom, Italy and the Netherlands, and especially Spain, with which Mexico had very low levels intra-industrial trade. With respect to remarkable changes, Germany and Italy stand out, showing a heavy decrease in this index towards the end of the period under consideration.

Graph 5.4. Intra-industrial trade in Mexico's bilateral trade with its main European Union partners Corrected Grubel-Lloyd index, 1993-2013

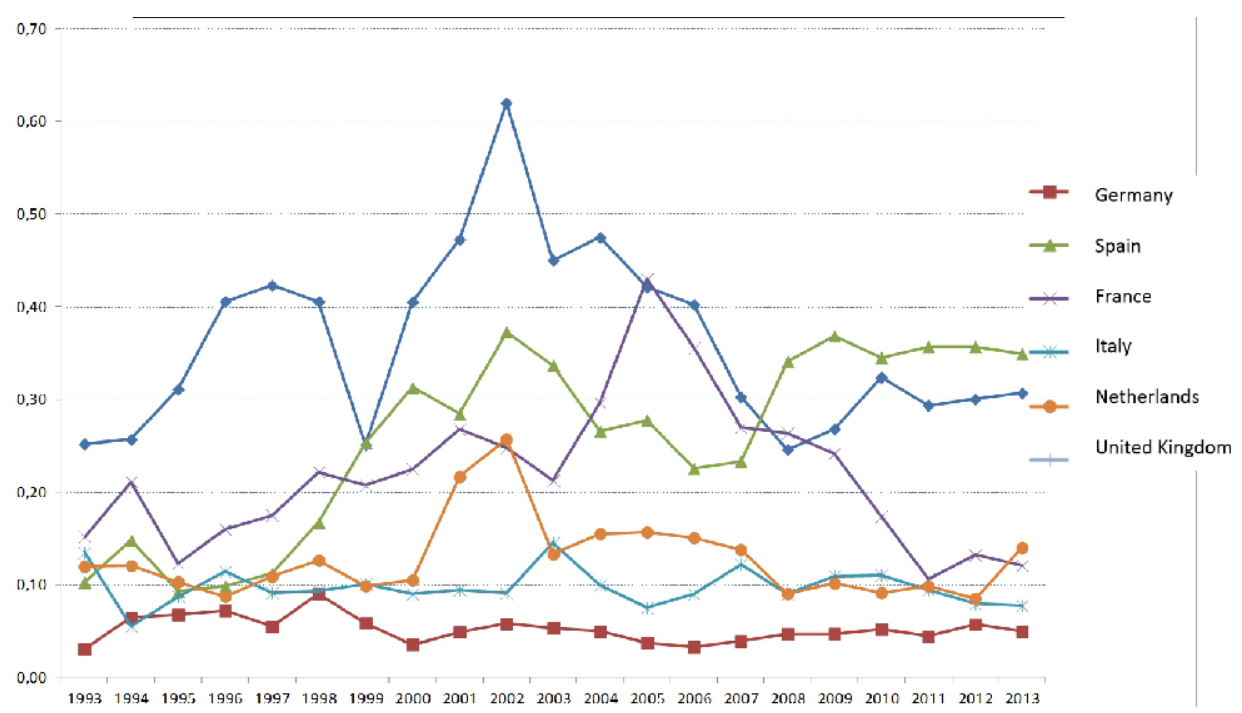

Source: Own elaboration based on UN-COMTRADE data

On the other hand, it is pertinent to note that the general change in the trend previously observed in the case of Brazil does not repeat itself for the Mexican case, which could be due to the different external insertion of the Mexican economy, which is strongly anchored in the United States market and has more stable trade relations with the EU than Brazil. Precisely this greater trade stability in its relations with its European partners could help to explain the persistence of intra-industrial trade levels over the whole period under consideration. 


\subsubsection{Overview disaggregated by product}

As for the case of Brazil, the analysis of intra-industrial trade at a more disaggregated (six digits) level allows us to see to what extent the most relevant products in Mexico's trade with its main European partners coincides or not with the general characterization of low intra-industrial insertion with the EU.

In the specific case of bilateral trade between Mexico and Germany, the twenty products, in six-digit disaggregation, with most trade weight represent two-fifths (40.5\%) of this trade (Table 5.11).

In terms of analysis of intra-industrial trade, very moderate GLI values predominate, which is indicative of a low intra-industrial character. Only three exceptions are worth pointing out: Automobiles (code 870323), Motors for automobiles (code 840734), and Apparatuses or automatic instruments of regulation or control (code 903289), which have GLI figures close to or higher than $50 \%$, indicating a notable volume of intra-sectorial exchanges.

In the case of Mexico's bilateral trade with Spain, the twenty products, at a six-digit disaggregation level, with most trade weight representing $58.9 \%$ of this trade (Table 5.12). Furthermore, it should be stressed that Mexico's crude oil exports (code 270900) acquire an important role. The analysis of the intra-industrial trade in all these exchanges shows a clear predominance of zero or very low values of GLI, which is indicative of an essentially inter-industrial trade pattern.

In the case of bilateral trade between Brazil and France, the twenty products, in six-digit disaggregation, with most trade weight representing nearly a third $(29.6 \%)$ of this trade (Table 5.13). The analysis of intra-industrial trade shows, in this case as well, a general predominance of low GLI figures, with some exceptions with relatively high figures worth mentioning: Parts and material of telephony (code 851770); Parts of turbojets and turboprops (code 841191); and Parts and accessories of automobiles (code 870899). In any case, in general there is a predominance of exchanges in a single direction (intersectorial trade).

In the case of Mexico's bilateral trade with Italy, the twenty products, in six-digit disaggregation, with most trade weight representing a quarter $(24.5 \%)$ of this trade (Table 5.14). The analysis of the trade flows shows a very low intra-industrial trade profile, with most GLIs zero or close to zero, which points to the predominance of exchanges in a single direction (inter-industrial trade). 
Table 5.11. Intra-industrial trade of the 20 main products (6-digit classification) of Mexico's bilateral trade with Germany. Grubel-Lloyd Index. Average 1993-2013

\begin{tabular}{|c|c|c|}
\hline $\begin{array}{c}\text { Product } \\
\text { (6-digit HS2012 code) }\end{array}$ & $\begin{array}{l}\text { Trade } \\
\text { weight (\%) } \\
\text { average } \\
1993-2013\end{array}$ & $\begin{array}{l}\text { GLI } \\
\text { average } \\
1993- \\
2013\end{array}$ \\
\hline $\begin{array}{l}870323 \text { (Other vehicles, with spark-ignition internal combustion } \\
\text { reciprocating piston engine, of a cylinder capacity exceeding } 1,500 \mathrm{cc} \text { but not } \\
\text { exceeding } 3,000 \mathrm{cc} \text { ) }\end{array}$ & $8.4 \%$ & 0.58 \\
\hline $\begin{array}{l}870332 \text { (Other vehicles, with compression-ignition internal combustion piston } \\
\text { engine (diesel or semi-diesel), of a cylinder capacity exceeding } 1,500 \mathrm{cc} \text { but not } \\
\text { exceeding } 2,500 \mathrm{cc} \text { ) }\end{array}$ & $6.8 \%$ & 0.06 \\
\hline $\begin{array}{l}870829 \text { (Other parts and accessories of bodies (including cabs) of the motor } \\
\text { vehicles of headings Nos. } 87.01 \text { to } 87.05 \text { ) }\end{array}$ & $3.6 \%$ & 0.19 \\
\hline $\begin{array}{l}840734 \text { (Reciprocating piston engines of a kind used for the propulsion of } \\
\text { vehicles of Ch. } 87 \text { / Of a cylinder capacity exceeding 1,000 cc) }\end{array}$ & $2.3 \%$ & 0.48 \\
\hline $\begin{array}{l}870840 \text { (Gear boxes and their parts of the motor vehicles of headings Nos. } \\
87.01 \text { to } 87.05)\end{array}$ & $2.1 \%$ & 0.07 \\
\hline $\begin{array}{l}300490 \text { (Other medicaments (excluding goods of heading No. } 30.02,30.05 \text { or } \\
30.06 \text { ) consisting of mixed or unmixed products for therapeutic or prophylactic } \\
\text { uses, put up in measured doses (including those intended for administration by } \\
\text { trans...) }\end{array}$ & $2.0 \%$ & 0.08 \\
\hline $\begin{array}{l}840991 \text { (Other parts suitable for use solely or principally with the engines of } \\
\text { heading No. } 84.07 \text { or } 84.08 \text { suitable for use solely or principally with } \\
\text { spark-ignition internal combustion piston engines) }\end{array}$ & $1.6 \%$ & 0.26 \\
\hline $\begin{array}{l}870899 \text { (Other parts and accessories of the motor vehicles of headings No. } \\
87.01 \text { to 87.05) }\end{array}$ & $1.6 \%$ & 0.21 \\
\hline $\begin{array}{l}847989 \text { (Machines and mechanical appliances having individual functions, not } \\
\text { specified or included elsewhere in Ch. 84). }\end{array}$ & $1.3 \%$ & 0.12 \\
\hline 840820 (Engines of a kind used for the propulsion of vehicles of Ch. 87) & $1.3 \%$ & 0.03 \\
\hline 9999AA (Commodities specified according to kind) & $1.2 \%$ & 0.03 \\
\hline 903289 (Other automatic regulating or controlling instruments and apparatus) & $1.2 \%$ & 0.49 \\
\hline $\begin{array}{l}870324 \text { (Other vehicles, with spark-ignition internal combustion reciprocating } \\
\text { piston engine, of a cylinder capacity exceeding } 3,000 \mathrm{cc} \text { ) }\end{array}$ & $1.2 \%$ & 0.13 \\
\hline 999999 (Commodities not specified according to kind) & $1.1 \%$ & 0.17 \\
\hline $\begin{array}{l}853690 \text { (Other apparatus for switching or protecting electrical circuits, or for } \\
\text { making connections to or in electrical circuits (for example, switches, relays, } \\
\text { fuses, surge suppressors, plugs, sockets, lamp-holders, junction boxes...) }\end{array}$ & $0.9 \%$ & 0.03 \\
\hline $\begin{array}{l}870850 \text { (Parts and accessories of the motor vehicles of headings Nos. } 87.01 \\
\text { to } 87.05 \text {./ Drive-axles with differential, whether or not provided with other } \\
\text { transmission components) }\end{array}$ & $0.9 \%$ & 0.09 \\
\hline $\begin{array}{l}870322 \text { (Other vehicles, with spark-ignition internal combustion reciprocat- } \\
\text { ing piston engine, of a cylinder capacity exceeding } 1,000 \mathrm{cc} \text { but not exceeding } \\
1,500 \mathrm{cc} \text { ) }\end{array}$ & $0.9 \%$ & 0.20 \\
\hline $\begin{array}{l}392690 \text { (Other articles of plastics and articles of other materials of headings } \\
\text { Nos. } 39.01 \text { to } 39.14 \text {.) }\end{array}$ & $0.8 \%$ & 0.10 \\
\hline 842139 (Other filtering or purifying machinery and apparatus for gases) & $0.7 \%$ & 0.18 \\
\hline $\begin{array}{l}853890 \text { (Other parts suitable for use solely or principally with the engines of } \\
\text { heading No. } 85.35,85.36 \text { or } 85.37 \text {.) }\end{array}$ & $0.6 \%$ & 0.07 \\
\hline Subtotal & $40.5 \%$ & \\
\hline
\end{tabular}


Table 5.12. Intra-industrial trade in the 20 main products (6-digit classification) in Mexico's bilateral trade with Spain. Grubel-Lloyd Index. Average 1993-2013

\begin{tabular}{|c|c|c|}
\hline $\begin{array}{c}\text { Product } \\
\text { (6-digit HS2012 code) }\end{array}$ & $\begin{array}{l}\text { Trade } \\
\text { weight (\%) } \\
\text { average } \\
1993-2013\end{array}$ & $\begin{array}{l}\text { GLI } \\
\text { average } \\
1993- \\
2013\end{array}$ \\
\hline 270900 (Petroleum oils and oils obtained from bituminous minerals, crude) & $43.8 \%$ & 0.00 \\
\hline $\begin{array}{l}870323 \text { (Other vehicles, with spark-ignition internal combustion } \\
\text { reciprocating piston engine, of a cylinder capacity exceeding } 1,500 \mathrm{cc} \text { but not } \\
\text { exceeding } 3,000 \mathrm{cc} \text { ) }\end{array}$ & $3.2 \%$ & 0.09 \\
\hline $\begin{array}{l}490199 \text { Other printed books, brochures, leaflets and similar printed matter, } \\
\text { whether or not in single sheets) }\end{array}$ & $1.6 \%$ & 0.09 \\
\hline 850231 (Other wind-powered generating sets) & $0.9 \%$ & 0.00 \\
\hline 291736 (Terephthalic acid and its salts) & $0.8 \%$ & 0.00 \\
\hline $\begin{array}{l}690890 \text { (Other glazed ceramic flags and paving, hearth or wall tiles; glazed } \\
\text { ceramic mosaic cubes and the like, whether or not on a backing) }\end{array}$ & $0.8 \%$ & 0.00 \\
\hline 220820 (Spirits obtained by distilling grape wine or grape marc) & $0.8 \%$ & 0.00 \\
\hline $\begin{array}{l}860310 \text { (Self-propelled railway or tramway coaches, vans and trucks, other } \\
\text { than those of heading No. } 86.04 \text { / Powered from an external source of } \\
\text { electricity) }\end{array}$ & $0.7 \%$ & 0.00 \\
\hline $\begin{array}{l}840734 \text { (Reciprocating piston engines of a kind used for the propulsion of } \\
\text { vehicles of Ch. } 87 \text { / Of a cylinder capacity exceeding } 1,000 \mathrm{cc} \text { ) }\end{array}$ & $0.6 \%$ & 0.06 \\
\hline 71320 (Chickpeas) & $0.6 \%$ & 0.00 \\
\hline $\begin{array}{l}220421 \text { (Other wine; grape must with fermentation prevented or arrested by } \\
\text { the addition of alcohol) }\end{array}$ & $0.6 \%$ & 0.00 \\
\hline 940600 (Prefabricated buildings) & $0.6 \%$ & 0.01 \\
\hline $\begin{array}{l}300490 \text { (Medicaments (excluding goods of heading No. } 30.02,30.05 \text { or } 30.06 \text { ) } \\
\text { consisting of mixed or unmixed products for therapeutic or prophylactic uses, } \\
\text { put up in measured doses (including those intended for administration by } \\
\text { trans...) }\end{array}$ & $0.6 \%$ & 0.02 \\
\hline $\begin{array}{l}262099 \text { (Ash and residues (other than from the manufacturing of iron or steel), } \\
\text { containing metals or metal compounds. }\end{array}$ & $0.6 \%$ & 0.00 \\
\hline 290124 (Unsaturated acyclic hydrocarbons, buta-1,3-diene and isoprene) & $0.5 \%$ & 0.00 \\
\hline 999999 (Commodities not specified according to kind) & $0.5 \%$ & 0.36 \\
\hline $\begin{array}{l}870899 \text { (Other parts and accessories of the motor vehicles of headings No. } \\
87.01 \text { to } 87.05)\end{array}$ & $0.5 \%$ & 0.27 \\
\hline $\begin{array}{l}490290 \text { (Other newspapers, journals and periodicals, whether or not illustrated } \\
\text { or containing advertising material) }\end{array}$ & $0.4 \%$ & 0.02 \\
\hline $\begin{array}{l}847989 \text { (Machines and mechanical appliances having individual functions, not } \\
\text { specified or included elsewhere in Ch. 84). }\end{array}$ & $0.4 \%$ & 0.02 \\
\hline $\begin{array}{l}721632 \text { (Angles, shapes and sections of iron or non-alloy steel/U, I or } \mathrm{H} \\
\text { sections, not further worked than hot-rolled, hot-drawn or extruded of a } \\
\text { height of } 80 \mathrm{~mm} \text { or more/l sections) }\end{array}$ & $0.4 \%$ & 0.03 \\
\hline Subtotal & $58.9 \%$ & \\
\hline
\end{tabular}


Table 5.13. Intra-industrial trade in the 20 main products (6-digit classification) in Mexico's bilateral trade with France. Grubel-Lloyd Index. Average 1993-2013

\begin{tabular}{|c|c|c|}
\hline $\begin{array}{c}\text { Product } \\
\text { (6-digit HS2012 code) }\end{array}$ & $\begin{array}{l}\text { Trade } \\
\text { weight (\%) } \\
\text { average } \\
1993-2013\end{array}$ & $\begin{array}{l}\text { GLI } \\
\text { average } \\
1993- \\
2013\end{array}$ \\
\hline $\begin{array}{l}300490 \text { (Medicaments (excluding goods of heading No. } 30.02,30.05 \text { or } 30.06 \text { ) } \\
\text { consisting of mixed or unmixed products for therapeutic or prophylactic uses, } \\
\text { put up in measured doses (including those intended for administration by trans...) }\end{array}$ & $3.6 \%$ & 0.01 \\
\hline 999999 (Commodities not specified according to kind) & $3.0 \%$ & 0.26 \\
\hline 300220 (Vaccines for human medicine) & $2.6 \%$ & 0.02 \\
\hline 901831 (Syringes, with or without needles) & $2.1 \%$ & 0.07 \\
\hline 330300 (Perfumes and toilet waters) & $2.1 \%$ & 0.01 \\
\hline $\begin{array}{l}840734 \text { (Reciprocating piston engines of a kind used for the propulsion of } \\
\text { vehicles of Ch. } 87 \text { / Of a cylinder capacity exceeding } 1,000 \mathrm{cC} \text { ) }\end{array}$ & $1.6 \%$ & 0.05 \\
\hline $\begin{array}{l}870323 \text { (Other vehicles, with spark-ignition internal combustion reciprocating } \\
\text { piston engine, of a cylinder capacity exceeding 1,500 cc but not exceeding 3,000 } \\
\text { cc) }\end{array}$ & $1.5 \%$ & 0.06 \\
\hline $\begin{array}{l}330499 \text { (Other beauty or make-up preparations and preparations for the care of } \\
\text { the skin (other than medicaments), including sunscreen or sun tan preparations; } \\
\text { manicure or pedicure preparations) }\end{array}$ & $1.5 \%$ & 0.01 \\
\hline $\begin{array}{l}840991 \text { (Other parts suitable for use solely or principally with the engines of } \\
\text { heading No. } 84.07 \text { or } 84.08 \text { suitable for use solely or principally with } \\
\text { sparkignition internal combustion piston engines) }\end{array}$ & $1.5 \%$ & 0.31 \\
\hline $\begin{array}{l}851762 \text { (Machines for the reception, conversion and transmission or regeneration } \\
\text { of voice, images or other data, including switching and routing apparatus) }\end{array}$ & $1.3 \%$ & 0.22 \\
\hline $\begin{array}{l}851770 \text { (Telephone sets, including telephones for cellular networks or for other } \\
\text { wireless networks; other apparatus for the transmission or reception of voice, } \\
\text { images or other data, including apparatus for communication in a wired or wire- } \\
\text { less network (such as a local or wide area network); parts thereof) }\end{array}$ & $1.0 \%$ & 0.65 \\
\hline 841191 (Parts of turbojets or turbopropellers) & $1.0 \%$ & 0.58 \\
\hline $\begin{array}{l}847989 \text { (Machines and mechanical appliances having individual functions, not } \\
\text { specified or included elsewhere in Ch. 84). }\end{array}$ & $1.0 \%$ & 0.08 \\
\hline $\begin{array}{l}847730 \text { (Blow moulding machinery for working rubber or plastics or for the } \\
\text { manufacturing of products from these materials, not specified or included } \\
\text { elsewhere in this Ch.) }\end{array}$ & $0.9 \%$ & 0.01 \\
\hline $\begin{array}{l}293329 \text { (Other compounds containing an unfused pyridine ring (whether or not } \\
\text { hydrogenated) in the structure) }\end{array}$ & $0.9 \%$ & 0.00 \\
\hline $\begin{array}{l}853890 \text { (Other parts suitable for use solely or principally with the engines of } \\
\text { heading No. } 85.35,85.36 \text { or } 85.37 \text {.) }\end{array}$ & $0.9 \%$ & 0.04 \\
\hline 882012 (Helicopters of an unladen weight exceeding 2,000 kg) & $0.9 \%$ & 0.02 \\
\hline $\begin{array}{l}853690 \text { (Other apparatus for switching or protecting electrical circuits, or for } \\
\text { making connections to or in electrical circuits (for example, switches, relays, } \\
\text { fuses, surge suppressors, plugs, sockets, lamp-holders, junction boxes...) }\end{array}$ & $0.8 \%$ & 0.03 \\
\hline $\begin{array}{l}854430 \text { (Ignition wiring sets and other wiring sets of a kind used in vehicles, } \\
\text { aircraft or ships) }\end{array}$ & $0.7 \%$ & 0.05 \\
\hline $\begin{array}{l}870899 \text { (Other parts and accessories of the motor vehicles of headings No. } 87.01 \\
\text { to } 87.05 \text { ) }\end{array}$ & $0.7 \%$ & 0.40 \\
\hline Subtotal & $29.6 \%$ & \\
\hline
\end{tabular}


Table 5.14. Intra-industrial trade in the 20 main products (6-digit classification) in Mexico's bilateral trade with Italy. Grubel-Lloyd Index. Average 1993-2013

\begin{tabular}{|c|c|c|}
\hline $\begin{array}{c}\text { Product } \\
\text { (6-digit HS2012 code) }\end{array}$ & $\begin{array}{l}\text { Trade } \\
\text { weight (\%) } \\
\text { average } \\
1993-2013\end{array}$ & $\begin{array}{l}\text { GLI } \\
\text { average } \\
1993- \\
2013\end{array}$ \\
\hline $\begin{array}{l}721913 \text { (Hot rolled stainless steel coil, } w>600 \mathrm{~mm}(\ldots) \text {, of a thickness of } 3 \mathrm{~mm} \text { or } \\
\text { more but less than } 4.75 \mathrm{~mm} \text { ) }\end{array}$ & $3,4 \%$ & 0,00 \\
\hline $\begin{array}{l}721914 \text { (Hot rolled stainless steel coil, } w>600 \mathrm{~mm}(. . .) \text {, of a thickness of } 3 \mathrm{~mm} \text { or } \\
\text { more but less than } 3 \mathrm{~mm} \text { ) }\end{array}$ & $2,3 \%$ & 0,00 \\
\hline $\begin{array}{l}870332 \text { (Other vehicles, with compression-ignition internal combustion piston } \\
\text { engine (diesel or semi-diesel), of a cylinder capacity exceeding 1,500 cc but not } \\
\text { exceeding } 2,500 \mathrm{cc} \text { ) }\end{array}$ & $1,8 \%$ & 0,00 \\
\hline $\begin{array}{l}842230 \text { (Machinery for filling, closing, sealing, or labelling bottles, cans, boxes, } \\
\text { bags or other containers; machinery for capsuling bottles, jars, tubes and } \\
\text { similar containers; machinery for aerating beverages) }\end{array}$ & $1,7 \%$ & 0,01 \\
\hline $\begin{array}{l}300490 \text { (Other medicaments (excluding goods of heading No. } 30.02,30.05 \text { or } \\
30.06 \text { ) consisting of mixed or unmixed products for therapeutic or prophylactic } \\
\text { uses, put up in measured doses (including those intended for administration by } \\
\text { trans...) }\end{array}$ & $1,4 \%$ & 0,06 \\
\hline 999999 (Commodities not specified according to kind) & $1,4 \%$ & 0,03 \\
\hline $\begin{array}{l}842240 \text { (Other packing or wrapping machinery, including heat-shrink wrapping } \\
\text { machinery) }\end{array}$ & $1,3 \%$ & 0,01 \\
\hline $\begin{array}{l}847989 \text { (Machines and mechanical appliances having individual functions, not } \\
\text { specified or included elsewhere in Ch. 84). }\end{array}$ & $1,3 \%$ & 0,01 \\
\hline 270900 (Petroleum oils and oils obtained from bituminous minerals, crude) & $1,1 \%$ & 0,00 \\
\hline $\begin{array}{l}847480 \text { (Machinery for sorting, screening, separating, washing, crushing, } \\
\text { grinding, mixing or kneading earth, stone, ores or other mineral substances, in } \\
\text { solid (including powder or paste) form; machinery for agglomerating, shaping } \\
\text { or moulding...) }\end{array}$ & $1,0 \%$ & 0,00 \\
\hline $\begin{array}{l}271012 \text { (Petroleum oils and oils obtained from bituminous minerals, other than } \\
\text { crude; preparations not elsewhere specified or included, containing by weight } \\
70 \% \text { or more of petroleum oils or of oils obtained from bituminous minerals, } \\
\text { these oils being the basic constituents of the preparations, other than those } \\
\text { containing biodiesel and other than waste oils: Other) }\end{array}$ & $1,0 \%$ & 0,00 \\
\hline $\begin{array}{l}721912 \text { (Hot rolled stainless steel coil, w }>600 \mathrm{~mm}(\ldots) \text {, of a thickness of } 4.75 \mathrm{~mm} \\
\text { or more but less than } 10 \mathrm{~mm} \text { ) }\end{array}$ & $1,0 \%$ & 0,00 \\
\hline $\begin{array}{l}711319 \text { (Jewellery and parts of other precious metal, whether or not plated or } \\
\text { clad with precious metal) }\end{array}$ & $0,9 \%$ & 0,02 \\
\hline 845521 ( Other rolling mills / Hot or combination hot and cold) & $0,8 \%$ & 0,04 \\
\hline 291736 (Terephthalic acid and its salts) & $0,7 \%$ & 0,00 \\
\hline $\begin{array}{l}293410 \text { (Compounds containing an unfused thiazole ring (whether or not } \\
\text { hydrogenated) in the structure) }\end{array}$ & $0,7 \%$ & 0,00 \\
\hline 848071 (Moulds for rubber or plastics / Injection or compression types) & $0,7 \%$ & 0,09 \\
\hline $\begin{array}{l}392690 \text { (Other articles of plastics and articles of other materials of headings } \\
\text { Nos. } 39.01 \text { to } 39.14 \text {.) }\end{array}$ & $0,6 \%$ & 0,11 \\
\hline 900410 (Sunglasses) & $0,6 \%$ & 0,02 \\
\hline $\begin{array}{l}848180 \text { (Other appliances for pipes, boiler shells, tanks, vats or the like, } \\
\text { including pressure-reducing valves and thermostatically controlled valves) }\end{array}$ & $0,6 \%$ & 0,04 \\
\hline Subtotal & $24.5 \%$ & \\
\hline
\end{tabular}

In the case of Mexico's bilateral trade with the Netherlands, the twenty products, at a six-digit disaggregation level, representover half (55.2\%) of this trade (Table 5.15). Once again, the analysis of the intra-industrial trade shows generally low GLI values, reflecting the preponderance of inter-sectorial (one-way) trade. 
Table 5.15. Intra-industrial trade in the 20 main products (6-digit classification) in Mexico's bilateral trade with the Netherlands. Grubel-Lloyd Index. Average 1993-2013

$$
\begin{gathered}
\text { Product } \\
\text { (6-digit HS2012 code) }
\end{gathered}
$$

\begin{tabular}{|c|c|}
\hline $\begin{array}{c}\text { Trade } \\
\text { weight (\%) }\end{array}$ & $\begin{array}{c}\text { GLI } \\
\text { average }\end{array}$ \\
average & $1993-$ \\
$1993-2013$ & 2013 \\
\hline
\end{tabular}

$16.0 \%$

0.03

271012 (Petroleum oils and oils obtained from bituminous minerals, other than crude; preparations not elsewhere specified or included, containing by weight $70 \%$ or more of petroleum oils or of oils obtained from bituminous minerals, these oils being the basic constituents of the preparations, other than those containing biodiesel and other than waste oils: Other)

851762 (Machines for the reception, conversion and transmission or regeneration of voice, images or other data, including switching and routing apparatus)

270900 (Petroleum oils and oils obtained from bituminous minerals, crude)

851770 (Telephone sets, including telephones for cellular networks or for other wireless networks; other apparatus for the transmission or reception of voice, images or other data, including apparatus for communication in a wired or wireless network (such as a local or wide area network); parts thereof)

847180 (Other units of automatic data processing machines)

999999 (Commodities not specified according to kind)

$2.0 \%$

901839 (Syringes, needles, catheters, cannulae and the like/Other)

$1.9 \%$

0.34

261310 (Molybdenum ores and concentrates)

847330 (Parts and accessories of the machines of heading No. 84.71)

$1.8 \%$

0.00

902620 (Equipment to measure or check pressure)

$1.8 \%$

0.21

$1.6 \%$

0.03

732690 (Other articles of iron or steel)

$1.6 \%$

0.16

847150 (Automatic data processing machines and units thereof; magnetic or optical readers, machines for transcribing data onto data media in coded form and machines for processing such data, not elsewhere specified or included)

870323 (Other vehicles, with spark-ignition internal combustion reciprocating piston engine, of a cylinder capacity exceeding 1,500 cc but not exceeding 3,000 cc)

847170 (Machines for transcribing data onto data media in coded form and machines for processing such data, not elsewhere specified or included/Storage units)

40690 (Other cheese)

60110 (Bulbs, tubers, tuberous roots, corms, crowns and rhizomes, dormant, in 12.12)

120991 (Vegetable seeds)

200911 (Orange juice / Frozen)

$0.9 \%$

0.01

271019 (Petroleum oils and oils obtained from bituminous minerals, other than crude; preparations not elsewhere specified or included, containing by weight

$70 \%$ or more of petroleum oils or of oils obtained from bituminous minerals, these oils being the basic constituents of the preparations, other than those containing biodiesel and other than waste oils: Other)

293723 (Oestrogens and progestogens)

In the case of bilateral trade between Mexico and the United Kingdom, the twenty products, in six-digit disaggregation, with most trade weight represent about two-fifths $(39.8 \%)$ of this trade (Table 5.16$)$. 
The analysis of intra-industrial trade shows that practically all the products considered have predominantly low GLI figures, indicating a predominance of one-way exchanges (inter-sectorial trade). However, exchanges involving Parts and accessories of machines (code 847330) and Parts of engines (code 840999), which have an average GLI of about 0.50 , show different behaviour. Here, a certain presence of two-way exchanges is deduced, showing a profile of intra-industrial trade insertion with the United Kingdom in this type of products in Chapter 84 (mechanical machinery and equipment).

Table 5.16. Intra-industrial trade in the 20 main products (6-digit classification) in Mexico's bilateral trade with the United Kingdom. Grubel-Lloyd Index. Average 1993-2013

\begin{tabular}{|c|c|c|}
\hline $\begin{array}{c}\text { Product } \\
\text { (6-digit HS2012 code) }\end{array}$ & $\begin{array}{l}\text { Trade } \\
\text { weight (\%) } \\
\text { average } \\
\text { 1993-2013 }\end{array}$ & $\begin{array}{l}\text { GLI } \\
\text { average } \\
1993- \\
2013\end{array}$ \\
\hline $\begin{array}{l}710812 \text { (Other gold (including gold plated with platinum) unwrought or in } \\
\text { semi-manufactured forms, or in powder form/ Non-monetary) }\end{array}$ & $9.5 \%$ & 0.03 \\
\hline $\begin{array}{l}300490 \text { (Medicaments (excluding goods of heading No. } 30.02,30.05 \text { or } 30.06 \text { ) } \\
\text { consisting of mixed or unmixed products for therapeutic or prophylactic uses, } \\
\text { put up in measured doses (including those intended for administration by } \\
\text { trans...) }\end{array}$ & $4.1 \%$ & 0.07 \\
\hline 270900 (Petroleum oils and oils obtained from bituminous minerals, crude) & $3.3 \%$ & 0.00 \\
\hline 999999 (Commodities not specified according to kind) & $2.3 \%$ & 0.20 \\
\hline 220830 (Whiskies) & $2.3 \%$ & 0.00 \\
\hline $\begin{array}{l}870323 \text { (Other vehicles, with spark-ignition internal combustion } \\
\text { reciprocating piston engine, of a cylinder capacity exceeding } 1,500 \mathrm{cc} \text { but not } \\
\text { exceeding } 3,000 \mathrm{cc} \text { ) }\end{array}$ & $1.9 \%$ & 0.20 \\
\hline 847330 (Parts and accessories of the machines of heading No. 84.71) & $1.7 \%$ & 0.50 \\
\hline 710691 (Silver, incl. silver plated with gold or platinum, unwrought) & $1.7 \%$ & 0.00 \\
\hline $\begin{array}{l}720712 \text { (Semi-finished products of iron or non-alloy steel }<0.25 \% \mathrm{C} \text { / Other, of } \\
\text { rectangular (other than square) cross-section) }\end{array}$ & $1.7 \%$ & 0.00 \\
\hline $\begin{array}{l}840999 \text { (Other parts suitable for use solely or principally with the engines of } \\
\text { heading No. } 84.07 \text { or } 84.08 \text {.) }\end{array}$ & $1.5 \%$ & 0.47 \\
\hline 840820 (Engines of a kind used for the propulsion of vehicles of Ch. 87) & $1.3 \%$ & 0.04 \\
\hline 851712 (Telephones for cellular networks or for other wireless networks) & $1.2 \%$ & 0.01 \\
\hline 220300 (Beer made from malt) & $1.1 \%$ & 0.01 \\
\hline $\begin{array}{l}851762 \text { (Machines for the reception, conversion and transmission or } \\
\text { regeneration of voice, images or other data, including switching and routing } \\
\text { apparatus) }\end{array}$ & $1.1 \%$ & 0.16 \\
\hline 847180 (Other units of automatic data processing machines) & $1.1 \%$ & 0.26 \\
\hline 901839 (Syringes, needles, catheters, cannulae and the like/Other) & $0.9 \%$ & 0.20 \\
\hline $\begin{array}{l}847170 \text { (Machines for transcribing data onto data media in coded form and } \\
\text { machines for processing such data, not elsewhere specified or } \\
\text { included/ Storage units) }\end{array}$ & $0.8 \%$ & 0.16 \\
\hline 841112 (Turbo-jet engines of a thrust exceeding $25 \mathrm{kN}$ ) & $0.8 \%$ & 0.21 \\
\hline $\begin{array}{l}870899 \text { (Other parts and accessories of the motor vehicles of headings Nos. } \\
87.01 \text { to } 87.05 \text { ) }\end{array}$ & $0.8 \%$ & 0.38 \\
\hline $\begin{array}{l}870324 \text { (Other vehicles, with spark-ignition internal combustion reciprocating } \\
\text { piston engine, of a cylinder capacity exceeding } 3,000 \mathrm{cc} \text { ) }\end{array}$ & $0.7 \%$ & 0.01 \\
\hline Subtotal & $39.8 \%$ & \\
\hline
\end{tabular}




\subsection{Dynamic analysis of Brazil and Mexico's intra-industrial trade with the main European economies}

In the previous sections, we analysed intra-industrial trade from a static perspective. As has been said, the Grubel-Lloyd Index (GLI) is useful to quantify the amount of intraindustrial trade existing in a particular year, as well as for comparison between two or more specific years. Nevertheless, this indicator does not allow intra-industrial trade to be studied from a dynamic point of view, i.e., to analyse to what extent the changes in flows from one year to another are predominantly intra-industrial or if they are, on the contrary, inter-industrial in nature. For this reason, other dynamic indices have been designed, such as Brülhart's marginal intra-industrial trade index (Index A), which was explained with its formulae in the methodological section, and which we use in this section.

\subsubsection{Overview}

Calculation of Brülhart's global index $\left(\mathrm{A}_{\text {global }}\right)$ allows us to find out how far Brazil and Mexico's intra-industrial trade flows with their main European partners have advanced, adding a dynamic perspective to the study of their intra-industrial trade. In this regard, in general, considering the different trade relations, a very moderate advance in bilateral intra-industrial trade was observed. In fact, in most cases (variations in Brazil and Mexico's bilateral trade by country and year), the values of $A_{\text {global }}$ were below 0.08 . This means that the variations undergone in this bilateral trade were essentially inter-industrial in nature, while advances in intra-industrial trade remained relegated to an almost negligible role.

This does not mean there were not certain behaviours which, although they were atypical, are worth pointing out. We refer, in the case of Brazil, for example, to the variations displayed by the United Kingdom and, to a lesser extent, Germany or France in specific years. In the case of Mexico, such exceptions were also seen with respect to its trade with Germany and, to a lesser extent, with France.

In any case, from the perspective of trends and also from the dynamic perspective provided by $\mathrm{A}_{\text {global }}$, the general change of trend in practically all the bilateral trade considered should be stressed. This change shows itself in an initial sequence of increase in the intra-industrial component in the changes undergone by this trade, up to the years when the global crisis appeared, followed by a second sequence in the opposite direction, i.e., reduction of the intra-industrial character of the variations observed in bilateral trade flows. 
Graph 5.5. Advance of Brazil's intra-industrial trade with its main European Union partners. Brülhart's marginal index (1993-2013)

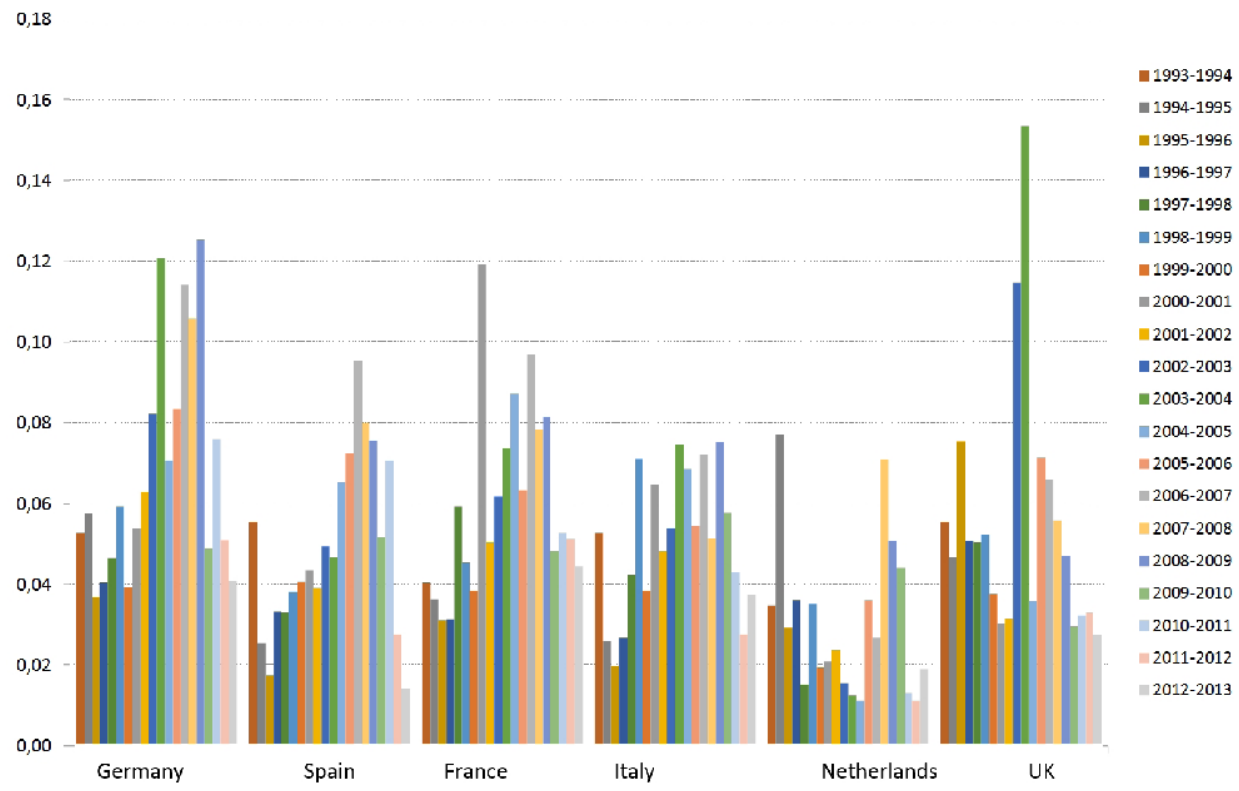

Source: Own elaboration based on UN-COMTRADE data

Graph 5.6. Advance of Mexico's intra-industrial trade with its main European Union partners. Brülhart's marginal index (1993-2013)

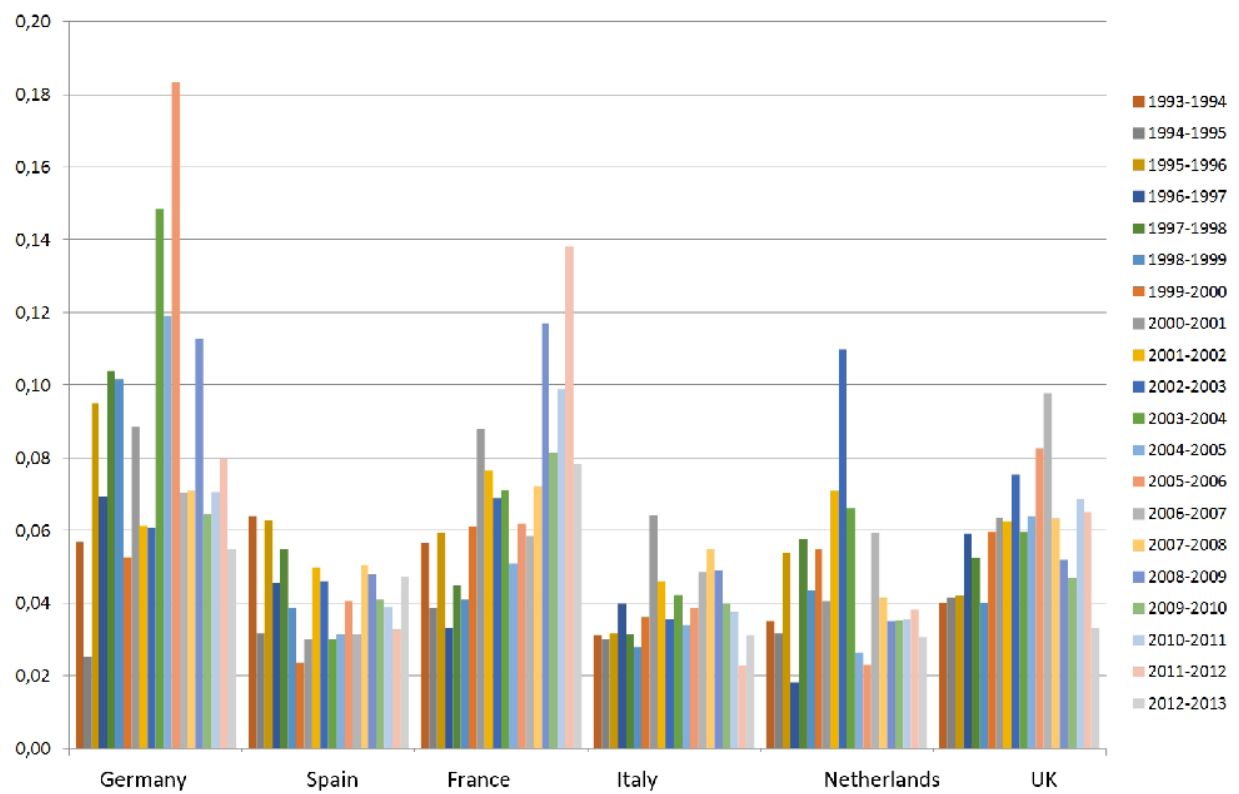

Source: Own elaboration based on UN-COMTRADE data 


\subsubsection{Overview disaggregated by product}

The analysis of the dynamics of intra-industrial trade from a disaggregated sectorial perspective provides a specific view of the patterns followed by the different products comprising Brazil and Mexico's bilateral trade flows with their main European partners that could not be seen in the previous, aggregate analysis. In this regard, we now turn to the analysis of the progress of the intra-industrial component in the main exchanges, concentrating on the behaviour of the main chapters ( 2 digits) and subheadings (6 digits of HS2012 nomenclature) in which this trade was concentrated.

With regard to trade between Brazil and Germany, considering the ten chapters of most trade weight (around $70 \%$ of the total trade flow), the biggest advances in Brülhart's marginal index (average 1993-2013) occurred in the exchanges involving automobiles, iron and steel, organic chemicals, electrical and electronic equipment, machinery and plastics and plastic articles (Graph 5.7). To a much lesser extent, some advances were also seen in exchanges of pharmaceutical products and of optical, photographic, technical, medical, etc. instruments and apparatuses.

Graph 5.7. Progress of intra-industrial trade in the main chapters of Brazil's bilateral trade with Germany. Brülhart's marginal index (A). Average 1993-2013

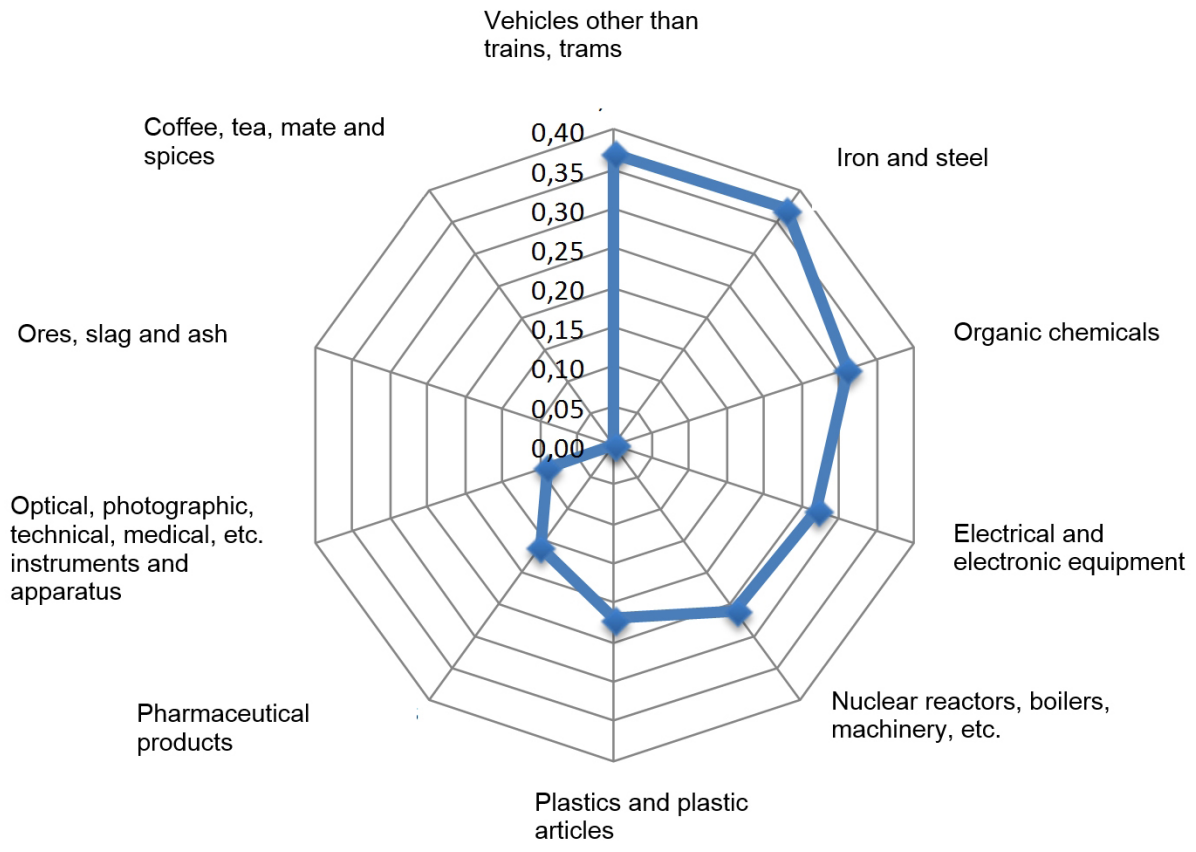


At a greater level of detail (disaggregation to 6 digits of HS2012 nomenclature), it can be seen that only four product types, of the twenty most important in trade, displayed relevant amounts of intra-industrial trade. Three of them corresponded to Chapter 84 (two first figures of the corresponding HS2012 code), mechanical machinery and apparatuses, and one to Chapter 29, organic chemicals. These were Parts for engines (codes 840999 and 840991); Fuel pumps for engines (code 841330); and a particular kind of organic chemical (code 293339; see Table 5.17).

Looking at the ten chapters with most trade weight (a little over $58 \%$ of the total trade flow) in trade between Brazil and Spain, the biggest advances in Brülhart's marginal index, although quite moderate compared with the previous case (Brazil-Germany), took place in exchanges of electrical and electronic equipment; organic chemicals; automobiles; iron and steel; fuels and machinery (Graph 5.8). To a lesser extent, advances in exchanges of aeronautical transport equipment and minerals were also observed.

Applying a more sectorial disaggregation (6 digits of HS2012 nomenclature), the low level of intra-industrial trade in twenty product types of most trade weight can be seen. In this regard and in a context of generally low importance of intra-industrial trade, only a few advances of appreciable size were noticeable in some products related with transport equipment (Ch. 87: automobiles and Ch. 88: aircraft). These were Parts and accessories of automobiles (code 870899); Aircraft (code 880240); and Parts of airplanes or helicopters (code 880330; see Table 5.18). 
Table 5.17. Progress of intra-industrial trade in the main products (HS2012, 6 digits) in Brazil's bilateral trade with Germany. Brülhart's marginal index (A). Average 1993-2013

\begin{tabular}{|c|c|c|}
\hline $\begin{array}{c}\text { Product } \\
\text { (6-digit HS2012 code) }\end{array}$ & $\begin{array}{l}\text { Trade } \\
\text { weight (\%) } \\
\text { average } \\
\text { 1993-2013 }\end{array}$ & $\begin{array}{l}\text { A Index } \\
\text { average } \\
1993- \\
2013\end{array}$ \\
\hline 90111 (Coffee, not roasted, not decaffeinated) & $5.0 \%$ & 0.00 \\
\hline $\begin{array}{l}260111 \text { (Iron ores and concentrates, other than roasted iron } \\
\text { pyrites/Non-agglomerated) }\end{array}$ & $4.5 \%$ & 0.00 \\
\hline $\begin{array}{l}870323 \text { (Other vehicles, with spark-ignition internal combustion } \\
\text { reciprocating piston engine, of a cylinder capacity exceeding } 1,500 \mathrm{cc} \text { but not } \\
\text { exceeding } 3,000 \mathrm{cc} \text { ) }\end{array}$ & $2.7 \%$ & 0.06 \\
\hline $\begin{array}{l}230400 \text { (Oil-cake and other solid residues, whether or not ground or in the } \\
\text { form of pellets, resulting from the extraction of soybean oil) }\end{array}$ & $2.2 \%$ & 0.00 \\
\hline 310420 (Mineral or chemical fertilizers, potassic /Potassium chloride) & $2.1 \%$ & 0.00 \\
\hline $\begin{array}{l}840999 \text { (Other parts suitable for use solely or principally with the engines of } \\
\text { heading No. } 84.07 \text { or } 84.08 \text {.) }\end{array}$ & $2.0 \%$ & 0.48 \\
\hline $\begin{array}{l}260112 \text { (Iron ores and concentrates, other than roasted iron } \\
\text { pyrites/Agglomerated) }\end{array}$ & $1.9 \%$ & 0.00 \\
\hline $\begin{array}{l}870899 \text { (Other parts and accessories of the motor vehicles of headings Nos. } \\
87.01 \text { to } 87.05 \text { ) }\end{array}$ & $1.8 \%$ & 0.08 \\
\hline $\begin{array}{l}300210 \text { (Antisera and other blood fractions and modified immunological } \\
\text { products, whether or not obtained by means of biotechnological processes) }\end{array}$ & $1.2 \%$ & 0.01 \\
\hline 240120 (Tobacco, partly or wholly stemmed/stripped) & $1.2 \%$ & 0.00 \\
\hline $\begin{array}{l}300490 \text { (Medicaments (excluding goods of heading No. } 30.02,30.05 \text { or } 30.06 \text { ) } \\
\text { consisting of mixed or unmixed products for therapeutic or prophylactic uses, } \\
\text { put up in measured doses (including those intended for administration by } \\
\text { trans...) }\end{array}$ & $1.2 \%$ & 0.11 \\
\hline $\begin{array}{l}870322 \text { (Other vehicles, with spark-ignition internal combustion } \\
\text { reciprocating piston engine, of a cylinder capacity exceeding } 1,000 \mathrm{cc} \text { but not } \\
\text { exceeding } 1,500 \mathrm{cc} \text { ) }\end{array}$ & $1.1 \%$ & 0.05 \\
\hline 260300 (Copper ores and concentrates) & $1.0 \%$ & 0.00 \\
\hline $\begin{array}{l}840991 \text { (Other parts suitable for use solely or principally with the engines of } \\
\text { heading No. } 84.07 \text { or } 84.08 \text { suitable for use solely or principally with } \\
\text { spark-ignition internal combustion piston engines) }\end{array}$ & $0.9 \%$ & 0.19 \\
\hline $\begin{array}{l}870840 \text { (Gear boxes and their parts of the motor vehicles of headings No. } 87.01 \\
\text { to } 87.05 \text { ) }\end{array}$ & $0.9 \%$ & 0.10 \\
\hline $\begin{array}{l}847989 \text { (Machines and mechanical appliances having individual functions, not } \\
\text { specified or included elsewhere in Ch.84) }\end{array}$ & $0.8 \%$ & 0.10 \\
\hline $\begin{array}{l}841330 \text { (Fuel, lubricating or cooling medium pumps for internal combustion } \\
\text { piston engines) }\end{array}$ & $0.8 \%$ & 0.29 \\
\hline $\begin{array}{l}870829 \text { (Other parts and accessories of bodies (including cabs) of the motor } \\
\text { vehicles of headings Nos. } 87.01 \text { to } 87.05 \text { ) }\end{array}$ & $0.7 \%$ & 0.10 \\
\hline 903289 (Other automatic regulating or controlling instruments and apparatus) & $0.7 \%$ & 0.04 \\
\hline $\begin{array}{l}293339 \text { (Other compounds containing an unfused pyridine ring (whether or not } \\
\text { hydrogenated) in the structure) }\end{array}$ & $0.6 \%$ & 0.21 \\
\hline Subtotal & $33.3 \%$ & \\
\hline
\end{tabular}


Table 5.18. Progress of intra-industrial trade in the main products (HS2012, 6 digits) in Brazil's bilateral trade with Spain. Brülhart's marginal index (A). Average 1993-2013

\begin{tabular}{|c|c|c|}
\hline $\begin{array}{c}\text { Product } \\
\text { (6-digit HS2012 code) }\end{array}$ & $\begin{array}{l}\text { Trade } \\
\text { weight (\%) } \\
\text { average } \\
1993-2013\end{array}$ & $\begin{array}{l}\text { A Index } \\
\text { average } \\
1993- \\
2013\end{array}$ \\
\hline 880330 (Parts of aeroplanes or helicopters) & $5.4 \%$ & 0.12 \\
\hline $\begin{array}{l}230400 \text { (Oil-cake and other solid residues, whether or not ground or in the } \\
\text { form of pellets, resulting from the extraction of soya bean oil) }\end{array}$ & $4.2 \%$ & 0.00 \\
\hline $\begin{array}{l}270900 \text { (Petroleum oils, oils from bituminous minerals, crude/Petroleum oils } \\
\text { and oils obtained from bituminous minerals, crude) }\end{array}$ & $3.8 \%$ & 0.00 \\
\hline 120190 (Other soya beans, whether or not broken) & $3.2 \%$ & 0.00 \\
\hline $\begin{array}{l}260111 \text { (Iron ores and concentrates, other than roasted iron } \\
\text { pyrites/Non-agglomerated) }\end{array}$ & $3.1 \%$ & 0.02 \\
\hline 90111 (Coffee, not roasted) & $2.9 \%$ & 0.00 \\
\hline 100590 (Maize except seed corn) & $2.4 \%$ & 0.00 \\
\hline $\begin{array}{l}260112 \text { (Iron ores and concentrates, other than roasted iron } \\
\text { pyrites/Non-agglomerated) }\end{array}$ & $2.3 \%$ & 0.00 \\
\hline 260300 (Copper ores and concentrates) & $1.6 \%$ & 0.00 \\
\hline $\begin{array}{l}271019 \text { (Petroleum oils and oils obtained from bituminous minerals, other than } \\
\text { crude; preparations not elsewhere specified or included, containing by weight } \\
70 \% \text { or more of petroleum oils or of oils obtained from bituminous minerals, } \\
\text { these oils being the basic constituents of the preparations, other than those } \\
\text { containing biodiesel and other than waste oils: Other) }\end{array}$ & $1.4 \%$ & 0.12 \\
\hline 20714 (Frozen cuts and offal of fowl of the species Gallus domesticus) & $1.1 \%$ & 0.00 \\
\hline $\begin{array}{l}870899 \text { (Other parts and accessories of the motor vehicles of headings Nos. } \\
87.01 \text { to } 87.05 \text { ) }\end{array}$ & $1.0 \%$ & 0.16 \\
\hline $\begin{array}{l}300490 \text { (Medicaments (excluding goods of heading No. } 30.02,30.05 \text { or } 30.06 \text { ) } \\
\text { consisting of mixed or unmixed products for therapeutic or prophylactic uses, } \\
\text { put up in measured doses (including those intended for administration by } \\
\text { trans...) }\end{array}$ & $0.9 \%$ & 0.14 \\
\hline $\begin{array}{l}880240 \text { (Aeroplanes and other aircraft, of an unladen weight exceeding } \\
15,000 \mathrm{~kg} \text { ) }\end{array}$ & $0.9 \%$ & 0.15 \\
\hline 20230 (Meat of bovine animals, frozen / boneless) & $0.9 \%$ & 0.00 \\
\hline 310420 Mineral or chemical fertilizers, potassic / Potassium chloride & $0.8 \%$ & 0.00 \\
\hline $\begin{array}{l}860310 \text { (Self-propelled railway or tramway coaches, vans and trucks, other } \\
\text { than those of heading No. 86.04, powered from an external source of } \\
\text { electricity) }\end{array}$ & $0.8 \%$ & 0.12 \\
\hline $\begin{array}{l}470329 \text { (Pulp of wood/of other fibrous cellulosic material; waste etc. Chem } \\
\text { wood pulp, soda/sulphate, other than dissolving/Semi-bleached or bleached/ } \\
\text { Non-coniferous) }\end{array}$ & $0.7 \%$ & 0.00 \\
\hline 293090 (Other organo-sulphur compounds) & $0.7 \%$ & 0.00 \\
\hline 720110 (Non-alloy pig iron containing by weight $0.5 \%$ or less of phosphorus) & $0.7 \%$ & 0.00 \\
\hline Subtotal & $38.9 \%$ & \\
\hline
\end{tabular}


Graph 5.8. Progress of intra-industrial trade in the main chapters of Brazil's bilateral trade with Spain. Brülhart's marginal index (A). Average 1993-2013

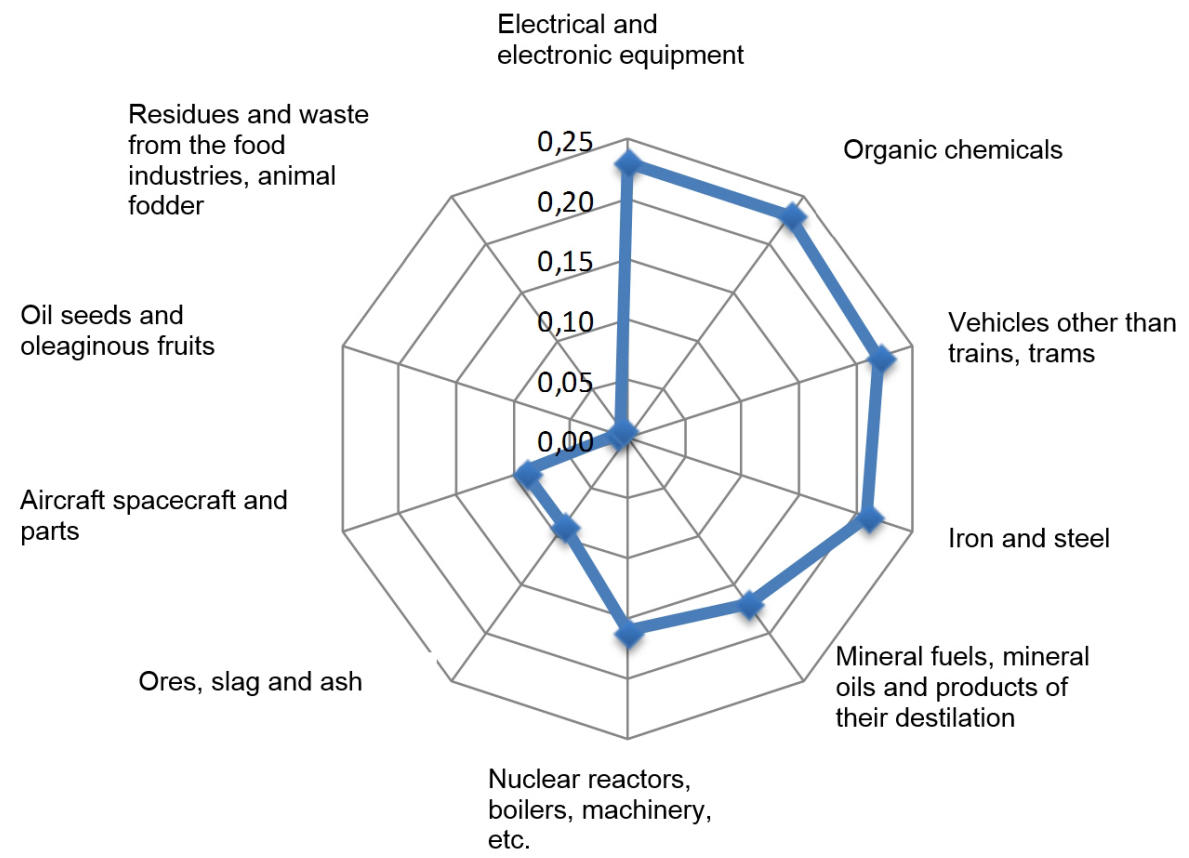

Source: Own elaboration based on UN-COMTRADE data

With regard to the trade between Brazil and France, looking at the ten chapters with most trade weight (about two-thirds of total trade flow), the biggest advances in Brülhart's marginal index (in a context where intra-industrial trade is generally of little importance) were seen in exchanges of organic chemicals, mechanical machinery and equipment, automobiles, electrical and electronic equipment and aircraft (Graph 5.9). To a lesser extent, some progress occurred in exchanges of pharmaceutical products, fuels, and plastics and plastic articles. 
Graph 5.9. Progress of intra-industrial trade in the main chapters of Brazil's bilateral trade with France. Brülhart's marginal index (A). Average 1993-2013

Organic chemicals

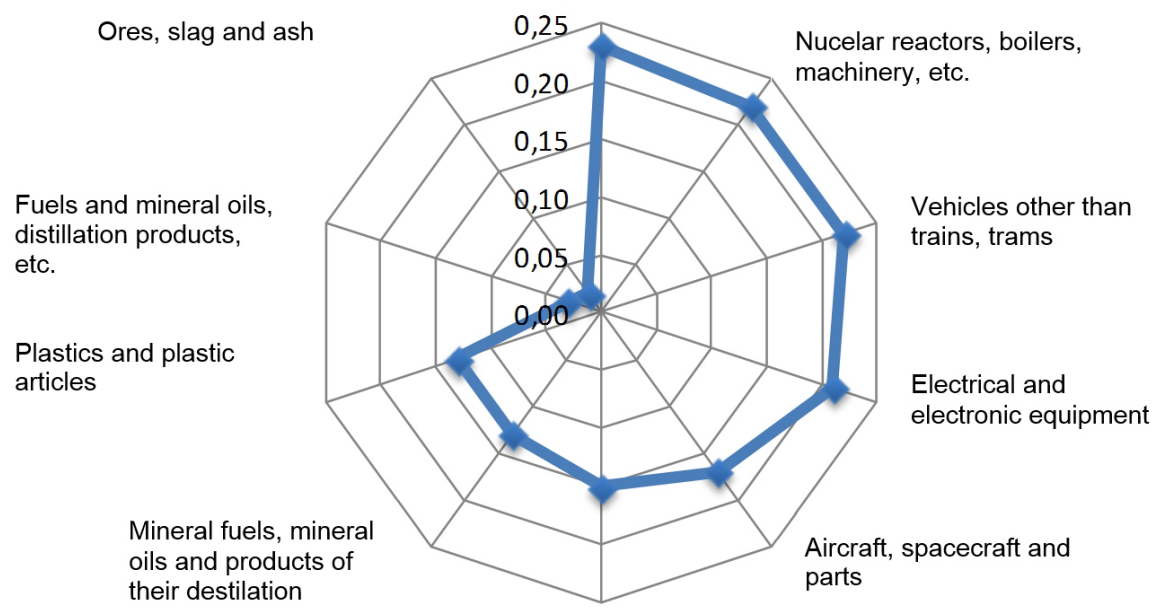

Pharmaceutical products

Source: Own elaboration based on UN-COMTRADE data

Zooming in (disaggregation to HS2012 nomenclature 6 digits), only three types of products, of the twenty most important in trade, displayed relevant progress in terms of intra-industrial trade. Two corresponded to transport equipment and material, specifically Chapters 87 (automobiles) and 88 (aircraft), and one (with the biggest advance) to Chapter 84, mechanical machinery and apparatuses. Specifically, these referred to Parts of airplanes or helicopters (code 880330); Parts and accessories of automobiles (code 870899); and Parts of engines (code 840991; see Table 5.19).

With regard to the ten most important chapters in bilateral trade between Brazil and Italy (about two-thirds of total trade flow), the biggest advances in Brülhart's marginal index (in a context where there is little progress of intra-industrial trade overall) occurred in exchanges of organic chemicals, automobiles, and iron and steel products (Graph 5.10). To a much lesser extent, advances couldbe seen in exchanges of mechanical machinery and equipment and of electrical and electronic equipment. 
Table 5.19. Progress of intra-industrial trade in the main products (HS2012, 6 digits) in Brazil's bilateral trade with France. Brülhart's marginal index (A). Average 1993-2013

\begin{tabular}{|c|c|c|}
\hline $\begin{array}{c}\text { Product } \\
\text { (6-digit HS2012 code) }\end{array}$ & $\begin{array}{l}\text { Trade } \\
\text { weight (\%) } \\
\text { average } \\
1993-2013\end{array}$ & $\begin{array}{l}\text { A Index } \\
\text { average } \\
\text { 1993- } \\
2013\end{array}$ \\
\hline $\begin{array}{l}230400 \text { (Oil-cake and other solid residues, whether or not ground or in the } \\
\text { form of pellets, resulting from the extraction of soya bean oil) }\end{array}$ & $10.6 \%$ & 0.00 \\
\hline $\begin{array}{l}260111 \text { (Iron ores and concentrates, other than roasted iron } \\
\text { pyrites/Non-agglomerated) }\end{array}$ & $5.7 \%$ & 0.00 \\
\hline 880330 (Parts of aeroplanes or helicopters) & $2.8 \%$ & 0.26 \\
\hline 270900 (Petroleum oils and oils obtained from bituminous minerals, crude) & $2.6 \%$ & 0.00 \\
\hline 90111 (Coffee, not roasted) & $1.8 \%$ & 0.00 \\
\hline $\begin{array}{l}300490 \text { (Medicaments (excluding goods of heading No. } 30.02,30.05 \text { or } 30.06 \text { ) } \\
\text { consisting of mixed or unmixed products for therapeutic or prophylactic uses, } \\
\text { put up in measured doses (including those intended for administration by } \\
\text { trans...) }\end{array}$ & $1.8 \%$ & 0.06 \\
\hline $\begin{array}{l}470329 \text { (Pulp of wood/of other fibrous cellulosic material; waste etc. Chem } \\
\text { wood pulp, soda/sulphate, other than dissolving/ Semi-bleached or bleached/ } \\
\text { Non-coniferous) }\end{array}$ & $1.7 \%$ & 0.00 \\
\hline $\begin{array}{l}870829 \text { (Other parts and accessories of bodies (including cabs) of the motor } \\
\text { vehicles of headings Nos. } 87.01 \text { to } 87.05 \text { ) }\end{array}$ & $1.7 \%$ & 0.12 \\
\hline $\begin{array}{l}880240 \text { (Aeroplanes and other aircraft, of an unladen weight exceeding } \\
15,000 \mathrm{~kg} \text { ) }\end{array}$ & $1.6 \%$ & 0.06 \\
\hline $\begin{array}{l}260112 \text { (Iron ores and concentrates, other than roasted iron pyrites/Non- } \\
\text { agglomerated) }\end{array}$ & $1.3 \%$ & 0.00 \\
\hline $\begin{array}{l}293319 \text { (Other compounds containing an unfused pyridine ring (whether or not } \\
\text { hydrogenated) in the structure) }\end{array}$ & $1.2 \%$ & 0.00 \\
\hline $\begin{array}{l}870323 \text { (Other vehicles, with spark-ignition internal combustion } \\
\text { reciprocating piston engine, of a cylinder capacity exceeding } 1,500 \mathrm{cc} \text { but not } \\
\text { exceeding } 3,000 \mathrm{cc} \text { ) }\end{array}$ & $1.2 \%$ & 0.11 \\
\hline $\begin{array}{l}870899 \text { (Other parts and accessories of the motor vehicles of headings Nos. } \\
87.01 \text { to } 87.05 \text { ) }\end{array}$ & $1.2 \%$ & 0.30 \\
\hline 300220 (Vaccines for human medicine) & $1.2 \%$ & 0.02 \\
\hline $\begin{array}{l}880230 \text { (Aeroplanes and other aircraft, of an unladen weight superior to } 2,000 \\
\mathrm{~kg} \text { but inferior or equal to } 15,000 \mathrm{~kg} \text { ) }\end{array}$ & $1.0 \%$ & 0.01 \\
\hline 882012 (Helicopters of an unladen weight exceeding $2,000 \mathrm{~kg}$ ) & $1.0 \%$ & 0.00 \\
\hline $\begin{array}{l}840991 \text { (Other parts suitable for use solely or principally with the engines of } \\
\text { heading No. } 84.07 \text { or } 84.08 \text { suitable for use solely or principally with } \\
\text { spark-ignition internal combustion piston engines) }\end{array}$ & $0.9 \%$ & 0.36 \\
\hline $\begin{array}{l}870840 \text { (Gear boxes and their parts of the motor vehicles of headings Nos. } \\
87.01 \text { to } 87.05 \text { ) }\end{array}$ & $0.9 \%$ & 0.06 \\
\hline 292690 (Other nitrile-function compounds) & $0.8 \%$ & 0.01 \\
\hline $\begin{array}{l}260200 \text { (Manganese ores and concentrates, including ferruginous manganese } \\
\text { ores and concentrates with a manganese content of } 20 \% \text { or more, calculated } \\
\text { on the dry weight.) }\end{array}$ & $0.7 \%$ & 0.00 \\
\hline Subtotal & $41.6 \%$ & \\
\hline
\end{tabular}


Graph 5.10. Progress of intra-industrial trade in the main chapters of Brazil's bilateral trade with Italy. Brülhart's marginal index (A). Average 1993-2013

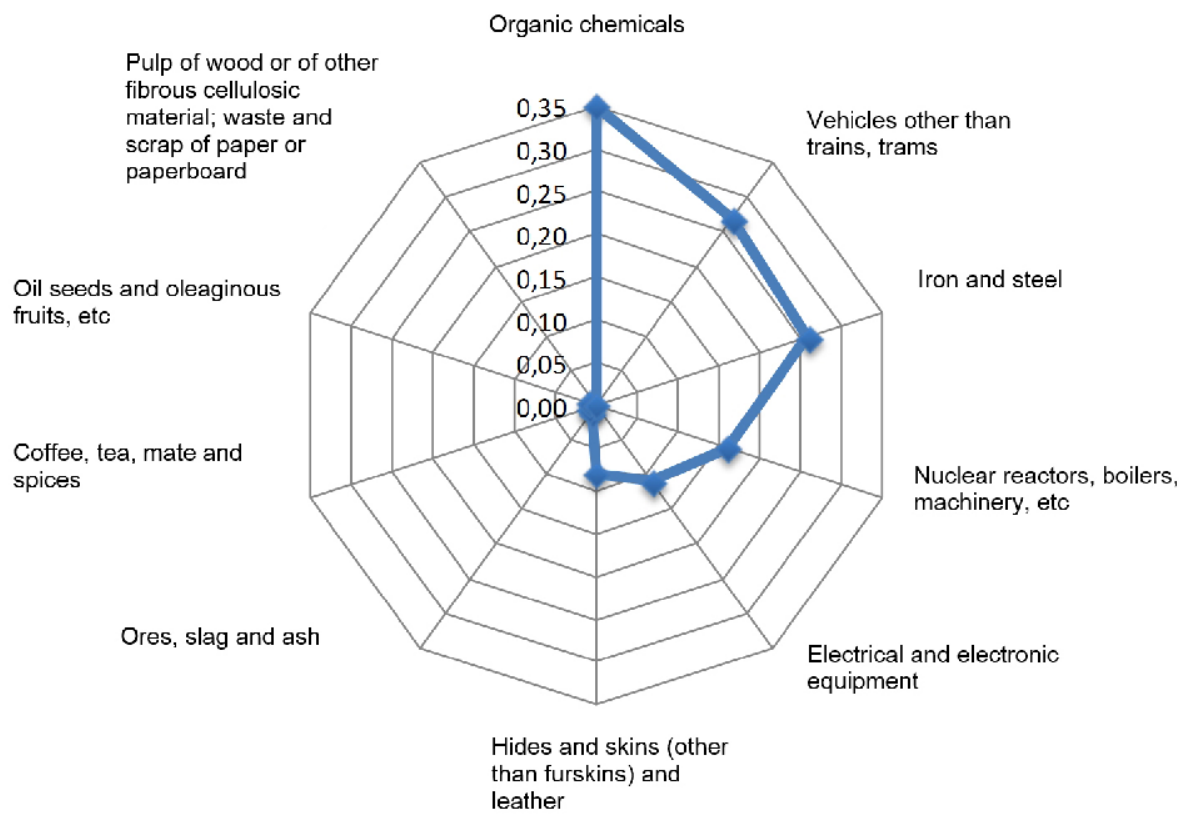

Source: Own elaboration based on UN-COMTRADE data

At a greater level of detail, considering the twenty classes of products of greatest trade weight in agreement with the disaggregation to 6 digits of HS2012 nomenclature, it can be seen that only a very small number of products made appreciable advances in terms of intra-industrial trade. Specifically, these were two products belonging to Chapter 84 (mechanical machinery and equipment), with codes 840999 (Parts of engines) and 842240 (Packing or wrapping machinery); and two products regarding Chapter 87 (automobiles, their parts and accessories), with codes 870323 (automobiles with petrol engine) and 870421 (diesel trucks; see Table 5.20). 
Table 5.20. Progress of intra-industrial trade in the main products (HS2012, 6 digits) in Brazil's bilateral trade with Italy. Brülhart's marginal index (A). Average 1993-2013

\begin{tabular}{|c|c|c|}
\hline $\begin{array}{c}\text { Product } \\
\text { (6-digit HS2012 code) }\end{array}$ & $\begin{array}{l}\text { Trade } \\
\text { weight (\%) } \\
\text { average } \\
1993-2013\end{array}$ & $\begin{array}{l}\text { A Index } \\
\text { average } \\
1993- \\
2013\end{array}$ \\
\hline 90111 (Coffee, not roasted) & $5.5 \%$ & 0.00 \\
\hline $\begin{array}{l}260112 \text { (Iron ores and concentrates, other than roasted iron } \\
\text { pyrites / Agglomerated) }\end{array}$ & $4.2 \%$ & 0.00 \\
\hline $\begin{array}{l}470329 \text { (Pulp of wood/of other fibrous cellulosic material; waste etc. Chem } \\
\text { wood pulp, soda/sulphate, other than dissolving/Semi-bleached or bleached/ } \\
\text { Non-coniferous) }\end{array}$ & $3.7 \%$ & 0.00 \\
\hline $\begin{array}{l}260111 \text { (Iron ores and concentrates, other than roasted iron } \\
\text { pyrites/Non-agglomerated) }\end{array}$ & $3.7 \%$ & 0.00 \\
\hline $\begin{array}{l}230400 \text { (Oil-cake and other solid residues, whether or not ground or in the } \\
\text { form of pellets, resulting from the extraction of soya bean oil) }\end{array}$ & $2.2 \%$ & 0.00 \\
\hline $\begin{array}{l}410411 \text { (Bovine (including buffalo) or equine hides and leather, without hair on, } \\
\text { whether or not split but not further prepared) }\end{array}$ & $1.8 \%$ & 0.11 \\
\hline $\begin{array}{l}870899 \text { (Other parts and accessories of the motor vehicles of } \\
\text { headings Nos. } 87.01 \text { to } 87.05 \text { ) }\end{array}$ & $1.5 \%$ & 0.14 \\
\hline 20230 (Meat of bovine animals, frozen / boneless) & $1.5 \%$ & 0.00 \\
\hline $\begin{array}{l}870323 \text { (Other vehicles, with spark-ignition internal combustion } \\
\text { reciprocating piston engine, of a cylinder capacity exceeding } 1,500 \mathrm{cc} \text { but not } \\
\text { exceeding } 3,000 \mathrm{cc} \text { ) }\end{array}$ & $1.4 \%$ & 0.21 \\
\hline 410712 (Whole hides and skins) & $1.1 \%$ & 0.03 \\
\hline $\begin{array}{l}847989 \text { (Machines and mechanical appliances having individual functions, not } \\
\text { specified or included elsewhere in Ch. 84). }\end{array}$ & $1.1 \%$ & 0.09 \\
\hline $\begin{array}{l}870829 \text { (Other parts and accessories of bodies (including cabs) of the motor } \\
\text { vehicles of headings Nos. } 87.01 \text { to } 87.05 \text { ) }\end{array}$ & $1.0 \%$ & 0.04 \\
\hline $\begin{array}{l}840999 \text { (Other parts suitable for use solely or principally with the engines of } \\
\text { heading No. } 84.07 \text { or } 84.08 \text {.) }\end{array}$ & $1.0 \%$ & 0.44 \\
\hline $\begin{array}{l}271019 \text { (Petroleum oils and oils obtained from bituminous minerals, other than } \\
\text { crude; preparations not elsewhere specified or included, containing by weight } \\
70 \% \text { or more of petroleum oils or of oils obtained from bituminous minerals, } \\
\text { these oils being the basic constituents of the preparations, other than those } \\
\text { containing biodiesel and other than waste oils: Other) }\end{array}$ & $0.9 \%$ & 0.10 \\
\hline $\begin{array}{l}870421 \text { (Other vehicles with compression-ignition internal combustion piston } \\
\text { engine (diesel or semi-diesel)/g.v.w. not exceeding } 5 \text { tonnes) }\end{array}$ & $0.9 \%$ & 0.16 \\
\hline $\begin{array}{l}300490 \text { (Medicaments (excluding goods of heading No. } 30.02,30.05 \text { or } 30.06 \text { ) } \\
\text { consisting of mixed or unmixed products for therapeutic or prophylactic uses, } \\
\text { put up in measured doses (including those intended for administration by } \\
\text { trans...) }\end{array}$ & $0.9 \%$ & 0.01 \\
\hline $\begin{array}{l}880240 \text { (Aeroplanes and other aircraft, of an unladen weight exceeding } \\
15,000 \mathrm{~kg} \text { ) }\end{array}$ & $0.8 \%$ & 0.00 \\
\hline 841430 (Compressors of a kind used in refrigerating equipment) & $0.7 \%$ & 0.04 \\
\hline $\begin{array}{l}842240 \text { (Other packing or wrapping machinery (including heat-shrink } \\
\text { wrapping machinery) }\end{array}$ & $0.7 \%$ & 0.15 \\
\hline $\begin{array}{l}842230 \text { (Machinery for filling, closing, sealing, or labelling bottles, cans, boxes, } \\
\text { bags or other containers; machinery for capsuling bottles, jars, tubes and } \\
\text { similar containers; machinery for aerating beverages) }\end{array}$ & $0.7 \%$ & 0.03 \\
\hline Subtotal & $35.3 \%$ & \\
\hline
\end{tabular}


In the case of trade relations between Brazil and the Netherlands, looking at the ten most important chapters (almost two-thirds of the total bilateral trade), the biggest advances in Brülhart's marginal index were related to exchanges of fuels and machinery and mechanical apparatus, whereas the advances in the other products were much smaller (Graph 5.11).

At a more disaggregated level (6 digits of HS2012 nomenclature), if the twenty most important product classes were considered, advances in terms of intra-industrial trade were barely observable (Table 5.21).

Graph 5.11. Progress of intra-industrial trade in the main chapters of Brazil's bilateral trade with the Netherlands. Brülhart's marginal index (A). Average 1993-2013

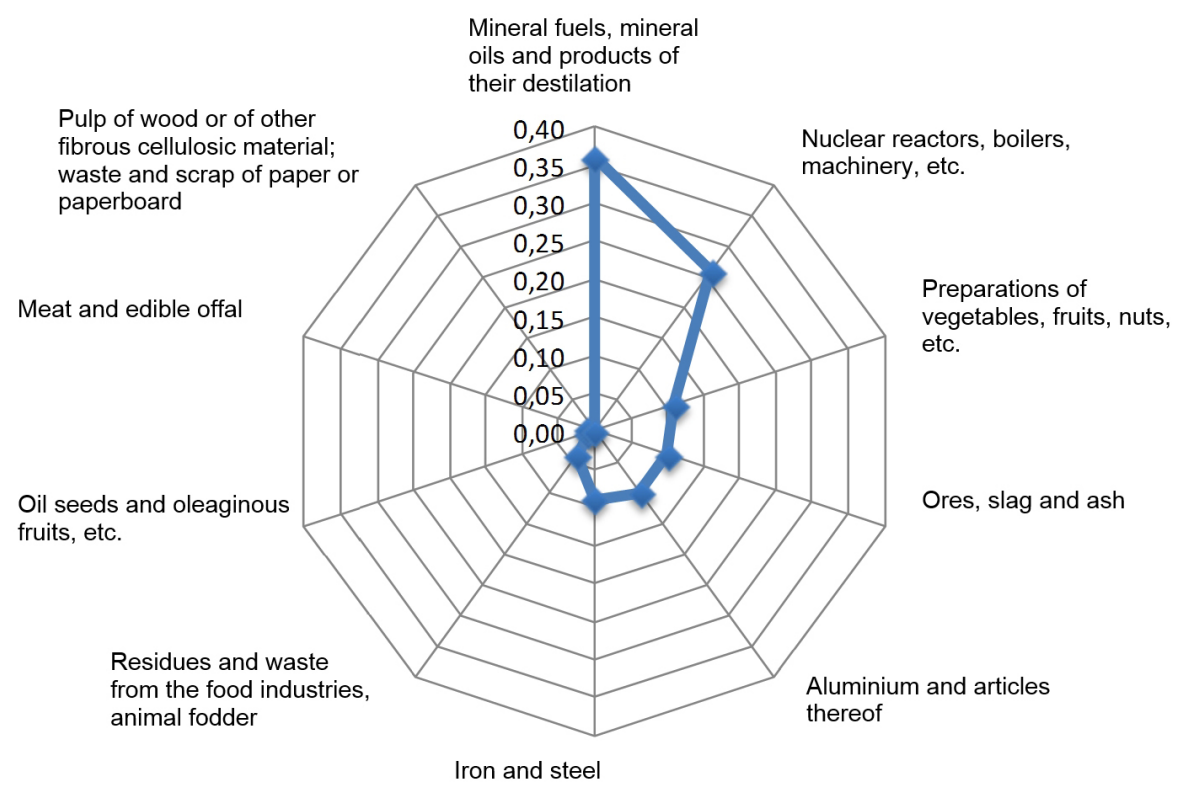

Source: Own elaboration based on UN-COMTRADE data

At most, products with code 271019 (bituminous mineral oils and oils obtained, except oils crude, and preparations expressed nor not included elsewhere, with a content in weight of $70 \%$ or of oils of bituminous mineral more petroleum or oils obtained) can be highlighted as those with the largest advance, but this only means an average of 0.14 for Brülhart's marginal index over the period under consideration (1993-2013). 
Table 5.21. Progress of intra-industrial trade in the main products (HS2012, 6 digits) in Brazil's bilateral trade with the Netherlands. Brülhart's marginal index (A). Average 1993-2013

\begin{tabular}{|c|c|c|}
\hline $\begin{array}{c}\text { Product } \\
\text { (6-digit HS2012 code) }\end{array}$ & $\begin{array}{l}\text { Trade } \\
\text { weight (\%) } \\
\text { average } \\
\text { 1993-2013 }\end{array}$ & $\begin{array}{l}\text { A Index } \\
\text { average } \\
1993- \\
2013\end{array}$ \\
\hline $\begin{array}{l}230400 \text { (Oil-cake and other solid residues, whether or not ground or in the } \\
\text { form of pellets, resulting from the extraction of soya bean oil) }\end{array}$ & $13.8 \%$ & 0.00 \\
\hline $\begin{array}{l}271019 \text { (Petroleum oils and oils obtained from bituminous minerals, other than } \\
\text { crude; preparations not elsewhere specified or included, containing by weight } \\
70 \% \text { or more of petroleum oils or of oils obtained from bituminous minerals) }\end{array}$ & $5.3 \%$ & 0.14 \\
\hline $\begin{array}{l}470329 \text { (Pulp of wood/of other fibrous cellulosic material; waste etc. Chem } \\
\text { wood pulp, soda/sulphate, other than dissolving/Semi-bleached or bleached/ } \\
\text { Non-coniferous) }\end{array}$ & $5.1 \%$ & 0.00 \\
\hline $\begin{array}{l}260111 \text { (Iron ores and concentrates, other than roasted iron } \\
\text { pyrites/Non-agglomerated) }\end{array}$ & $3.9 \%$ & 0.00 \\
\hline 270900 (Petroleum oils and oils obtained from bituminous minerals, crude) & $3.6 \%$ & 0.00 \\
\hline 200911 (Orange juice / Frozen) & $3.4 \%$ & 0.00 \\
\hline 720293 (Ferro-niobium) & $2.9 \%$ & 0.00 \\
\hline 890520 (Floating or submersible drilling or production platforms) & $2.6 \%$ & 0.00 \\
\hline 830710 (Flexible tubing of base metal, with or without fittings / of iron or steel) & $2.5 \%$ & 0.00 \\
\hline 200919 (Orange juice) & $2.1 \%$ & 0.00 \\
\hline 760110 (Unwrought aluminium, not alloyed) & $2.0 \%$ & 0.01 \\
\hline $\begin{array}{l}848180 \text { (Other appliances for pipes, boiler shells, tanks, vats or the like, includ- } \\
\text { ing pressure-reducing valves and thermostatically controlled valves) }\end{array}$ & $1.8 \%$ & 0.11 \\
\hline $\begin{array}{l}271012 \text { (Petroleum oils and oils obtained from bituminous minerals, other than } \\
\text { crude; preparations not elsewhere specified or included, containing by weight } \\
70 \% \text { or more of petroleum oils or of oils obtained from bituminous minerals, } \\
\text { these oils being the basic constituents of the preparations, other than those } \\
\text { containing biodiesel and other than waste oils: Other) }\end{array}$ & $1.8 \%$ & 0.01 \\
\hline 21099 & $1.7 \%$ & 0.00 \\
\hline 20714 (Frozen cuts and offal of fowl of the species Gallus domesticus) & $1.6 \%$ & 0.00 \\
\hline $\begin{array}{l}220710 \text { (Undenatured ethyl alcohol of an alcoholic strength by volume of } 80 \% \\
\text { vol or higher; ethyl alcohol and other spirits, denatured, of any strength...) }\end{array}$ & $1.5 \%$ & 0.07 \\
\hline 760120 (Unwrought aluminium/alloyed) & $1.2 \%$ & 0.01 \\
\hline $\begin{array}{l}160232 \text { (Other prepared or preserved meat, offal or blood of fowl of the } \\
\text { species Gallus domesticus) }\end{array}$ & $1.2 \%$ & 0.00 \\
\hline 240120 (Tobacco, partly or wholly stemmed/stripped) & $1.1 \%$ & 0.00 \\
\hline $\begin{array}{l}260112 \text { (Iron ores and concentrates, other than roasted iron } \\
\text { pyrites / Non-agglomerated) }\end{array}$ & $1.1 \%$ & 0.00 \\
\hline Subtotal & $60,2 \%$ & \\
\hline
\end{tabular}

With regard to the ten most important chapters in bilateral trade between Brazil and the United Kingdom (nearly $60 \%$ of the total trade flow), the biggest advances in Brülhart's marginal index occured in the exchanges related to machinery and mechanical apparatuses (Ch. 84); fuels and mineral oils (Ch. 27); and as well, to a much less extent, aircraft (Ch. 88; see Graph 5.12). Much smaller, with an average below 0.10 , were advances in other chapters, such as pearls and precious stones and metals. 
With greater disaggregation (to 6 digits of HS2012 nomenclature), and focusing the analysis on the twenty most relevant product classes in bilateral trade between Brazil and the United Kingdom, advances were barely observed, pointing to ta profile of little intraindustrial activity (Table 5.22). Only one product class, code 840999 (Parts of engines), is worth pointing out, with an average figure for Brülhart's marginal index of 0.30 over the period 1993-2013.

Graph 5.12. Progress of intra-industrial trade in the main chapters of Brazil's bilateral trade with the United Kingdom. Brülhart's marginal index (A). Average 1993-2013

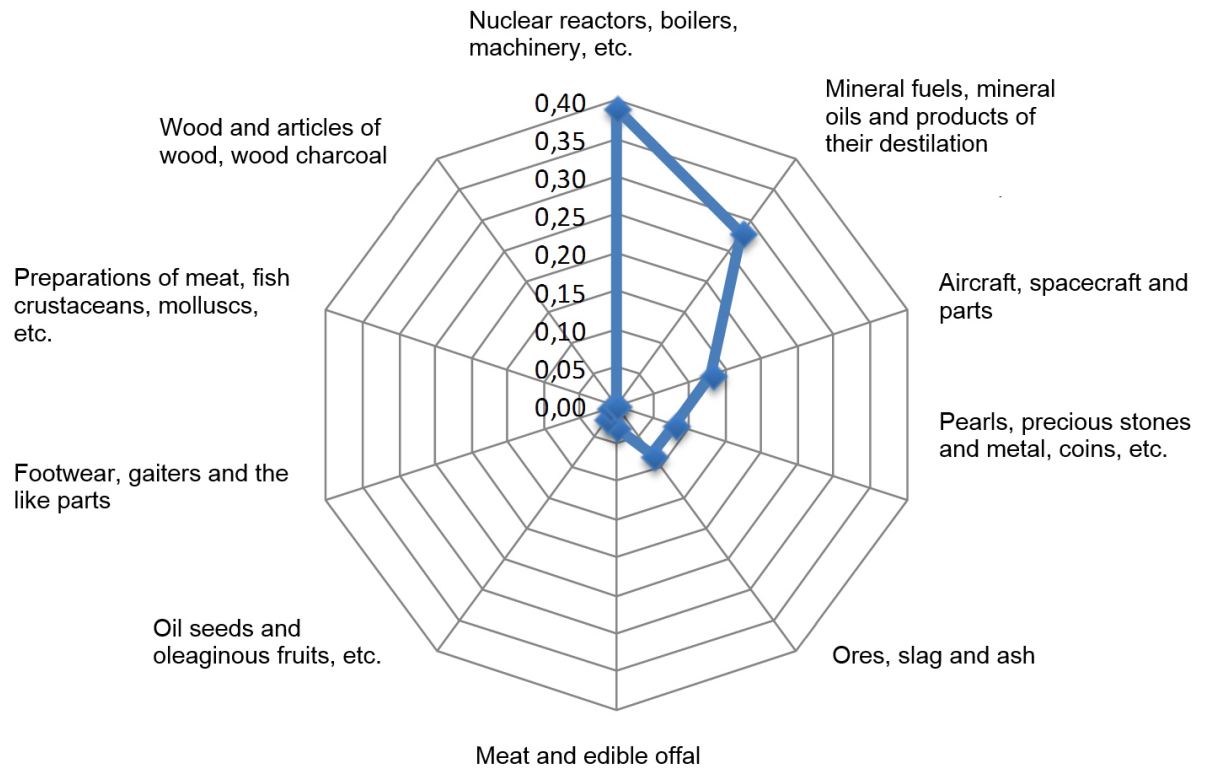

Source: Own elaboration based on UN-COMTRADE data

From a sectorial perspective, the analysis of the bilateral trade between Mexico and Germany draws a picture of a certain intra-industrial activity. Specifically, with regard to the ten chapters which account for a very large part (86\%) of these two countries' bilateral trade, the biggest advances in Brülhart's marginal index occured in the exchanges related to iron and steel products; automobiles; optical, photographic, technical, medical etc. instruments; electrical and electronic equipment; organic chemicals; and mechanical machinery and equipment (Graph 5.13). With rather more moderate advances, pharmaceutical products as well as articles of iron or steel could be mentioned. 
Table 5.22. Progress of intra-industrial trade in the main products (HS2012, 6 digits) in Brazil's bilateral trade with the United Kingdom. Brülhart's marginal index (A). Average 1993-2013

\begin{tabular}{|c|c|c|}
\hline $\begin{array}{c}\text { Product } \\
\text { (6-digit HS2012 code) }\end{array}$ & $\begin{array}{l}\text { Trade } \\
\text { weight (\%) } \\
\text { average } \\
1993-2013\end{array}$ & $\begin{array}{l}\text { A Index } \\
\text { average } \\
1993- \\
2013\end{array}$ \\
\hline $\begin{array}{l}710813 \text { (Other gold (including gold plated with platinum) unwrought or in } \\
\text { semi-manufactured forms, or in powder form/Non-monetary) }\end{array}$ & $6.8 \%$ & 0.00 \\
\hline $\begin{array}{l}260111 \text { (Iron ores and concentrates, other than roasted iron } \\
\text { pyrites/Non-agglomerated) }\end{array}$ & $4.5 \%$ & 0.00 \\
\hline $\begin{array}{l}160250 \text { (Other prepared or preserved meat, meat offal or blood of bovine } \\
\text { animals) }\end{array}$ & $3.3 \%$ & 0.00 \\
\hline $\begin{array}{l}640399 \text { (Footwear with outer soles of rubber, plastics, leather or composition } \\
\text { leather and uppers of leather) }\end{array}$ & $2.1 \%$ & 0.01 \\
\hline $\begin{array}{l}230400 \text { (Oil-cake and other solid residues, whether or not ground or in the } \\
\text { form of pellets, resulting from the extraction of soya bean oil) }\end{array}$ & $2.1 \%$ & 0.00 \\
\hline 270900 (Petroleum oils and oils obtained from bituminous minerals, crude) & $2.0 \%$ & 0.09 \\
\hline $\begin{array}{l}470329 \text { (Pulp of wood/of other fibrous cellulosic material; waste etc. Chem. } \\
\text { wood pulp, soda/sulphate, other than dissolving/Semi-bleached or bleached/ } \\
\text { Non-coniferous) }\end{array}$ & $1.9 \%$ & 0.00 \\
\hline $\begin{array}{l}840999 \text { (Other parts suitable for use solely or principally with the engines of } \\
\text { heading No. } 84.07 \text { or } 84.08 \text {.) }\end{array}$ & $1.8 \%$ & 0.30 \\
\hline 380892 (Fungicides) & $1.8 \%$ & 0.00 \\
\hline $\begin{array}{l}300490 \text { (Other medicaments (excluding goods of heading No. } 30.02,30.05 \text { or } \\
\text { 30.06) consisting of mixed or unmixed products for therapeutic or prophylactic } \\
\text { uses, put up in measured doses (including those intended for administration by } \\
\text { trans...) }\end{array}$ & $1.7 \%$ & 0.03 \\
\hline 240120 (Tobacco, partly or wholly stemmed/stripped) & $1.7 \%$ & 0.01 \\
\hline $\begin{array}{l}840734 \text { (Reciprocating piston engines of a kind used for the propulsion of } \\
\text { vehicles of Ch. } 87 \text { of a cylinder capacity exceeding } 1,000 \mathrm{cc} \text { ) }\end{array}$ & $1.7 \%$ & 0.12 \\
\hline $\begin{array}{l}880230 \text { (Aeroplanes and other aircraft, of an unladen weight superior to } 2,000 \\
\mathrm{~kg} \text { but inferior or equal to } 15,000 \mathrm{~kg} \text { ) }\end{array}$ & $1.6 \%$ & 0.00 \\
\hline 220830 (Whiskies) & $1.5 \%$ & 0.01 \\
\hline $\begin{array}{l}880240 \text { (Aeroplanes and other aircraft, of an unladen weight exceeding } \\
15,000 \mathrm{~kg} \text { ) }\end{array}$ & $1.3 \%$ & 0.00 \\
\hline $\begin{array}{l}260112 \text { (Iron ores and concentrates, other than roasted iron } \\
\text { pyrites/Agglomerated) }\end{array}$ & $1.2 \%$ & 0.00 \\
\hline 90111 (Coffee, not roasted, not decaffeinated) & $1.1 \%$ & 0.00 \\
\hline 20714 (Frozen cuts and offal of fowl of the species Gallus domesticus) & $0.9 \%$ & 0.00 \\
\hline $\begin{array}{l}480256 \text { (Other paper and paperboard, not containing fibres obtained by a } \\
\text { mechanical process or of which not more than } 10 \% \text { by weight of the total fibre } \\
\text { content consists of such fibres weighing } 40 \mathrm{~g} / \mathrm{m} 2 \text { or more but not more than } \\
150 \mathrm{~g} / \mathrm{m} 2 \text { ) }\end{array}$ & $0.9 \%$ & 0.00 \\
\hline 200919 (Orange juice) & $0.8 \%$ & 0.00 \\
\hline Subtotal & $40,6 \%$ & \\
\hline
\end{tabular}


Graph 5.13. Progress of intra-industrial trade in the main chapters of Mexico's bilateral trade with Germany. Brülhart's marginal index (A). Average 1993-2013

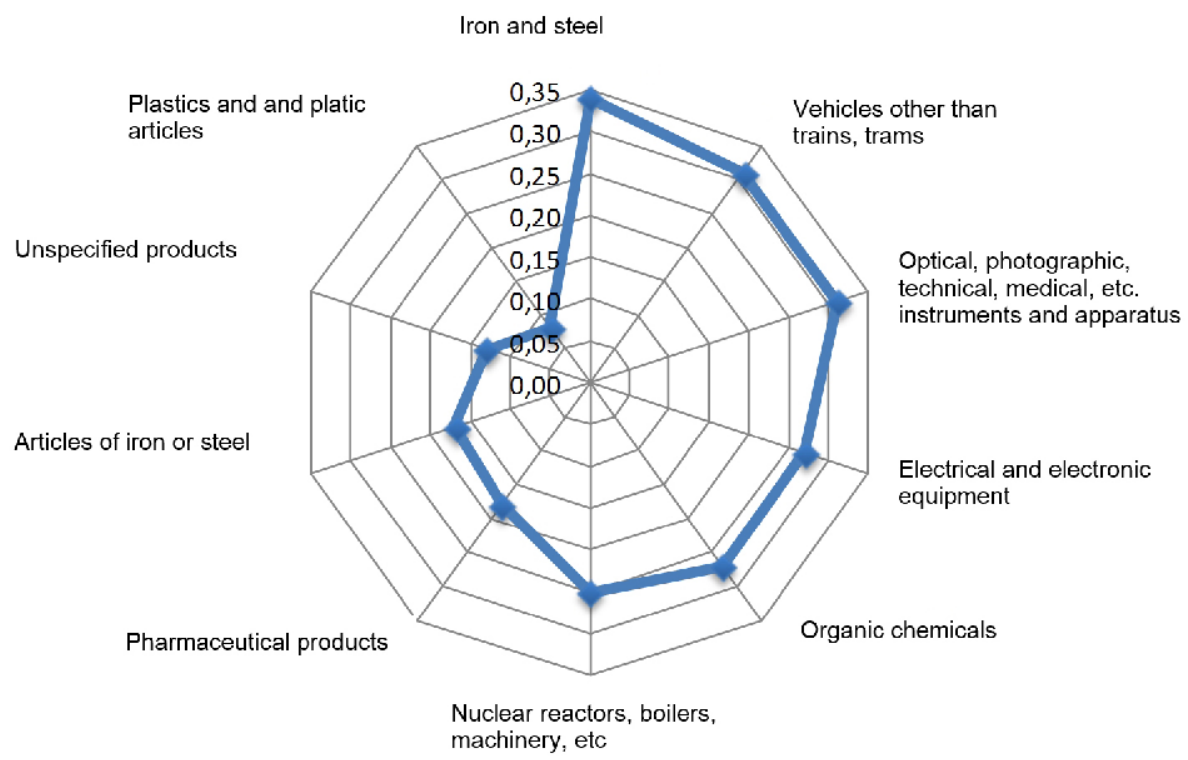

Source: Own elaboration based on UN-COMTRADE data

At a more disaggregated level (6 digits of HS2012 nomenclature), considering the twenty most important product classes in the trade between Mexico and Germany, various product classes can be identified which displayed notable advances in terms of intraindustrial trade (Table 5.23). Specifically, the product class with code 903289 (Automatic regulating/controlling equipment) can be pointed out, with an average figure for Brülhart's marginal index of 0.36 for the period. Considered. Also with notable advances were the classes with codes 870323 (Automobiles with gasoline engines) and 870829 (Parts and accessories of bodies for motor vehicles), as well as codes 840734 (Diesel engines), 842139 (Filtering or purifying machinery and apparatus for gases), 300490 (Other medicaments). 
Table 5.23. Progress of intra-industrial trade in the main products (HS2012, 6 digits) in Mexico's bilateral trade with Germany. Brülhart's marginal index (A). Average 1993-2013

\begin{tabular}{|c|c|c|}
\hline $\begin{array}{c}\text { Product } \\
\text { (6-digit HS2012 code) }\end{array}$ & $\begin{array}{l}\text { Trade } \\
\text { weight (\%) } \\
\text { average } \\
1993-2013\end{array}$ & $\begin{array}{l}\text { A Index } \\
\text { average } \\
1993- \\
2013\end{array}$ \\
\hline $\begin{array}{l}870323 \text { (Other vehicles, with spark-ignition internal combustion } \\
\text { reciprocating piston engine, of a cylinder capacity exceeding } 1,500 \mathrm{cc} \text { but not } \\
\text { exceeding } 3,000 \mathrm{cc} \text { ) }\end{array}$ & $8.4 \%$ & 0.18 \\
\hline $\begin{array}{l}870332 \text { (Other vehicles, with compression-ignition internal combustion piston } \\
\text { engine (diesel or semi-diesel), of a cylinder capacity exceeding } 1,500 \mathrm{cc} \text { but not } \\
\text { exceeding } 2,500 \mathrm{cc} \text { ) }\end{array}$ & $6.8 \%$ & 0.07 \\
\hline $\begin{array}{l}870829 \text { (Other parts and accessories of bodies (including cabs) of the motor } \\
\text { vehicles of headings No. } 87.01 \text { to } 87.05 \text { ) }\end{array}$ & $3.6 \%$ & 0.22 \\
\hline $\begin{array}{l}840734 \text { (Reciprocating piston engines of a kind used for the propulsion of } \\
\text { vehicles of Ch. } 87 \text { of a cylinder capacity exceeding } 1,000 \mathrm{cc} \text { ) }\end{array}$ & $2.3 \%$ & 0.24 \\
\hline $\begin{array}{l}870840 \text { (Gear boxes and their parts of the motor vehicles of headings No. } 87.01 \\
\text { to } 87.05 \text { ) }\end{array}$ & $2.1 \%$ & 0.08 \\
\hline $\begin{array}{l}300490 \text { (Other medicaments (excluding goods of heading No. } 30.02,30.05 \text { or } \\
30.06 \text { ) consisting of mixed or unmixed products for therapeutic or prophylactic } \\
\text { uses, put up in measured doses (including those intended for administration by } \\
\text { trans...) }\end{array}$ & $2.0 \%$ & 0.19 \\
\hline $\begin{array}{l}840991 \text { (Other parts suitable for use solely or principally with the engines of } \\
\text { heading No. } 84.07 \text { or } 84.08 \text { suitable for use solely or principally with } \\
\text { spark-ignition internal combustion piston engines) }\end{array}$ & $1.6 \%$ & 0.08 \\
\hline $\begin{array}{l}870899 \text { (Other parts and accessories of the motor vehicles of headings No. } \\
87.01 \text { to } 87.05 \text { ) }\end{array}$ & $1.6 \%$ & 0.15 \\
\hline $\begin{array}{l}847989 \text { (Machines and mechanical appliances having individual functions, not } \\
\text { specified or included elsewhere in Ch. 84). }\end{array}$ & $1.3 \%$ & 0.13 \\
\hline 840820 (Engines of a kind used for the propulsion of vehicles of Ch. 87) & $1.3 \%$ & 0.03 \\
\hline 9999AA (Commodities not elsewhere specified) & $1.2 \%$ & 0.06 \\
\hline 903289 (Other automatic regulating or controlling instruments and apparatus) & $1.2 \%$ & 0.36 \\
\hline $\begin{array}{l}870324 \text { (Other vehicles, with spark-ignition internal combustion reciprocating } \\
\text { piston engine, of a cylinder capacity exceeding } 3,000 \mathrm{cc} \text { ) }\end{array}$ & $1.2 \%$ & 0.07 \\
\hline 999999 (Commodities not specified according to kind) & $1.1 \%$ & 0.25 \\
\hline $\begin{array}{l}853690 \text { (Other apparatus for switching or protecting electrical circuits, or for } \\
\text { making connections to or in electrical circuits (for example, switches, relays, } \\
\text { fuses, surge suppressors, plugs, sockets, lamp-holders, junction boxes...) }\end{array}$ & $0.9 \%$ & 0.05 \\
\hline $\begin{array}{l}870850 \text { (Drive-axles with differential, whether or not provided with other trans- } \\
\text { mission components; parts thereof) }\end{array}$ & $0.9 \%$ & 0.01 \\
\hline $\begin{array}{l}870322 \text { (Other vehicles, with spark-ignition internal combustion } \\
\text { reciprocating piston engine, of a cylinder capacity exceeding } 1,000 \mathrm{cc} \text { but not } \\
\text { exceeding } 1,500 \mathrm{cc} \text { ) }\end{array}$ & $0.9 \%$ & 0.16 \\
\hline $\begin{array}{l}392690 \text { (Other articles of plastics and articles of other materials of headings } \\
\text { Nos. } 39.01 \text { to } 39.14 \text {.) }\end{array}$ & $0.8 \%$ & 0.10 \\
\hline 842139 (Other filtering or purifying machinery and apparatus for gases) & $0.7 \%$ & 0.23 \\
\hline $\begin{array}{l}853890 \text { (Other parts suitable for use solely or principally with the engines of } \\
\text { heading No. } 85.35,85.36 \text { or } 85.37 \text {.) }\end{array}$ & $0.6 \%$ & 0.11 \\
\hline Subtotal & $40,5 \%$ & \\
\hline
\end{tabular}


With regard to trade between Mexico and Spain, considering the ten most important chapters (77\% of the total trade flow), the biggest advances in Brülhart's marginal index (in a general context of little progress in intra-industrial trade) took place in exchanges of beverages, spirits and vinegar; machinery; articles of iron or steel; organic chemicals; plastics and plastic articles; and iron and steel (Graph 5.14). Some progress was also seen, to a lesser extent, in exchanges of automobiles, fuels and electrical and electronic equipment.

Graph 5.14. Progress of intra-industrial trade in the main chapters of Mexico's bilateral trade with Spain. Brülhart's marginal index (A). Average 1993-2013

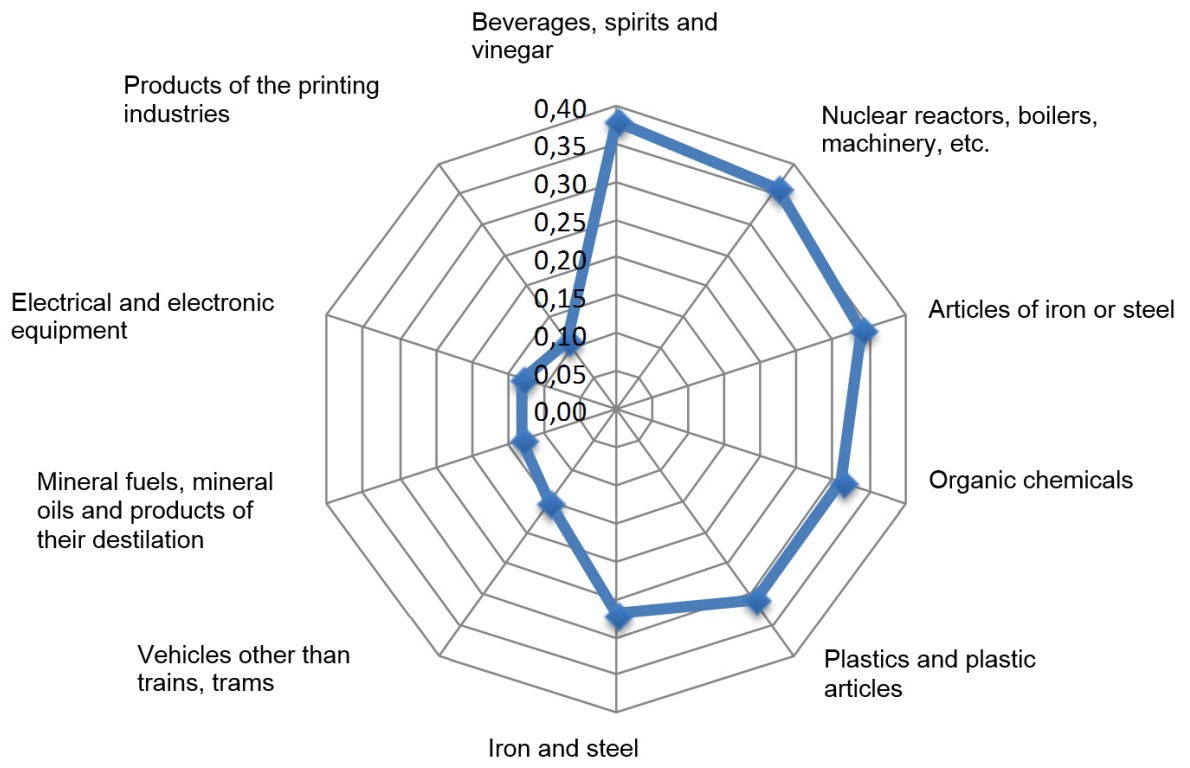

Source: Own elaboration based on UN-COMTRADE data

With greater disaggregation (to 6 digits of HS2012 nomenclature), and focusing the analysis on the twenty most relevant product classes in bilateral trade between Mexico and Spain, advances are barely observed, a picture of little intra-industrial activity being drawn (Table 5.24). Only one product class, code 870899 (Parts of engines), is worth pointing out, with an average figure for Brülhart's marginal index of 0.29 over the period 1993-2013. 
Table 5.24. Progress of intra-industrial trade in the main products (HS2012, 6 digits) in Mexico's bilateral trade with Spain. Brülhart's marginal index (A). Average 1993-2013

\begin{tabular}{|c|c|c|}
\hline $\begin{array}{c}\text { Product } \\
\text { (6-digit HS2012 code) }\end{array}$ & $\begin{array}{l}\text { Trade } \\
\text { weight (\%) } \\
\text { average } \\
1993-2013\end{array}$ & $\begin{array}{l}\text { A Index } \\
\text { average } \\
1993- \\
2013\end{array}$ \\
\hline 270900 (Petroleum oils and oils obtained from bituminous minerals, crude) & $43.8 \%$ & 0.00 \\
\hline $\begin{array}{l}870323 \text { (Other vehicles, with spark-ignition internal combustion reciprocating } \\
\text { piston engine, of a cylinder capacity exceeding } 1,500 \mathrm{cc} \text { but not exceeding } \\
3,000 \mathrm{cc} \text { ) }\end{array}$ & $3.2 \%$ & 0.13 \\
\hline $\begin{array}{l}490199 \text { (Other newspapers and print industry products; manuscripts/ } \\
\text { typescripts, maps and plans; printed books, brochures, leaflets and similar } \\
\text { printed matter, whether or not in single sheets) }\end{array}$ & $1.6 \%$ & 0.07 \\
\hline 850231 (Other wind-powered generating sets) & $0.9 \%$ & 0.00 \\
\hline 291736 (Terephthalic acid and its salts) & $0.8 \%$ & 0.00 \\
\hline $\begin{array}{l}690890 \text { (Other glazed ceramic flags and paving, hearth or wall tiles; glazed } \\
\text { ceramic mosaic cubes and the like, whether or not on a backing) }\end{array}$ & $0.8 \%$ & 0.01 \\
\hline 220820 (Spirits obtained by distilling grape wine or grape marc) & $0.8 \%$ & 0.01 \\
\hline $\begin{array}{l}860310 \text { (Self-propelled railway or tramway coaches, vans and trucks, other } \\
\text { than those of heading No. 86.04, powered from an external source of } \\
\text { electricity) }\end{array}$ & $0.7 \%$ & 0.00 \\
\hline $\begin{array}{l}840734 \text { (Reciprocating piston engines of a kind used for the propulsion of } \\
\text { vehicles of Ch. } 87 \text { of a cylinder capacity exceeding } 1,000 \mathrm{cc} \text { ) }\end{array}$ & $0.6 \%$ & 0.05 \\
\hline 71320 (Chickpeas) & $0.6 \%$ & 0.01 \\
\hline $\begin{array}{l}220421 \text { (Other wine; grape must with fermentation prevented or arrested by } \\
\text { the addition of alcohol//n containers) }\end{array}$ & $0.6 \%$ & 0.00 \\
\hline 940600 (Prefabricated buildings) & $0.6 \%$ & 0.03 \\
\hline $\begin{array}{l}300490 \text { (Medicaments (excluding goods of heading No. } 30.02,30.05 \text { or } 30.06 \text { ) } \\
\text { consisting of mixed or unmixed products for therapeutic or prophylactic uses, } \\
\text { put up in measured doses (including those intended for administration by } \\
\text { trans...) }\end{array}$ & $0.6 \%$ & 0.06 \\
\hline $\begin{array}{l}262099 \text { (Ash and residues (other than from the manufacture of iron or steel), } \\
\text { not elsewhere specified in Ch. 26) }\end{array}$ & $0.6 \%$ & 0.00 \\
\hline 290124 (Unsaturated acyclic hydrocarbons, buta-1,3-diene and isoprene) & $0.5 \%$ & 0.00 \\
\hline 999999 (Commodities not specified according to kind) & $0.5 \%$ & 0.21 \\
\hline $\begin{array}{l}870899 \text { (Other parts and accessories of the motor vehicles of headings No. } \\
87.01 \text { to } 87.05 \text { ) }\end{array}$ & $0.5 \%$ & 0.29 \\
\hline $\begin{array}{l}490290 \text { (Other newspapers, journals and periodicals, whether or not illustrated } \\
\text { or containing advertising material) }\end{array}$ & $0.4 \%$ & 0.03 \\
\hline $\begin{array}{l}847989 \text { (Machines and mechanical appliances having individual functions, not } \\
\text { specified or included elsewhere in Ch. 84). }\end{array}$ & $0.4 \%$ & 0.05 \\
\hline 721632 (Sections, I, iron or non-alloy steel...) & $0.4 \%$ & 0.04 \\
\hline Subtotal & $58,9 \%$ & \\
\hline
\end{tabular}

From a sectorial perspective focused on the ten main chapters of bilateral trade between Mexico and France (more than $70 \%$ of the total of all trade flows), the biggest advances in terms of intra-industrial trade were achieved by the chapters on electrical and electronic equipment (Ch. 85) and mechanical machinery and appliances (Ch. 84; see Graph 5.15). Less notable were the exchanges regarding optical, photographic, etc. instruments and apparatuses (Ch. 90); plastics and plastic articles (Ch. 39); and, to a lesser extent, organic 
chemicals (Ch. 29). Advances, though much more moderate, were also observable in exchanges of automobiles (Ch. 87) and pharmaceutical products (Ch. 30).

Graph 5.15. Progress of intra-industrial trade in the main chapters of Mexico's bilateral trade with France. Brülhart's marginal index (A). Average 1993-2013

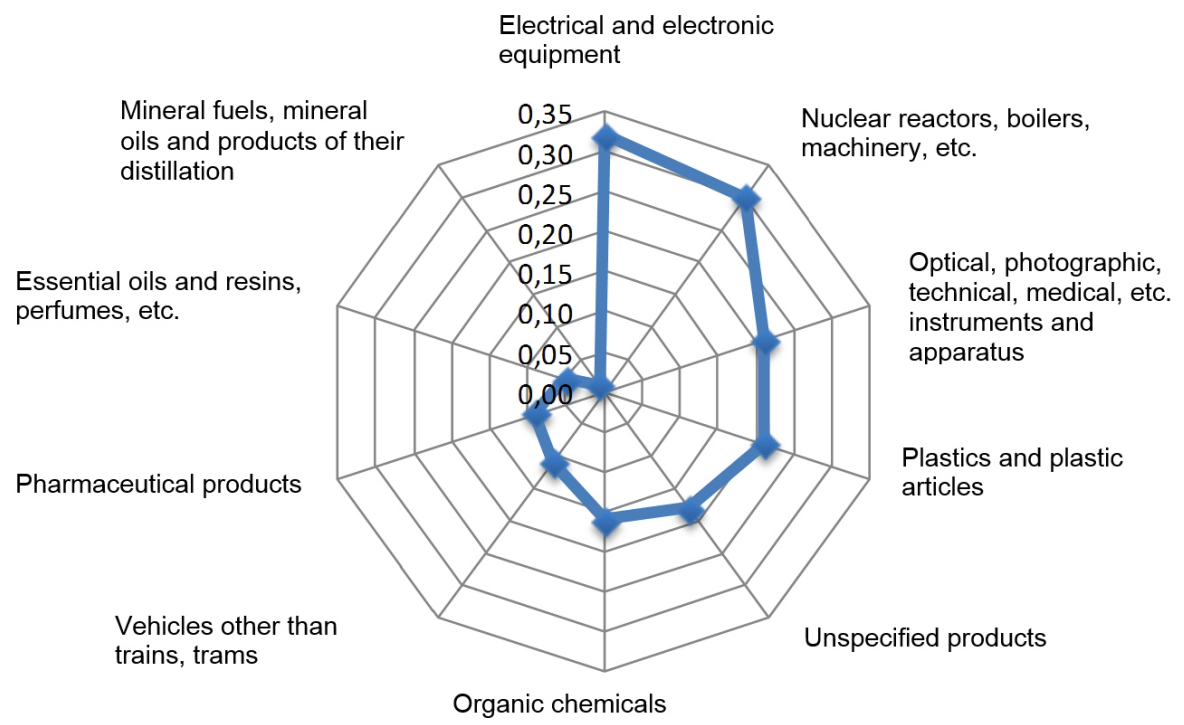

Source: Own elaboration based on UN-COMTRADE data

At a more disaggregated level (6 digits of HS2012 nomenclature), considering the twenty product classes of most relative weight in the trade between Mexico and France, four product classes made considerable advances in terms of intra-industrial trade (Table 5.25). Two product classes in Chapter 84 (mechanical machinery and apparatuses) stand out most, those with codes 840991 (Parts of engines) and 841191 (Parts of turbojets or turboprops), acquiring average figures in Brülhart's marginal index equal to or greater than 0.40 over the analysed period (1993-2013).

Secondly, the advances observed in product exchanges of classes with codes 851762 (Machines for the reception, conversion and transmission or regeneration of voice, images or other data) and 851770 (Parts of telephones) are also worth mentioning; both belong to Chapter 85 (electrical and electronic equipment) and displayed average figures in Brülhart's marginal index of 0.19 and 0.39 , respectively. 
Table 5.25. Progress of intra-industrial trade in the main products (HS2012, 6 digits) in Mexico's bilateral trade with France. Brülhart's marginal index (A). Average 1993-2013

\begin{tabular}{|c|c|c|}
\hline $\begin{array}{c}\text { Product } \\
\text { (6-digit HS2012 code) }\end{array}$ & $\begin{array}{l}\text { Trade } \\
\text { weight (\%) } \\
\text { average } \\
1993-2013\end{array}$ & $\begin{array}{l}\text { A Index } \\
\text { average } \\
1993- \\
2013\end{array}$ \\
\hline $\begin{array}{l}300490 \text { (Medicaments (excluding goods of heading No. } 30.02,30.05 \text { or } 30.06 \text { ) } \\
\text { consisting of mixed or unmixed products for therapeutic or prophylactic uses, } \\
\text { put up in measured doses (including those intended for administration by } \\
\text { trans...) }\end{array}$ & $3.6 \%$ & 0.05 \\
\hline 999999 (Commodities not specified according to kind) & $3.0 \%$ & 0.20 \\
\hline 300220 (Vaccines for human medicine) & $2.6 \%$ & 0.09 \\
\hline 901831 (Syringes, with or without needles) & $2.1 \%$ & 0.06 \\
\hline 330300 (Perfumes and toilet waters) & $2.1 \%$ & 0.02 \\
\hline $\begin{array}{l}840734 \text { (Reciprocating piston engines of a kind used for the propulsion of } \\
\text { vehicles of Ch. } 87 \text { of a cylinder capacity exceeding } 1,000 \mathrm{cc} \text { ) }\end{array}$ & $1.6 \%$ & 0.04 \\
\hline $\begin{array}{l}870323 \text { (Other vehicles, with spark-ignition internal combustion } \\
\text { reciprocating piston engine, of a cylinder capacity exceeding } 1,500 \mathrm{cc} \text { but not } \\
\text { exceeding } 3,000 \mathrm{cc} \text { ) }\end{array}$ & $1.5 \%$ & 0.06 \\
\hline $\begin{array}{l}330499 \text { (Other beauty or make-up preparations and preparations for the care } \\
\text { of the skin (other than medicaments), including sunscreen or sun tan } \\
\text { preparations; manicure or pedicure preparations) }\end{array}$ & $1.5 \%$ & 0.01 \\
\hline $\begin{array}{l}840991 \text { (Other parts suitable for use solely or principally with the engines of } \\
\text { heading No. } 84.07 \text { or } 84.08 \text { suitable for use solely or principally with } \\
\text { spark-ignition internal combustion piston engines) }\end{array}$ & $1.5 \%$ & 0.40 \\
\hline $\begin{array}{l}851762 \text { (Machines for the reception, conversion and transmission or regenera- } \\
\text { tion of voice, images or other data, including switching and routing apparatus) }\end{array}$ & $1.3 \%$ & 0.19 \\
\hline $\begin{array}{l}851770 \text { (Telephone sets, including telephones for cellular networks or for other } \\
\text { wireless networks; other apparatus for the transmission or reception of voice, } \\
\text { images or other data, including apparatus for communication in a wired or } \\
\text { wireless network (such as a local or wide area network); parts thereof) }\end{array}$ & $1.0 \%$ & 0.39 \\
\hline 841191 (Parts of turbojets or turbopropellers) & $1.0 \%$ & 0.44 \\
\hline $\begin{array}{l}847989 \text { (Machines and mechanical appliances having individual functions, not } \\
\text { specified or included elsewhere in Ch. 84) }\end{array}$ & $1.0 \%$ & 0.07 \\
\hline $\begin{array}{l}847730 \text { (Blow moulding machinery for working rubber or plastics or for the } \\
\text { manufacturing of products from these materials, not specified or included } \\
\text { elsewhere in this chapter) }\end{array}$ & $0.9 \%$ & 0.00 \\
\hline $\begin{array}{l}293329 \text { (Other compounds containing an unfused pyridine ring (whether or not } \\
\text { hydrogenated) in the structure) }\end{array}$ & $0.9 \%$ & 0.00 \\
\hline $\begin{array}{l}853890 \text { (Other parts suitable for use solely or principally with the engines of } \\
\text { heading No. } 85.35,85.36 \text { or } 85.37 \text {.) }\end{array}$ & $0.9 \%$ & 0.09 \\
\hline 882012 (Helicopters of an unladen weight exceeding $2,000 \mathrm{~kg}$ ) & $0.9 \%$ & 0.02 \\
\hline $\begin{array}{l}853690 \text { (Other apparatus for switching or protecting electrical circuits, or for } \\
\text { making connections to or in electrical circuits (for example, switches, relays, } \\
\text { fuses, surge suppressors, plugs, sockets, lamp-holders, junction boxes...) }\end{array}$ & $0.8 \%$ & 0.07 \\
\hline $\begin{array}{l}854430 \text { (Ignition wiring sets and other wiring sets of a kind used in vehicles, } \\
\text { aircraft or ships) }\end{array}$ & $0.7 \%$ & 0.02 \\
\hline $\begin{array}{l}870899 \text { (Other parts and accessories of the motor vehicles of headings No. } \\
87.01 \text { to } 87.05 \text { ) }\end{array}$ & $0.7 \%$ & 0.14 \\
\hline Subtotal & $29,6 \%$ & \\
\hline
\end{tabular}


With regard to trade between Mexico and Italy, considering the ten most important chapters (almost $73 \%$ of total bilateral trade), the biggest advances in Brülhart's marginal index were achieved in exchanges of organic chemicals and articles of iron or steel (Graph 5.16). Advances were also observed, though of less magnitude and in order of decreasing importance, in exchanges of fuels; electrical and electronic equipment; optical, photographic, technical, medical, etc. instruments; plastics and plastic articles; iron and steel; mechanical machinery and equipment; and automobiles.

Graph 5.16. Progress of intra-industrial trade in the main chapters of Mexico's bilateral trade with France. Brülhart's marginal index (A). Average 1993-2013

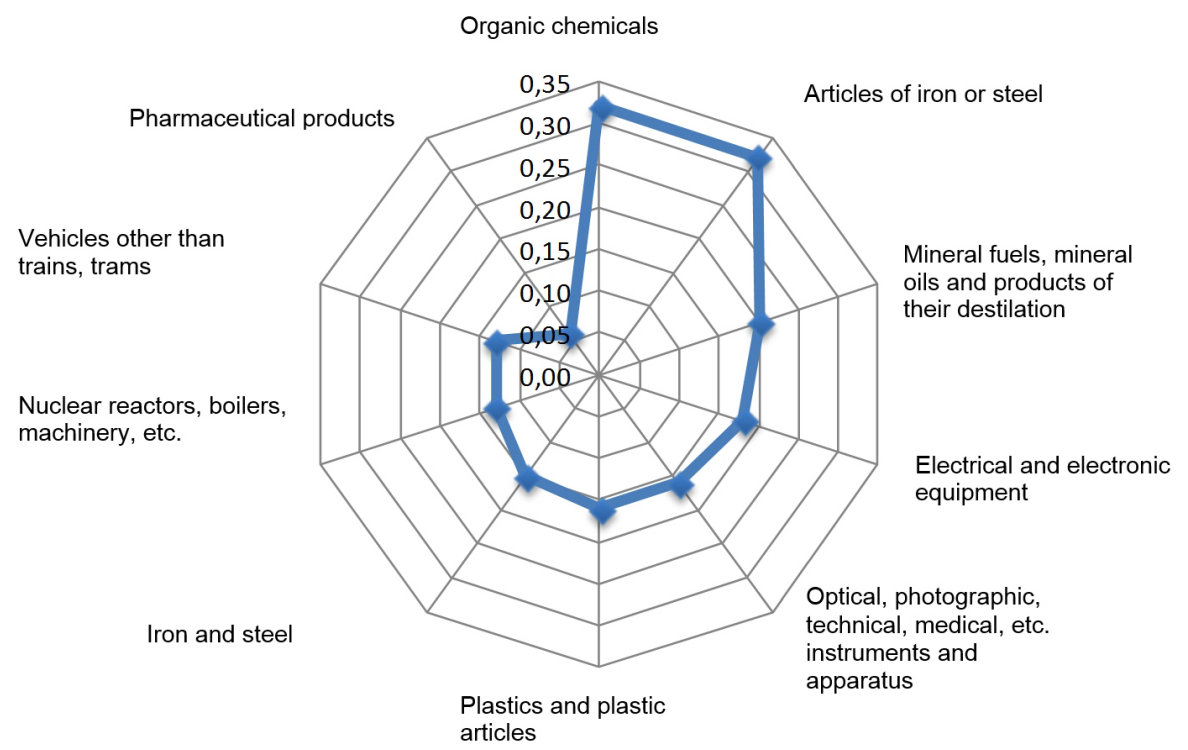

Source: Own elaboration based on UN-COMTRADE data

With a greater level of disaggregation (6 digits of HS2012 nomenclature) and analysing the behaviour of the twenty product classes of most relative weight in the trade between Mexico and Italy, advances were barely observed, reflecting thereby a very limited degree of intra-industrial activity (Table 5.26). The only product class worthy of mention is code 848071 (Molds for rubber or plastic/injection or compression), in Chapter 84 (mechanical machinery and equipment), which obtained an average figure in Brülhart's marginal index of 0.22 over the 1993-2013 period, the highest of the twenty selected product classes. 
Table 5.26. Progress of intra-industrial trade in the main products (HS2012, 6 digits) in Mexico's bilateral trade with Italy. Brülhart's marginal index (A). Average 1993-2013

\begin{tabular}{|c|c|c|}
\hline $\begin{array}{c}\text { Product } \\
\text { (6-digit HS2012 code) }\end{array}$ & $\begin{array}{l}\text { Trade } \\
\text { weight (\%) } \\
\text { average } \\
1993-2013\end{array}$ & $\begin{array}{l}\text { A Index } \\
\text { average } \\
1993- \\
2013\end{array}$ \\
\hline $\begin{array}{l}721913 \text { (Hot rolled stainless steel coil, } w>600 \mathrm{~mm}(\ldots) \text { of a thickness of } 3 \mathrm{~mm} \text { or } \\
\text { more but less than } 4.75 \mathrm{~mm} \text { ) }\end{array}$ & $3.4 \%$ & 0.00 \\
\hline $\begin{array}{l}721914 \text { (Hot rolled stainless steel coil, } w>600 \mathrm{~mm} \text { (...) of a thickness less than } \\
3 \mathrm{~mm} \text { ) }\end{array}$ & $2.3 \%$ & 0.00 \\
\hline $\begin{array}{l}870332 \text { (Other vehicles, with compression-ignition internal combustion piston } \\
\text { engine (diesel or semi-diesel), of a cylinder capacity exceeding } 1,500 \mathrm{cc} \text { but not } \\
\text { exceeding } 2,500 \mathrm{cc} \text { ) }\end{array}$ & $1.8 \%$ & 0.00 \\
\hline $\begin{array}{l}842230 \text { (Machinery for filling, closing, sealing, or labelling bottles, cans, boxes, } \\
\text { bags or other containers; machinery for capsuling bottles, jars, tubes and } \\
\text { similar containers; machinery for aerating beverages) }\end{array}$ & $1.7 \%$ & 0.04 \\
\hline $\begin{array}{l}300490 \text { (Medicaments (excluding goods of heading No. } 30.02,30.05 \text { or } 30.06 \text { ) } \\
\text { consisting of mixed or unmixed products for therapeutic or prophylactic uses, } \\
\text { put up in measured doses (including those intended for administration by } \\
\text { trans...) }\end{array}$ & $1.4 \%$ & 0.13 \\
\hline 999999 (Commodities not specified according to kind) & $1.4 \%$ & 0.05 \\
\hline $\begin{array}{l}842240 \text { (Other packing or wrapping machinery (including heat-shrink } \\
\text { wrapping machinery) }\end{array}$ & $1.3 \%$ & 0.08 \\
\hline $\begin{array}{l}847989 \text { (Machines and mechanical appliances having individual functions, not } \\
\text { specified or included elsewhere in Ch. 84). }\end{array}$ & $1.3 \%$ & 0.05 \\
\hline 270900 (Petroleum oils and oils obtained from bituminous minerals, crude) & $1.1 \%$ & 0.00 \\
\hline $\begin{array}{l}847480 \text { (Machinery for sorting, screening, separating, washing, crushing, grind- } \\
\text { ing, mixing or kneading earth, stone, ores or other mineral substances, in solid } \\
\text { (including powder or paste) form; machinery for agglomerating, shaping or } \\
\text { moulding...) }\end{array}$ & $1.0 \%$ & 0.02 \\
\hline $\begin{array}{l}271012 \text { (Petroleum oils and oils obtained from bituminous minerals, other than } \\
\text { crude; preparations not elsewhere specified or included, containing by weight } \\
70 \% \text { or more of petroleum oils or of oils obtained from bituminous minerals, } \\
\text { these oils being the basic constituents of the preparations, other than those } \\
\text { containing biodiesel and other than waste oils: Other) }\end{array}$ & $1.0 \%$ & 0.00 \\
\hline $\begin{array}{l}721912 \text { (Hot rolled stainless steel coil, } w>600 \mathrm{~mm}(\ldots) \text { of a thickness of } 4.75 \mathrm{~mm} \\
\text { or more but less than } 10 \mathrm{~mm} \text { ) }\end{array}$ & $1.0 \%$ & 0.00 \\
\hline $\begin{array}{l}711319 \text { (Jewellery and parts of other precious metal, whether or not plated or } \\
\text { clad with precious metal) }\end{array}$ & $0.9 \%$ & 0.06 \\
\hline 845521 (Other rolling mills / Hot or combination hot and cold) & $0.8 \%$ & 0.00 \\
\hline 291736 (Terephthalic acid and its salts) & $0.7 \%$ & 0.00 \\
\hline $\begin{array}{l}293410 \text { (Organic chemicals / Nucleic acids \& their salts, whether or not } \\
\text { chemically defined / Other heterocyclic compounds/ Compounds containing } \\
\text { an thiazole ring (whether or not hydrogenated) in the structure) }\end{array}$ & $0.7 \%$ & 0.00 \\
\hline 848071 (Moulds for rubber or plastics / injection or compression types) & $0.7 \%$ & 0.22 \\
\hline $\begin{array}{l}392690 \text { (Other articles of plastics and articles of other materials of headings } \\
\text { No. } 39.01 \text { to } 39.14 \text {.) }\end{array}$ & $0.6 \%$ & 0.10 \\
\hline 900410 (Sunglasses) & $0.6 \%$ & 0.03 \\
\hline $\begin{array}{l}848180 \text { (Other appliances for pipes, boiler shells, tanks, vats or the like, } \\
\text { including pressure-reducing valves and thermostatically controlled valves) }\end{array}$ & $0.6 \%$ & 0.13 \\
\hline Subtotal & $24,5 \%$ & \\
\hline
\end{tabular}


that the biggest advances in Brülhart's marginal index occurred in exchanges of organic chemicals; plastics and plastic articles; iron and steel; pharmaceutical products; and mechanical machinery and equipment (Graph 5.17). They were followed, though with more moderate advances and in decreasing order, by the exchanges of articles of iron and steel; fuels; optical, photographic, technical, medical, etc. instruments and apparatuses; and electrical and electronic equipment.

Graph 5.17. Progress of intra-industrial trade in the main chapters of Mexico's bilateral trade with the Netherlands. Brülhart's marginal index (A). Average 1993-2013

Organic chemicals

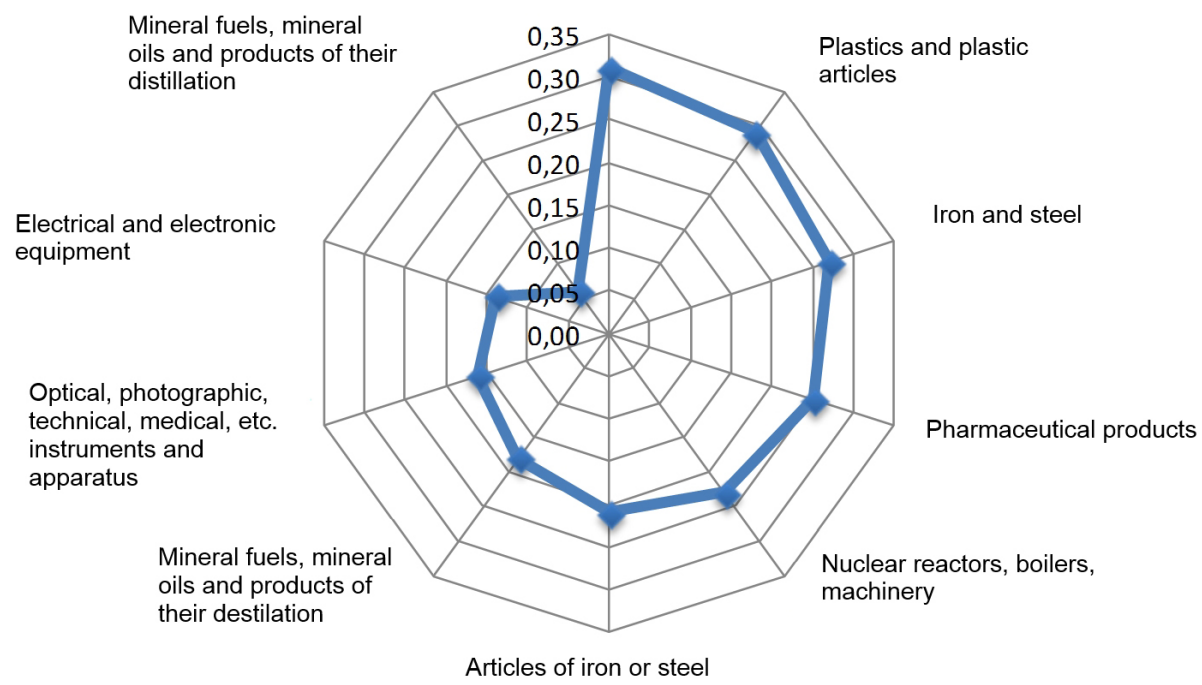

Source: Own elaboration based on UN-COMTRADE data

Zooming in to a 6-digit level of disaggregation (HS2012 nomenclature), it can be seen that only one specific product class, of the twenty with most trade weight, stood out due to its advances in terms of intra-industrial trade (Table 5.27). Specifically, this class relates to products with code 847150 (automatic data processing units), corresponding to the chapter on machinery and mechanical equipment (Ch. 84). Other product classes with much more moderate advances were those with codes 293723 (Oestrogens and progestogens), 847170 (machines for data storage), 901839 (Syringes, needles, catheters, cannulae and the like), 120991 (Seeds of vegetables), 847180 (Other machines of automatic data processing). 
Table 5.27. Progress of intra-industrial trade in the main products (HS2012, 6 digits) in Mexico's bilateral trade with the Netherlands. Brülhart's marginal index (A) Average 1993-2013

\begin{tabular}{|c|c|c|}
\hline $\begin{array}{c}\text { Product } \\
\text { (6-digit HS2012 code) }\end{array}$ & $\begin{array}{l}\text { Trade } \\
\text { weight (\%) } \\
\text { average } \\
1993-2013\end{array}$ & $\begin{array}{l}\text { A Index } \\
\text { average } \\
\text { 1993- } \\
2013\end{array}$ \\
\hline $\begin{array}{l}271012 \text { (Petroleum oils and oils obtained from bituminous minerals, other than } \\
\text { crude; preparations not elsewhere specified or included, containing by weight } \\
70 \% \text { or more of petroleum oils or of oils obtained from bituminous minerals, } \\
\text { these oils being the basic constituents of the preparations, other than those } \\
\text { containing biodiesel and other than waste oils: Other) }\end{array}$ & $16.0 \%$ & 0.02 \\
\hline $\begin{array}{l}851762 \text { (Machines for the reception, conversion and transmission or regenera- } \\
\text { tion of voice, images or other data, including switching and routing apparatus) }\end{array}$ & $7.4 \%$ & 0.01 \\
\hline 270900 (Petroleum oils and oils obtained from bituminous minerals, crude) & $5.1 \%$ & 0.00 \\
\hline $\begin{array}{l}851770 \text { (Telephone sets, including telephones for cellular networks or for other } \\
\text { wireless networks; other apparatus for the transmission or reception of voice, } \\
\text { images or other data, including apparatus for communication in a wired or } \\
\text { wireless network (such as a local or wide area network); parts thereof) }\end{array}$ & $3.9 \%$ & 0.00 \\
\hline 847180 (Other units of automatic data processing machines) & $3.3 \%$ & 0.11 \\
\hline 999999 (Commodities not specified according to kind) & $2.0 \%$ & 0.41 \\
\hline 901839 (Syringes, needles, catheters, cannulae and the like/Other) & $1.9 \%$ & 0.12 \\
\hline 261310 (Molybdenum ores and concentrates) & $1.8 \%$ & 0.00 \\
\hline 847330 (Parts and accessories of the machines of heading No. 84.71) & $1.8 \%$ & 0.08 \\
\hline 902620 (Equipment to measure or check pressure) & $1.6 \%$ & 0.09 \\
\hline 732690 (Other articles of iron or steel) & $1.6 \%$ & 0.07 \\
\hline $\begin{array}{l}847150 \text { (Automatic data processing machines and units thereof; magnetic or } \\
\text { optical readers, machines for transcribing data onto data media in coded form } \\
\text { and machines for processing such data, not elsewhere specified or included) }\end{array}$ & $1.4 \%$ & 0.24 \\
\hline $\begin{array}{l}870323 \text { (Other vehicles, with spark-ignition internal combustion } \\
\text { reciprocating piston engine, of a cylinder capacity exceeding } 1,500 \mathrm{cc} \text { but not } \\
\text { exceeding } 3,000 \mathrm{cc} \text { ) }\end{array}$ & $1.0 \%$ & 0.00 \\
\hline $\begin{array}{l}847170 \text { (Machines for transcribing data onto data media in coded form and } \\
\text { machines for processing such data, not elsewhere specified or } \\
\text { included/ Storage units) }\end{array}$ & $1.0 \%$ & 0.13 \\
\hline 40690 (Cheese and curd/Other cheese) & $1.0 \%$ & 0.00 \\
\hline $\begin{array}{l}60110 \text { (Bulbs, tubers, tuberous roots, corms, crowns and rhizomes, dormant, in } \\
\text { growth or in flower; chicory plants and roots other than roots of heading } \\
\text { No. 12.12) }\end{array}$ & $0.9 \%$ & 0.00 \\
\hline 120991 (Vegetable seeds) & $0.9 \%$ & 0.12 \\
\hline 200911 (Orange juice/Frozen) & $0.9 \%$ & 0.00 \\
\hline $\begin{array}{l}271019 \text { (Petroleum oils and oils obtained from bituminous minerals, other than } \\
\text { crude; preparations not elsewhere specified or included, containing by weight } \\
70 \% \text { or more of petroleum oils or of oils obtained from bituminous minerals) }\end{array}$ & $0.8 \%$ & 0.04 \\
\hline 293723 (Oestrogens and progestogens) & $0.8 \%$ & 0.14 \\
\hline Subtotal & $55,2 \%$ & \\
\hline
\end{tabular}

With regard to trade between Mexico and the United Kingdom, focusing on the ten most important chapters (almost three-quarters of the total bilateral trade), the biggest advances in Brülhart's marginal index could be observed in the exchanges related to optical, photographic, technical, medical, etc. instruments and apparatuses (Ch. 90); mechanical machinery and equipment (Ch. 84); organic chemicals (Ch.29); and fuels (Ch. 
27) (Graph 5.18). Other chapters in which some dynamism of intra-industrial trade was observed were those related to electrical and electronic equipment (Ch. 85); automobiles (Ch. 87); and, to a much lesser extent, pharmaceutical products (Ch. 30).

Graph 5.18. Progress of intra-industrial trade in the main chapters of Brazil's bilateral trade with the United Kingdom. Brülhart's marginal index (A). Average 1993-2013

Optical, photographic, technical, medical, etc. instruments and apparatus

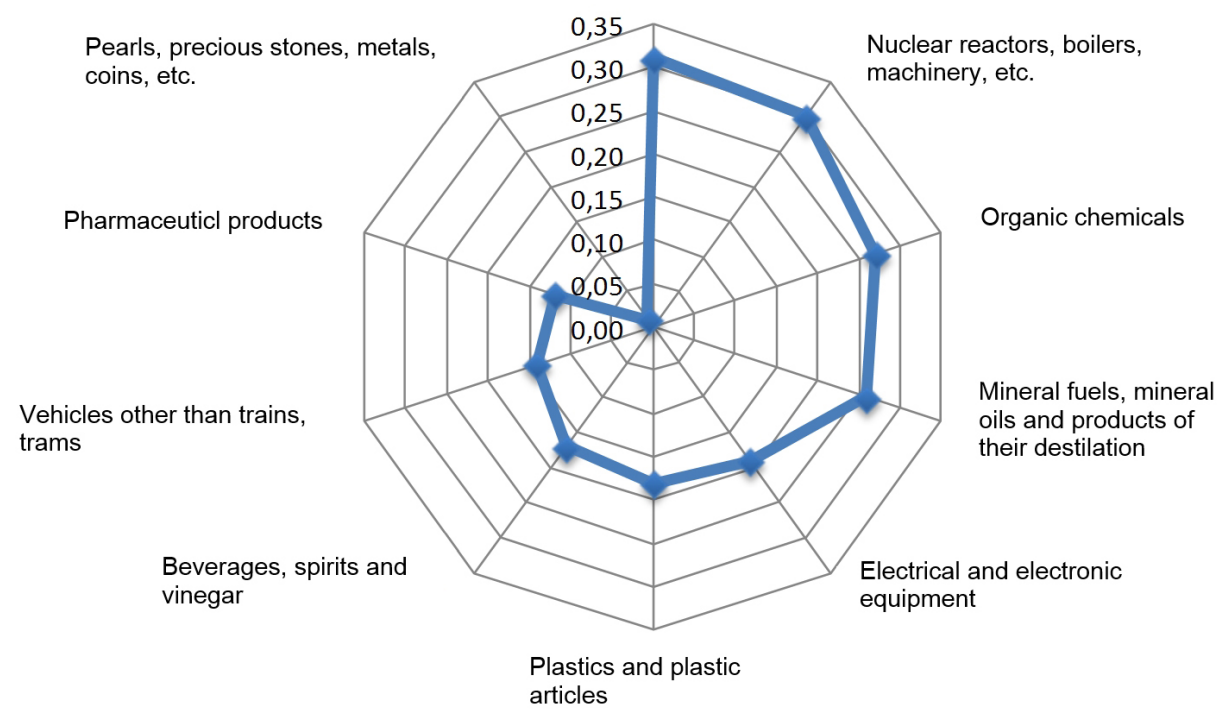

Source: Own elaboration based on UN-COMTRADE data

At a more disaggregated level (6 digits of HS2012 nomenclature), considering the twenty product classes of most relative weight in the trade between Mexico and the United Kingdom, the product class with code 870899 (Parts and accessories of automobiles) stands out, reaching an average figure in Brülhart's marginal index of 0.31 over the analysed period (1993-2013; see Table 5.28). Also, three product classes, with codes 847170 (storage units of automatic data processing machines); 840999 (Parts of engines) and 847330 (Parts and accessories of machines), also show relevant advances in terms of intra-industrial trade, although of less size than in the previous case, as is also true of code 901839 class (Syringes, needles, catheters, cannulae and the like). 
Table 5.28. Progress of intra-industrial trade in the main products (HS2012, 6 digits) in Mexico's bilateral trade with the United Kingdom. Brülhart's marginal index (A). Average 1993-2013

\begin{tabular}{|c|c|c|}
\hline $\begin{array}{c}\text { Product } \\
\text { (6-digit HS2012 code) }\end{array}$ & $\begin{array}{l}\text { Trade } \\
\text { weight (\%) } \\
\text { average } \\
1993-2013\end{array}$ & $\begin{array}{l}\text { A Index } \\
\text { average } \\
1993- \\
2013\end{array}$ \\
\hline $\begin{array}{l}710812 \text { (Other gold (including gold plated with platinum) unwrought or in } \\
\text { semi-manufactured forms, or in powder form/Non-monetary) }\end{array}$ & $9.5 \%$ & 0.09 \\
\hline $\begin{array}{l}300490 \text { (Medicaments (excluding goods of heading No. } 30.02,30.05 \text { or } 30.06 \text { ) } \\
\text { consisting of mixed or unmixed products for therapeutic or prophylactic uses, } \\
\text { put up in measured doses (including those intended for administration by } \\
\text { trans...) }\end{array}$ & $4.1 \%$ & 0.12 \\
\hline 270900 (Petroleum oils and oils obtained from bituminous minerals, crude) & $3.3 \%$ & 0.00 \\
\hline 999999 (Commodities not specified according to kind) & $2.3 \%$ & 0.15 \\
\hline 220830 (Whiskies) & $2.3 \%$ & 0.01 \\
\hline $\begin{array}{l}870323 \text { (Other vehicles, with spark-ignition internal combustion } \\
\text { reciprocating piston engine, of a cylinder capacity exceeding } 1,500 \mathrm{cc} \text { but not } \\
\text { exceeding } 3,000 \mathrm{cc} \text { ) }\end{array}$ & $1.9 \%$ & 0.11 \\
\hline 847330 (Parts and accessories of the machines of heading No. 84.71) & $1.7 \%$ & 0.23 \\
\hline 710691 ( Silver, incl. silver plated with gold or platinum, unwrought) & $1.7 \%$ & 0.00 \\
\hline $\begin{array}{l}720712 \text { (Semi-finished products of iron or non-alloy steel }<0.25 \% C \text { /Other, of } \\
\text { rectangular (other than square) cross-section) }\end{array}$ & $1.7 \%$ & 0.00 \\
\hline $\begin{array}{l}840999 \text { (Other parts suitable for use solely or principally with the engines of } \\
\text { heading No. } 84.07 \text { or } 84.08 \text {.) }\end{array}$ & $1.5 \%$ & 0.18 \\
\hline 840820 (Engines of a kind used for the propulsion of vehicles of Ch. 87) & $1.3 \%$ & 0.13 \\
\hline 851712 (Telephones for cellular networks or for other wireless networks) & $1.2 \%$ & 0.01 \\
\hline 220300 (Beer made from malt) & $1.1 \%$ & 0.02 \\
\hline $\begin{array}{l}851762 \text { (Machines for the reception, conversion and transmission or regenera- } \\
\text { tion of voice, images or other data, including switching and routing apparatus) }\end{array}$ & $1.1 \%$ & 0.08 \\
\hline 847180 (Other units of automatic data processing machines) & $1.1 \%$ & 0.16 \\
\hline 901839 (Syringes, needles, catheters, cannulae and the like/Other) & $0.9 \%$ & 0.19 \\
\hline $\begin{array}{l}847170 \text { (Machines for transcribing data onto data media in coded form and } \\
\text { machines for processing such data, not elsewhere specified or } \\
\text { included/ Storage units) }\end{array}$ & $0.8 \%$ & 0.24 \\
\hline 841112 (Turbo-jet engines of a thrust exceeding $25 \mathrm{kN}$ ) & $0.8 \%$ & 0.15 \\
\hline $\begin{array}{l}870899 \text { (Other parts and accessories of the motor vehicles of headings } \\
\text { No. } 87.01 \text { to } 87.05 \text { ) }\end{array}$ & $0.8 \%$ & 0.31 \\
\hline $\begin{array}{l}870324 \text { (Other vehicles, with spark-ignition internal combustion reciprocating } \\
\text { piston engine, of a cylinder capacity exceeding } 3,000 \mathrm{cc} \text { ) }\end{array}$ & $0.7 \%$ & 0.01 \\
\hline Subtotal & $39,8 \%$ & \\
\hline
\end{tabular}




\section{ANALYSIS OF FOREIGN DIRECT INVESTMENT BETWEEN THE EUROPEAN UNION, BRAZIL AND MEXICO}

In this section, the FDI between the EU and Brazil and Mexico is studied from a deeper, more individualized perspective, by concentrating in the bilateral relations between the six main countries of the EU and Brazil and Mexico. The analysis is carried out at global and sectorial levels and also offers a look at the recent evolution of FDI. The selected EU countries are Germany, Spain, France, Italy, the Netherlands and the United Kingdom because, as was shown in section 3.3, they are most important in terms of FDI. Moreover, this procedure also allows for a more homogeneous comparison with the analysis of trade flows. In this section, these six European countries will be referred to jointly as EU-6.

\subsection{Comparative analysis of Brazil and Mexico's foreign direct investment with the main European economies today}

\subsubsection{Overview}

A fuller analysis of Brazil and Mexico's FDI requires the study of their bilateral relations with the main economies of the EU, which also participate in the FDI of these two LA countries, especially as issuers and, increasingly, as recipients.

Beginning with the case of Brazil, Table 6.1 summarizes the inward and outward flows and stocks between Brazil and the six European countries included in this study in 2012. The first EU country by amount of FDI issued in Brazil in 2012 is Germany, which exceeded 2,000 million euros, followed by France, which invested 1,926 million euros. Third is the Netherlands, which dedicated 1,435 million euros of FDI to Brazil. Spain was in fourth position in 2012, with an amount of FDI dedicated to Brazil of 972 million euros. It must 
be said that, as we will explain in more detail when we deal with evolution, the amount of FDI received in Brazil from Spain in 2012 was exceptionally low. In fact, essentially as a result of divestments made in LA (particularly Mexico), the flow of FDI issued in 2012 by Spain was negative. The United Kingdom and Italy are the countries with least importance of those analysed, having issued FDI in Brazil of 1,435 and 958 million euros, respectively.

Brazil's FDI outflow directed towards the countries of the EU was much lower. Spain stood out as the main destination for the FDI stemming from Brazil, receiving 835 million euros in 2012. The other countries obtained very small amounts of investment from Brazil. The second destination among the main European economies for FDI from Brazil was Italy, although with a much lower amount of 89 million euros. The third place corresponded to the Netherlands, with an amount of FDI with origin in Brazil of 25 million euros. The United Kingdom was the fourth country of the six analysed by reception of investment of Brazil, with an inflow of 6 million euros. Finally, France and Germany had negative figures of 19 and 10 million euros, respectively.

\begin{tabular}{l|c|c|c|c}
\hline \multicolumn{1}{c}{ Table 6.1. FDI between Brazil and the main countries of the EU in 2012 (in millions of euros) } \\
\hline \multicolumn{2}{c}{ Country } & \multicolumn{3}{c}{ Flows } \\
\hline & $\begin{array}{c}\text { Received in } \\
\text { Brazil }\end{array}$ & Issued by Brazil & $\begin{array}{c}\text { Received in } \\
\text { Brazil }\end{array}$ & Issued by Brazil \\
Germany & 2,029 & -10 & 13,836 & 212 \\
Spain & 972 & 835 & 51,020 & 9,291 \\
France & 1,926 & -19 & 24,682 & 426 \\
Italy & 782 & 89 & 6,616 & 485 \\
The Netherlands & 1,435 & 25 & 12,361 & 44 \\
United Kingdom & 958 & 6 & 13,996 & 26
\end{tabular}

Due to the volatile nature of FDI flows and, especially, the exceptionally low figure for Brazil's FDI inflow from Spain in 2012 and the negative figures for Brazil's outflow towards France and Germany, the analysis needs to be completed with information on stocks (also shown in Table 6.1), in order to obtain a better understanding of the bilateral relations. The analysis of stocks shows the great importance of Spain as the main EU investor in Brazil. In fact, its accumulated FDI stock in 2012 exceeded 51,000 million euros. A considerable way behind was France, the second country of the six analysed with most FDI in Brazil, with 24,682 million euros, less than half the figure corresponding to Spain. It was followed in importance by the United Kingdom and Germany, with very similar figures (approximately 14,000 million euros for the United Kingdom and 13,836 Germany) and the Netherlands (with 13,996 million euros). As with Brazil's FDI inflows, Italy was the country with the lowest FDI stock, 6,616 million euros. 
Brazil's outward FDI stocks towards the six European countries under consideration clearly identify Spain as the main destination, accumulating 9,291 million euros in 2012. None of the other countries reached 500 million euros, although the second country in importance, Italy, came close, with FDI amounting to 485 million euros received from Brazil up to 2012. It was closely followed by France, with a figure of 426 million euros. The fourth destination for FDI issued by Brazil in the main economies of the EU was Germany, with 212 million euros. The Netherlands and the United Kingdom were the countries with the least importance in the FDI outflow of Brazil, with only 44 and 26 million euros, respectively.

In the case of Mexico, Table 6.2 shows the inward and outward FDI between Mexico and the six European countries. The FDI received in Mexico in 2012 corresponding to the EU- 6 was mainly of German origin, accounting for 808 million euros. Next in importance were the Netherlands and France, with considerably lower amounts (364 and 272 million euros, respectively). The figures for Spain and Italy were negative, and the negative amount was especially high in the case of Spain (-2,566 million euros, compared with -90 for Italy). It must be said that these negative figures were exceptional; they arise from Spain's intense share sales in 2012, which were concentrated on Mexico and which resulted in a negative total FDI outflow in that year. The analysis of its evolution (Section 6.3) will show the traditional importance of Spain as the main EU investor in Mexico. Finally, in the case of the United Kingdom, the data available for 2012 are very limited, but if the previous year is taken as reference, its investment would amount to 1,170 million euros, thus reflecting its relevance for Mexican FDI which is only surpassed by Spain, the European economy with most productive presence in Mexico.

The FDI issued by Mexico in the countries of the EU-6 in 2012 was much smaller, except for the Netherlands. The extraordinarily high figure of 4,058 million euros converted this country the main EU-6 destination for FDI from Mexico. Spain was the second European country to which Mexico dedicated its FDI, reaching 673 million euros. France and Germany occupied the third and fourth places, with 129 and 83 million euros, respectively. Italy only received 11 million euros in FDI with origin in Mexico. Again, in the case of the United Kingdom, the information corresponding to 2012 and 2011 is not available. The last data for 2010 gave evidence of an amount of FDI issued from Mexico to the United Kingdom of only 1 million euros.

As the data for 2012 are insufficient for the United Kingdom and show anomalous behaviour in the case of Spain, which does not reflect neither its trend nor its importance in either absolute or relative terms for the Mexican economy, the analysis is completed by the situation of FDI stocks between Mexico and the six countries of the accumulated EU up to 2012. 


\begin{tabular}{l|c|c|c|c}
\hline \multicolumn{1}{c}{ Table 6.2. FDI between Mexico and the main countries of the EU in 2012 (in millions of euros) } \\
\hline \multicolumn{3}{c}{ Country } & \multicolumn{3}{c}{ Flows } \\
& $\begin{array}{c}\text { Received in } \\
\text { Mexico }\end{array}$ & $\begin{array}{c}\text { Issued by } \\
\text { Mexico }\end{array}$ & $\begin{array}{c}\text { Received in } \\
\text { Mexico }\end{array}$ & $\begin{array}{c}\text { Issued by } \\
\text { Mexico }\end{array}$ \\
Germany & 808 & 81 & 6,681 & 172 \\
Spain & $-2,566$ & 673 & 36,264 & 4,160 \\
France & 272 & 129 & 2,829 & 1,331 \\
Italy & -90 & 11 & 1,199 & 47 \\
The Netherlands & 364 & 4,058 & 9,311 & 1,597 \\
United Kingdom & - & - & 5,368 & -
\end{tabular}

Source: Own elaboration based on Eurostat data

With regard to the stock received by Mexico, Spain was the most important investing country, its investment amounting to 36,264 million euros in 2012, a figure which doubled the combined stock of the other five EU countries. This top position shows Spain's highpriority role in Mexico's FDI, although in the last two years considered (2011 and 2012), it was affected by large divestments which make its annual flow figure negative. The second country by volume of FDI issued towards Mexico was the Netherlands $(9,311$ million euros), followed by Germany and the United Kingdom (with 6,681 and 5,368 million euros, respectively). France was in fifth place with an amount of FDI in Mexico of 2,829 million euros. Finally, Italy had accumulated FDI in Mexico equivalent to approximately 1,200 million euros.

With regard to the stock of FDI coming from Mexico to the EU-6 in 2012, Spain again stood out as the main destination, with an accumulated amount of 4,160 million euros. The Netherlands and France were the second and third countries in terms of inward FDI from Mexico, with 1,597 and 1,331 million euros, respectively. Germany's accumulated FDI from Mexico was 172 million euros and Italy had the smallest figure, with 47 million euros. The United Kingdom figure for 2012 is not available, which is why the last available figure - 13 million euros - corresponding to 2010, was used as reference.

Therefore, the present reality of bilateral relations of the main economies of the EU with Brazil and Mexico shows the greater importance of inflows from the EU-6 in the two economies of LA, with Brazil playing a larger role in this respect. When the EU countries were the recipients, only Netherlands and France received a greater amount of FDI in absolute terms with origin in Mexico than in Brazil. In both Brazil and Mexico, the role of Spain stood out, in both directions, as investor and recipient. This is especially true when stocks were analysed, because Spain made important divestments in 2012 that affected Mexico in particular. 


\subsubsection{Sectorial analysis}

The characterization of the bilateral relation between Brazil and Mexico and the main economies of the EU should not limit itself to the study of flows and aggregate inward and outward stocks and their evolution, but needs to be completed by a sectorial approach. The information on sectorial flows and stocks between two countries stem from Eurostat, - the only source that allows the two variables (country and sector) to be combined. Still, the data available are more limited than desired in order to undertake a more comprehensive analysis and comparable to the analysis of trade data. The two main limitations are that the period for which sectorially disaggregated data are available is reduced to the most recent years, 2005-2012 (and for most countries the disaggregated data are only presented up to the year 2011), and the classification is more aggregated than the one used for trade. Although the statistics offered by Eurostat use the two-digit NACE classification, they are not complete, because some related branches are grouped into one and data are not available for all sectors for reasons of confidentiality. These limitations are larger in the case of Mexico, where sectorial information available for fewer branches than in the case of Brazil.

Considering the variability of flows and the limitations of the data, for this sectorial characterization, stocks of accumulated FDI in Brazil and Mexico from the six EU countries considered in this study are used.

The distribution of Brazil's inward stocks of FDI by sector of activity is shown in Table 6.3. The sectorial classification establishes the category Others, which includes activities that are neither manufacturing nor service activities. Given the existing availability of data, the contribution of activities like agriculture, mining and extractive activities, power or construction cannot be identified in all countries.

Important differences in the sectorial composition of Brazil's inward FDI could be observed according to the country considered. Thus, the manufacturing sector was clearly predominant in three countries (Germany, Italy and the Netherlands), in which it accounted for approximately three quarters of the total FDI directed to Brazil. Services constituted the sector in which the FDI from France was most concentrated (89\%) and it was also the main activity to which FDI of Spanish origin goes (57.6\%). In the case of the United Kingdom the main activity were Other sectors, because of the importance of its activities related with natural resources. This activity also had a relevant weight, although much smaller than that of the United Kingdom, in Spain (13.2\%). In this case the FDI were essentially directed to the power sector, without forgetting the construction sector. In the other countries, the importance of the Others sector was very low, between $1 \%$ and $2 \%$. The smallest relative weight of the FDI dedicated to the manufacturing 
sector corresponded to France (only 9\%) and to the United Kingdom (17.8\%). Italy and the United Kingdom were the countries with the lowest relevance of services $(16.7 \%$ and $19.7 \%$, respectively), this activity representing approximately a quarter of the total FDI issued towards Brazil by the Netherlands and Germany. In general, considering the EU-6 countries analysed in this study, the sectorial distribution demonstrates the importance of the services sector, which represented half the FDI received by Brazil from the EU-6. Manufacturing represented approximately a third (34.1\%) and the remaining $14.8 \%$ corresponded to other sectors, such as power, agriculture, mining and extractive industries and construction.

Table 6.3. Sectorial distribution of Brazil's inward FDI stocks from the main EU countries in 2011 (in millions of euros)

\begin{tabular}{|c|c|c|c|}
\hline Country/Sector & Manufacturing & Services & Others \\
\hline Germany & $73.2 \%$ & $25.6 \%$ & $1.2 \%$ \\
\hline Spain & $29.2 \%$ & $57.6 \%$ & $13.2 \%$ \\
\hline France & $9.0 \%$ & $88.8 \%$ & $2.2 \%$ \\
\hline Italy & $81.3 \%$ & $16.7 \%$ & $2.0 \%$ \\
\hline The Netherlands & $76.2 \%$ & $22.0 \%$ & $1.8 \%$ \\
\hline United Kingdom & $17.8 \%$ & $19.7 \%$ & $62.5 \%$ \\
\hline EU-6 & $34.1 \%$ & $51.1 \%$ & $14.8 \%$ \\
\hline
\end{tabular}

This overview of the sectorial distribution is followed by the presentation of the main branches of the industrial and services sector and their importance in percentage in tBrazil's FDI stock received from the main European economies up to 2012. Although there are some differences in the arrangement of the branches depending on the country considered, the main activities can be identified.

So, from an overall perspective for the six countries, the three most important manufacturing branches by reception of FDI in Brazil (Graph 6.1) were Petroleum production, the chemicals industry and rubber and plastic products; metallurgy and manufacturing of metal products; and manufacturing of motor vehicles and other transport equipment. They were followed in relevance by metallurgy and manufacturing of metal products; and Food, beverages and tobacco.

The sectorial analysis of each country's bilateral relations with Brazil tended to coincide with their production specialization. Spain dedicated most of its FDI in Brazil in the branch of metallurgy and manufacturing of metal products (with $54.2 \%$ of the total), followed by Petroleum, the chemicals industry and rubber and plastic products $(32.1 \%)$. Therefore, three quarters of the Spanish FDI in Brazil were concentrated in these two branches, while Manufacturing of vehicles and other transport equipment represented $7 \%$ of the total. Italy dedicateed a third of its FDI in Brazil to the branch of Manufacturing of vehicles 
and other transport equipment; and a quarter to Petroleum, the chemicals industry and rubber and plastic products. The latter branch represented half the FDI dedicated to Brazil by the Netherlands (54.5\%), a country whose investment was heavily concentrated, because the second branch, Food, beverages and tobacco, accounted for $41.1 \%$ of its FDI in Brazil. The Netherlands displayed a negative figure in the Others sector because of the behaviour of the branch Manufacturing of computer, electronic and optical products. The disaggregated information available for the United Kingdom is limited and does not allow for an identification of the distribution by branch of $93.2 \%$ of its FDI in Brazil. It can only be stated that the branch Petroleum, the chemicals industry and rubber and plastic products represented $6.5 \%$ of its total FDI in Brazil. With France, as was the case for Italy, manufacturing of motor vehicles accounted for a little more half of its manufacturing foreign investment issued in Brazil (53.8\%). The second most important branch was Other manufacturing branches with $20.8 \%$ of the total of FDI, among which the activity Wood and paper industry, publishing and reproduction stood out. The branch Petroleum, the chemicals industry and rubber and plastic products represented $14.4 \%$ of France's accumulated FDI in Brazil up to 2012. In the case of Germany, two thirds of its manufacturing FDI in Brazil was concentrated in the two branches Manufacturing of vehicles and other transport equipment; and Petroleum, the chemicals industry and rubber and plastic products. Each represented 35.3\% of Germany's total FDI, the first of them being slightly higher.

Graph 6.1. Main manufacturing branches by FDI stock received in Brazil from the EU-6 up to 2011

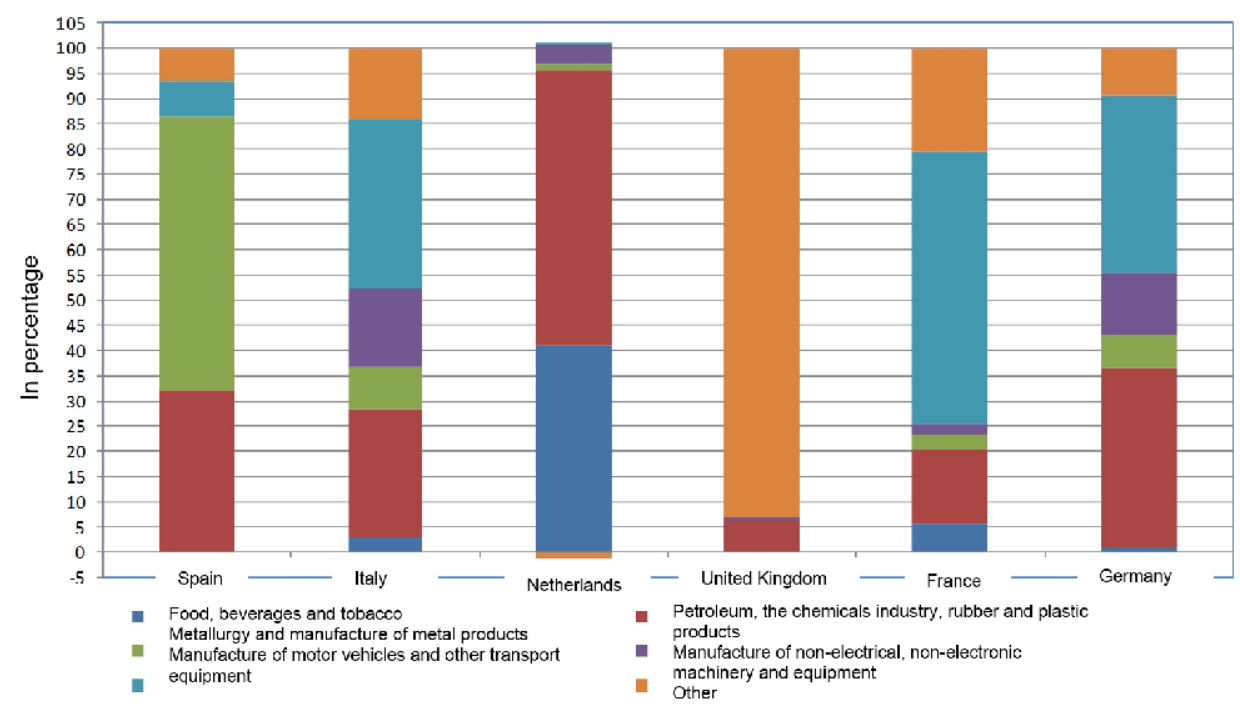

Source: Own elaboration based on Eurostat data 
Within the services sector, from the overall perspective of FDI received in Brazil from the EU-6, the most important branches were Financial activities and insurance; and Information and communications. Next in importance were the branches Professional, scientific and technical activities; and Trade (which includes wholesale and retail trade and repair of motor vehicles and motorcycles). Smaller amounts were dedicated to the branches Transport and storage and, especially, to Real estate activities.

The relative importance of these branches differed according to the country considered (Graph 6.2). Spain dedicated a little over half its FDI stock in Brazil until 2011 in the services sector to the branch of Information and communications. The second most important branch were financial and insurance activities, which represented $39.3 \%$ of the total Spanish FDI in services. So the Spanish investment was very concentrated in these two branches, which together accounted for $91.3 \%$ of Spain's total FDI outflow towards Brazil in the services sector. The category Other branches showed a negative figure, explained by the behaviour of the branch Administrative activities and auxiliary services. Italy's sectorial distribution was more diversified, with the branch of financial and insurance activities acquiring the highest importance (representing $39.4 \%$ of the total), followed by Trade and Professional, scientific and technical activities, with $21.6 \%$ and $16.4 \%$, respectively, of Italy's total FDI stock in Brazil corresponding to the services sector. The Netherlands dedicated most of the FDI in Brazil to the branch financial and insurance activities, which represented $72.7 \%$ of the total in the services sector. Among the other branches, Trade (9.4\%) and Transport and storage (8.7\%) stood out. A little over half $(58.1 \%)$ of the United Kingdom's FDI stock in Brazil in services was directed to the branch of financial and insurance activities. A quarter of the United Kingdom's FDI in Brazil's services sector corresponded to Other branches, which also occurred in the manufacturing sector and can be explained by the low availability of sectorial data for 2011 for that country. France's FDI was highly concentrated, with two thirds of its FDI stock in Brazil's services sector issued in financial and insurance activities (65.3\%); and a little more than a quarter (26.4\%) in Professional, scientific and technical activities. Finally, Germany's two most important branches, with a very similar contribution of nearly a third of its tertiary FDI, were Trade (32.2\%) and financial and insurance activities (32.0\%). They were followed in importance by the branch Professional, scientific and technical activities, which represented $19.7 \%$ of Germany's total FDI stock in Brazil's services sector. Spain and Germany were the only two countries in which financial and insurance activities did not represent the most important services branch in Brazil's accumulated inward FDI but the second, although in the case of Germany, the figure reached was very close to the first. 
Graph 6.2. Main branches of the services sector by FDI stock received in Brazil from the EU-6 up to 2011

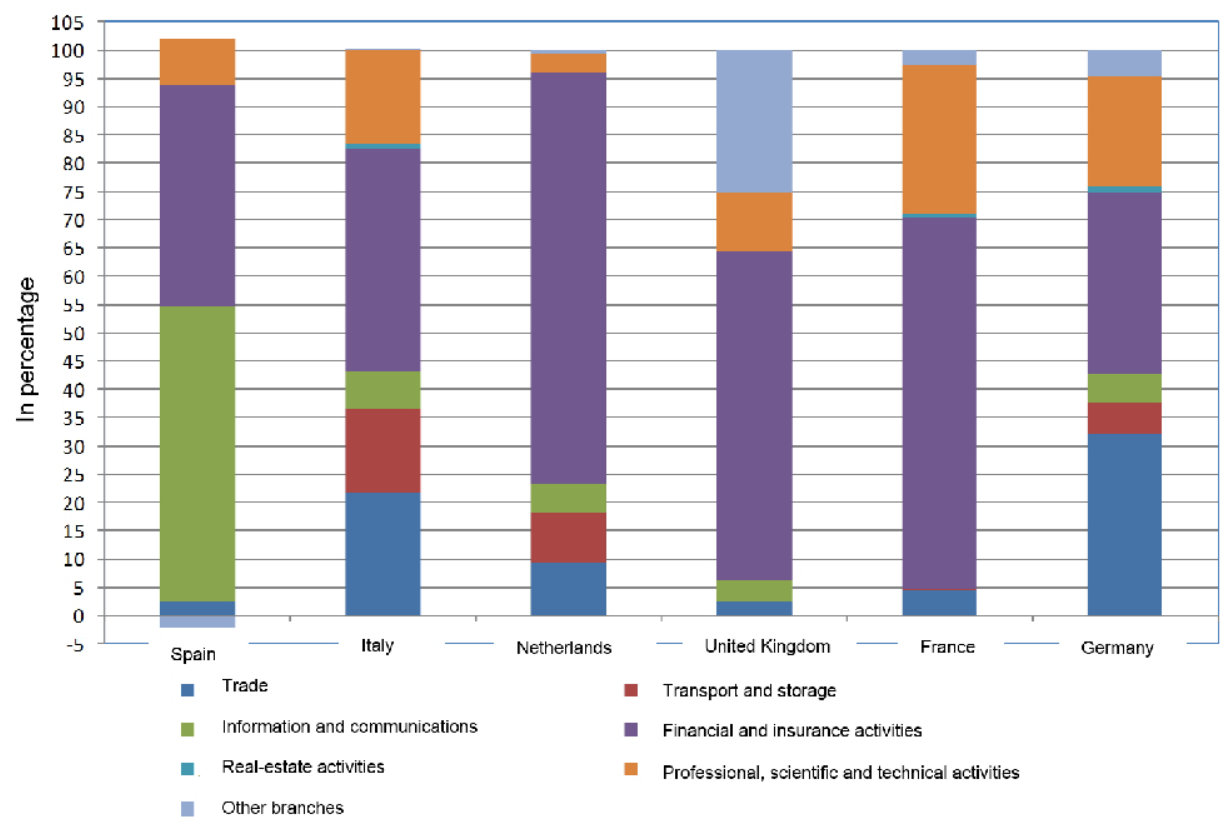

Source: Own elaboration based on Eurostat data

With respect to Brazil's inward and outward stock for the EU-6 overall and by country at sectorial level, from the point of view of outward FDI stocks at the EU-6 level, the main sector was manufacturing, representing $59.5 \%$ of the total, while $33.0 \%$ corresponded to services. Within the manufacturing activities, the importance of Brazil's FDI outflow in the branch of metallurgy and manufacturing of metal products (especially towards Spain) stood out. The second branch, with much smaller importance, were metallurgy and manufacturing of metal products, which were directed particularly to Italy. In the services sector, the main branch was financial and insurance activities (especially towards Spain). Although the amounts were much smaller, the activities of the Hotel trade (with France as the main destination) and Trade (where Germany is the main recipient) should also be mentioned.

Having characterized Brazil's FDI from and in the main European economies, a similar analysis will now be carried out for the case of Mexico, bearing in mind the lower degree of sectorial disaggregation given the reduced availability of data for this country.

The sectorial distribution of Mexico's inward FDI stock (Table 6.4) stemming from the EU-6 as a wholedemosntrates the importance of the services sector, representing $62.4 \%$ 
of the FDI received. The manufacturing sector was the destination for a little more than a quarter (27.5\%) of the accumulated FDI in Mexico with origin in the EU-6. Activities under Other activities added up to $10.0 \%$ of the total, with power and mining activities and, to a lesser extent, construction standing out.

\begin{tabular}{|c|c|c|c|}
\hline Country/Sector & Manufacturing & Services & Others \\
\hline Germany & 68.44 & 31.37 & 0.19 \\
\hline Spain & 9.13 & 79.07 & 11.80 \\
\hline France & 9.30 & 89.67 & 1.03 \\
\hline Italy & 87.82 & 8.77 & 3.41 \\
\hline The Netherlands & 71.66 & 26.47 & 1.86 \\
\hline United Kingdom & 3.42 & 68.59 & 27.99 \\
\hline EU-6 & 27.54 & 62.44 & 10.01 \\
\hline
\end{tabular}

This general description differs according to the country that we consider. Thus, Germany's distribution was oriented towards manufacturing, which exceeded two thirds of the total FDI (68.4\%) it dedicated to Mexico, while services represented approximately a third (31.3\%), whereas the contribution of other large sectors was only marginal $(0.2 \%)$. Spain had a relatively higher stake in services vis-à-vis the EU-6 group as a whole, it accounted for more than three quarters of its total FDI issued in Mexico (79.1\%). The importance of other sectors was remarkable by contributing $11.8 \%$ of the total to this sector, and hence more than to manufacturing $(9.1 \%)$, the reason of which being the significant presence of the power sector and, to a lesser extent, construction. The services sector was of most relative importance for France $(89.7 \%)$, which dedicated $9.3 \%$ of its total FDI stock in Mexico to manufacturing. Italy and the Netherlands found themselves in the opposite situation, with an important concentration of their FDI in Mexico in manufacturing (which represented $87.8 \%$ and $71.7 \%$, respectively). Finally, for the United Kingdom, services constituted the main sector to which its accumulated FDI in Mexico was dedicated, representing $68.6 \%$ of the total. Other sectors amounted to $28.0 \%$ - a very high figure -, partly because of the non-availability of disaggregated data for all branches.

After the overall sectorial distribution of the FDI received in Mexico from the EU-6, we shall now examine the importance of the branches of the industrial and services sectors. Because of the limited sectorial disaggregation allowed by available data, the category Other branches achieved very high figures. The most important manufacturing sector branches for the EU-6 overall were Manufacturing of motor vehicles and other transport equipment, followed by Petroleum, the chemicals industry and rubber and plastic products. 
Differences in the structure of the industrial FDI could be observed according to the country considered (Graph 6.3). Other branches, the category containing all the industrial branches for which separate information was not offered, amounted to more than $50 \%$ of the total manufacturing FDI, and for Italy and the Netherlands, it even reached $90 \%$. However, for the United Kingdom it represented about a third of the total (31.2\%) and for Germany only $18.7 \%$, which indicates that their FDI had a more concentrated sectorial profile.

For Spain, the two main branches of the EU-6 group stood out, although the second of them was more important (17.0\% compared with 14.2\%). Italy's most important branch was also Petroleum, the chemicals industry and rubber and plastic products (12.2\%), while the figure for manufacturing of motor vehicles and other transport equipment was negative $(-2.1 \%)$. In second place was the branch Manufacturing of computer, electronic and optical products, although the amount was very low $(0.4 \%)$. In the case of the Netherlands, the first and second branches in importance were Petroleum, the chemicals industry and rubber and plastic products (8.6\%) and Manufacturing of computer, electronic, and optical products (1.2\%). For the United Kingdom, the branch Petroleum, the chemicals industry and rubber and plastic products predominates clearly, representing two thirds (68.8\%) of the total manufacturing FDI. France's FDI stock in Mexico was also dedicated mainly to that branch of activity, which accounts for $44.4 \%$ of the manufacturing total, and the branch Manufacturing of computer, electronic and optical products represents $3.6 \%$ of the total. For Germany, the branch manufacturing of motor vehicles and other transport equipment stood out, representing more than half of its FDI stock in the manufacturing sector in Mexico (56.3\%). The second most important branch for Germany was Petroleum, the chemicals industry and rubber and plastic products, to which $21.8 \%$ of its total manufacturing FDI was dedicated.

In the services sector, the main branch from the general perspective of the FDI stock dedicated to Mexico by the EU- 6 was constituted by Financial and insurance activities, representing $63.9 \%$ of the total. Next in importance, at a considerable distance, were the branches Trade (which includes wholesale and retail trade and repair of motor vehicles and motorcycles and accounts for $12.2 \%$ of the total) and Information and communications (10.1\%). The branch Professional, scientific and technical activities received $5.9 \%$ of the FDI stock the EU-6 dedicated to the services sector in Mexico.

Because there is greater sectorial disaggregation in the case of services, the relative importance of Other branches turned out less relevant than the one of the manufacturing sector, displaying a figure of $5.3 \%$ for the EU-6 overall, though it was more relevant in the case of Germany (representing $21 \%$ of its total FDI corresponding to the services sector). 
Graph 6.3. Main manufacturing branches by FDI stock received in Mexico from the EU-6 up to 2011

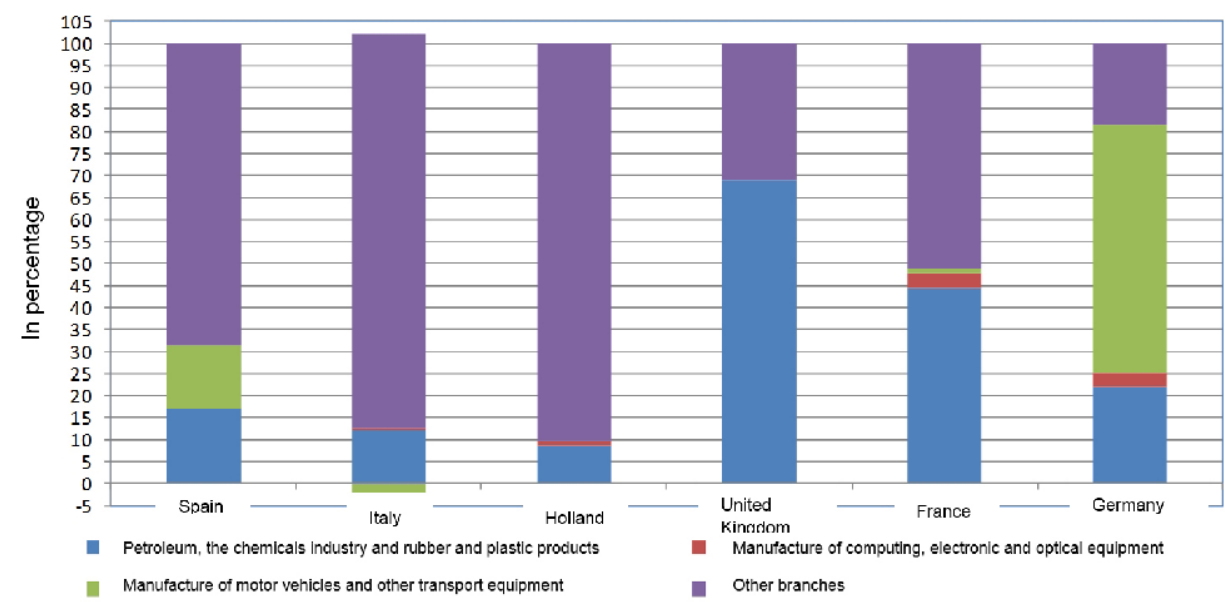

Source: Own elaboration based on Eurostat data

The relative importance of the service sector branches differed according to the country analysed (Graph 6.4). So, although the branch Financial and insurance activities was most important for four of the six countries considered (not for Italy and Germany), its weight in the total varied from a little more a third (34.4\%) of the figure corresponding to services for the Netherlands, to $85.8 \%$ for the United Kingdom. For Spain, it constituted the most important branch in which two thirds of the total FDI was concentrated. The next most important branches were Information and communications (14.2\%) and Trade (7.8\%). In the case of Italy most of its FDI in services in Mexico was directed to the branch of Trade $(79.7 \%)$. The two following and much less important branches were Scientific, professional and technical activities, and Transport and storage, which represented 8.9\% and $8.0 \%$ Italy's total FDI stock in Mexican services activities. Finally, it should be mentioned that the branch Information and communications represented a negative figure, equivalent to $8.9 \%$.

Trade constituted the Netherlands' most important branch, in which over half of the tertiary sector FDI stock (59.4\%) received by Mexico from that country was concentrated. The second branch was Financial and insurance activities, with a little more than a third; and third was Transport and storage, with 3.8\%. For the United Kingdom, the large weight of the Financial and insurance activities branch left the second most important branch, Information and communications, with a percentage of only $3.0 \%$ of the total. 
Graph 6.4. Main services branches by FDI stock received in Mexico from the EU-6 up to 2011

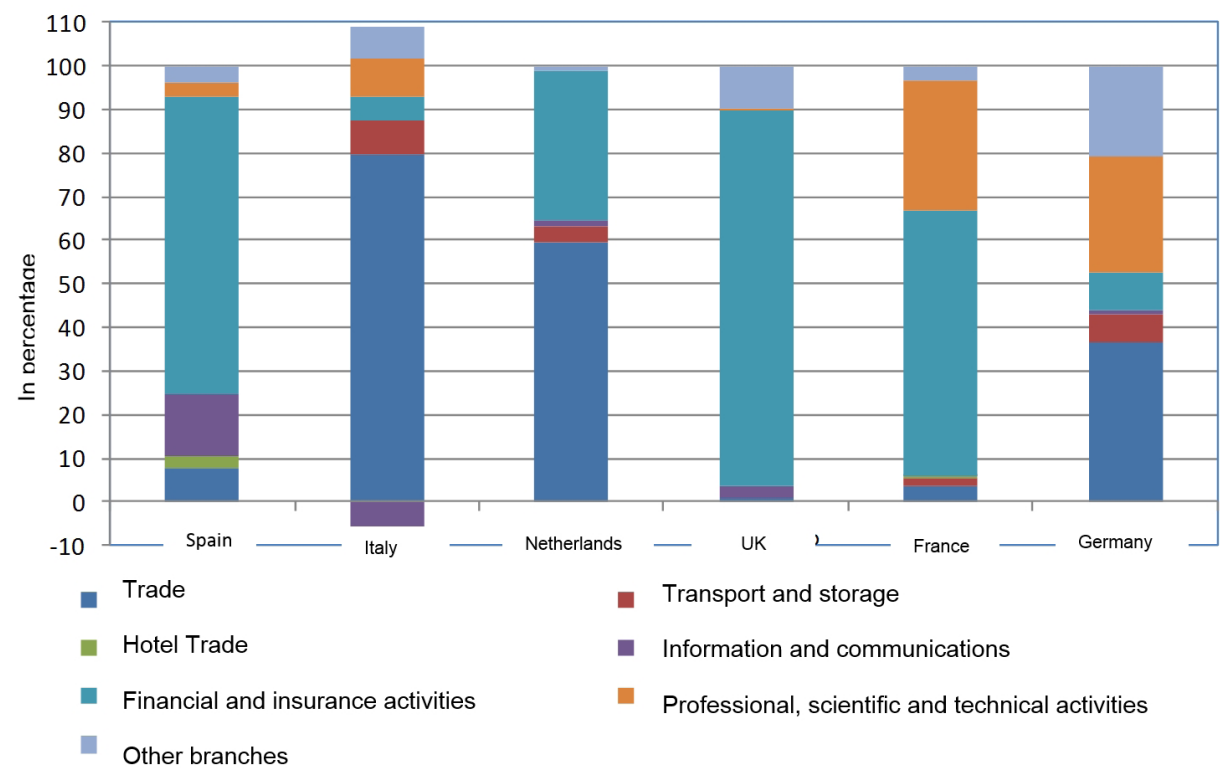

Source: Own elaboration based on Eurostat data

Around 90\% of France's FDI in Mexico's services sector was concentrated in two branches, the first of which, Financial and insurance activities, accounted for $60.7 \%$, followed by the branch Professional, scientific and technical activities, which represented $29.6 \%$ of the total. Finally, for Germany, two branches were of specific importance: Trade (36.6\%) and Professional, scientific and technical activities (26.3\%). The third branch was financial and insurance activities, with only $8.8 \%$ of the total.

As far as Mexico's inward and outward FDI stock by country and for the EU-6 overall at sectorial level is concerned, Mexico's outward FI stocks towards the EU- 6 were mostly dedicated to the services sector, where $80.9 \%$ of the total was concentrated; while $11.6 \%$ of its total FDI was dedicated to the manufacturing sector. In countries like the Netherlands and Italy, manufacturing branches represented more than a third of the FDI issued in Mexico, and reaching $42.4 \%$ for the case of Germany. The most important branch of the manufacturing sector was Petroleum production, the chemicals industry and rubber and plastic products, which was mainly directed to the Netherlands. In services activities, the notable branches were financial and insurance activities (essentially dedicated to Spain), Professional, scientific and technical activities (with Spain and France as the main destinations) and Information and communications (towards the Netherlands). It should be stressed that a relevant proportion of the investment made by Mexico abroad, especially in the sphere of services, was dedicated to knowledge-intensive sectors. 


\subsection{Patterns in the evolution of Brazil's foreign direct investment with the main European economies}

After analysing Brazil's FDI with the economies of the EU-6, we now turn to its evolution, first from an overall perspective and then from a sectorial perspective. The time period chosen is from the beginning of the nineties to 2012 (the last data available), although the data corresponding to all the countries of the EU-6 were not available for every year in the period.

\subsubsection{Overview}

Growth in Brazil's FDI inflow from the EU-6 (Graph 6.5) displays large oscillations in the period 1992-2012, reflected in the fact that only Italy, France and, especially, Germany, registered growth in their annual FDI in the period 1999-2012 (data for all the countries before 1999 were not available). The differences between the trajectories followed by the countries (and between the different stages in the period, such as before and after the current crisis) made it difficult to identify a common pattern and lead to changes in the importance of the countries considered.

A pattern of strong oscillations matches the growth followed by Spain which, because of its importance in the EU-6 group, marks the trend for the region. From 1999 to 2012, Spain decreased FDI flow to Brazil at a compound annual rate of 9.6\%. Beginning with a figure of 3,618 million euros, the strong growth of 2000 took it to a very high figure $(12,583$ million euros). The fluctuations in the following years led it to the negative figure of 1,812 million euros in 2002. The growth of the 2008-2010 period (especially intense in the last year) meant that its peak of 16,169 million euros was recorded in 2010 , followed by an important reduction, which put the flow corresponding to 2012 at 972 million euros, the minimum positive figure in the whole period.

In the case of the Netherlands, which began in second position in 1999, with an FDI of 2,456 million euros (its peak), the oscillations of the following years took it to negative figures (specially large in 2004 and 2008, reaching 591 and 736 million euros, respectively). After 2009, it continued to have annual oscillations, although every year it recorded figures over 1,000 million euros. The trend of the United Kingdom was also downward, although its reduction was smaller (compound annual reduction rate (CARR) of 2.3\%). There were important fluctuations in its trajectory, with a minimum figure of 27 million euros being recorded in 2002 and the peak of 1,985 million euros in 2011. 


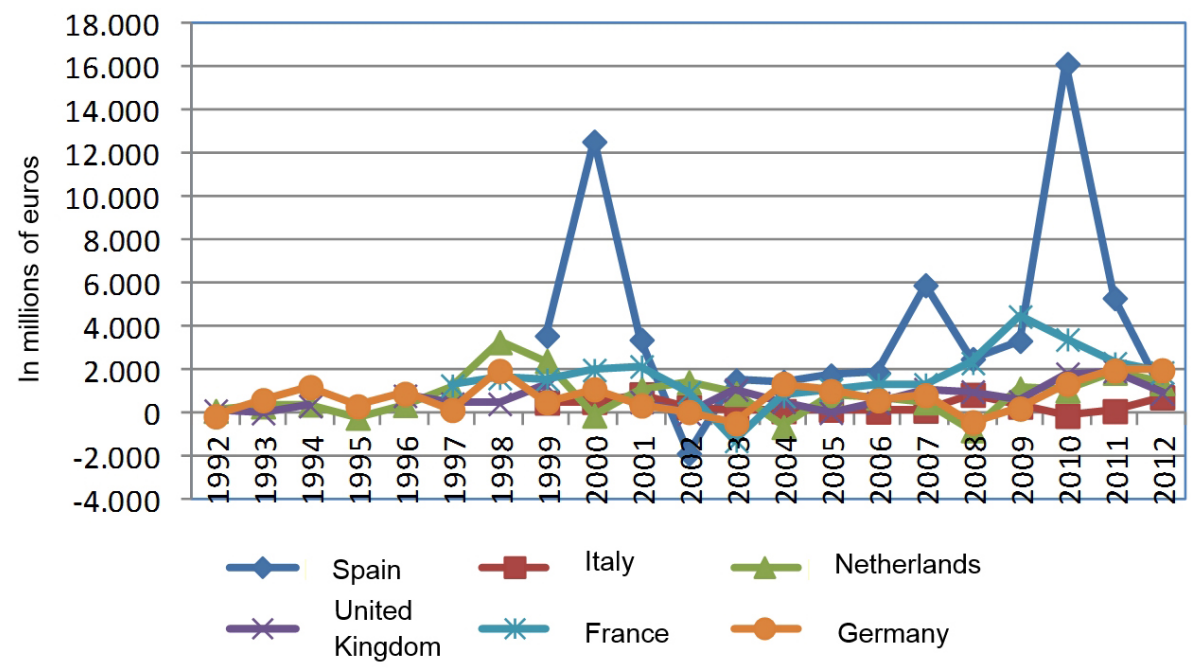

Source: Own elaboration based on Eurostat data

France had a compound annual growth rate of 1.4\% over the period 1999-2012. In 1999 it issued 1,600 million euros of FDI in Brazil. After a period of growth, the annual flow was reduced after 2002 to a negative figure of 1,231 million euros in 2003. After that year a period of growth began, continuing (and intensifying from 2007) until the peak of 4,510 million euros in 2009. After that, the trend was of continuous reduction, the flow corresponding to 2012 being 1,926 million euros. Italy was the second country by rate of growth in the period under consideration. After growth in the initial period (until 2001 when a peak of 918 million euros was achieved), a decreasing trend followed until 2006 (except for 2005), reaching its lowest figure of 127 million euros. After that an oscillating trend was observable, with years of strong growth (such as 2008 and 2012) and notable reductions (such as 2009). Finally, Germany was the country that registered the greatest growth, with a cumulative annual growth rate of $10.4 \%$. Thus, it developed from fifth position in the EU-6 in the annual FDI dedicated to Brazil in 1999, with the amount of 558 million euros, to become the most important economy in 2012, reaching its historic peak of 2,029 million euros. Throughout the period, its trajectory was variable, displaying a dynamic behaviour and strong growth in the context of the present crisis (period 20072012, except for the negative figure of 373 million euros corresponding to 2008).

Graph 6.6 shows the relative importance of the 6 EU countries considered, with the category Others referring to the other countries making up the EU. ${ }^{45}$ The bilateral FDI 
between Brazil and the EU-28 was essentially concentrated in the EU-6. Although there were variations throughout the period, the EU- 6 represented most of the FDI issued by the EU in Brazil, with percentages varying from the minimum of $78.2 \%$ in 2010 to $99.8 \%$ in 2009. The most habitual figures ranged between $87 \%$ and $95 \%$. Fluctuations in relative importance did not follow a trend which could lead to the conclusion that the relative weight of the EU-6 was rising or falling among the EU overall with regard to the FDI dedicated to Brazil. It appears that annual variations in the weight of the EU-6 and the other countries of the EU were conditioned by the volatility inherent in the flows and by annual merger and acquisition transactions.

Traditionally Spain was the main EU investor in Brazil, followed by France. Other countries displayed lower shares, although in some years, their share could amount to very high rates. The changes in the relative importance of the different countries shown in Graph 6.5 can be explained by the evolution they followed in the period 2001-2012, as previously described.

Graph 6.6. Importance of Brazil's FDI inflows from the EU countries 2001-2012

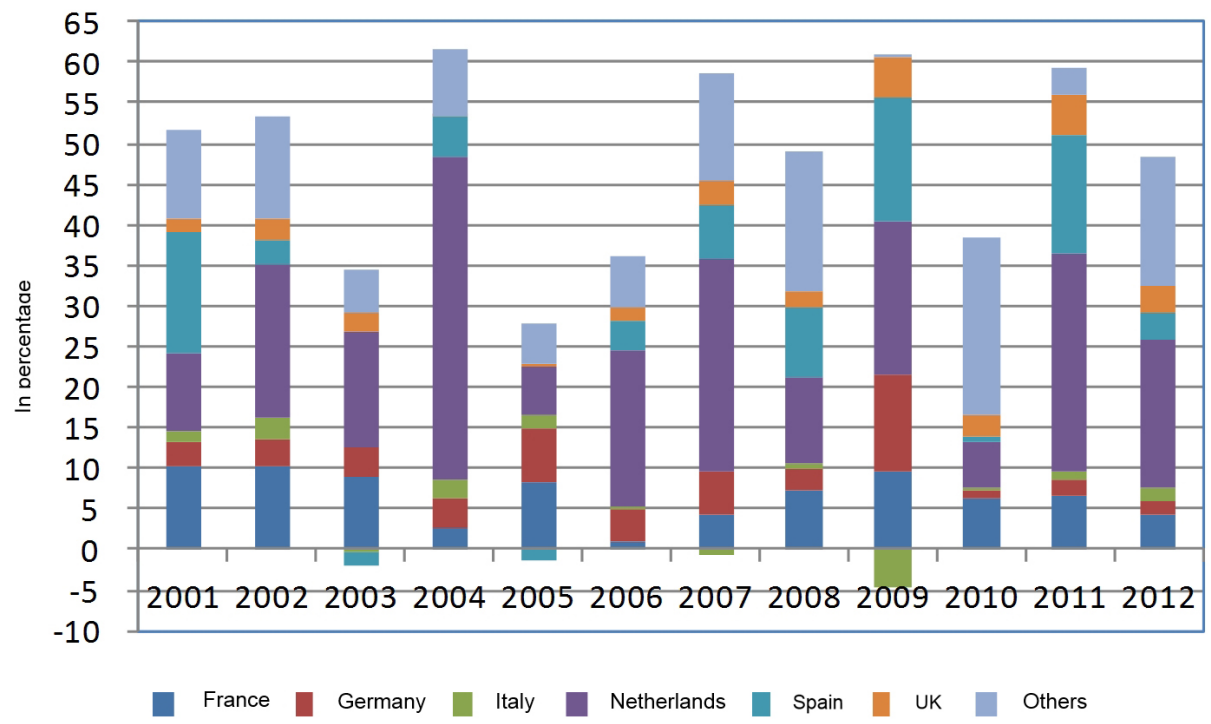

Source: Own elaboration based on UNCTAD data 


\subsubsection{Sectorial analysis}

Following the analysis of overall growth of the FDI between Brazil and the EU-6, changes in the sectorial distribution will now be approached. Considering the limited availability of disaggregated information for all the countries analysed and the variability of the flows for the period 2007-2011, it seems more adequate to concentrate on the evolution in the stock of the most important branches by country. Table 6.5 presents the rate of variation of accumulated stocks in Brazil from the EU-6, for the main branches of activity, both overall and by country.

For the EU-6 overall, the stock of accumulated FDI in Brazil increased by $93 \%$ in the period 2007-2011, an increase which affected manufacturing activity (140.5\%) more than services $(56.6 \%)$. Therefore, the relative weight of manufacturing increased from $27.4 \%$ in 2007 to $34.1 \%$ in 2011 , while the contribution of services fell from $63 \%$ to $51.1 \%$ in the same period. All the EU-6's manufacturing branches increased their stock, except Food, drinks and tobacco, because of the behaviour of France in that sector, with negative inflows in Brazil in 2008 and 2011. The biggest rates of increase in manufacturing branches were observed in Manufacturing of machinery and non-electrical and non-electronic equipment (763.2\%), followed by Petroleum, the chemicals industry and rubber and plastic products (201.7\%). With regard to services, the reduction in Real estate activities (91.5\%) stood out, and the biggest rates of growth were observed in Transport and storage (252.7\%), followed by Information and communications (138.7\%) and Trade (126.3\%).

The evolution at sectorial level was not homogeneous among the six countries considered. The countries with highest increase in manufacturing - which, for that reason gained in relative importance in the distribution of its FDI in the period 2007-2011 - were Spain and especially, Germany, which started off from a very low figure for manufacturing FDI. In Spain all the branches considered increased their FDI; both the activity Petroleum, the chemicals industry and rubber and plastic products in manufacturing and the branch Information and communications in services acquired a considerable weight. In the case of the Netherlands, the manufacturing sector also acquired more importance, as a result of a rate of increase of $80.1 \%$ and a reduction in the services sector of $66.1 \%$, which affected all the branches for which disaggregated information is available, except Transport and storage. The greatest growth in the manufacturing sector corresponded to the branch of Manufacturing of machinery and non-electrical and non-electronic equipment. 


\begin{tabular}{|c|c|c|c|c|c|c|c|}
\hline Sector/ Country & Spain & Italy & $\begin{array}{l}\text { The } \\
\text { Nether- } \\
\text { lands }\end{array}$ & $\begin{array}{l}\text { United } \\
\text { King- } \\
\text { dom }\end{array}$ & France & Germany & $\mathrm{EU}-6$ \\
\hline Food, drink and tobacco & - & 33.33 & 39.06 & - & -78.64 & - & -4.36 \\
\hline $\begin{array}{l}\text { Petroleum production, the } \\
\text { chemicals industry, rubber } \\
\text { and plastic products }\end{array}$ & 531.54 & 27.31 & 115.16 & -71.43 & -15.11 & - & 201.66 \\
\hline $\begin{array}{l}\text { Metallurgy and manufactur- } \\
\text { ing of metal products }\end{array}$ & 458.62 & 116.95 & 910.00 & - & -96.56 & - & 155.70 \\
\hline $\begin{array}{l}\text { Manufacturing of non- } \\
\text { electric, non-electronic } \\
\text { machinery and equipment }\end{array}$ & - & 289.25 & $2,171.43$ & -73.68 & 113.04 & - & 763.22 \\
\hline $\begin{array}{l}\text { Manufacturing of motor } \\
\text { vehicles and other transport } \\
\text { equipment }\end{array}$ & 106.32 & 29.00 & - & - & 24.88 & - & 160.73 \\
\hline Manufacturing & 328.05 & 62.81 & 80.46 & 20.94 & -49.44 & $39,900.00$ & 140.47 \\
\hline Trade & 43.21 & 218.46 & -61.46 & - & 336.44 & $2,780.56$ & 126.31 \\
\hline Transport and storage & - & 248.78 & 141.18 & - & 56.41 & - & 252.73 \\
\hline $\begin{array}{l}\text { Information and communi- } \\
\text { cations }\end{array}$ & 133.40 & 56.10 & - & - & $1,900.00$ & - & 138.69 \\
\hline $\begin{array}{l}\text { Financial and insurance } \\
\text { activities }\end{array}$ & 2.52 & 156.46 & -69.19 & - & 758.50 & - & 63.40 \\
\hline Real estate activities & - & 80.00 & - & - & 33.75 & - & -91.46 \\
\hline $\begin{array}{l}\text { Professional, scientific and } \\
\text { technical activities }\end{array}$ & 4.52 & -17.37 & -78.63 & 135.33 & -8.94 & - & 0.19 \\
\hline Services & 39.96 & 96.31 & -66.12 & 64.95 & 160.29 & $3,057.84$ & 56.60 \\
\hline Total & 75.11 & 57.59 & -7.48 & 233.32 & 89.52 & $9,878.57$ & 93.09 \\
\hline
\end{tabular}

In the FDI of the other countries (Italy and the United Kingdom), services displayed a higher growth than manufacturing, acquiring thereby more importance in the entire group. In the United Kingdom's FDI, with less sectorial disaggregation, growth of the branch Professional, scientific and technical activities stood out. The manufacturing branch with most growth in Italy's FDI was Manufacturing of machinery and non-electrical and non-electronic equipment, while in services the branch Transport and storage stood out, followed by Trade.

In the case of France the growth in services was accompanied by a reduction in the manufacturing sector, affecting Food, drinks and tobacco; Petroleum, the chemicals industry and rubber and plastic products; and metallurgy and manufacturing of metal products. The manufacturing branch recording most growth was Manufacturing of machinery and non-electrical and non-electronic equipment, while in services, Information and communications stood out, followed by financial and insurance activities. 


\subsection{Patterns in the evolution of Mexico's foreign direct investment with the main European economies}

Having analysed Mexico's FDI with the economies of the EU-6, we will now explore its evolution, first from an overall and then from a sectorial perspective. The time period chosen refers to the beginning of the nineties until 2012 (the last data available), although the data corresponding to all the countries of the EU-6 is not available for every year in the period.

\subsubsection{Overview}

Growth of the FDI inflows received in Mexico from the EU-6 (Graph 6.7) was fluctuating throughout the period 1992-2012; even so, a general positive growth trend could be identified, except for Spain which, as mentioned above, carried out important divestments in 2012.

Spain was the most important country of the EU-6 by amount of FDI in Mexico during almost all the period under consideration, except for 2006, 2010 and 2012, when its minimum figure ( $\$ 717$ million) was reached and when it turned negative. Its trajectory was variable; beginning from FDI issued in Mexico of 1,420 million euros, it reached its peak of 4,970 million euros in 2009 , following a trend of clear reduction after that. The Netherlands and Italy also had negative figures at times in the period 2011-2012.

Italy's importance in the FDI received by Mexico has traditionally been low, although its flow during the period analysed seemed to increase. In 1999 it showed a negative value of 27 million euros. The falling tendency at the beginning of the 2000s took it to its minimum positive figure of 1 million euros in 2003. After successive fluctuations, it reached its peak FDI of 250 million euros in 2008. In spite of its intense oscillations, the Netherlands followed a growth trend, because starting from an average of investment among the group of countries analysed of 242 million euros in 1999, it exceeded 1,000 million in 2001. It reached its peak of 5,453 million euros in 2010, becoming thereby the most important EU-6 country in FDI issued towards Mexico.

The United Kingdom followed an evolution marked by fluctuations; it registered important growth in the intermediate years of the period, which converted it into the most important country of the EU-6 in investment in Mexico in 2004 and 2006. In the latter year it reached its peak of 2,042 million euros. After that, its trend was downward, until in the last years of the period when it again changed toward increases in its annual flows. Germany was the country displaying a positive trend in recent years, leading it 
Graph 6.7. Growth in the flows of FDI received in Mexico from the EU-6 (1992-2012)

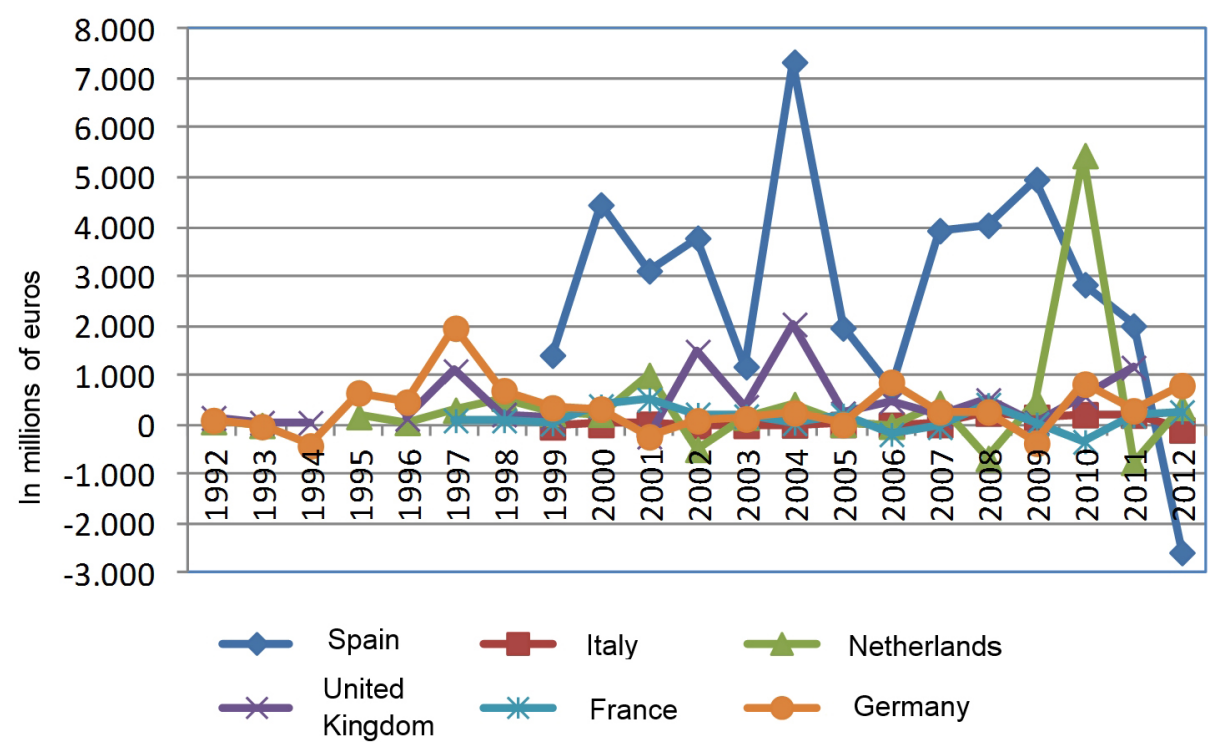

Source: Own elaboration based on Eurostat data

to become the most important country by of FDI in Mexico in 2008 and in the period 2010-2012. It reached its peak of 874 million euros in 2006. Although it did not achieve that figure again, in both 2010 in 2012, it still exceeded 800 million euros. Finally, France was the country with most growth in its annual flows in the period under consideration, recording an annual rate of increase of $16.8 \%$ in the period 1999-2002, although as with the other countries, its trend was fluctuating. It reached its peak of 523 million euros in 2001.

As a result of the different trajectories followed by the countries of the EU-6, changes in the relative importance of the countries occurred in the period 2001-2012, as can be observed in Graph 6.8. Spain was the country which traditionally issued most FDI towards Mexico and it had the highest relative contribution. But even if we would leave the peculiar situation of 2012 aside, its shares varied between figures of about $7 \%$ and the maximum of $31.2 \%$ that it reached in 2004. France reached its maximum contribution of $3 \%$ in 2003 . Germany reached $4.6 \%$ in 2012 , the only year in which Italy exceeded $1 \%$. The participation of the Netherlands was very variable, with figures ranging from $4.3 \%$ to the maximum of $39.9 \%$, although it tended to be placed between $8 \%$ and $16 \%$ of the total FDI received by Mexico. Finally, the share of the United Kingdom varied between $0.5 \%$ and $6.1 \%$. 
Graph 6.8. Importance of the FDI inflows of the main countries of the EU in Brazil 20012012

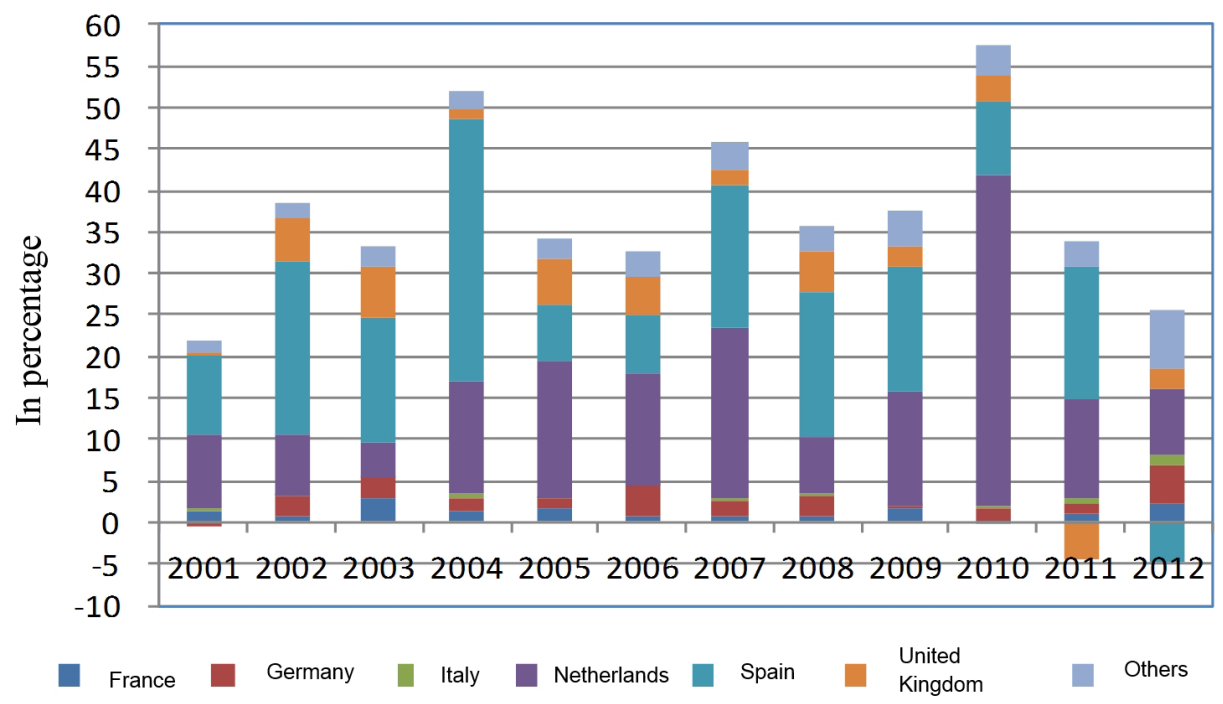

Source: Own elaboration based on UNCTAD data

Finally, it should be pointed out that the FDI issued towards Mexico by the EU was heavily concentrated in the six countries under consideration. Although the participation of the other countries in the EU ${ }^{46}$ varied over the period, the EU-6 represented a minimum of

93\% of the total EU FDI in Mexico, while reaching 97\% in most years of the period under consideration.

\subsubsection{Sectorial analysis}

After the analysis of the evolution of FDI received by Mexico from the EU- 6 from an overall view, this section is dedicated to the sectorial perspective. Because of the limitations of the data, especially with regard to the information disaggregated by branch, an approximation will be made for the period 2005-2011. The analysis concentrates on stocks, considering the limitations of the information and the volatility that are characteristic of flows.

From a general perspective, the amount of accumulated FDI received by Mexico from the EU-6 increased by $53.5 \%$ in the period 2005-2011; this increase was larger in 
services $(172.3 \%)$ than in manufacturing, which is why the relative weight of the former sector increased. The manufacturing sector branch registering the highest growth was manufacturing of motor vehicles and other transport equipment, while in services, the activities of Transport, storage and communications; and Trade stood out, followed by financial and insurance activities.

In contrast to the tendency among the EU-6 group and Germany, the growth rate of manufacturing activities was higher than that of services in the FDI of Spain, Italy and the Netherlands, why is the reason why services lost in relevance in relation to manufacturing activities.

The FDI of the United Kingdom ${ }^{47}$ and France in manufacturing activities decreased, while FDI in services as a whole increased. For France, this can be explained by the important reduction of stock in manufacturing of motor vehicles and other transport equipment and, to a lesser extent, in Petroleum, the chemicals industry and rubber and plastic products. As can be seen from Table 6.6 the behaviour pattern could be rather related to the country making the investment and, in particular, with the needs, opportunities and strategies of the multinational companies, than with the general trend in the sector, because in all branches both countries increasing stock and those reducing it could be found.

\begin{tabular}{|c|c|c|c|c|c|c|c|}
\hline Sector/ Country & Spain & Italy & $\begin{array}{l}\text { The } \\
\text { Nether- } \\
\text { lands }\end{array}$ & $\begin{array}{l}\text { United } \\
\text { King- } \\
\text { dom }\end{array}$ & France & $\begin{array}{l}\text { Ger- } \\
\text { many }\end{array}$ & EU-6 \\
\hline $\begin{array}{l}\text { Petroleum production, the } \\
\text { chemicals industry, rubber } \\
\text { and plastic products }\end{array}$ & - & 1280.00 & -75.76 & - & -27.54 & -22.06 & 19.90 \\
\hline $\begin{array}{l}\text { Manufacturing of com- } \\
\text { puter, electronic and optical } \\
\text { products }\end{array}$ & - & - & - & - & - & - & - \\
\hline $\begin{array}{l}\text { Manufacturing of motor } \\
\text { vehicles and other transport } \\
\text { equipment }\end{array}$ & - & - & - & - & -94.12 & 9.43 & 23.82 \\
\hline Manufacturing & 319.56 & 1429.73 & 182.13 & -86.52 & -24.75 & 0.69 & 65.02 \\
\hline Trade & - & 8900.00 & - & - & 97.50 & 224.75 & 1502.06 \\
\hline $\begin{array}{l}\text { Transportation, storage and } \\
\text { communications }\end{array}$ & - & - & 134.62 & - & 316.67 & 458.33 & 3868.18 \\
\hline Hotel industry & 85.63 & -100.00 & - & - & -77.78 & - & 62.07 \\
\hline $\begin{array}{l}\text { Financial and insurance } \\
\text { activities }\end{array}$ & - & -45.45 & -58.97 & 47.76 & 2890.91 & 441.38 & 367.26 \\
\hline $\begin{array}{l}\text { Professional, scientific and } \\
\text { technical activities }\end{array}$ & -82.32 & - & -100.00 & 50.00 & -48.48 & 51.28 & -67.03 \\
\hline Services & 353.50 & 18.95 & 12.97 & 61.72 & 27.95 & 172.80 & 172.33 \\
\hline Total & 46.43 & 249.32 & 99.77 & 43.64 & 73.60 & 25.84 & 53.52 \\
\hline \multicolumn{8}{|c|}{ Source: Own elaboration based on Eurostat data } \\
\hline
\end{tabular}




\section{INTEGRATION OF THE TWO DIMENSIONS: INSERTION OF TRADE AND PRODUCTION WITHIN THE FRAMEWORK OF GLOBAL INPUT-OUTPUT}

In the analysis carried out in the preceding sections, intra-industrial trade and FDI have been dealt with separately, although without denying their relation of interdependence. The great complexity of this relation, which we have already stressed in the theoretical section, conditions the enormous difficulty involved in empirically unravelling the connections in a framework of multilateral spatial relations.

From a broad territorial and sectorial perspective, like the one adopted here, such work is, if possible, even less feasible, and exceeding the initial objectives of this study. Nevertheless, we consider it appropriate and illuminating to include two types of complementary analysis in this section. The objective of the first one is to contributing evidence about the advance of global value chains through the growth of trade in intermediate goods, while the second seeks to identify aspects that provide information on the association between intra-industrial trade and FDI. For this reason, the study finishes with an exercise of approaching the relationship between FDI and the advance of intra-industrial trade by analysing the degree of concomitance between the presence of foreign capital and the greater or lesser advance of intra-industrial trade flows.

\subsection{Inter-sectorial relations within the input-output framework}

To understand the changes that are currently occurring in trade and productive relations in the world, the information available in the WIOD database (see Box 7.1) is of great help. 


\section{Box 7.1}

The WIOD (World Input-Output Database) contains annual information about world input-output tables in a time series from 1995 onward, as well as about the factor requirements for the same period (Timmer et al. 2015). These input-output tables were prepared following the methodology of the System of National Accounts (ISWGNA) and their construction is based on official input-output tables published by the corresponding national institutions, complemented by annual national accounts data, as well as international trade statistics. The second publication of the WIOD from November 2013 covers a time-series of input-output tables from 1995 to 2011, including data from 40 countries. The economies analysed include 27 members of the EU (except Croatia) and another 13 large economies. Australia, Brazil, Canada, China, India, Indonesia, Japan, Mexico, Russia, South Korea, Taiwan, Turkey and the United States. It should be pointed out that this sample of countries covers $85 \%$ of the world GDP in 2008 (at current exchange rates; ibid.). A model has also been prepared for the "rest of the world," which includes the previously unmentioned economies.

The different elements in the WIOD time-series are the world input-output tables (WIOT), which constitute a set of national input-output tables connected among themselves by the bilateral international trade flows (ibid.). In this regard, world input-output tables provide information about global transactions between industries and final consumers through countries. In this way, the columns offer information about consumptions in each sector or industry, whereas the rows show the destinations of production in each branch. The destinations of production in each productive branch may be made up of intermediate consumption (other sectors) or final demand (consumption and investment) directed towards different countries. Imports are also disaggregated by country and industry of origin. Altogether, there is detailed information on 35 industries or branches, following international classification ISIC Rev. 3 to two digits. The values of the world input-output tables are provided in basic prices in millions of dollars. On the other hand, international trade flows are valued in FOB (free on board).

With regard to its functionality, the WIPO has been applied to describe trends in international trade in global value chains, to study the emergence of regional clusters, and to analyse the creation of added value in exports, among other applications (ibid.) Source: Timmer, M. et al. 2015. An Illustrated User Guide to the World Input-Output Database: the Case of Global Automotive Production.

Review of International Economics, 23(3): 1-31.

The analysis of the inter-sectorial relations the world input-output tables in WIOD provide reveal, among other things, the destination for final or intermediate consumption of each 
type of product. This information opens up the possibility of investigating not just the degree of productive interrelation that exists between the different economies, but also of verifying its advance or backward movement in the context of global value chains. In the following two sections we analyse the existing inter-sectorial relations in the bilateral trade of Brazil and Mexico with their main EU partners in order to find out the specific destination (final or intermediate) of these flows. This analysis provides relevant information about the degree of insertion of these bilateral relations in the framework of global value chains and as well as about the presence of intra-company trade.

Most of the categories of exchanged goods are orientated towards intermediate consumption in other countries (in some cases, practically reaching 100 percent of the international flow considered), which reflects the high degree of extension reached in the framework of global value chains. Additionally, from a dynamic perspective, this type of destination in the set of international trade flows was intensified, confirming thereby the progress in the level of commercial and productive interpenetration of economies. It should be noted that, although these observations offered here are related to the bilateral relations of Brazil and Mexico with their main European partners, empirically they constitute a regular pattern throughout the world, as other studies have shown (Elms and Low 2013; Nicita et al. 2013; Timmer et al. 2014; García and Solís 2014; Los et al. 2015).

\subsubsection{The inter-sectorial relations of Brazil with its main European Union partners}

The analysis of Brazil's input-output relations with its main EU partners allows two general observations to be made. First, the large weight of flows with intermediate consumption as destination can be stressed, i.e., products that are consumed as supplies to productive processes taking place in countries other than the country of origin (Graph 7.1). Furthermore, this importance of the intermediate destination of flows becomes more evident in flows originating in Brazil (output of Brazil) as compared to flows with destination in that country (input of Brazil). This is particularly evident in Brazil's bilateral trade with Germany, Spain and France. A second observation of interest is that it is, in general, a growing phenomenon.

From the point of view of Brazil's exports (output), in 2011, the greatest importance of the intermediate goods was in those with destination France, Italy, Germany and Spain; with a relative weight of about $80 \%$ or even higher. On the import side (Brazil's input), except for Italy, the weight of these goods exceeded 60\%, and in one case (France) $70 \%$. 
Graph 7.1. Relative importance of intermediate goods and services in the bilateral relations of Brazil with its main European Union partners (1995-2011)

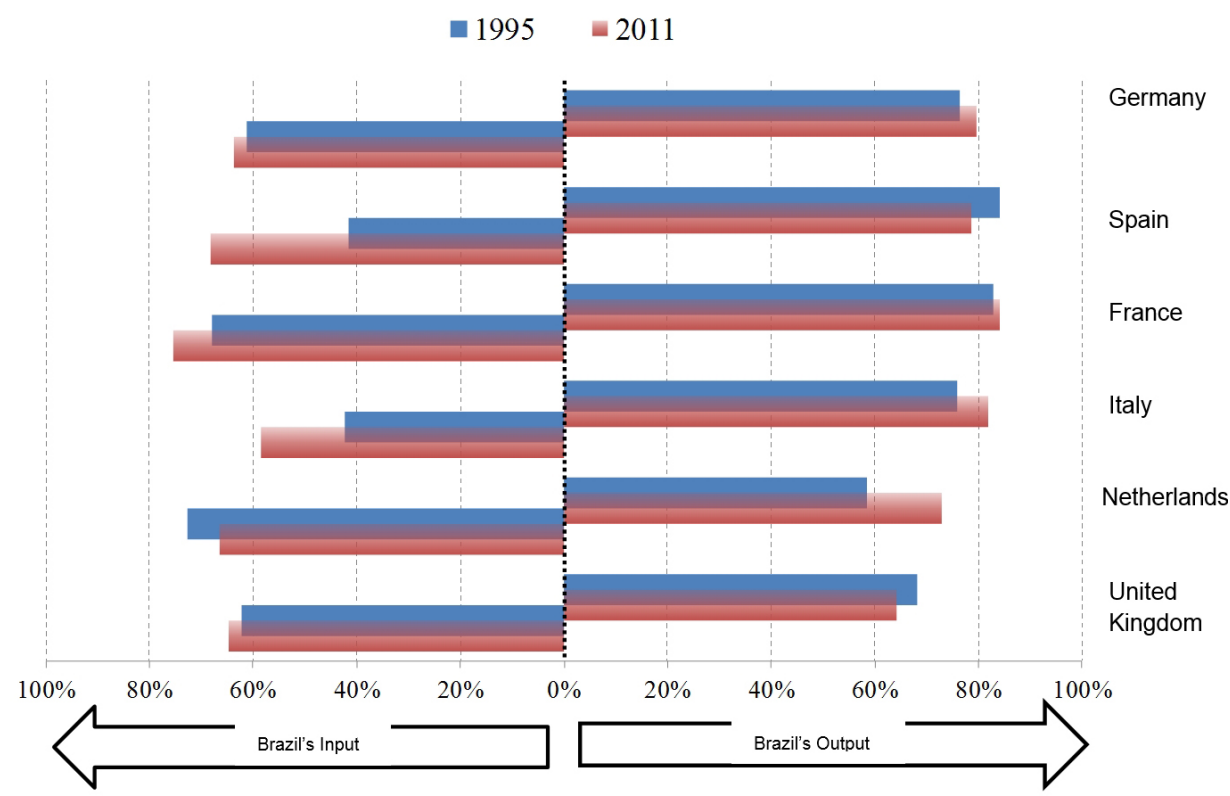

Source: Own elaboration based on the World Input-Output Database (WIOD)

In addition, it is of interest to continue with this characterization of the input-output framework from a sectorial perspective, which allows us not only to verify the level of orientation towards intermediate consumption but also to track its evolution over time. All this should contribute towards a better comprehension of the nature of the flows behind the changes observed in intra-industrial trade.

With regard to the case of bilateral trade between Brazil and Germany, we can extract several important observations when taking a look at their matrix of inter-sectorial relations (Graph 7.2). First, the main entries in Brazil of products from Germany (machinery, transport, electrical and electronic equipment), the chapters of which show intra-industrial trade in expansion (remember the analysis of Brülhart's dynamic index), displayed a certain asymmetry as far as the intermediate or final nature of their destination are concerned. In this regard, a greater weight of intermediate goods in the case of flows with origin Brazil and destination Germany was observed as compared to the flows in the opposite direction, which were more oriented towards attending to Brazil's final demand (consumer goods and investment). We thus perceive a pattern of commercial insertion, in which Brazil seemed preferably to integrate as a supplier of intermediate goods to Germany and as a consumer of final goods from there. It is quite true that in some of these sectors, such as transport equipment, the intermediate nature of flows predominated in 
both directions. In any case, the importance of intermediate goods in most inter-sectorial flows between Brazil and Germany was evident.

Graph 7.2. Changes in the relative importance of intermediate goods in the bilateral trade between Brazil and Germany by sector (1995-2011)

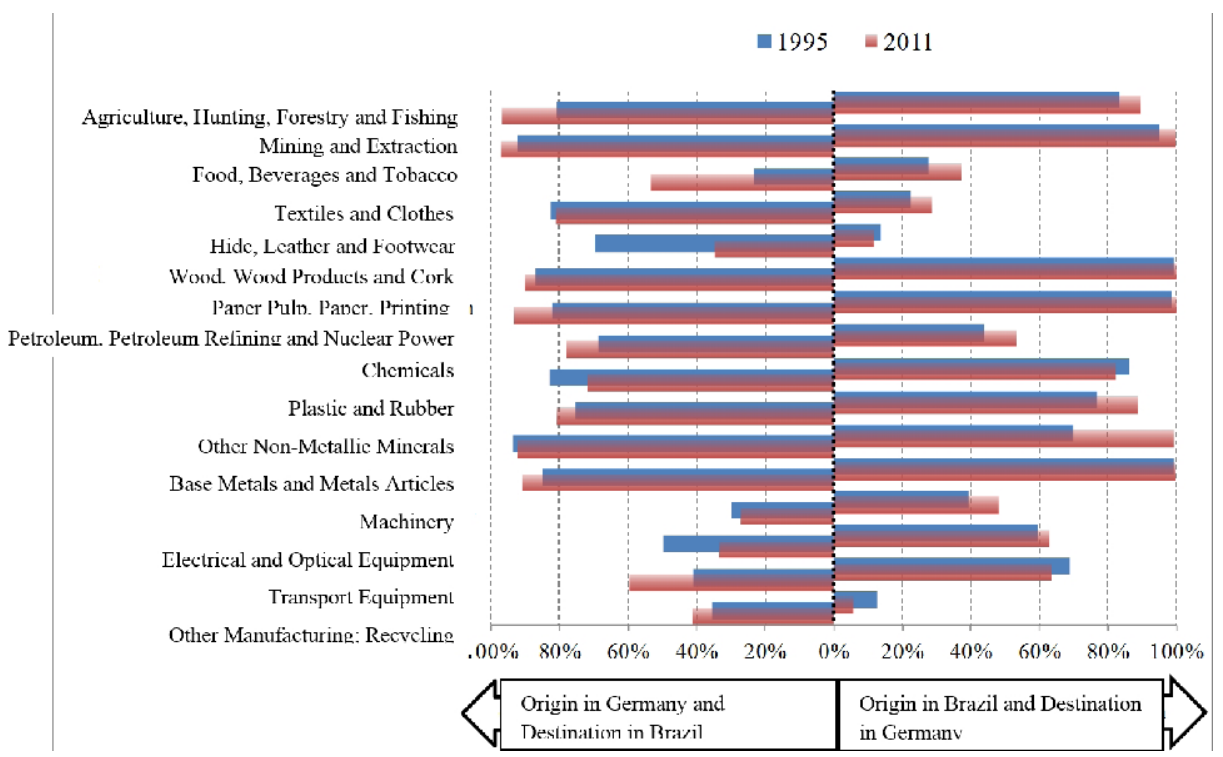

Source: Own elaboration based on the WIOD

The second observation is that this asymmetry has increased over time in the case of machinery and electrical equipment, while it has reduced in the case of transport equipment, with an important increase in the weight of intermediate goods in flows with origin in Germany. In the latter case, it must be said that it is, furthermore, a sector that showed a considerable dynamic index of intra-industrial trade, as was shown in the earlier analysis, and which also had an important presence of foreign capital in the spheres of both automobile and aircraft manufacturing. From this we can deduce the existence of intra-firm trade flows that form part of the operational logic of the global factory.

The lack of progress of intra-industrial trade seen in the bilateral relations of Brazil and Spain was accompanied by a profile of inter-sectorial relations that displayed considerable asymmetries in terms of the intermediate or final destination of goods exchanged. This was the case, for example, in agricultural products (soya bean, fruits, etc.) and food, which in Brazil's output had a noticeable character of intermediate goods, the opposite to what occurred in the case of flows with origin in Spain, which were predominantly dedicated to meeting Brazil's final demand (Graph 7.3). In both cases, however, a reduction in this orientation towards intermediate consumption could be observed in recent decades. 
In the case of machinery and mechanical equipment - another product of great importance in the bilateral trade between Brazil and Spain, although with little progress in terms of intra-industrial trade - an increasing orientation towards intermediate consumption was observable. A certain asymmetry in the relative weight of intermediate goods according to the direction of flow has also occurred in this case, with a preponderance of this type of goods in exports with origin in Brazil. A partially coincident characterization was repeated in the case of electrical and optical equipment, products which, on the other hand, have made the most notable advances in terms of intra-industrial trade between Brazil and Spain. In this case, the orientation towards intermediate consumption of exports with origin in Brazil has grown, compared with the increasing orientation towards final demand of exports with origin in Spain.

One particular feature was related to the transport equipment sector, which showed a strong asymmetry based on the direction of the flow considered, with a very marked growth (around 90\%) of intermediate goods in the case of exports with origin in Spain and an increasing orientation towards final demand in the exports from Brazil. Within this large sector, there were different behaviours in terms of the advance of intra-industrial trade, with bigger, though moderate advances in the sphere of the automobile sector as compared to the important aeronautical sector.

Graph 7.3. Changes in the relative importance of intermediate goods in the bilateral trade between Brazil and Spain by sector (1995-2011)

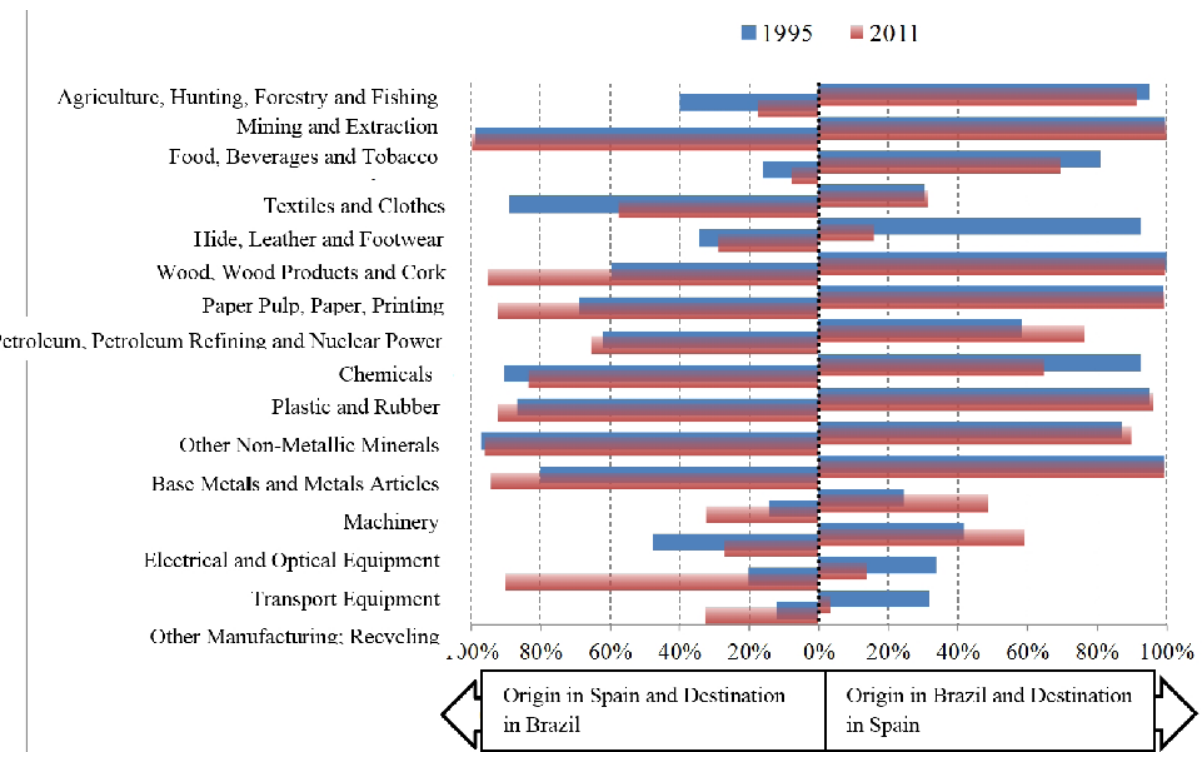

Source: Own elaboration based on the WIOD 
In the case of bilateral relations between Brazil and France the notable presence of flows related to global value chains was also evident. This was particularly true for a sector as relevant as that of transport equipment, which included products (automobiles and aircraft) with important trade weight and with which notable advances have been made in terms of intra-industrial trade between the two countries. Furthermore, it is a sector in which orientation towards intermediate consumption has become increasingly important in its trade flows in both directions (Graph 7.4). The important presence of multinational companies such as Airbus Helicopters with centres of production in both countries must be pointed out here.

Other sectors with important trade weight and advance of intra-industrial trade, like machinery, electrical equipment and chemical agents, also showed an outstanding orientation the intermediate consumption, although with a greater relevance in the case of the flows with origin in Brazil. With regard to these three sectors, the trends indicate an increase in intermediate character in the case of machinery and a reduction in the others.

Graph 7.4. Changes in the relative importance of intermediate goods in the bilateral trade between Brazil and France by sector (1995-2011)

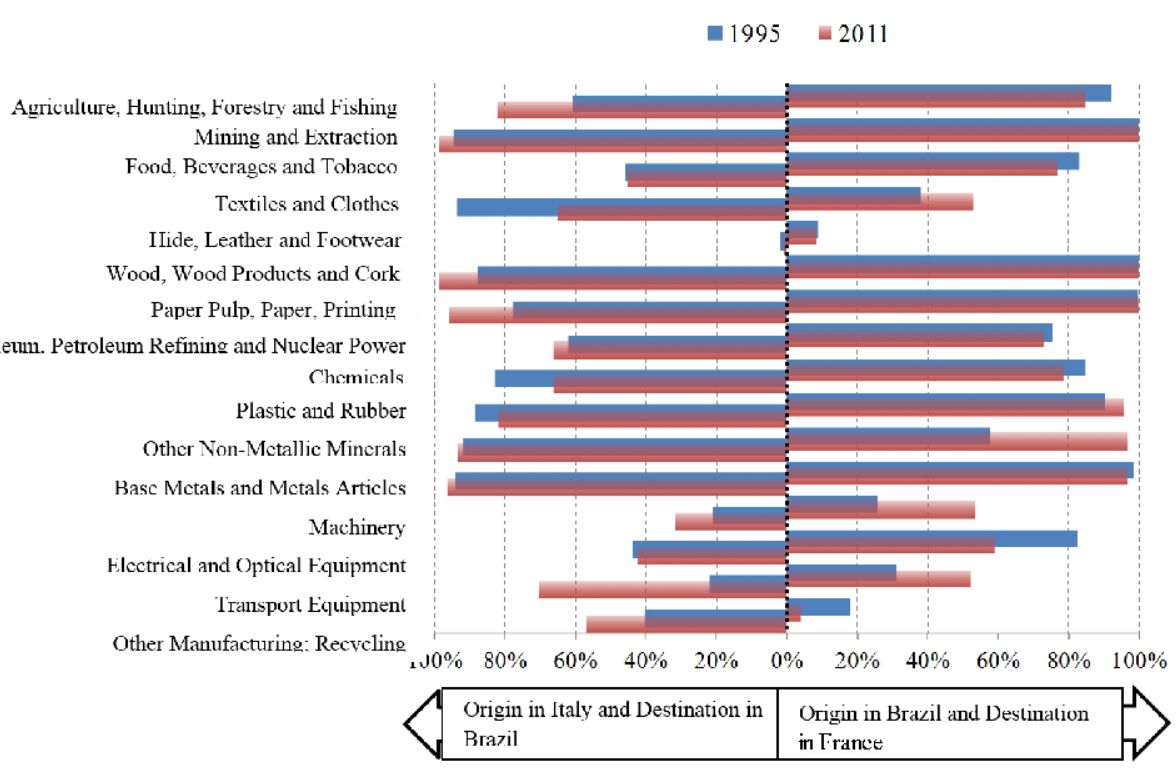

Source: Own elaboration based on the WIOD

The inter-sectorial relations of Brazil and Italy displayed a pattern which help explaining its behaviour in terms of intra-industrial trade. This has been the case, for instance, with the transport equipment sector, where $60 \%$ of the exports with origin in Italy were 
intermediate goods, as were just over 30\% of Brazil's exports (Graph 7.5). Between 1995 and 2011 the situation was reversed, since Brazil's exports in this sector in 1995 were more orientated towards intermediate consumption than its imports from Italy. These flows were related, among others, with the activity of the FIAT transnational group, which has its head office in Italy and production centres in Brazil. On the other hand, chemicals, which also show a notable advance of intra-industrial trade, displayed a strong orientation towards intermediate consumption, although with a falling trend in recent years.

On the other hand, Brazil's predominant profile as provider of intermediate inputs in the sphere of agricultural products including foods, skins and hides, leather and footwear, among others, was also observable, all of which being products with important trade weight in the bilateral relations between Brazil and Italy. In the specific case of agricultural products, an increasing orientation towards intermediate consumption was also observed which came close to the total trade flow in exports with origin Brazil. Given the nature of this type of products, based on advantages associated with provision of resources, little of this trade was intra-industrial in nature.

Graph 7.5. Changes in the relative importance of intermediate goods in the bilateral trade between Brazil and Italy by sector (1995-2011)

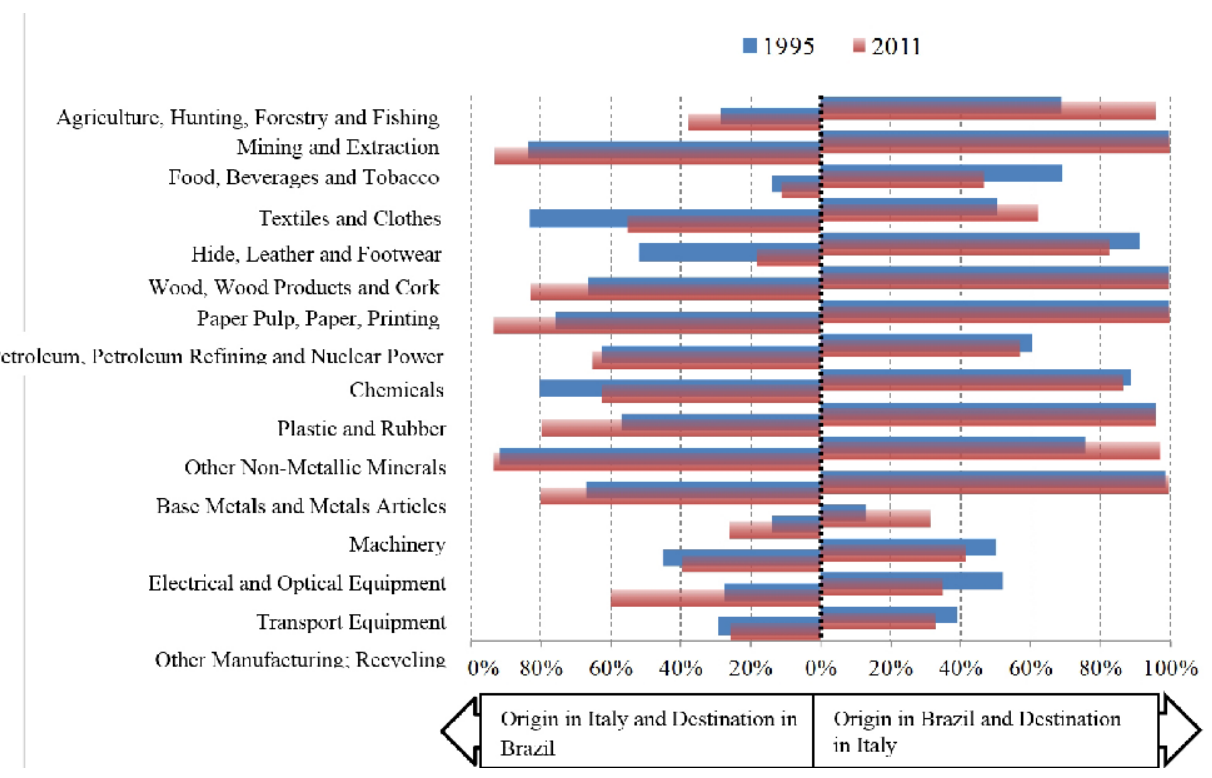

Source: Own elaboration based on the WIOD

Although there was an important amount of exchange of goods dedicated to intermediate consumption in bilateral trade between Brazil and the Netherlands, it showed more reductions than increases in this orientation between 1995 and 2011 (Graph 7.6). The 
matrix of inter-sectorial relations again drew a profile with certain asymmetries which, with exceptions (textiles), revealed a preponderance of intermediate goods in flows with origin in Brazil. This was the case, for example, of the bilateral trade of fuels (petroleum and derivatives) and machinery, - two sectors of considerable trade weight that concentrate the biggest advances in terms of the intra-industrial trade between both countries, although with a smaller relative presence of intermediate goods in its commercial exchanges.

The other sectors with trade relevance (agricultural products of plant and animal origin, foods, wood pulp, etc.) reflected a profile of trade insertion in which Brazil has positioned itself as supplier to Dutch industry, with an important weight of intermediate goods (in many cases reaching $100 \%$ ), giving rise to a traditional trade profile based on the exchange of different goods.

Graph 7.6. Changes in the relative importance of intermediate goods in bilateral trade between Brazil and the Netherlands by sector (1995-2011)

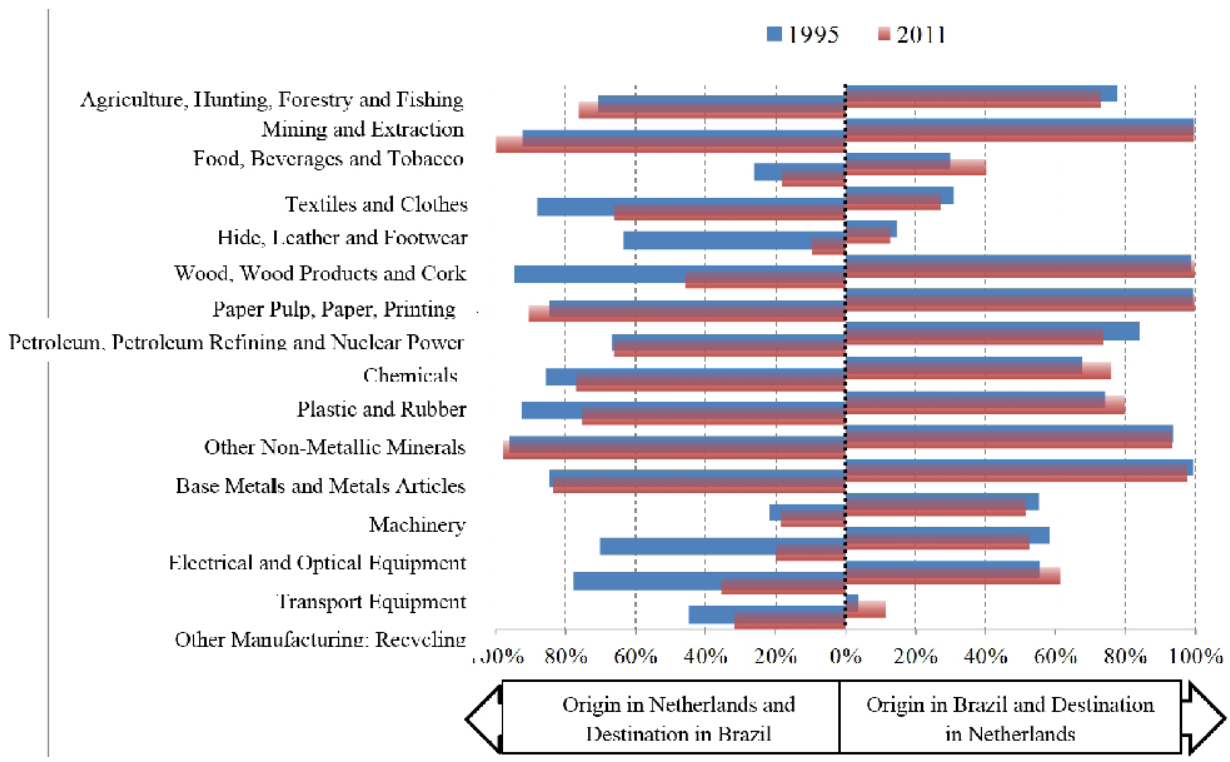

Source: Own elaboration based on the WIOD

With regard to the inter-sectorial relations between Brazil and the United Kingdom, a clearly asymmetric profile in the relative importance of intermediate goods was again observable, with more predominance of intermediate consumption in the flows with origin in Brazil. This was the case, for example, of the machinery and mechanical equipment sector, which displayed, on the other hand, considerable advance in intra-industrial trade. It can be said that this sector has lost part of its orientation towards intermediate consumption in the exports from Brazil and increased it slightly on the side of its imports from the United Kingdom. 
Graph 7.7. Changes in the relative importance of intermediate goods in bilateral trade between Brazil and the United Kingdom (1995-2011)

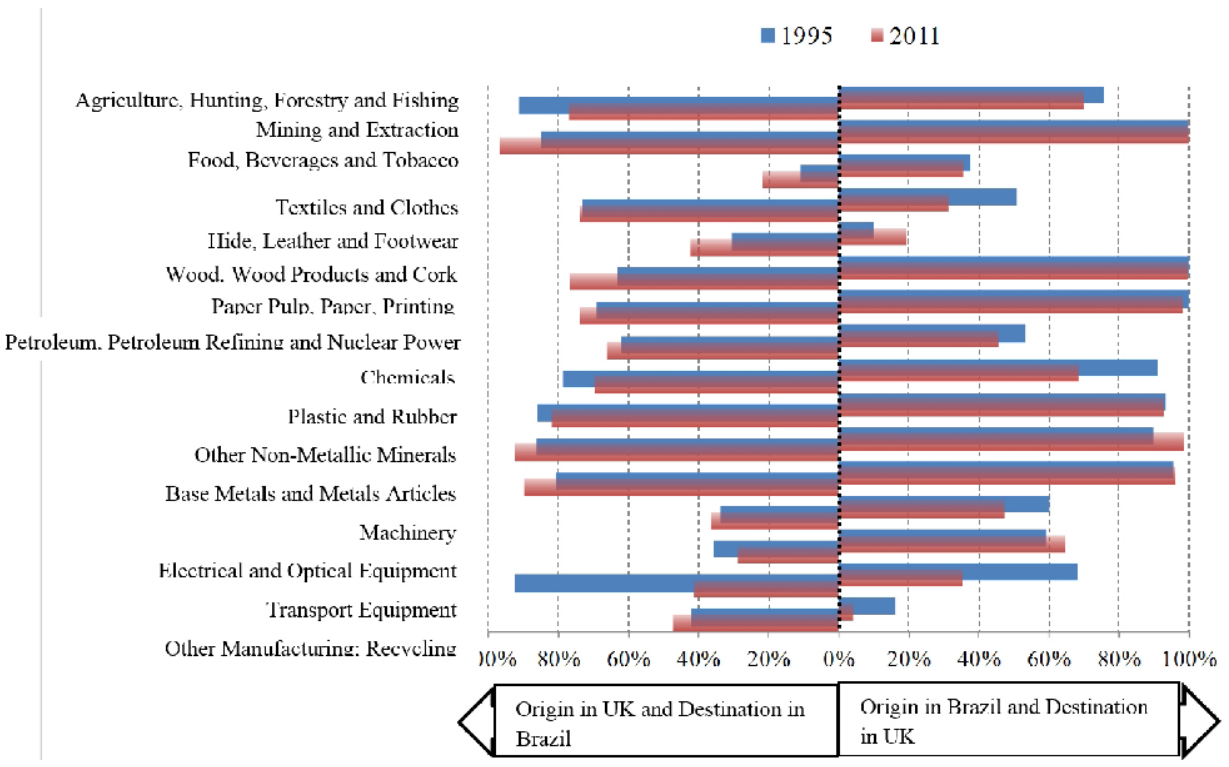

Source: Own elaboration based on the WIOD

\subsubsection{The inter-sectorial relations of Mexico with its main European Union partners}

Mexico's input-output relations with its main EU partners demonstrated characteristics similar to those described for the case of Brazil, although with a few notable differences. The similarities included both the important relative weight of intermediate goods and their asymmetric character and the greater importance they acquired in the case of outflows from Mexico (Mexico's output). As far as differences are concerned, the relative loss of importance that was observed in the weight of these goods between 1995 and 2011 can be pointed out (Graph 7.8).

From the point of view of Mexico's exports (output), the greatest importance of intermediate goods occurred in 2011, with Spain, France, the Netherlands and Italy as destinations, with a relative weight of between $70 \%$ and $90 \%$. On Mexico's import (input) side, the differences between countries were of little significance; the Netherlands and Germany stood out with a weight of intermediate goods of a little more than $60 \%$. 
Graph 7.8. Relative importance of intermediate goods and services in the bilateral relations of Mexico with its main European Union partners (1995-2011)

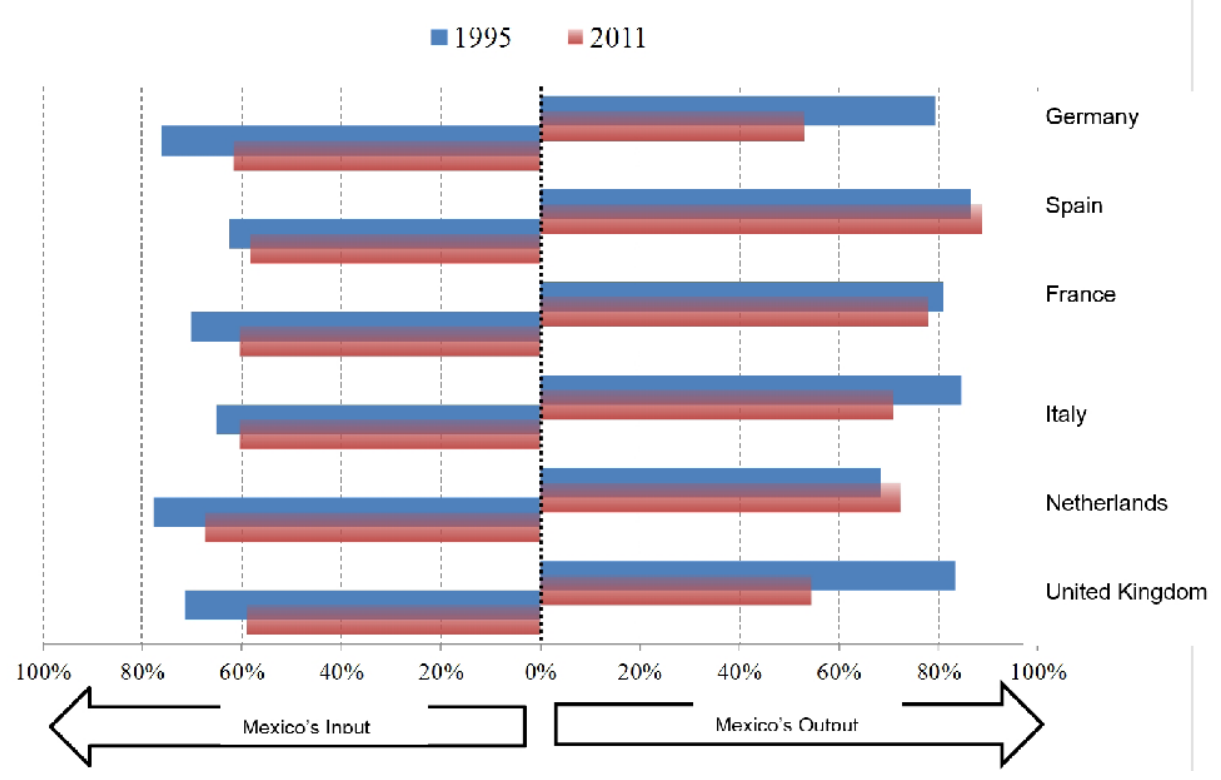

Source: Own elaboration based on the WIOD

The analysis of the matrix of inter-sectorial relations between Mexico and Germany verifies how advances revealed in intra-industrial trade were related to the different insertion profiles according to the sector considered. Thus, in the case of transport equipment - the main chapter of this bilateral trade - the advances in intra-industrial trade have occurred in the framework of a large increase in the importance of exchanges of final goods, especially in Mexico's outflows. Something similar occurred in the machinery sector, with advances in intra-industrial trade in a context of loss of importance of its orientation towards intermediate consumption. With regard to the electrical and optical equipment sector, which also experienced considerable advances in intra-industrial trade, the reduction in orientation towards intermediate consumption took place in flows with origin in Germany, while it increased in the flows with origin in Mexico.

Finally, other sectors with increasing intra-industrial trade within the framework of bilateral relations between Mexico and Germany, such as chemicals and metals and metal products, displayed a high, though decreasing orientation towards intermediate consumption. 
Graph 7.9. Changes in the relative importance of intermediate goods in bilateral trade between Mexico and Germany by sector (1995-2011)

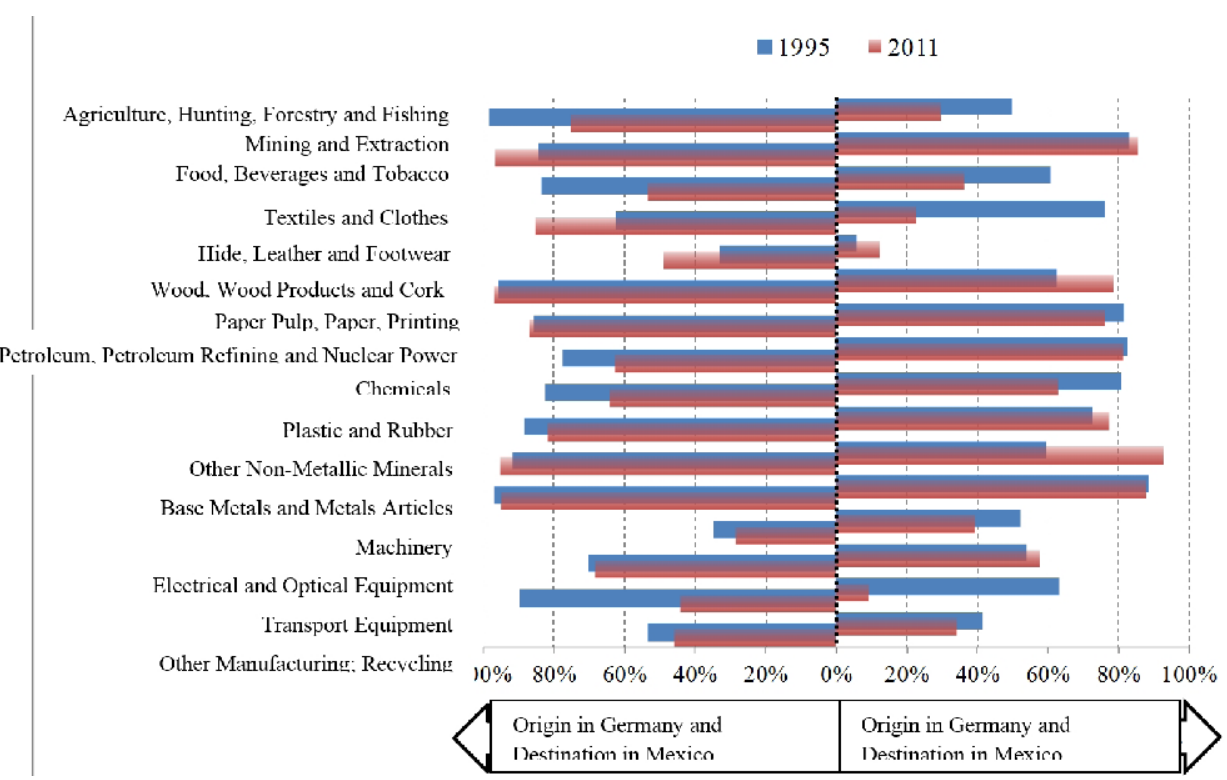

Source: Own elaboration based on the WIOD

Although bilateral trade between Mexico and Spain reflected a low profile of intra-industrial insertion, it was also characterized by certain advances at sectorial level. This was the case, for example, of the mechanical machinery and equipment sectors, beverages, articles of iron and steel, plastics and chemicals (organic). It should be indicated that all the sectors mentioned showed a reduction in their orientation towards intermediate consumption, except Mexican exports related to machinery, which were increasingly exported as supplies for production (Graph 7.10). In the case of food and beverages, furthermore, their strong orientation towards final demand stood out, with over $90 \%$ of flows oriented toward final consumption.

The other sectors represented a much greater weight of flows dedicated to intermediate consumption, in some cases (metals and metal products, plastic and rubber, fuels and minerals) reaching weights greater than $80 \%$ of the corresponding total flow. In the case of the sectors related to electrical equipment and transport equipment, with fairly moderate advances in terms of intra-industrial trade, they also acquired a considerable weight in the exchanges of intermediate goods. 
Graph 7.10. Changes in the relative importance of intermediate goods in bilateral trade between Mexico and Spain by sector (1995-2011)

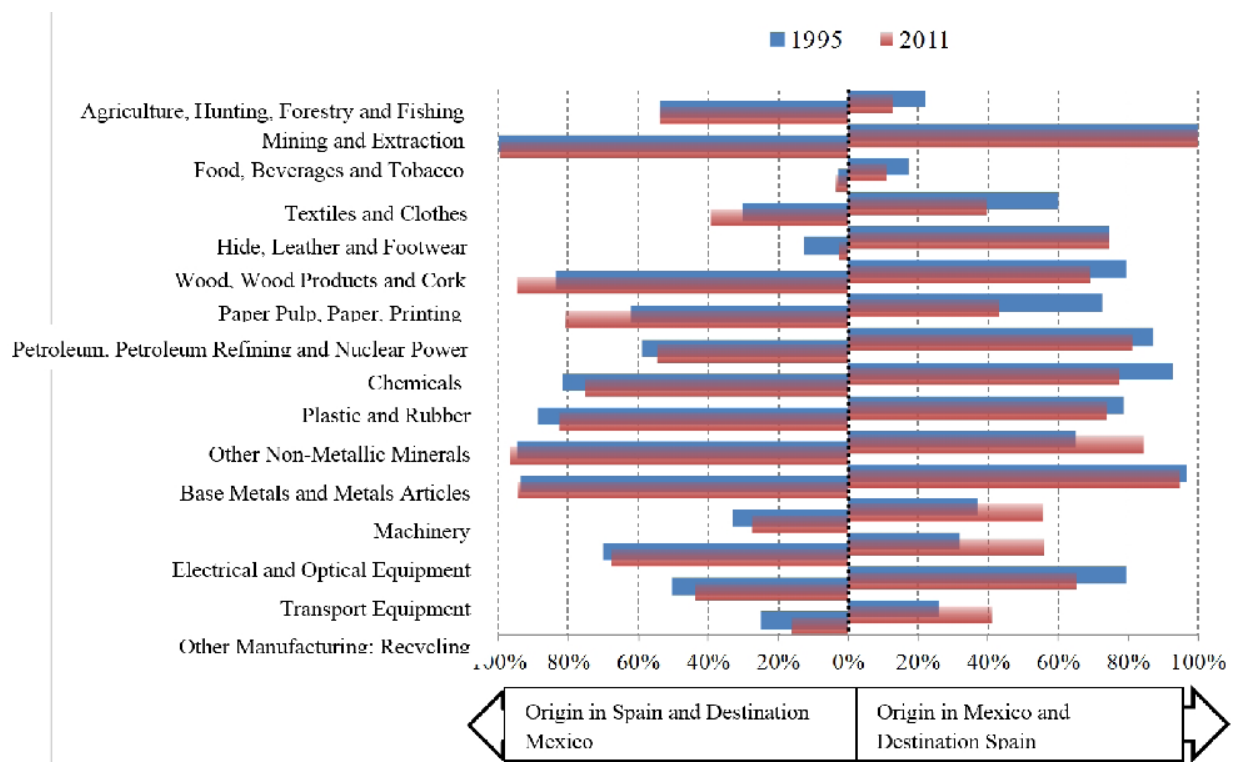

Source: Own elaboration based on the WIOD

The advances observed in the sphere of intra-industrial trade between Mexico and France were headed by the chapters related to mechanical machinery, electrical and optical equipment and, to a lesser extent, plastics. The analysis of the matrix of intersectorial relations of these two countries verifies that these advances have taken place in the framework of an important presence of flows of intermediate character, although with a decreasing trend over time (Graph 7.11). In this regard, it can be stressed that, in the outflows from Mexico, approximately half of the exchanges of machinery and electrical and optical equipment corresponded to goods produced for intermediate consumption in France, amounting to over $80 \%$ in the case of plastic and rubber. In the case of flows with origin in France, this weight increased to $70 \%$ in electrical and optical equipment and was reduced to less than $30 \%$ in the case of machinery.

The analysis of bilateral trade between Mexico and Italy allowed for the identification of a series of products that showed a certain dynamism in terms of intra-industrial trade during the period analysed. This was the case of the chapters on organic chemicals, iron and steel products, fuels (petroleum and derivatives) and electrical equipment. The analysis of the matrix of inter-sectorial relations of these two countries confirmed that these advances have taken place in the framework of an important presence of flows of intermediate character, although with various trends over time (Graph 7.12). 
Graph 7.11. Changes in the relative importance of intermediate goods in bilateral trade between Mexico and France by sector (1995-2011)

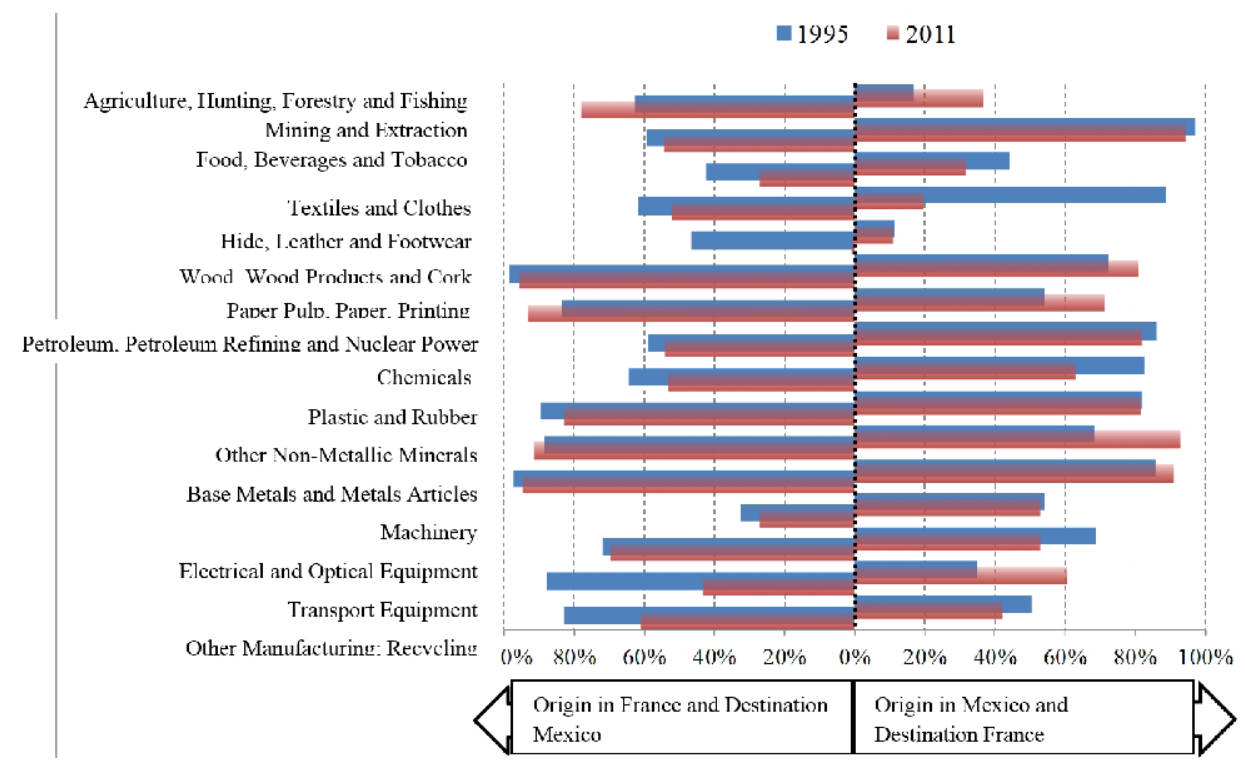

Source: Own elaboration based on the WIOD

There was a trend for the weight of intermediate goods to fall in the case of chemicals, petroleum and its derivatives, as well as electrical and optical equipment, among others. On the other hand, in basic metals and metal products, an increase in the weight of intermediate goods with origin in Italy was observable and became highly important in flows in both directions.

Finally, a notably increasing orientation of exchanges towards final demand was observed in other sectors, such as food, beverages and tobacco, textile products and transport equipment which, while not showing significant advances in intra-industrial trade, have acquired relevant weight within bilateral trade between Mexico and Italy.

The main advances that could be identified in the scope of intra-industrial trade between Mexico and the Netherlands were protagonised by the chapters related with chemicals (organic), plastic, iron and steel, pharmaceutical products and mechanical machinery. A second reading, in view of the matrix of inter-sectorial relations of these two countries, shoed that these advances have taken place in the context of very important flows of intermediate character, although with varying trends (Graph 7.13). 
Graph 7.12. Changes in the relative importance of intermediate goods in the bilateral trade between Mexico and Italy by sector (1995-2011)

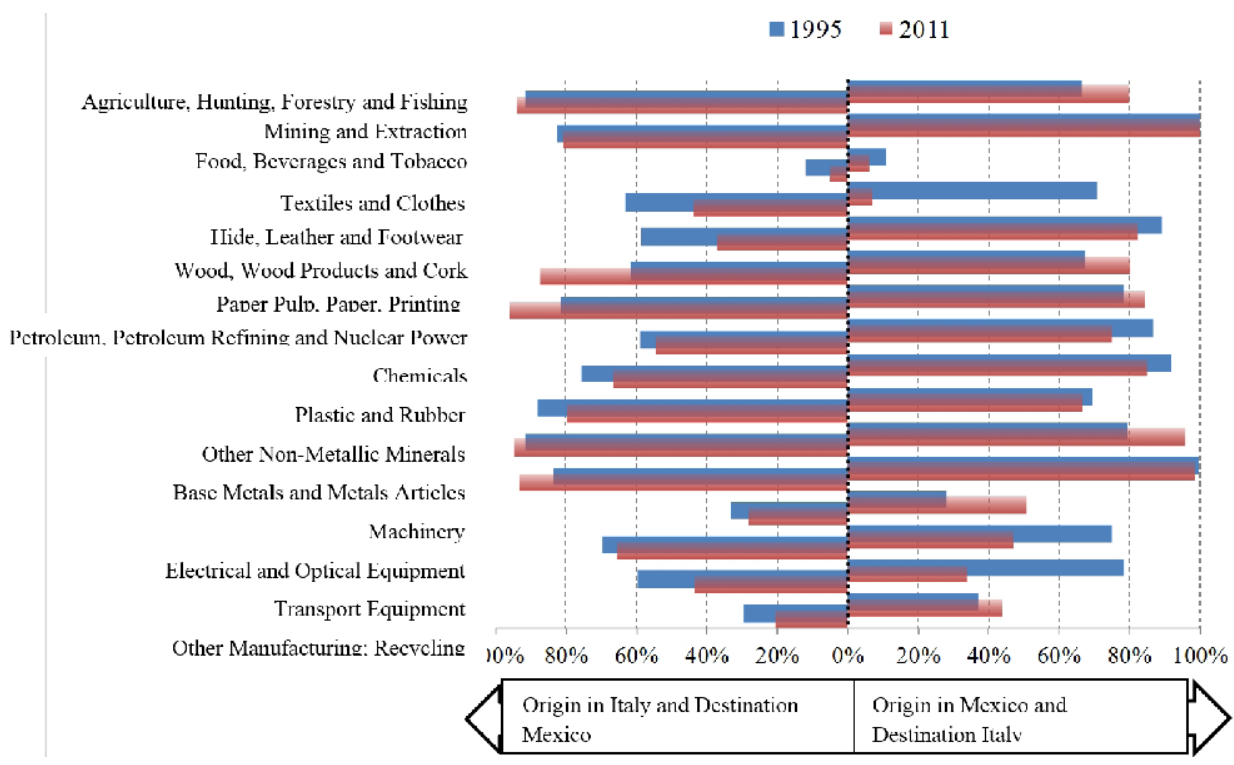

Source: Own elaboration based on the WIOD

Focusing on these goods, it can be stressed that in the flows with origin in Mexico, an increase was observed in the relative weight of intermediate goods in the machinery and chemicals sectors; meanwhile there was a decrease in the case of plastic and basic metals. On the other hand, in the flows with origin in the Netherlands, there was an increase in the intermediate destination of basic metals and machinery, as well as a reduction in the case of chemicals and plastic and rubber.

The analysis of the matrix of inter-sectorial relations between Mexico and the United Kingdom showed a generalized trend towards reduction in the weight of flows intended for intermediate consumption, with very few exceptions (Graph 7.14). This trend also affected sectors with considerable advances in the sphere of intra-industrial trade, such as the machinery, electrical and optical equipment, fuels (petroleum and derivatives) and organic chemicals sectors. Of these sectors, only in the case of the electric and optical appliances with origin in Mexico an increasing weight of goods for intermediate consumption was observable. Finally, the large change in orientation undergone by the transport equipment sector can be highlighted. Beginning with a weight of intermediate goods over 80\% in flows in 1995, it fell to a much lower weight (about 40\%) by 2011. 
Graph 7.13. Changes in the relative importance of intermediate goods in bilateral trade between Mexico and the Netherlands by sector (1995-2011)

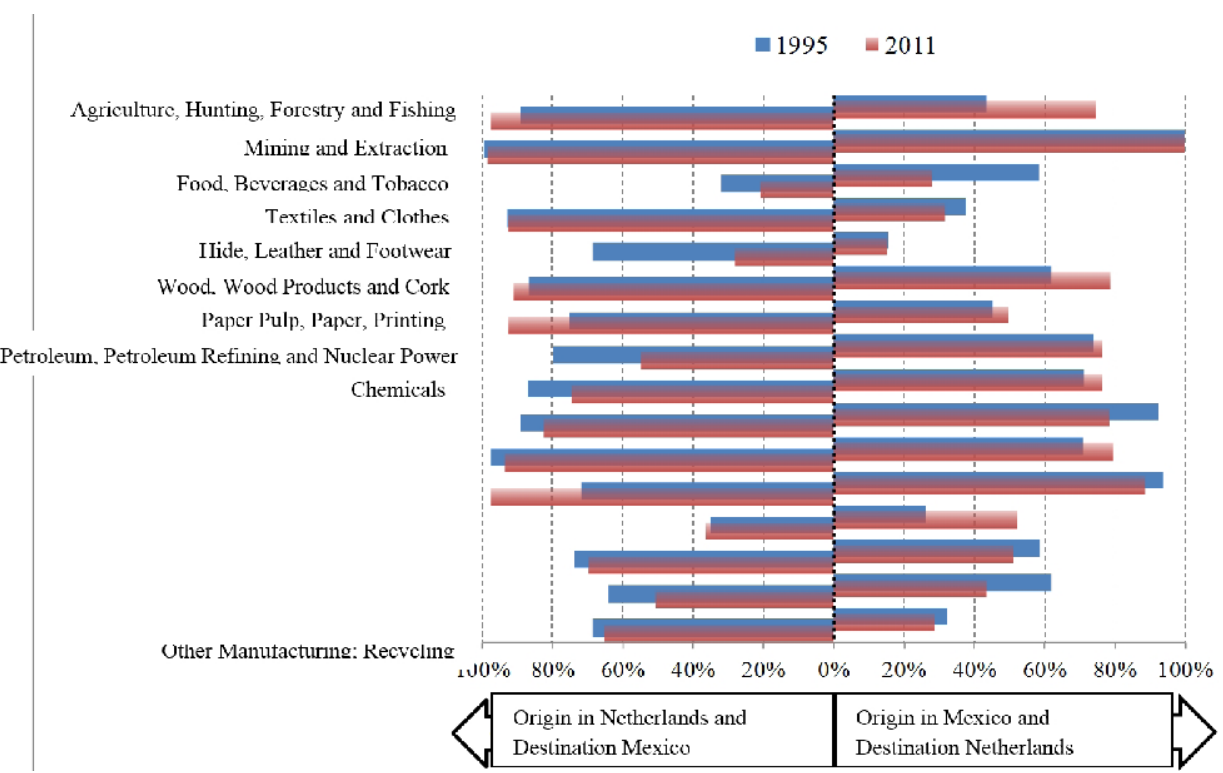

Source: Own elaboration based on the WIOD

Graph 7.14. Changes in the relative importance of intermediate goods in bilateral trade between Mexico and the United Kingdom (1995-2011)

France

$$
\text { France }=1995=2011
$$

Agriculture, IIunting, Forestry and Fishing

Minine and Extraction

Food, Beverages and Tobacco

Textiles and Clothes

Hide, Leather and Footwear Wood. Wood Products and Cork

Paper Pulp. Paper, Printing Petroleum. Petroleum Refining and Nuclear Power Chemicals

Plastic and Rubher Other Non-Metallic Mincrals Rase Metals and Metal Articles Machinery Tlectrical and Optical Tiquipment Transport Equipment Other Manufacturing; Recycling

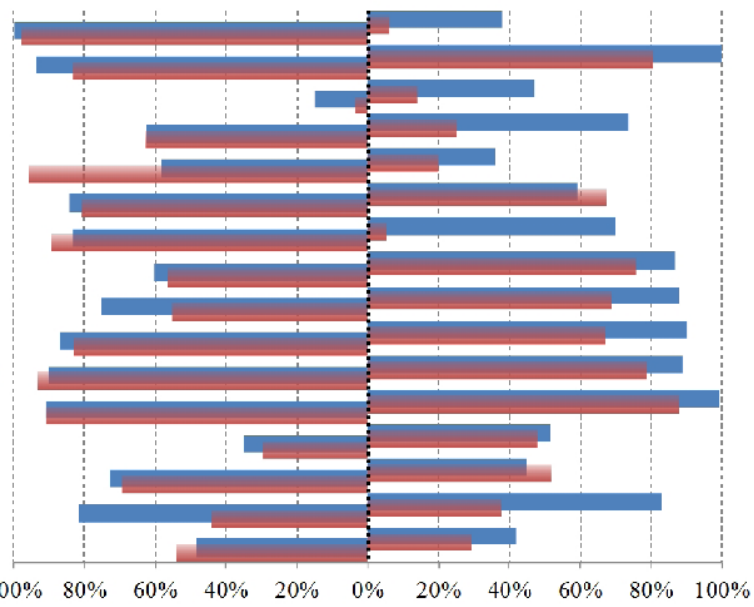

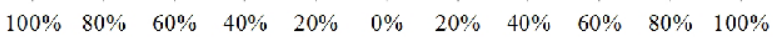
\begin{tabular}{|l|l}
\hline Origin in the UK and & Origin in Mexico and
\end{tabular} Destination Mexico Destination the UK

Source: Own elaboration based on the WIOD 


\subsection{Foreign direct investment and intra-industrial trade: Evidence of two connected realities}

Any attempt to establish a clear, direct connection between FDI and trade from a macro perspective implies a certain degree of audacity. Nevertheless, it is even more audacious to attempt to relate FDI with intra-industrial trade. In this sense, it should be noted that the intention of the analysis in this section is to approach a reality which, due of its complexity, is far from being simple and straightforward.

As mentioned in the theoretical section of this study, there are various approaches that take into account possible channels of influence and relationship between FDI and international trade (consider, for example, Vernon's Product Life-Cycle Theory or the explanatory models of horizontal, vertical and complex FDI). Although these theories can serve as a general framework for the study of these phenomena, it should be borne in mind that, behind the diverse approaches that try to explain the trade behaviour of economies globally, there are always specific, heterogeneous behaviours of enterprises, especially transnational corporations. These big companies articulate their strategies in a dynamic path that is not always easy to predict or to interpret at a macro level. Nevertheless, to gain a better understanding and precise knowledge of the logic behind their productive and commercial operations, it would be necessary to carry out an overwhelming number of analyses at the micro level, as specific case studies, which is outside the scope of this study.

At the conceptual level, the nature of intra-industrial trade is closely linked to the activity of transnational companies, which are the real engines behind FDI flows among economies. These companies dispose of the necessary capital and structures in order to vigorously spread their productive activity across international borders, as well as the capacity to take advantage of the existence of economies of scale and deepen the differentiation of products. This is the reason is why these companies are the real leading actors in international trade in general, and this type of trade in particular.

The analyses undertaken in the preceding sections of this study provide an idea of the importance foreign direct capital for both the intensity and the composition and the direction of of bilateral trade flows. However, at this point of the study, we try to go a step further, combing the two realities (FDI and intra-industrial trade), so that additional comparisons can be carried out which allow to verify the existence of certain approaches or concordance between the two phenomena.

To this end, and given the existing statistical restrictions, especially with regard to FDI at a sectorial level and from a bilateral (country with country) point of view, we have opted to 
make a brief selection of sectors characterised by a certain dynamism in terms of intraindustrial trade. So, a series of graphs follows (one for each sector) in which three variables are represented at the same time. First, the inward FDI stock in both the LA countries analysed (Brazil and Mexico) with each of their main European partners (Germany, Spain, France, Italy, the Netherlands and the United Kingdom), in 2011 (the last available year with disaggregated sectorial and bilateral data) and expressed in logarithms. Secondly, the average figure for the 1993-2013 period of Brülhart's marginal index for the equivalent product category, measuring the average degree of advance of bilateral flows in terms of intra-industrial trade. Thirdly, as a comparative point of reference, the global (aggregate) average of Brülhart's marginal index.

Although the selection of sectors is relatively small and asymmetrical for the case of Brazil and Mexico, certain analogies can be seen which indicate the existence of a connection between the presence of transnational companies (FDI stock) and the advances in intraindustrial trade, although with sectorial nuances. In any case, they provide evidence for a relation that, far from being simple and linear, encloses considerable complexity.

There is initial, partial evidence of the correspondence between FDI and the advance of intra-industrial trade in the case of Brazil's bilateral relations with its main European partners in relation with the fuel sector (petroleum and derivatives). Specifically, it can be seen that there is correspondence between FDI from the Netherlands in this sector and greater advance of intra-industrial trade between Brazil and the Netherlands in this sector in comparison with the average aggregate behaviour (Graph 7.15).

However, this does not occur in the case of the relations between Brazil and France, where significant differences are not observed between the sectorial and aggregate advance of intra-industrial trade. In this regard, it should be pointed out that the FDI with origin in France is related with the crude oil and natural gas extraction segment, which is a sector of natural resources inclined to one-way trade exchange (inter-industrial trade), which may explain its limited advance in terms of intra-industrial trade. In contrast, the FDI from the Netherlands is related with the segment of derived products (oil refining), which is a type of product (manufacturing) more prone to be involved in intra-industrial exchanges.

Much more obvious evidence of the correspondence between FDI and the advance of intra-industrial trade is seen in the case of Brazil's bilateral relations with its main European partners in the chemicals sector (organic chemicals, in the case of Brülhart's marginal index of intra-industrial trade). Here it can be seen clearly that there is correspondence between FDI and the advance of intra-industrial trade in this sector much greater than observed at the aggregate level (Graph 7.16). 
Graph 7.15. Advance of intra-industrial trade (Brülhart's marginal index, average 1993-2013) and foreign direct investment stock (inward FDI stock in 2011, values in logarithms, on second non-visible axis) of Brazil in the fuels sector (crude oil and refined derivatives)

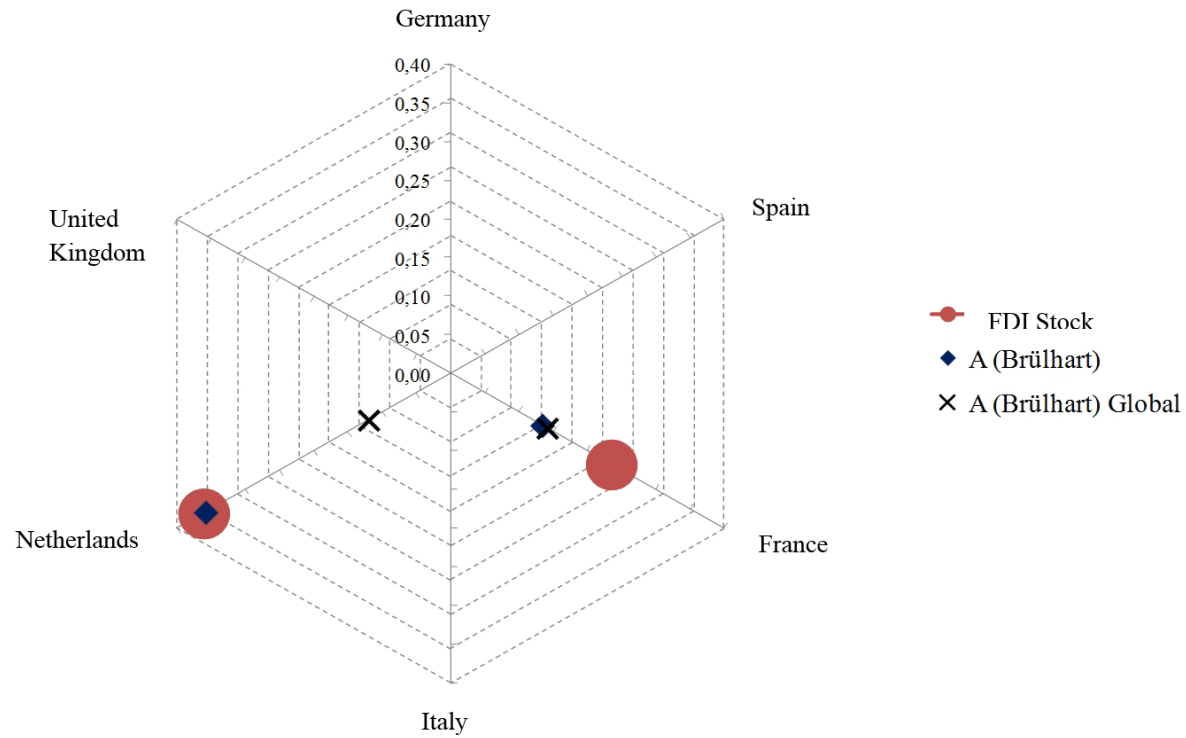

Source: Own elaboration based on UN-COMTRADE and UNCTAD data

In the case of Brazil's bilateral relations with its main European partners with regard to the metal products sector (iron and steel products with regard to intra-industrial trade), there is also clear evidence of a correspondence between FDI and the advance of intraindustrial trade, and advances in intra-industrial trade in this sector turn out to be greater, in general terms (with the only exception of the Netherlands), than those observed at the aggregate level (Graph 7.17).

There is also clear evidence of the concomitance between the FDI and the advance of intra-industrial trade when Brazil's bilateral relations with its European partners in the machinery sector and mechanical equipment are analysed (Graph 7.18). In this case, the fact that there is correspondence between FDI in this sector and an advance of intraindustrial trade greater than that observed at aggregate level is verified again. 
The automobile sector is another clear case in which correspondence between FDI and the advance of intra-industrial trade is observable (Graph 7.19). Anew, there is clear evidence of advances in the intra-industrial trade which are greater than those taking place at aggregate level.

Graph 7.16. Advance of intra-industrial trade (Brülhart's marginal index, average 1993-2013) and foreign direct investment stock (inward FDI stock in 2011, values in logarithms, on second non-visible axis) of Brazil in the chemicals sector

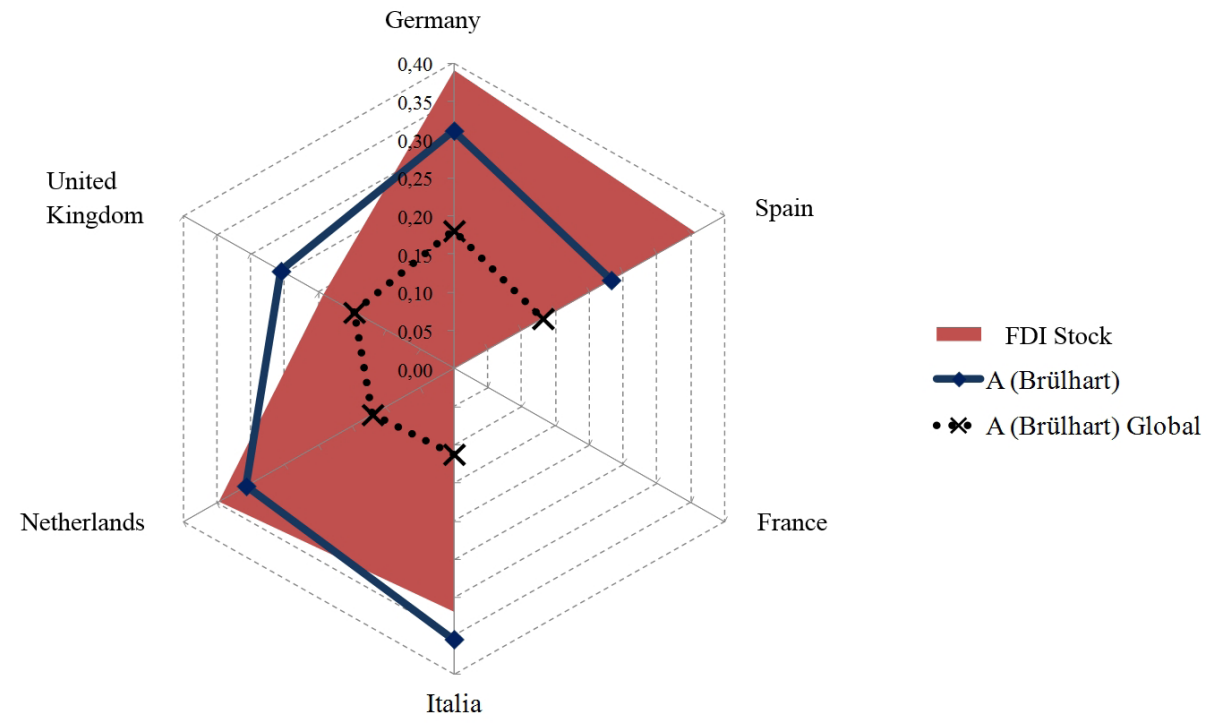

Source: Own elaboration based on UN-COMTRADE and UNCTAD data

In the case of Mexico's bilateral relations, these regularities indicating the existence of a correspondence between the presence of FDI and intra-industrial trade are also observable, although with certain nuances at sectorial level. In the specific case, for example, of Mexico's bilateral relations with its main European partners with regard to the fuel sector (Graph 7.20), a relatively dual behaviour is observed, with relations that follow this regularity (Mexico with the United Kingdom, the Netherlands and Italy) and others which do not seem to do so (Mexico with Germany, Spain and France). 
Graph 7.17. Advance of intra-industrial trade (Brülhart's marginal index, average 1993-2013) and foreign direct investment stock (inward FDI stock in 2011, values in logarithms, on second non-visible axis) of Brazil in the metal products sector

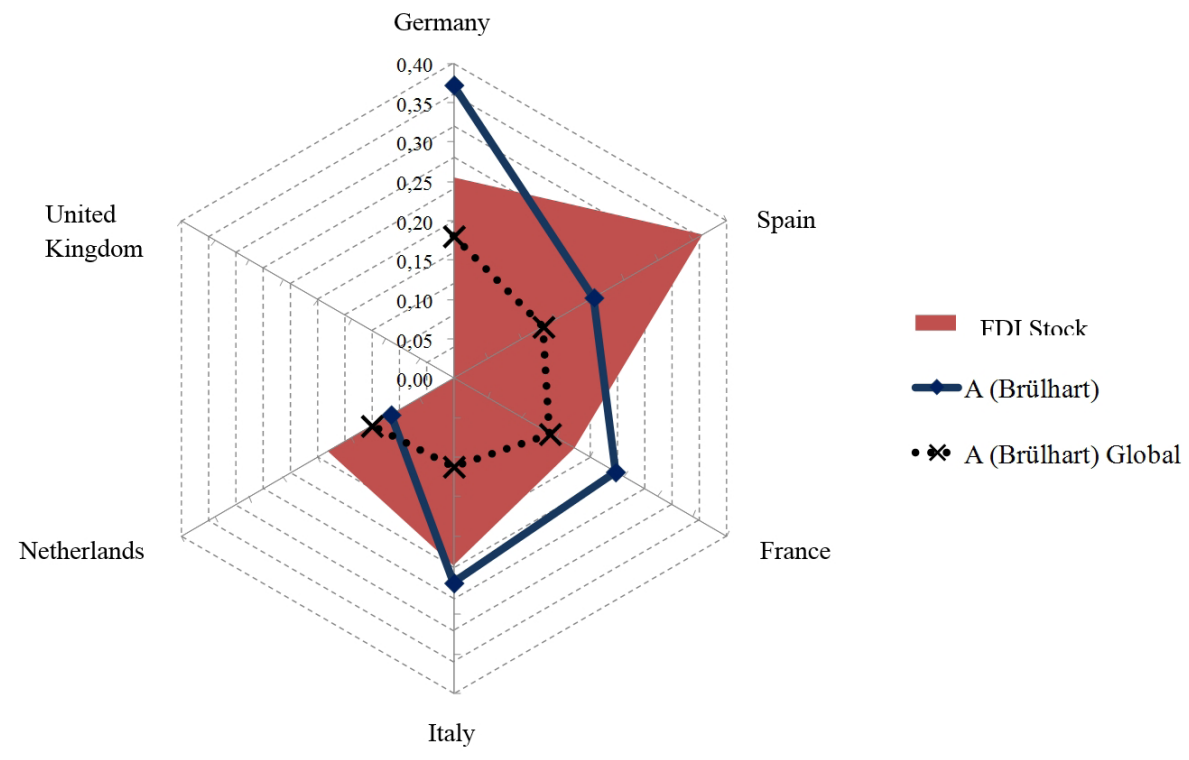

Source: Own elaboration based on UN-COMTRADE and UNCTAD data

Graph 7.18. Advance of intra-industrial trade (Brülhart's marginal index, average 1993-2013) and foreign direct investment stock (inward FDI stock in 2011, values in logarithms, on second non-visible axis) of Brazil in the mechanical machinery and apparatus sector

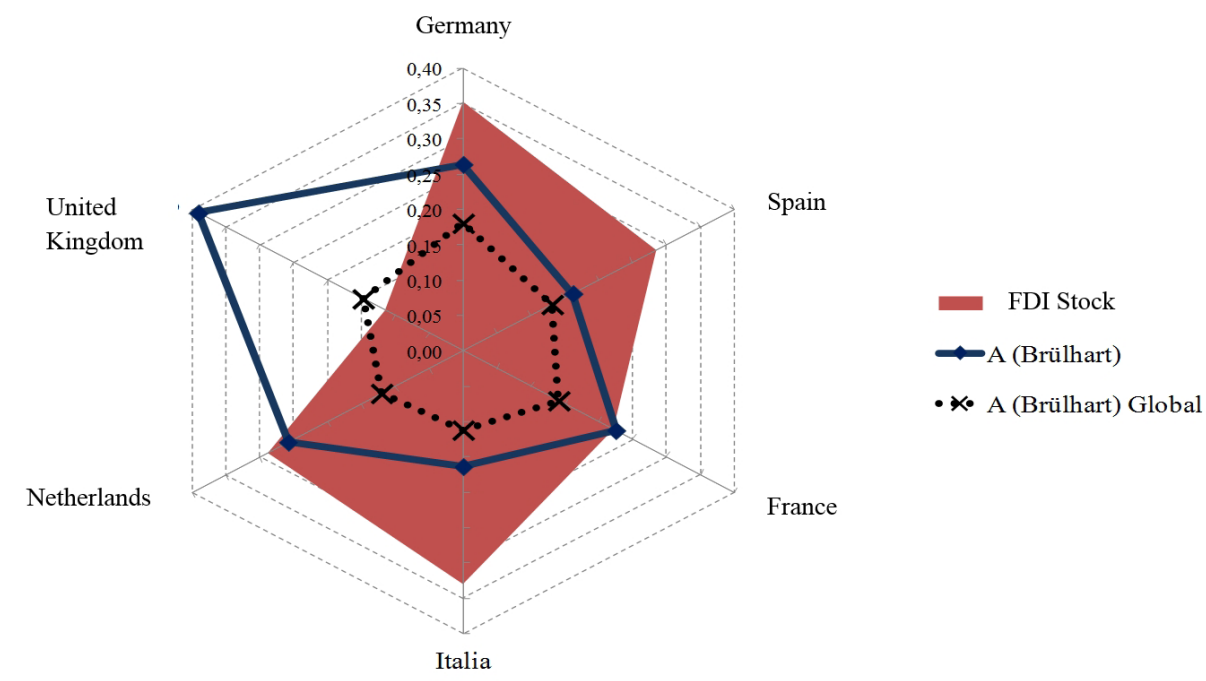

Source: Own elaboration based on UN-COMTRADE and UNCTAD data 
Graph 7.19. Advance of intra-industrial trade (Brülhart's marginal index, average 1993-2013) and foreign direct investment stock (inward FDI stock in 2011, values in logarithms, on second non-visible axis) of Brazil in the automobile sector

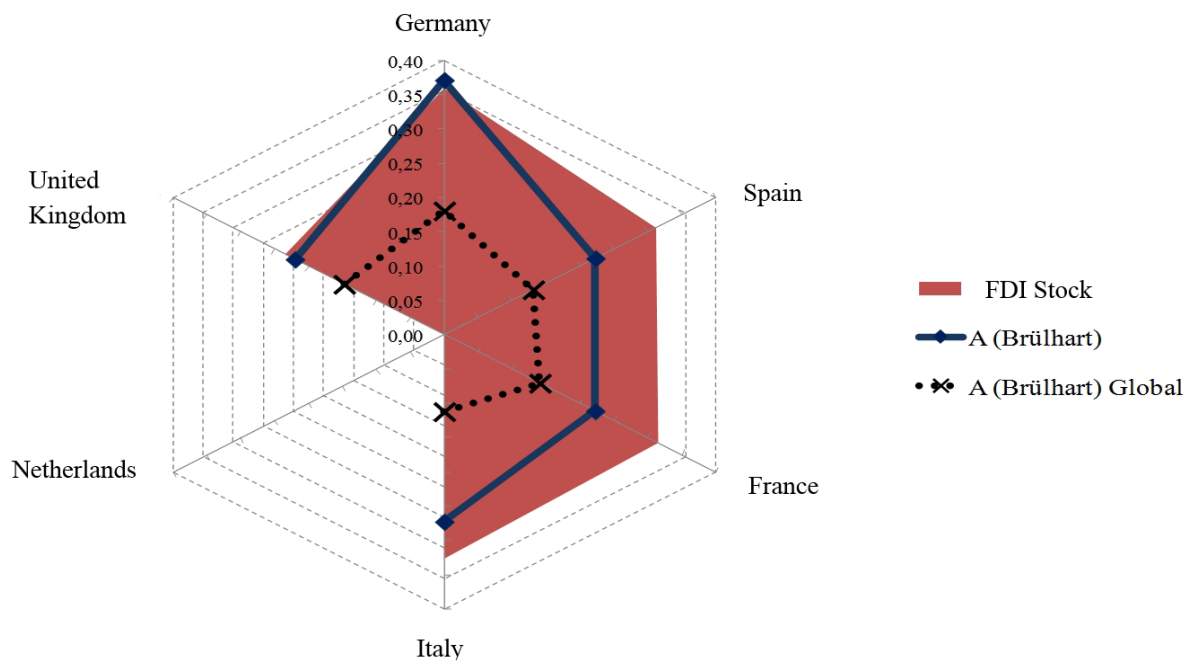

Source: Own elaboration based on UN-COMTRADE and UNCTAD data

Graph 7.20. Advance of intra-industrial trade (Brülhart's marginal index, average 1993-2013) and foreign direct investment stock (inward FDI stock in 2011, values in logarithms, on second non-visible axis) of Mexico in the fuels sector (crude oil and refined derivatives)

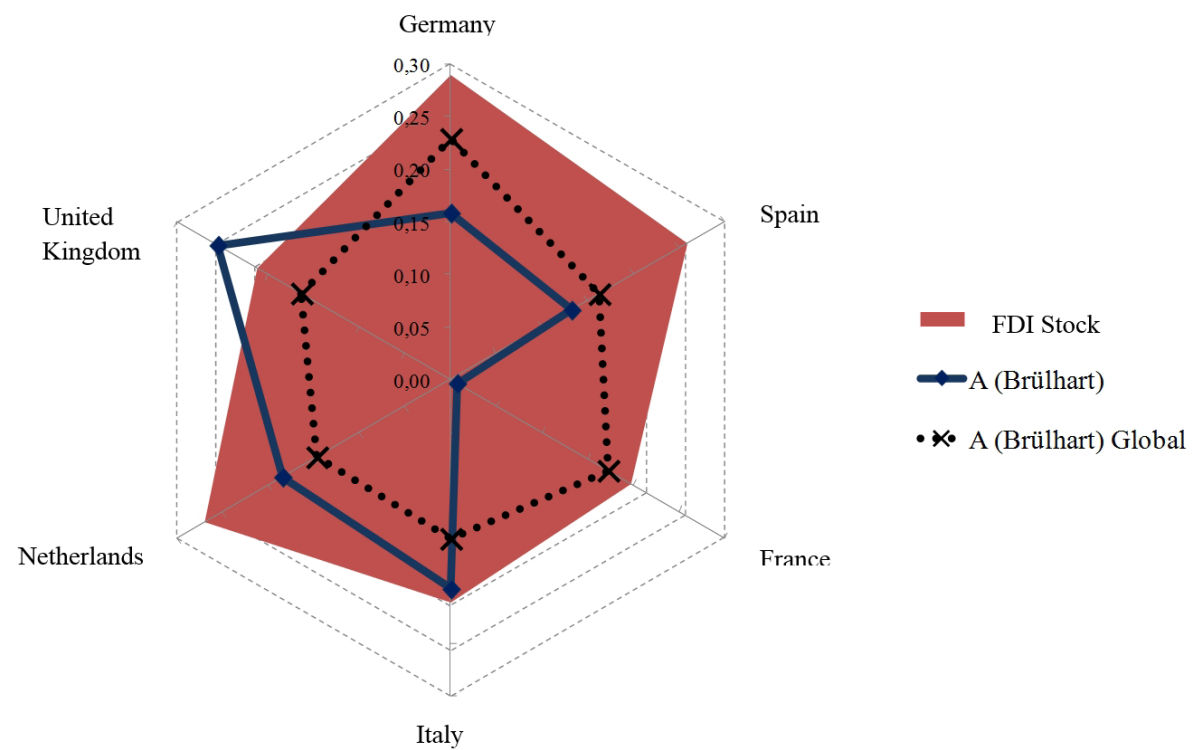

Source: Own elaboration based on UN-COMTRADE and UNCTAD data 
Graph 7.21. Advance of intra-industrial trade (Brülhart's marginal index, average 1993-2013) and foreign direct investment stock (inward FDI stock in 2011, values in logarithms, on second non-visible axis) of Mexico in the electrical and electronic equipment sector

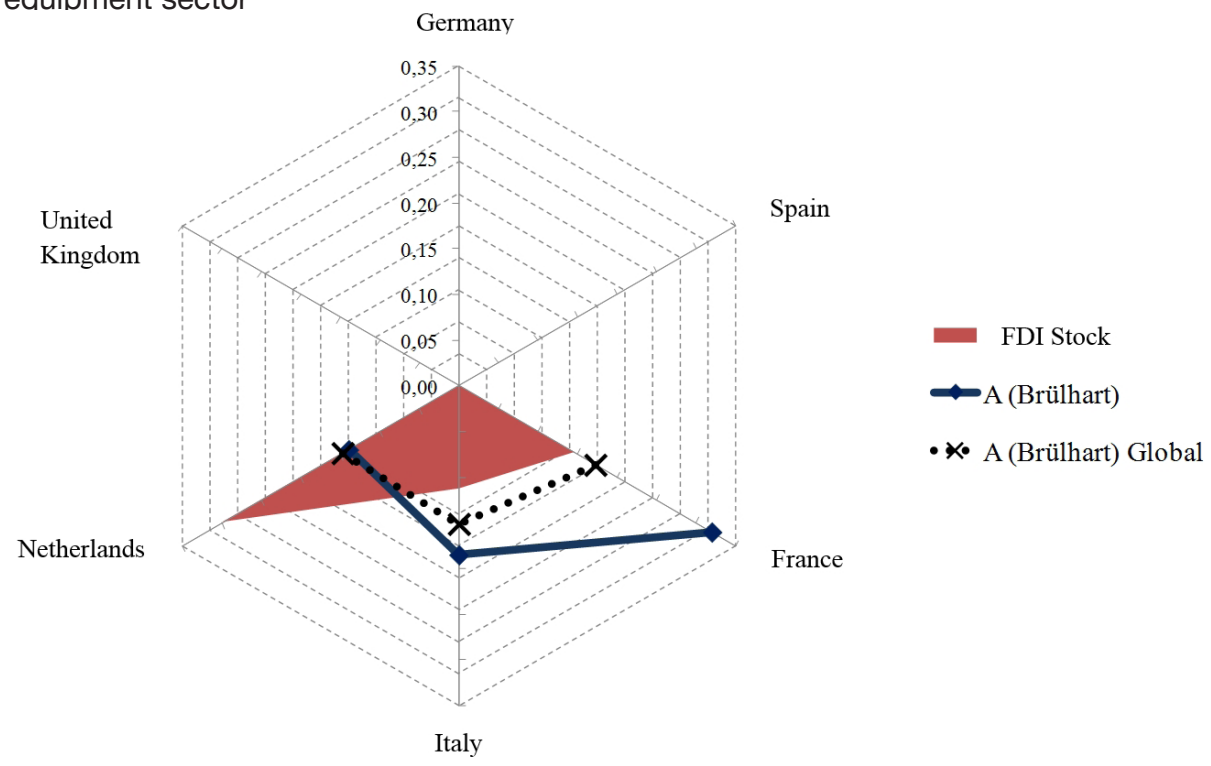

Source: Own elaboration based on UN-COMTRADE and UNCTAD data

Graph 7.22. Advance of intra-industrial trade (Brülhart's marginal index, average 1993-2013) and foreign direct investment stock (inward FDI stock in 2011, values in logarithms, on second non-visible axis) of Mexico in the automobile sector

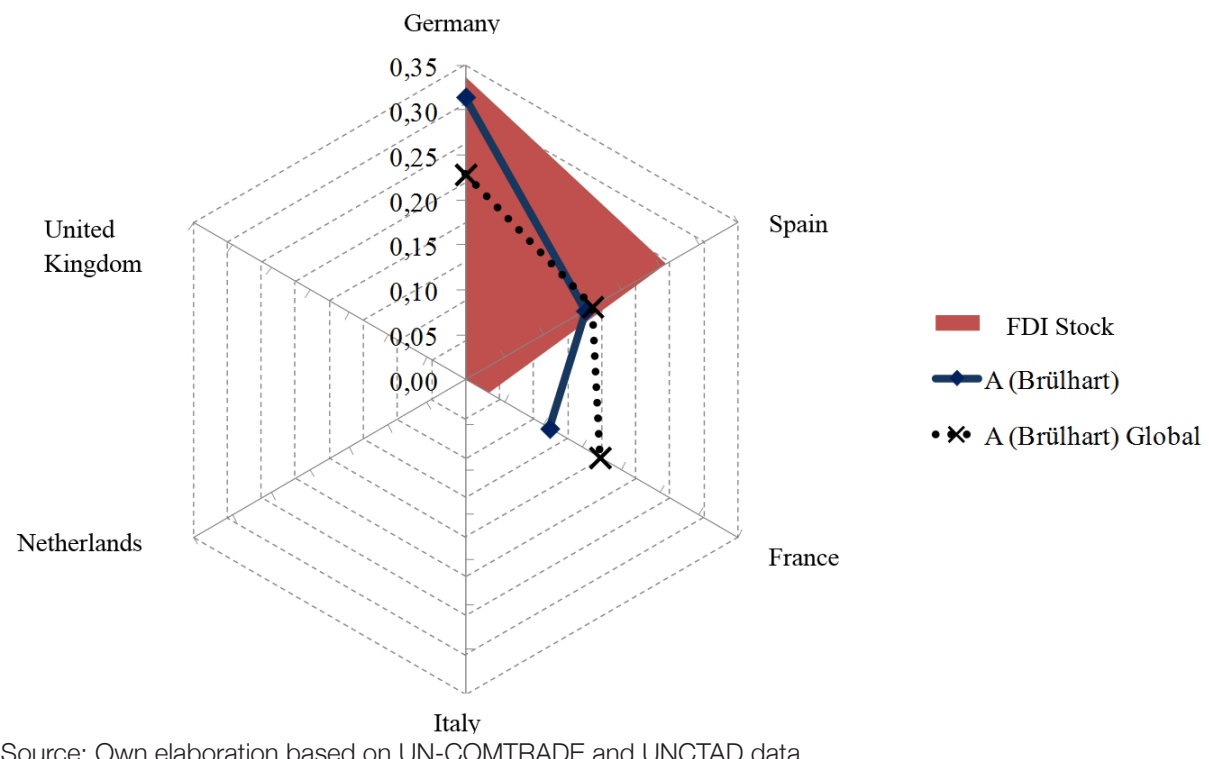


Another case where there are certain indications of an association between FDI and the advance of intra-industrial trade in Mexico's bilateral relations with its European partners in the electrical and electronic equipment sector (Graph 7.21). In this sector, in a context where FDI are present, Mexico's trade relations with Italy and France (not the Netherlands) show greater advance of intra-industrial trade than is observed at aggregate level.

Finally, there are signs of a relation between FDI and the advance of intra-industrial trade in Mexico's bilateral relations with Germany in the automobile sector (Graph 7.22). Although this association is not observable in the case of Mexico's relations with the other two European investors in this sector (Spain and France), there is a certain progression of the marginal intra-industrial trade index in accordance with the corresponding amount (stock) of foreign capital.

In short, it can be said that the indications pointing to a concordance between the presence of FDI and a higher degree of intra-industrial trade constitute an interesting result, which is agreement with the hypothesis that transnational companies have an important influence on the creation of intra-industrial trade. Although the advances observed at aggregate level in the amount of intra-industrial insertion of Brazil and Mexico in their relations with the EU are still quite moderate, they are less so in certain sectors which are involved in a significant part of the bilateral exchanges and which display a dynamism that cannot be explained without the logic regulating the productive and commercial operation of the transnational companies behind them. 


\section{Conclusions}

Various changes have occurred on a global economic level that have caused a shift in the centre of gravity of the world economy and in the transformation of production chains. In this regard, two particularly relevant phenomena can be pointed out: economic globalisation and the emergence of global value chains. The combination of these two processes has led to multiple changes affecting, among other things, international patterns of trade and investment, in a context characterised by the superposition of regional integration processes and production relocation. Evidence of these changes is, for example, the increasing importance of intermediate goods in the composition of trade flows between countries. In fact, at present, the countries participating in these global value chains acquire inputs for the production of goods which will finally be exported by other countries.

In this new situation, it is of great interest to inquire into the patterns of commercial specialisation and particularly, changes in the realm of intra-industrial trade, - whereby the latter is understood to refer to the exchange of different varieties of the same good. Taking this as starting point, in this study a general analysis of the trade and productive relations between the EU and LA was carried out, combined with a more detailed examination of Brazil and Mexico's relations with their main European partners. In particular, the main objective of the study was to explore the changes occurring in the patterns of intraindustrial trade between the EU and the countries of LA over the last two decades. The central axis of analysis revolved around Brazil and Mexico for two main reasons. First, because of their size and relative importance in LA, and secondly, because of their considerable dynamism in the current economic globalisation process.

From a theoretical point of view, the study was developed within the framework of new theories of international trade, which coincide in their explanation of the phenomenon of intra-industrial trade vis-à-vis traditional (inter-industrial) trade. In addition, some basic propositions of neo-technological theories such as Product Life-Cycle Theory were taken into account, as well as other contributions within the explanatory framework of FDI (OLI paradigm, Capital-Knowledge Model, Export-Platform Theory, etc.), which add elements to an integrative framework for theories of trade and FDI.

As a feature of additional interest, this study incorporates the North-South dimension to the study of the intra-industrial trade, unlike most traditional studies, which are essentially focused on North-North relations. In this regard, the study departed from the assumption that little presence of intra-industrial trade would exist in bilateral relations between the EU countries and those of LA, given the relative degree of complementarity observed in the profiles of commercial specialisation, especially in the case of Brazil and the EU. 
While, in general terms, this hypothesis was confirmed by the study, the real leitmotiv of the investigation was to explore the sectorial patterns and trends with regard to the evolution of intra-industrial trade, as well as to shed light on its possible relation with FDI processes.

The recent literature suggests that behind the assumed relations between trade and FDI superimposed FDI processes could be found: horizontal (extension or replication of the same production unit across international borders) and vertical (integration of different segments of the same production chain located in different countries). These FDI processes are highly complex, and understanding them presupposes much more detailed, in-depth studies in order to unravel the mysteries of intra-firm trade, which is outside the scope of this study. These aspects must be considered when it comes to drawing conclusions about the changes observed at macro level.

\section{Trade relations between the European Union and Latin America}

As was noted at the beginning of this study, trade in goods between the EU and LA has undergone a very positive evolution during the last two decades, tripling between 2000 and 2014 (ECLAC 2015b). In 2013 the maximum level of trade between the two regions was reached, at around $\$ 280,000$ million. Comparatively, trade relations of the two regions with the world have shown greater dynamism in the case of LA than in the case of the EU, which has translated into a narrowing of the breach separating their relative global trade weight. In 2014 , this relative weight was about $15 \%$ of global trade in the case of the EU and a little over $7 \%$ in the case of LA.

The result of the trade relations between the two regions has developed in parallel to the economic cycle, facing alternating stages in which the trade balance has been favourable to the EU (1993-2001, 2012-2014) and others in which the situation has been reversed, when LA experienced a surplus (2002-2011). Since 2012, LA's trade deficit with the EU has increased substantially because of a heavy decrease in its exports, which suffered a reduction of $17.9 \%$ between 2011 and 2014, while their imports increased $3.7 \%$ in the same period.

The cases of Brazil and Mexico, the EU's two main trading partners in LA, deserve to be highlighted in this respect. In fact, these two LA economies carry out more than half the exchanges of goods between the two regions. Brazil, in which $32.8 \%$ of LA's exports and $34.3 \%$ of its imports with destination/origin in the EU were concentrated in 2014, saw its exports to the EU reduced by $23.9 \%$ between 2011 and 2014, which caused severe worsening of its trade balance, which has been negative since 2012. Furthermore, Mexico, in which $18.9 \%$ of LA's exports and $26.4 \%$ of its imports with destination/origin 
in the EU were concentrated in 2014, saw its traditional deficit with the EU with even worse figures, due to the increase in its imports from that region (13.5\% between 2011 and 2014). In this regard, the existence of differentiated patterns between the different sub-regions making up LA is confirmed, with a more favourable balance in the case of South America (with Brazil as the main protagonist) than in the case of Mexico, Central America and the Caribbean, in line with what has been observed by other studies (ECLAC 2015b).

On the other hand, there is considerable asymmetry in the commercial importance of one region with respect to the other. In this regard, a greater share of the EU in LA's foreign trade is observed (about 12\% in 2014) than of LA in EU's foreign trade (around $6 \%$ in 2014). Nevertheless, it can be pointed out that this gap has tended to shrink over the period analysed, essentially because of the EU's loss of share in LA's foreign trade, which was over $16 \%$ in 1993 . This phenomenon is closely associated with the entry of China after it joined the WTO in 2001. The Asian giant saw its share in LA's exports multiplied by 9 (from 1\% to $9 \%$ ) and in its imports by LA by 8 (from $2 \%$ to $16 \%$ ) between 2000 and 2014. This has caused the EU to cede to China the second place (behind the United States) as market of origin of LA's imports, although it still keeps second place (also behind the United States) as market of destination for LA's exports (ECLAC $2015 b)$. On the other hand, China also has entered into the foreign trade of the EU, which has prevented a significant increase in LA's share of the EU's foreign trade, which has remained relatively stable in the time.

In general, the analysis of the sectorial composition of trade in goods between the EU and LA shows a profile based on complementarity, with exports from LA to the EU concentrated in raw materials, basic products and semi-manufactured products of little added value, and imports of manufactured products or goods of a certain technological content with origin in the EU. The case of Brazil reflects this pattern perfectly, although certain particularities regarding the export of goods with a certain technological content are also observed, connected with the presence of European manufacturers in both the automobile sector (Volkswagen, Fiat, Renault or PSA, for example) and the aeronautical sector (Airbus Helicopters, for example). A more differentiated profile is observed in the case of Mexico, which has a considerable productive integration with the EU in relevant such as, for example, the manufacturing of automobiles (Volkswagen, Fiat or Daimler AG, for example), from which a pattern of trade exchanges is derived within the framework of the logic in which multinational companies operate. Consequently, Mexico stands out for EU imports of intermediate goods (supplies) which are then incorporated in the production of final goods for sale in the national market, but especially to operate as a platform for export to the United States' market. 


\section{Foreign direct investment between the European Union and Latin America}

FDI constitutes an element of foreign relations of growing importance; it is an essential element to be taken into account to understand internationalisation of economies from a global perspective and, especially, in the productive realm.

The magnitude of the FDI has increased substantially in recent decades. The FDI received in the world in 2014 amounted to 1.23 billion dollars. And for the first time, the developing economies have become the main recipients of FDI in the world, representing $55.5 \%$ of the world total. This is a result of the greater growth of FDI of the developing economies. The FDI issued globally in 2014 amounted to 1.35 billion dollars, with the developed economies being main issuers of foreign investment (60.8\% of the world total).

Comparatively, the EU received $21 \%$ of the world FDI in 2014, and LA and the Caribbean $13 \%$. The EU's FDI outflow represented $20.7 \%$ of the world total, whereas the importance of LA and the Caribbean was much lower (1.7\% of the world total). Therefore, these two regions have greater importance in received FDI that in FDI issued, although the EU28's relative importance globally in the two is very similar, while the difference is very significant in LA and the Caribbean.

The FDI received by the EU followed a clear growth trend in the period 1990-2014, at a compound annual growth rate of $4.2 \%$, the amount being multiplied by 2.7 . Growth was greater in LA and the Caribbean, which grew at a rate of $12.6 \%$, with which the figure of 1990 was multiplied by 18.7. As a result of this evolution, the EU's relative weight was reduced by half; while LA and the Caribbean tripled its importance in the world.

Fluctuations over time are observed in both regions, usually related to the economic cycle, as is observable in the currently on-going crisis, which especially affects the EU. However, FDI is influenced by multiple factors beyond economic ones (the economic cycle, exchange rates, fluctuations in product prices, especially in the case of primary sector activities), including institutional aspects. Processes like regional integration, privatization or changes in regulation of investments are relevant for the evolution of FDI. Among the 20 main economies by volume of FDI received in 2014 there are seven European countries and four LA ones (Brazil, Chile, Mexico and Colombia). Traditionally, Brazil is the top FDI recipient in LA, receiving $5.1 \%$ of the world total in 2014 , followed by Chile and Mexico.

$69.7 \%$ of the accumulated foreign investment in Europe up to 2013 were issued by another European country (intra-EU investments), and 17.5\% stemmed from North and Central America (essentially the United States). South America only contributes $0.5 \%$ of 
the FDI received in Europe, which is the destination for half its foreign investment. Most of the FDI accumulated by South America comes from Europe (55.1\%), while 20.7\% has its origin in North and Central America. South America dedicates $22.6 \%$ of the total FDI issued to the same region. These data provide evidence of two facts that should be underlined: the relevance of the bilateral relation between LA and the EU, and the increasing importance of intra-regional FDI. In this regard, $14 \%$ of the foreign investment received by LA and the Caribbean stems from companies of the same region, as a result of the increasing importance of the Translatinas (mainly from Brazil and Mexico), which are even increasing their relevance at a global level.

In the bilateral relation between the EU and LA, the most important direction is the inflow of investment issued by the EU towards LA. The EU was the main origin of the FDI received by Brazil during the whole 2001-2012 period, representing 48.4\% in 2012 . The United States is traditionally the main investor in Mexico, although in 2004, 2007 and 2010, Spain became the most important investor globally, which traditionally constituted the main EU country with investments in Mexico. Bilateral FDI between Brazil and Mexico and the EU-28 is concentrated essentially in the EU-6.

The growth of FDI flows received by Brazil and Mexico from its main European partners (Germany, Spain, France, Italy, the Netherlands and the United Kingdom, which, to summarise, we collectively call EU-6) displayed considerable oscillations in the period 1992-2012. The differences between the paths followed by the different countries (and between different stages in the period, such as before and after the current crisis) make it difficult to identify a common pattern and lead to changes in the relative importance of the EU- 6 countries. These fluctuations do not allow for the identification of a trend that could lead to the conclusion that relative weight increases or falls with the EU as a whole related with the FDI directed to Brazil or Mexico. It appears that annual variations in the weight of the EU-6 and the other countries of the EU are conditioned by the volatility inherent in the flows and by annual merger and acquisition transactions.

The FDI received by Brazil from the EU-6 is mainly dedicated to the services sector (51.1\%), while manufacturing accounts for approximately a third (34.1\%), and other sectors (power, mining and extractive industries and construction) represent $14.8 \%$ of the total. The main branches of services are financial and insurance activities; information and communications; professional, scientific and technical activities; and trade. In the manufacturing sector, the outstanding activities are petroleum production, the chemicals industry and rubber and plastic products; metallurgy and manufacturing of metal products, and manufacturing of motor vehicles and other transport equipment. 
The FDI received in Mexico from the EU-6 mainly goes to the services sector $(62.4 \%)$, while the manufacturing sector represents a little more the quarter (27.5\%). The relative importance of other activities (power, mining activities and construction) is significant. The most important branches of the manufacturing sector are manufacturing of motor vehicles and other transport equipment; petroleum, the chemicals industry and rubber and plastic products. In the services sector, the important branches are financial and insurance activities; trade; information and communications; and professional, scientific and technical activities.

In the EU-6 group, the stock of accumulated FDI in Brazil rose by $93 \%$ in the period 2007 2011, - an increase which affected manufacturing activity (140.5\%) more than services (56.6\%). Consequently, the relative weight of manufacturing increased from $27.4 \%$ in 2007 to $34.1 \%$ in 2011 , while services saw their contribution reduced from $63 \%$ to $51.1 \%$ in the same period. The biggest rate of increase in manufacturing was observed in the branch of manufacturing of machinery and non-electrical and non-electronic equipment, followed by petroleum, the chemicals industry and rubber and plastic products. With regard to services, the reduction (91.5\%) in real estate activities stands out, and the biggest rates of growth were recorded in transport and storage, followed by information and communications (138.7\%) and trade.

The amount of accumulated FDI received by Mexico from the EU- 6 increased by $53.5 \%$ in the period 2005-2011; this increase was larger in services (172.3\%) than in manufacturing, which is why the relative weight of the former sector increased. The manufacturing sector branch with most growth is manufacturing of motor vehicles and other transport equipment, while in services, the activities of transport, storage and communications; and trade, followed by financial and insurance activities stand out.

The relative importance of branches of activity is different for each country and growth at a sectorial level is not homogeneous among the six European countries considered. The behaviour pattern seems to be more related to the country issuing the investment and, in particular, with the needs, opportunities and strategies of the multinational companies, than with the general trend in the sector, because in all branches situations of stock growth and reduction are found.

Finally, the FDI issued towards the EU-6 has different profiles in the cases of Brazil and Mexico. The FDI from Brazil was mainly directed toward the manufacturing sector $(59.5 \%$ of the total; the main branch being metallurgy and manufacturing of metal products, followed with much less importance by metallurgy and manufacturing of metal products), while in the services sector (representing 33\% of the total), financial and insurance activities stands out as the main branch. However, the FDI originating in Mexico to the 
$\mathrm{EU}$ is mostly oriented towards the services sector (in which $80.9 \%$ of the total FDI is concentrated), and financial and insurance activities also constituted the most important branch. The manufacturing sector represents $11.6 \%$ of the total of FDI, with particular importance of the branch of petroleum production, the chemicals industry and rubber and plastic products. It should be underlined that bilateral FDI between the EU and Brazil and Mexico in both directions is not limited to traditional activities based on natural resources, as a relevant proportion of FDI was directed toward knowledge-intensive sectors.

\section{Intra-industrial trade between the European Union and Latin America}

The analysis of intra-industrial trade was focused on the main bilateral trade flows between the EU and LA, i.e., those with Brazil or Mexico as its LA protagonists and one of their six main European partners (Germany, Spain, France, Italy, the Netherlands or the United Kingdom) as its counterpart. Although this analysis has shown the prevalence of a low profile of intra-industrial insertion between the two regions, it has also allowed for the identification of various sectorial nuances which reflect the existence of certain advances in the presence of this type of exchange.

It can be stressed that this analysis was carried out at different levels of sectorial disaggregation according to the Harmonised System (HS2012) classification of international trade. In particular, analyses were carried out at the two digit (chapter) and six digit (subheadings) levels, following methodological recommendations that suggest studies of intra-industrial trade be carried out at a high level of disaggregation. Being aware that a low level of disaggregation can overestimate intra-industrial trade and a high level of disaggregation may lead to its underestimation, we would like to state that observations based on the results obtained should always be treated with a certain caution and moderation.

Overall, there is little intra-industrial content in Brazil and Mexico's trade relations with their main EU partners. This is shown by the calculation of the aggregate GLI (GLIglobal), the simple version of which does not reach figures greater than $0.20(20 \%)$ in the whole 1993-2013 period, and in the last year (2013) it did not even exceed 0.11. Furthermore, although the corrected version of this index helps smoothening this valuation out a little by correcting the distorting effect of the trade balance, it does not reach much higher levels either. From the foregoing, a clear picture is derived of the scant intra-industrial profile characterising the insertion of these two LA countries in their trade relations with the countries of the EU, - at least from an overall perspective. In aggregate temporal perspective, increasing growth of intra-industrial trade can be observed, although a change of trend is observed from 2007 onwards, coinciding with the emergence of the global crisis. 
Comparing countries, although always within a context of little intra-industrial exchange, bilateral trade with Germany stands out, especially in the case of Mexico. In the case of Mexico, intra-industrial trade with France and to a lesser extent Italy also stand out, although in both cases, they only vary between $20 \%$ and $30 \%$. The bilateral exchanges of Brazil and Mexico with the remaining European countries considered demonstrate very low levels of intra-industrial trade. The most extreme case is that of Brazil and Mexico's bilateral trade with Spain, where a very small intra-industrial insertion is observed, with figures below $10 \%$.

These results are not surprising if we consider that we deal with trade relations between economies with very different levels of development, which is consistent with the general hypothesis that associates intra-industrial trade presence with similar levels of development, as was discussed in the theoretical section.

At the first level of sectorial disaggregation (two digits), interesting nuances are observable when the main chapters are analysed in terms of trade exchange. At this level, Brazil has a low level of intra-industrial content which is indicative of the predominance of interindustrial trade. In this sense, the pre-eminence of certain industrial chapters in bilateral relations with its European partners can be underlined, such as the chapters regarding mechanical machinery (Ch. 84), automobiles (Ch. 87), electrical and electronic machinery and equipment (Ch. 85), among others. Other chapters on provision of natural resources, raw materials or fuels also stand out, such as Chapters 26 (ores) or 27 (mineral fuels). It is, in any case, significant that in no case high GLI figures are observable, indicating the pre-eminently inter-industrial nature of Brazil's trade with its European partners.

This is not true of Mexico's foreign trade with its European partners, which shows greater intra-industrial content. Clear examples are the bilateral trade between Mexico and Germany in automobiles (Ch. 87), which is $70 \%$ of an intra-industrial nature, and that in machinery and mechanical equipment (Ch. 84) between Mexico and the United Kingdom, at a similar level in terms of its intra-industrial nature.

Adopting a disaggregated sectorial perspective at the 6-digit level has not only shown the specific subheadings that display the biggest intra-industrial trade levels, but also those with the biggest advances in dynamic terms, according to Brülhart's marginal index. Although the picture fairly varied because of the large number of bilateral trade connections considered, the biggest advances are observed in headings included in the chapters on machinery and mechanical equipment (mainly in engines and parts of engines); automobiles and their parts; electrical and electronic equipment material and apparatus; aircraft (in the case of Brazil); organic chemicals; and metal products, among others. 
The great complexity of the connections between trade and FDI makes it enormously difficult to try to empirically unravel the relations in a framework of multilateral spatial relations. From a broad territorial and sectorial perspective like the one adopted here, this undertaking is even less feasible and exceeds the initial objectives of this study. However, it was considered timely and illuminating to include two complementary analyses which might help to identify evidence of the existing associations.

The first of these analyses consisted of the study of the Input-Output relations, with the aim of finding evidence about the advance of global value chains in which multinational companies' strategies are inserted, trying to capture the weight and growth of trade in intermediate goods. To summarise, it was observed that most of the categories of goods exchanged were oriented towards intermediate consumption in other countries, in some cases, reaching practically 100 percent of the international flow considered. This result reflects the high degree of extension achieved in the framework of global value chains. We should add that, from a dynamic perspective, this type of destination in international trade flows has intensified, confirming thereby the advance in the degree of trade and productive interpenetration of the economies analysed.

The second analysis carried out consisted of an approach to the relationship between FDI and the advance of intra-industrial trade by examining the level of agreement between the presence of foreign capital and the greater or lesser level of advance of intra-industrial trade flows. In this regard, the analysis carried out for various bilateral exchanges allowed us to observe a certain degree of concordance between the presence of FDI and a greater level of advance of intra-industrial trade. This is, without doubt, an interesting result which is coherent with the idea that transnational companies positively influence the emergence of intra-industrial trade. Therefore, although the advances observed at the aggregate level in Brazil's and Mexico's intra-industrial insertion in their relations with the EU are still quite moderate, they are less so in certain sectors in which a significant part of their bilateral exchanges is carried out. In a way, it would not be possible to understand the dynamism of these exchanges without considering the role and operational logic of the multinational companies which are, ultimately, the real protagonists.

The results of these analyses suggest interesting extensions and lines of investigation to deepening the study of the existing connections between FDI flows and trade at a more specific, detailed level. In particular, studies applied to specific sectors and cases (automotive industry, aeronautics industry, manufacturing of machines and motors, etc.) are of utmost interest, although without losing the necessary multilateral perspective inherent to global value chains and discussed in the theoretical section. 
Finally, although it is outside the scope of this study, we should not ignore the changes which could affect the regulatory framework of relations between the two regions (the EU and LA). In this regard, it should be taken into consideration that the regulatory context is dynamic and can definitively affect the trends observed. For this reason, apart from the advances made in the agreements between the two parties leading to elimination of various kinds of barriers, there are other questions, such as the still unfinished negotiations between the EU and the United States within the framework of the Transatlantic Trade and Investment Partnership (TTIP) which might negatively affect certain realms (new technical standards, for example) of trade between the EU and LA. 


\section{BIBLIOGRAPHY}

ALADI (2012) Evolución del Comercio Intraindustrial en la ALADI. Montevideo: ALADI/ SEC/Estudio 201.

Aravena, C., Fernández, J., Hofman, A. and Mas, M. (2014) Structural change in four Latin American countries. An international perspective. Santiago de Chile: ECLAC.

Archibugi, D. and Iammarino, S. (2002) The globalization of technological innovation and evidence. Review of International Political Economy, 9(1): 98-122.

Audretsch, D. B. and Feldman, M.P. (1996) R\&D spillovers and the geography of innovation and production. American Review, 86: 630-40.

Bacaria-Colom, J., Osorio-Caballero, M. I. and Artal-Tur, A. (2013) Evaluación del Acuerdo de Libre Trade México-Unión Europea mediante un modelo gravitacional. Economía Mexicana. Nueva Época, 1: 143-163.

Bajo-Rubio, O. and López-Pueyo, C. (2002) FDI in a process of economic integration: The case of Spanish manufacturing, 1986-1992. Journal of Economic Integration, 17(1): 85-103.

Bajo-Rubio, O. and Montero-Muñoz, M. (2001) Foreign direct investment and trade: a causality analysis. Open Economies Review, 12(3): 305-323.

Balassa, B. (1963) European integration: problems and issues. The American Economic Review, 53(2): 175-184.

Balassa, B. (1965) Trade Liberalization and Revealed Comparative Advantage. Manchester School of Economic and Social Studies, 33(2): 99-123.

Balassa, B. (1966) Tariff reductions and trade in manufactures among the industrial countries. American Economic Review, 56: 466-472.

Balassa, B. (1967) Trade creation and trade diversion in the European Common Market. The Economic Journal, 77(305): 1-21.

Balassa, B. (1986) Intra-Industry specialization: A cross-country analysis. European Economic Review, 30(1): 27-42.

Balassa, B. and Bauwens, L. (1987) Intra-Industry Specialization in a Multi-country and Multi-industry Framework. The Economic Journal, 97: 923-929.

Baltagi, B.H., Egger, P. and Pfaffermayr, M. (2007) Estimating models of complex FDI: Are there third-country effects? Journal of Econometrics, 140(1): 260-281.

Bank of Spain (2013) Balanza de pagos de España 2012. Madrid: Bank of Spain.

Bárcena, A. and Prado, A. (eds.) (2015) Neoestructuralismo y corrientes heterodoxas en América Latina y el Caribe a inicios del siglo XXI. Santiago de Chile: ECLAC.

Bendesky, L., Garza, E., Melgoza, J. and Salas, C. (2003) La industria maquiladora de exportación: mitos y realidades. Mexico City: Instituto de Estudios Laborales. 
Bergstrand, J. and Egger, P. (2007) A knowledge-and-physical-capital model of international trade flows, foreign direct investment, and multinational enterprises. Journal of International Economics, 73 (2): 278-308.

Blonigen, B.A. (2005) A Review of the Empirical Literature on FDI Determinants. Atlantic Economic Journal, 33(4): 383-403.

Blonigen, B.A., Davies, R.B., Waddell, G.R. and Naughton, H. (2007) FDI in space: Spatial autoregressive relationships in foreign direct investment. European Economic Review, 51(5): 1303-1325.

Brainard, S.L. (1993) A Simple Theory of Multinationals Corporations and Trade with a Trade-off between Proximity and Concentration. NBER Working Paper Series 4269.

Brainard, S.L. (1997) An empirical assessment of the proximity-concentration trade-off between multinational sales and trade. American Economic Review, 87(4): 520544.

Brülhart, M. (1994) Marginal Intra-Industry Trade: Measurement and Relevance for the Pattern of Industrial Adjustment. Weltwirtschaftliches Archiv, 130: 600-613.

Brülhart, M. (2002) Marginal Intra-Industry Trade: Towards a Measure of Non-Disruptive Trade Expansion. In: Lloyd, P.J. and Lee, H. (eds.) Frontiers of Research on Intraindustry Trade. Basingstoke: Palgrave-Macmillan.

Brülhart, M. and Hine, R. (1999) Intra-Industry Trade and Adjustment, the European Experience. London: Macmillan.

Bulmer-Thomas, V. (2000) Regional Integration and Intraindustry Trade. Paper prepared for the Workshop on Regional Integration in Latin America and the Caribbean (LAC): An Evaluation of the Political Economy of Open Regionalism. 50th Congress of Americanists, Warsaw, Poland, 11-14 July, 2000.

Calderón, C. and Cuevas, V. (eds.) (2011) Integración de México en el TLCAN. Sus efectos sobre el crecimiento, la reestructuración productiva y el desarrollo económico. Mexico City: UAM-A-Miguel Ángel Porrúa.

Canals, C. and Noguer, M. (2007) La inversión extranjera directa en España: ¿qué podemos aprender del tigre celta? Documentos de Economía La Caixa 7.

Caputo, O. (1999) La economía mundial actual y la ciencia económica. In: Estay, J., Girón A. y Martínez, O. (eds.) La globalización de la economía mundial. Mexico City and Havana: IIE-UNAM, BUAP, CIEM.

Cárdenas, H.L. (2013) El comercio intraindustrial de México: Un comparativo entre China y Estados Unidos (1995-2011). In: Dussel E. (ed.) América Latina y el Caribe-China. Economía, Comercio e Inversiones. Mexico City: Ediciones de la Unión de Universidades de América Latina y China.

Carrera, M. (1992) Los factores tecnológicos en la explicación del comercio. Información Comercial Española, 705: 109-124.

Castellani, D. and Pier, P. (2015) Outward Investment and Productivity: Evidence from European Regions. Regional Studies, published on-line 12 Jan 2015. 
Caves, R.E. (1981) Intra-industry trade and market structure in the industrial countries. Oxford Economic Papers, 33: 203-223.

CEFP (2006) Comentarios al informe en materia arancelaria, 2005, CEFP/022/2006. Mexico City: Centro de Estudios de las Finanzas Públicas.

ECLAC (2013) Comercio internacional y desarrollo inclusivo. Construyendo sinergias. Santiago de Chile: United Nations.

ECLAC (2014) Integración regional: hacia una estrategia de cadenas de valor inclusivas. Santiago de Chile: United Nations.

ECLAC (2015a) La Inversión Extranjera Directa en América Latina y el Caribe 2015. Santiago de Chile: United Nations.

ECLAC (2015b) La Unión Europea y América Latina y el Caribe ante la nueva coyuntura económica y social. Santiago de Chile: United Nations.

Cimoli, M., Pereima, J.B. and Porcile, G. (2015) Cambio estructural y crecimiento. Serie Desarrollo Productivo, 197. Santiago de Chile: ECLAC.

Coase, R. (1937) The Nature of the Firm. Economica. New Series, 4(16): 386-405.

Cohen, W.M. and Levinthal, D.A. (1989) Innovation and Learning: The Two Faces of R\&D. The Economic Journal, 99: 569-596.

De la Cruz, J. and Marín, C. (2011) El impacto de China sobre América Latina en el mercado de Estados Unidos, un análisis de causalidad. Perfil de Coyuntura Económica, 18. Medellín: Universidad de Antioquia.

De la Cruz, J., Núñez, J.A. and Ruiz-Porras, A. (2008) El impacto de la inversión extranjera directa de Estados Unidos en América Latina y China: Evidencia empírica de causalidad. In: Ivanova A. and Guillén, A. (eds.) Globalización y regionalismo: Economía y sustentabilidad. Mexico City: Editorial Miguel Ángel Porrúa

Díaz, C. (2002) La ventaja comparativa como determinante del patrón de comercio intraindustrial vertical: evidencia para la Union Europea. Información Comercial Española, 796: 55-65.

Díaz, R. (2003) Las teorías de la localización de la inversión extranjera directa: una aproximación. Revista Galega de Economía, 12(1): 1-12.

Dornbusch, R. and Rudiger (1992) En defensa de la apertura comercial en los países en desarrollo. Análisis Económico, 10(20). Mexico City: Universidad Autónoma Metropolitana-Azcapotzalco.

Dosi, G. (1988) Sources, procedures, and microeconomic effects of innovation. Journal of Economic Literature, 26: 1120-1171.

Dosi,G., Pavitt, K and Soete, L. (1990) The Economics of Technological Change and International Trade. Brighton, Wheatsheaf: Harvester Press.

Dunning, J.H. (1973) The determinants of international production. Oxford Economic Papers, 25(3): 289-330.

Dunning, J.H. (1980) Towards an eclectic theory of international production: some empirical tests. Journal of International Business Studies, 11(1): 9-31. 
Dunning, J.H. (1988) Explaining international production. London: Unwin Hyman.

Dunning, J.H. (1993) Multinational enterprises and the global economy. Wokingham, Berkshire: Addison Wesley.

Dunning, J.H. (2000) The eclectic paradigm as an envelope for economic and business theories of MNE activity. International Business Review, 9: 163-190.

Durán Lima, J.E. and Ventura-Dias, V. (2003) Comercio intra-firma: concepto, alcance y magnitud. Santiago de Chile: ECLAC.

Dussel, E. (ed.) (2013) América Latina y el Caribe-China. Economía, Comercio e Inversiones. Mexico City: Ediciones de la Unión de Universidades de América Latina y China.

Dussel, E. and Gallagher, K.P. (2013) El huésped no invitado del TLCAN: China y la desintegración del comercio en América del Norte. Revista CEPAL, 110 (LC/ G.2572-P).

Dussel, E. and León González Pacheco, A. (2001) El comercio intra-industrial en México, 1990-1999. Comercio Exterior, 51(7): 652-664

Dussel, E. and Trápaga, Y. (coord.) (2007) China y México. Implicaciones de una nueva relación. Mexico City: Jornada Ediciones.

Egger, P.H., Larch, M. and Pfaffermayr, M. (2004) Multilateral trade and investment liberalization: effects on welfare and GDP per capita convergence. Economics Letters, 84(1): 133-140.

Ekanayake, E.M., Veeramacheneni, B. and Moslares, C. (2006) Una estimación empírica del comercio intra-industrial entre EE.UU. y España / An Empirical Estimation of the U.S. Intra-Industry Trade with Spain. Estudios de Economía Aplicada, 24(2): 677-689.

Ekholm, K., Forslid, R. and Markusen; J.R. (2007) Export Platform Foreign Direct Investment. Journal of the European Economic Association, 5(4): 776-795.

Elms, D.K. and Low, P. (eds.) (2013) Global value chains in a changing world. Fung Global Institute (FGI), Nanyang Technological University (NTU) and World Trade Organization (WTO), WTO Publications.

Ethier, W.J. and Horn, H. (1990) Managerial Control of International Firms and Patterns of Direct Investment. Journal of International Economics, 28(1-2): 25-45.

Fagerberg, J. and Srholec, M. (2004) Structural Changes in International Trade. Revue Économique, 55(6): 1071-1098.

Fagerberg, J., Srholec, M. and Knell, M. (2007) The Competitiveness of Nations: Why Some Countries Prosper While Others Fall Behind? World Development, 35(10): 1595-1620.

Feenstra, R.C. (1998) Integration of Trade and Disintegration of Production in the Global Economy. Journal of Economic Perspectives, 12(4): 31-50.

Feenstra, R.C. (2002) Border effects and the gravity equation: Consistent methods for estimation. Scottish Journal of Political Economy, 49(5): 491-506. 
Feenstra, R.C. and H. Looi Kee (2009) Trade liberalization and export variety: a comparison of Mexico and China. In: Lederman, D., Olarreaga, M. and. Perry, G (eds.) China's and India's Challenge to Latin America. Opportunity or Threat? Washington, D.C.: World Bank

Ferrando, A.P. (2013) Las Cadenas Globales de Valor y la medición del comercio internacional en valor agregado. Buenos Aires: Instituto de Estrategia Internacional, Cámara de Exportadores de la República Argentina.

Filippetti, A., Frenz, M. and Ietto-Gillies, G. (2013) The role of internationalization as a determinant of innovation performance. An analysis of 42 countries. CIMR Research Working Paper Series, No. 10.

Findlay, R. (1978) Relative Backwardness, Foreign Direct Investment, and the Transfer of Technology: A Simple Dynamic Model. The Quarterly Journal of Economics, 92(1): 1-16.

Findlay, R. and O'Rourke, K. H. (2002) Commodity Market Integration 1500- 2000. In: Bordo, M., Taylor, A. M. and Williamson, J. G. (eds.) Globalization in Historical Perspective. Chicago: University of Chicago Press, 13-62.

Fontagné, L. and Freudenberg, M. (1997) Intra Industry Trade: Methodological Issues Reconsidered. Working Papers 1, Centre d'etudes prospective et d'informations internacionales (CEPII)

http://www.cepii.fr/\%5C/anglaisgraph/workpap/pdf/1997/wp97-02.pdf (accessed 3 December 2015)

Fontagné, L., Freudenberg, M. and Gaulier, G. (2005) Disentangling Horizontal and Vertical Intra-Industry Trade. Working Papers 10, Centre d'etudes prospective et d'informations internacionales (CEPII)

http://www.cepii.fr/pdf_pub/wp/2005/wp2005-10.pdf

(accessed 3 December 2015)

Frank, A.G. and Gills, B.K. (1993) The World. System. Five Hundred Years or Five Thousand. London: Routledge.

Fujita, M., Krugman, P. and Venables, A.J. (1999) The spatial economy: cities, regions and internacional trade. Cambridge: MIT Press.

Parliamentary Gazette (2012) Informes sobre el uso de la facultad conferida al Ejecutivo federal en materia arancelaria, que se presenta de conformidad con el artículo 131 de la Constitución Política de los Estados Unidos Mexicanos, year 16, №3662-D, Saint Lazarus Legislative Palace, 7 December, 2012.

García, A.S. and Solís, V. (2014) Comercio internacional: Cadenas globales de valor. Una aproximación desde las teorías de redes. Revista de Economía Mundial, 37: 151-180.

Gazol, A. (2007a) Integración o absorción. Mexico City: Macroeconomía.

Gazol, A. (2007b) Un nuevo tipo de proteccionismo (o el retorno del permiso previo). Economía-UNAM, 4(12). 
González, J.L. (1991) Comercio intraindustrial e integración económica. El caso de Castilla y León. Información Comercial Española, 693: 123-137.

González, J.M. (2013) China y América Latina y el Caribe en el nuevo milenio. Logros, retos, perspectivas y limitaciones de su patrón económico commercial. In: Enrique Dussel Peters (Coordinator) América Latina y el Caribe-China. Economía, Comercio e Inversiones. Mexico City: Ediciones de la Unión de Universidades de América Latina y China.

Greenaway, D. and Hine, R.C. (1991) Intra-Industry Specialization, Trade Expansion and Adjustment in the European Economic Space. Journal of Common Market Studies, 29(6): 603-622.

Grossman, G. and Helpman, E. (1995) Technology and Trade. In: Grossman and Rogoff (eds.) Handbook of International Economics, III. North-Holland.

Grossman, G.M. and Helpman, E. (1990) Trade, innovation and growth. American Economic Review, 80(2): 86-91.

Grubel, H.G. (1967) Intra-industry specialization and the pattern of trade. Canadian Journal of Economics and Political Science, 33(3): 374-388.

Grubel, H.G. and Lloyd, P.J. (1971) The empirical measurement of intra-industry trade. Economic Record, 47(4): 494-517

Grubel, H.G. and Lloyd, P.J. (1975) Intra-industry trade: the theory and measurement of international trade in differentiated products, London: Macmillan.

Guillén, A. (2007) Mito y realidad de la globalización neoliberal. Mexico City: UAM.

Gutiérrez, S. and Cantavella-Jordá, M. (2007) Export-led growth: are the results robust across methodologies and/or data sets? A case study of Latin America. Applied Economics, 39: 1475-1500.

Hamilton, C. and Kniest, P. (1991) Trade liberalization, structural adjustment and intraindustry trade: a note. Weltwirtschaftliches Archiv, 127(2).

Hayakawa, K. and Matsuura, T. (2011) Complex vertical FDI and firm heterogeneity: Evidence from East Asia. Journal of the Japanese and International Economies, 25(3): 273-289.

Heckscher, E. (1919) The Effects of Foreign Trade on the Distribution of Income. Ekonomisk Tidskrift, 21: 497-512.

Helpman, E. (1984) A Simple Theory of International Trade with Multinational Corporations. Journal of Political Economy, 92(3): 451-471.

Helpman, E. (1987) Imperfect Competition and International Trade: Evidence from Fourteen Industrial Countries. Journal of the Japanese and International Economies, 1: 62-81.

Helpman, E. (2006) Trade, FDI, and the organization of firms. Journal of Economic Literature, 44(3): 589-630.

Helpman, E. (2011) Understanding global trade. Harvard University Press.

Helpman, E. and Krugman, P. (1985) Market Structure and International Trade. Cambridge and London: MIT Press. 
Helpman, E. and Krugman, P. (1992) Trade policy and market structure. Cambridge and London: MIT Press.

Herzog, C. and Ünal, D. (2012) Panorama de la spécialisation européenne. CEPII.

Horstmann, I. and Markusen, J. (1992) Endogenous Market Structures in International Trade. Journal of International Economics, 32: 109-129.

Ietto-Gillies, G. (2012) Transnational corporations and International production: Concepts, Theories and Effects. Cheltenham: Edward Elgar International.

International Monetary Fund (2009) Balance of payments and international investment position manual, Sixth Edition (BPM6), Washington, D.C.: IMF.

Ito, T. and Okubo, T. (2012) New aspects of Intra-industry trade in EU countries. IDE Discussion Paper No. 361, Institute of Developing Economies, Keio University.

JETRO (Japanese External Trade Organization) (2010) 2010 JETRO Global Trade and Investment Report. A Global Strategy for Japanese Companies to Open New Frontiers in Overseas Markets. Tokyo.

Kalinova, B., Palerm, A. and Thomsen, S. (2010) OECD's FDI Restrictiveness Index: 2010 Update. Working Papers on International Investment, 2010/03, OECD Publishing. http//dx.doi.org/10.1787/5km91p02zj7g-en (accessed 12 August 2015).

Kalinova, B., Palerm, A. and Thomsen, S. (2010) OECD's FDI Restrictiveness Index: 2010 Update. OECD Working Papers on International Investment, 2010/03, OECD.

Keller, W. (2010) International Trade, Foreign Direct Investment, and Technology Spillovers. In: Hall Bronwyn, H. y Rosenberg, N. (eds.) Handbook of the economics of innovation. Amsterdam: North-Holland.

Krugman, P. (1979) Increasing Returns, Monopolistic Competition, and International Trade. Journal of International Economics 9: 469-479.

Krugman, P. (1980) Scale Economies, Product Differentiation and the Pattern of Trade. American Economic Review, 70(5): 950-959.

Krugman, P. (1995) Growing world trade: causes and consequences. Brookings Papers on Economic Activity, 26(1) Washington, D.C: The Brookings Institution.

Krugman, P. (1995) Increasing Returns, Imperfect Competition and the Positive Theory of International Trade. In: Grossman and Rogoff (eds.) Handbook of International Economics, III. North-Holland.

Krugman, P. (2004) El internacionalismo "moderno": la economía internacional y las mentiras de la competitividad. Barcelona: Crítica.

Krugman, P.R. and Obstfeld, M. (1995) Economía Internacional: Teoría y política, Mc Graw Hill.

Lancaster, K. (1980) Intra-industry trade under perfect monopolistic competition. Journal of International Economics, 10(2): 151-175.

Laursen, K. (2000) Trade specialisation, technology and economic growth: theory and evidence from advanced countries. Cheltenham: Edward Elgar. 
Linder, S.B. (1961) An Essay on Trade and Transformation. New York: Wiley and Sons.

Lindert, P. H. and Williamson, J. G. (2002) Does Globalization Make the World More Unequal?. In Bordo, M., Taylor, A. M. and Williamson, J. G. (eds.) Globalization in Historical Perspective. Chicago: University of Chicago Press: 227-270.

López, J.A. and Peláez, O. (2010) Globalización neoliberal, mercado de trabajo y emigración desde Chiapas. Paper presented at the XXIX International Congress of the Latin American Studies Association, 8 October, Toronto, Canada.

López, J.A. and Rodil, O. (2008) Comercio intrandustrial e intrafirma en México en el contexto del proceso de integración de América del Norte (1993-2006). Economía UNAM, 5(13) Mexico City.

López, J.A., Rodil, O. and Valdez, S. (2014) La irrupción de China en el NAFTA: efectos sobre el comercio intra-industrial de México. Economía UNAM, 11(31): 84-113.

López, J.A., Rodil, O. and Valdez, S. (2014) The impact of China's incursion into the North American Free Trade Agreement (NAFTA) on intra-industry trade. Revista CEPAL, 114: 83-100.

Los, B., Timmer, M.P. and de Vries, G.J. (2015) How global are global value chains? A new approach to measure international fragmentation. Journal of Regional Science, 55(1): 66-92.

Lucángeli, J. (2007) La especialización intra-industrial en Mercosur. Serie Macroeconomía del Desarrollo 64. Santiago de Chile: ECLAC.

Manuelito, S. and Jiménez, L.F. (2015) Rasgos estilizados de la relación entre inversión y crecimiento en América Latina, 1980-2012. Revista CEPAL, 115: 7-25.

Markusen, J.R. (1984) Multinationals, Multi-Plant Economies and the Gains from Trade. Journal of International Economics, 16: 205-226.

Markusen, J.R. (1995) The Boundaries of Multinational Enterprises and the Theory of International Trade. Journal of Economic Perspectives, 9(2): 169-189.

Markusen, J.R. (2002) Multinational Firms and the Theory of International Trade, The MIT Press, Cambridge.

Markusen, J.R. and Maskus, K.E. (2002) Discriminating among alternative theories of the multinational enterprise. Review of International Economics, 10(4): 694-707.

Markusen, J.R. and Venables, A.J. (1998) Multinational firms and the new trade theory. Journal of International Economics, 46: 183-203.

Markusen, J.R. and Venables, A.J. (2000) The theory of endowment, intra-industry and multi-national trade. Journal of International Economics, 52(2): 209-234.

Marquetti, A. and Campos, M. (2014) Patrones de progreso técnico en la economía brasileña, 1952-2008. Revista CEPAL, 113: 61-78.

Martín, J. and Orts, V. (1995) Comercio intraindustrial en España: determinantes nacionales y sectoriales. Revista de Economía Aplicada, 7(3): 45-62.

Martín, J. and Orts, V. (1996) Naturaleza y causas del comercio intra-industrial. Revista Ekonomiaz, 36: 79-101. 
Martínez González-Tablas, A. (2000) Economía política de la globalización, Barcelona: Editorial Ariel.

Martínez González-Tablas, A. (2003) Reflexión metodológica en torno a la globalización. Revista de Economía Mundial, 9: 83-110.

Martínez, J. (2001) El capitalismo global. Límites al desarrollo y a la cooperación. Barcelona: Icaria-Antrazyt.

Martínez, J. (2007) El capitalismo global en China vs. China en el sistema capitalista global. Madrid: Actas de la IX Reunión de Economía Mundial.

Maza, A. and Villaverde, J. (2012) Inward Foreign Direct Investment in the European Union: Regional Distribution and Determinants, SIEPS Report No. 6.

McCombie, J.S.L. and Thirlwall, A.P. (1994) Economic Growth and the Balance of Payments Constraint. New York: St. Martin's Press.

Melitz, M.J. (2003) The impact of trade on intra-industry reallocations and aggregate industry productivity. Econometrica, 71(6): 1695-1725.

Michael, H. and Negri, A. (2005) Imperio. Barcelona: Paidós

Mogrovejo, J.A. (2004) Factores determinantes de la inversión extranjera directa en algunos países de Latinoamérica. Estudios Económicos de Desarrollo Internacional. AEEADE, 5(2): 63-94.

Molero, J. (1995) Technological Innovations, Multinational Corporations and New International Competitiveness: the case of intermediate countries. Harwood Academic Publishers. Reading.

Molero, J. (2001) Innovación tecnológica y Competitividad en Europa. Madrid: Síntesis.

Molero, J. (2002) The innovative behaviour of MNCs subsidiaries in uneven European Systems of Innovation: A comparative study of the German and Irish cases. The Journal of Interdisciplinary Economics, 13(1-3).

Motta, M. and Norman, G. (1996) Does economic integration cause foreign direct investment? International Economic Review, 37(4): 757-783.

Mundell, R. (1957) International Trade and Factor Mobility. The American Economic Review, 47(3): 321-335.

Myro, R. (Dir.) (2014) España en la inversión directa internacional. Madrid: Instituto de Estudios Económicos.

Navaretti, G.B., Haaland, J.I. and Venables, A. (2002) Multinational corporations and global production networks: the implications for trade policy. London: CEPR report for the European Commission.

Neme, O. (2006) La competencia entre México y China: La disputa por el mercado de Estados Unidos. Mexico City: UNAM National Autonomous University of Mexico/ Miguel Ángel Porrúa.

Nicita, A., Ognivtsev, V. and Shirotori, M. (2013) Global Supply Chains: Trade and Economic Policies for Developing Countries. Policy Issues in International Trade and Commodities Study Series 55. Geneva: UNCTAD. 
O'Rourke, K. H. and Williamson, J. G. (1999) Globalization and History. Cambridge: MIT Press.

Obstfeld, M. and Taylor, A. M. (2002) Globalization and Capital Markets. In: Bordo, M., Taylor, A. M. and Williamson, J. G. (eds.) Globalization in Historical Perspective. Chicago: University of Chicago Press, 121-183.

OECD (2002a) Intra-industry and intra-firm trade and the internationalization of production. Paris: OECD Economic Outlook, 71.

OECD (2002b) Foreign Direct Investment for Development - Maximising Benefits, Minimising Costs. Paris: OECD.

OECD (2002c) Foreign Direct Investment and Development: Where Do We Stand?, Paris: OECD.

OECD (2007) Moving Up the Value Chain: Staying Competitive in the Global Economy. Paris: OECD.

OECD (2008) OECD Benchmark Definition of Foreign Direct Investment - 4th Edition. Paris: OECD.

OECD (2012) Eliminación de restricciones a la participación extranjera en México. Evaluación de los beneficios potenciales en algunas industrias. Report written by the OECD Secretariat and Mexico's Federal Competition Commission. http://www.oecd.org/daf/competition/IEDreporteOCDECFC.pdf (accessed 3 December 2015)

Ohlin, B. (1933) Interregional and International Trade. Cambridge: Harvard University Press.

Onodera, O. (2008) Trade and Innovation Project. A synthesis paper. OECD Trade Policy Working Paper, No. 72, OECD.

Porter, M. (1991) La Ventaja competitiva de las naciones. Barcelona: Plaza y Janés.

Posner, M.V. (1961) International Trade and Technical Change. Oxford Economic Papers, New Series, Vol. 13(3): 323-341.

Ricardo, D. (1817) On the Principles of Political Economy and Taxation. London: John Murray.

del Río, F.J. (1996) Evolución histórica y tendencias recientes en el comercio intraindustrial de los países de la CE. Información Comercial Española, 749: 159-168.

Robinson, William (2013) Una teoría sobre el capitalismo global. Producción, clase y Estado en un mundo transnacional. Mexico City: Editorial Siglo XXI.

Rodil, O. and López, J.A. (2011) Efectos del Tratado de Libre Comercio de América del Norte sobre el comercio de México: Creación de comercio y especialización intraindustrial. Revista de Economía Mundial, 27: 249-278.

Rodríguez-Pose, A. and Petrakos, G. (2004) Integración económica y desequilibrios territoriales en la Unión Europea EURE, Revista Latinoamericana de Estudios Urbanos Regionales, 89: 63-80.

Rosales O. and Kuwayama, M. (2007) América Latina al encuentro de China e India: perspectivas y desafíos en comercio e inversion. Revista CEPAL, 93. 
Rosales, O. and Kuwayama, M. (2012) China y América Latina y el Caribe. Hacia una relación económica y comercial estratégica. Libros de la CEPAL, 114 (LC/ G.2519-P), Santiago de Chile: CEPAL .

Santiso, J. (2008) La emergencia de las multilatinas. Revista CEPAL, 95: 7-30.

Santiso, J. (2011) La década de las multilatinas. Madrid: Siglo XXI.

Souza, A. and Garcia, F. (2015) Un análisis comparativo de la productividad en las industrias manufactureras del Brasil y México. Revista CEPAL, 115: 197-215.

Storper, M. (1997) The regional world. New York: Guilford Press.

Timmer, M.P., Erumban, A.A., Los, B., Stehrer, R. and de Vries, G.J. (2014) Slicing Up Global Value Chains. Journal of Economic Perspectives, 28(2): 99-118.

Timmer, M.P., Dietzenbacher, E., Los, B., Stehrer, R. and de Vries, G.J. (2015) An Illustrated User Guide to the World Input-Output Database: the Case of Global Automotive Production. Review of International Economics, 23: 575-605.

UNCTAD (2013) World Investment Report 2013: Global Value Chains: Investment and Trade for Development. Switzerland: ONU.

UNCTAD (2015) World Investment Report 2015. Geneva: United Nations.

Vázquez, R. (2014) Inserción global, desarticulación y competitividad en el sector electromecánico de México: un análisis structural. Revista CEPAL, 114: 145162.

Verdoorn, P. (1960) The Intra-Bloc Trade of Benelux. In E.A.G. Robinson (ed.) The Economic Consequences of the Size of Nations. New York: Macmillan, 291-329.

Vernon, R. (1966) International Investment and International Trade in the Product Cycle. The Quarterly Journal of Economics, 80(2): 190-207.

Villaverde, J. and Maza, A. (2015) A New FDI Potential Index: Design and Application to the EU Regions. European Planning Studies, Published online: 23 March 2015

Villaverde, J. and Maza, A. (2015) The determinants of inward foreign direct investment: Evidence from the European regions. International Business Review, 24(2): 209223.

Viner, J. (1950) The Customs Union Issue. New York, Carnegie Endowment for International Peace.

Wakelin, K. (1997) Trade and innovation: theory and evidence. Cheltenham: Edward Elgar.

Wang, J. (2004) China's Changing Role in Asia. In: Kokubun, R. and Wang, J. (eds.) The Rise of China and a Changing East Asian Order; Tokyo: Japan Center for International Exchange, 3-21.

http://www.cei.gov.ar/userfiles/7\%20China\%20y\%20los\%20acuerdos $\% 20$ de\%20libre\%20comercio.pdf (accessed 3 December 2015).

Xingmin, Y. (2007) Nuevas vías para el desarrollo del comercial entre China y América Latina, Oportunidades en la relación económica y comercial entre China y México. Mexico City: CEPAL. 
Yu, Ch., Xue, L.X. and Hong, S. (2006) China y los acuerdos de libre comercio. Comercio Exterior e Integración, 7 , Centro de Economía Internacional (CEI),

Zago, A.F. and Massuquetti, A. (2015) Exportaciones del sector automotor brasileño al Mercado Común del Sur: ¿desviación de comercio o reducción de costos? Revista CEPAL, 115: 159-179.

\section{STATISTICAL SOURCES AND DATA ON TRADE:}

UN COMTRADE DATABASE, United Nations, Department of Economic and Social Affairs, Statistics Division [online: http//comtrade.un.org]. UN Comtrade is a statistical depository of official trade and relevant analytical tables, publishing annual trade statistics starting from 1962 onwards and monthly trade statistics beginning from 2010. It constitutes the main source for data used in the present study.

TARIFF AND TRADE DATA, World Trade Organisation [online: https://www. wto.org/english/res_e/statis_e/statis_e.htm]. This website offers quantitative information regarding economic and commercial policies. Its databases facilitate the access to data on trade flows, tariffs, non-tariff barriers, added value-based trade, with an ample disaggregation based on location, sector, and new developments.

WORLD TRADE REPORT, World Trade Organisation [online: https://www.wto.org/ english/res_e/reser_e/wtr_e.htm]. These reports constitute the main analytical publication of the IMF with regard to global trade governance, focusing on specific topics, analyse and new developments.

CEPALSTAT, Databases and Statistical Publications, Economic Commission for Latin America and the Caribbean [online: http://estadisticas.cepal. org/cepalstat/web_cepalstat/estadisticasIndicadores.asp?idioma=i]. ECLAC's statistical website offers access to an ample database on commercial flows; moreover it includes a graphic data system of international trade (SIGCl-Plus) which is of great value for the analysis of commercial advantages and intraindustrial trade.

EUROSTAT International Trade Database [online: http//ec.europa.eu/eurostat/web/ international-trade/data/database]. At this website, extensive statistical data on international trade by the EU countries are published.

DATACOMTEX, Foreign Trade Statistical Database of the Ministry for Economics and Competitiveness of the Spanish Government [online: http//datacomex. comercio.es]. Multidimensional databases (OLAP cubes) on foreign trade of the EU with the option to analyse specific EU member states, partner states, groups of partner states, classification of products or merchandise (TARIC, economic 
sectors, CUCl), export and import flows, types of trade, periodization (annual series), variables (monetary value, weight, tariff units).

\section{STATISTICAL SOURCES AND DATA ON FOREIGN DIRECT INVESTMENT:}

A.T. Kearney (2015) The 2015 A.T. Kearney Foreign Direct Investment Confidence Index. Connected Risks: Investing in a Divergent World. Available from https:// www.atkearney.com/research-studies/foreign-direct-investment-confidenceindex/2015/publication (accessed 3 May 2015).

ECLAC (2014) Capital Flows to Latin America and the Caribbean: Recent Developments, ECLAC WASHINGTON Office, LC/WAS/L.131, Washington: ECLAC.

EUROSTAT (1994-2012) Foreign Direct Investment Statistics. Luxembourg: EUROSTAT. EUROSTAT (1994-2012) Foreign Affiliates. Luxembourg: EUROSTAT.

IMF (2009-2013) Coordinated Direct Investment Survey. Washington: IMF.

IMF (1990-2013) World Economic Outlook Database. Washington: IMF.

OECD (1990-2012) FDI Statistics Database [Note: This FDI statistics database using data compiled according to new international standards was launched on 17 March 2015. Access the data on OECD.Stat (categorised under Globalisation), compiled using BMD4.]. Paris: OECD.

OECD (1997-2013): OECD FDI Regulatory Restrictiveness Index. Paris: OECD.

OECD (2014): FDI in Figures. Paris: OECD.

OECD (2003): Foreign Direct Investment Restrictions in OECD Countries. En: OECD Economic Outlook, 2003(1).

http//www.oecd.org/eco/outlook/2956455.pdf (accessed 3 May 2015).

OECD (2012): Eliminación de restricciones a la participación extranjera en México. Evaluación de los beneficios potenciales en algunas industrias. http//www.oecd. org/daf/competition/IEDreporteOCDECFC.pdf (accessed 3 May 2015).

OECD (1990-2013): Economic Outlook: GDP Growth. Paris: OECD.

UNCTAD (2001-2012): FDI/TNC database. FDI Statistics Division on Investment and Enterprise. Geneva: UNCTAD.

\section{STATISTICAL SOURCES AND DATA ON GLOBAL INPUT-OUPUT TABLES:}

World Input-Output Database (WIOD), WIOD Project, Seventh Framework Programme. Available from: http://www.wiod.org (accessed 3 May 2015).

See also: Timmer, M.P., Dietzenbacher, E., Los, B., Stehrer, R. and de Vries, G.J. (2015) An Illustrated User Guide to the World Input-Output Database: the Case of Global Automotive Production. Review of International Economics, 23: 575-605. 
EU-LAC FOUNDATION 2016 